\title{
Addition of Zeolite ZSM-5 to an Iron-based Fischer-Tropsch Catalyst supported on Activated Carbon: Effect of Reactor Conditions
}

Avinashkumar V. Karre

West Virginia University

Follow this and additional works at: https://researchrepository.wvu.edu/etd

\section{Recommended Citation}

Karre, Avinashkumar V., "Addition of Zeolite ZSM-5 to an Iron-based Fischer-Tropsch Catalyst supported on Activated Carbon: Effect of Reactor Conditions" (2011). Graduate Theses, Dissertations, and Problem Reports. 3318.

https://researchrepository.wvu.edu/etd/3318

This Thesis is protected by copyright and/or related rights. It has been brought to you by the The Research Repository @ WVU with permission from the rights-holder(s). You are free to use this Thesis in any way that is permitted by the copyright and related rights legislation that applies to your use. For other uses you must obtain permission from the rights-holder(s) directly, unless additional rights are indicated by a Creative Commons license in the record and/ or on the work itself. This Thesis has been accepted for inclusion in WVU Graduate Theses, Dissertations, and Problem Reports collection by an authorized administrator of The Research Repository @ WVU. For more information, please contact researchrepository@mail.wvu.edu. 


\title{
Addition of Zeolite ZSM-5 to an Iron-based Fischer-Tropsch Catalyst supported on Activated Carbon: Effect of Reactor Conditions
}

\author{
Avinashkumar V. Karre \\ Thesis Submitted to the College of Engineering and Mineral Resources \\ at West Virginia University \\ in partial fulfillment of the requirements \\ for the degree of \\ Master of Science \\ in \\ Chemical Engineering
}

Dady B. Dadyburjor, Ph.D., Chair

Edwin L. Kugler, Ph.D.

Charter D. Stinespring, Ph.D.

Department of Chemical Engineering

Morgantown, West Virginia

2011

Keywords: Fischer-Tropsch; Iron-based catalyst; ZSM-5; activated carbon Copyright 2011 Avinashkumar V. Karre 


\section{ABSTRACT}

\section{Addition of Zeolite ZSM-5 to an Iron-based Fischer-Tropsch Catalyst supported on Activated \\ Carbon: Effect of Reactor Conditions}

\section{Avinashkumar V. Karre}

An iron-based catalyst containing $6 \mathrm{wt} \% \mathrm{Mo}, 16 \mathrm{wt} \% \mathrm{Fe}, 0.8 \mathrm{wt} \% \mathrm{Cu}$, and $0.9 \mathrm{wt} \% \mathrm{~K}$ supported on Norit SX Ultra activated carbon is used as a FTS catalyst. Zeolite ZSM-5 (of medium acidity and $\mathrm{Si} / \mathrm{Al}=50$ ) is used to check its effect on FT base catalyst to form aromatic compounds and to reduce the size of long-chain hydrocarbons. The influence of ZSM-5 amounts, bed arrangements, and the temperature on the product distribution were investigated.

The performance of ZSM-5 along with the base catalyst was analyzed in two catalyst bed configurations: separate-bed and mixed-bed. Both separate-bed and mixed-bed catalyst arrangements show conversion of alcohols to hydrocarbons and water. The separate-bed arrangement gives higher conversions of $\mathrm{CO}$ and $\mathrm{H}_{2}$, and higher yields of liquid hydrocarbons. The decline in FT activity in the mixed bed is probably due to lowering of the alkali content of the iron catalyst because of alkali migration from FT catalyst to ZSM-5, as confirmed by energy-dispersive X-ray spectroscopy of the spent ZSM-5.

Product profiles were analyzed for changing ZSM-5 weight from 50 to $200 \%$ of the FTS amount in the separate bed and the mixed bed catalyst arrangements. Oligomerization, aromatization, isomerization, and cracking reactions are enhanced with increasing ZSM-5 weight in both the catalyst arrangements. The base catalyst shows no selectivity towards aromatic compounds, but addition of ZSM-5 in both arrangements forms $\mathrm{C}_{7-10}$ aromatic compounds. Long-chain hydrocarbon molecules $\left(\mathrm{C}_{13+}\right)$ formed by the base catalyst are effectively cracked, and isomerized on the ZSM-5 catalyst surface in both type of catalyst arrangements.

Product profiles were analyzed for change in the temperature from 280 to $320^{\circ} \mathrm{C}$ in the base catalyst as well as in the separate-bed catalyst arrangement. Amounts of small-chain hydrocarbons $\left(\mathrm{C}_{1-5}\right)$ increase with increase in temperature because of higher FTS rates. Liquid hydrocarbon production rate (in both the base catalyst and the separate bed) is increased at $300^{\circ} \mathrm{C}$ due to increase in FTS rate. Further increase in the temperature causes these rates to drop to give small-chain hydrocarbon $\left(\mathrm{C}_{1-4}\right)$ species. Aromatic yields are found to reach a maximum at $300^{\circ} \mathrm{C}$ in the separate bed. The alcohol rate for the base catalyst increases with increase in temperatures probably because of higher FTS rates. $280^{\circ} \mathrm{C}$ is sufficient to convert all the alcohols formed by the base catalyst in the separate bed.

The base catalyst and ZSM-5 together were tested for $240 \mathrm{~h}$ time on stream (TOS) to check the stability of the combination of the catalysts in the separate-bed arrangement. The base catalyst shows stability up to $120 \mathrm{~h}$ and slow decline in activity up to $240 \mathrm{~h}$. A progressive loss of the ZSM-5 activity occurred with TOS. Coke deposition on ZSM-5, confirmed by energy-dispersive X-ray spectroscopy, decreases aromatic compound yield, and increases olefin selectivity with time on stream due to reduction in oligomerization reactions. 
Dedicated to my family 


\section{ACKNOWLEDGEMENTS}

I am greatly thankful to my research advisers Dr. Dady Dadyburjor and Dr. Edwin Kugler for all the guidance and their experience that they shared with me. The financial support from US Department of Energy through Consortium of Fossil Fuel Science is respectfully acknowledged.

I would like to thank to Gabriela Perhinschi for performing the XRD analysis and Adrienne McGraw for performing the SEM analysis.

I sincerely thank Jim Hall, Bonita Helmick, and Linda Rogers for helping me out with nonacademic issues. I would like to thank to my lab mates Ashish, Ramanjanelu, Josh, Soumya, Mayuri for their concern and their time for me. I really appreciate the help from Dr. Kababji and Dr. Gugilla for helping me understand the gas and the liquid GC operations. I would like to thank every graduate student and faculty at the Chemical Engineering Department, WVU, for their guidance and hospitality that made my stay in Morgantown a beautiful experience. Personally I would like to thanks my friends Rohith, Aniketh, Vivek, Uday, Karthik, Hemant, Rahul, Vikas, Srinath, Manohar, Kiran, Terry for all the things they have done for me during my stay at West Virginia.

Thank you all. 


\section{TABLE OF CONTENTS}

TITLE PAGE

$\begin{array}{ll}\text { ABSTRACT } & \text { ii }\end{array}$

ACKNOWLEDGEMENTS

TABLE OF CONTENTS $\quad$ V

LIST OF FIGURES $\quad$ xii

LIST OF TABLES $\quad$ xvi

CHAPTER 1

INTRODUCTION 1

1.1 FISCHER TROPSCH PROCESS 1

1.2 INTEREST IN FISCHER-TROPSCH PROCESS 2

1.3 CHALLENGES IN FISCHER-TROPSCH PROCESS 3

1.4 COMMERCIAL FISCHER-TROPSCH PLANTS 3

1.5 OBJECTIVE OF THIS STUDY 3

$\begin{array}{lc}\text { CHAPTER } 2 & 5\end{array}$

LITERATURE REVIEW

2.1 OVERVIEW 25

2.2 REACTION INVOLVED IN THE FISCHER TROPSCH PROCESS 5

2.3 KINETICS OF FISCHER TROPSCH PROCESS

2.4 REACTION MECHANISMS

$\begin{array}{ll}\text { 2.4.1 Alkyl mechanism } & 7\end{array}$

$\begin{array}{lr}\text { 2.4.2 Alkenyl mechanism } & 8\end{array}$ 
$\begin{array}{ll}2.4 .4 \mathrm{CO} \text { insertion mechanism } & 11\end{array}$

2.5 IRON-BASED CATALYST COMPARED TO COBALT-BASED CATALYST 12

$\begin{array}{ll}\text { 2.6 STUDY OF IRON BASED CATALYST ACTIVITY } & 15\end{array}$

$\begin{array}{ll}\text { 2.6.1 Preparation of the base catalyst } & 15\end{array}$

2.6.2 Promotional effect of mixed metals on iron catalyst and selection of metals 15

2.6.2.1 Selection of copper $(\mathrm{Cu})$ and potassium $(\mathrm{K})$ as a promoter 16

$\begin{array}{ll}\text { 2.6.2.2 Selection of Molybdenum (Mo) as a promoter } & 17\end{array}$

$\begin{array}{ll}\text { 2.6.3 Effect of catalyst supports } & 19\end{array}$

$\begin{array}{ll}2.7 \text { ZEOLITE STUDIES IN FISCHER TROPSCH PROCESS } & 20\end{array}$

$\begin{array}{lr}2.7 .1 \text { Overview } & 20\end{array}$

2.7.2 Effects of zeolite types on Fischer-Tropsch liquid distribution 21

$\begin{array}{lr}\text { CHAPTER } 3 & 24\end{array}$

$\begin{array}{ll}\text { EXPERIMENTAL SETUP AND PROCEDURE } & 24\end{array}$

$\begin{array}{ll}\text { 3.1 CATALYST PREPARATION PROCEDURE } & 24\end{array}$

$\begin{array}{ll}3.1 .1 \text { Base catalyst preparation procedure } & 24\end{array}$

$\begin{array}{ll}\text { 3.1.2 ZSM-5 catalyst } & 24\end{array}$

$\begin{array}{ll}3.2 \text { EQUIPMENT DESCRIPTION } & 24\end{array}$

$\begin{array}{ll}3.3 \text { EXPERIMENTAL PROCEDURE } & 27\end{array}$

$\begin{array}{ll}3.3 .1 \text { Reactor Loading } & 27\end{array}$

$\begin{array}{ll}\text { 3.3.2 Pretreatment and Reaction } & 28\end{array}$ 
4.1 SCANNING ELECTRON MICROSCOPY (SEM) AND ENERGY-DISPERSIVE X-RAY SPECTROSCOPY (EDX) ANALYSIS

4.2 X-RAY DIFFRACTION ANALYSIS (XRD)

4.3 TEMPERATURE-PROGRAMMED REDUCTION (TPR)

CHAPTER 5

5.1 INTRODUCTION 
6.2.1 EFFECT OF ZSM-5 WEIGHT CHANGE ON PRODUCT DISTRIBUTION IN SEPARATE-BED CATALYST ARRANGEMENT 
7.1 Conversions 
8.1 EFFECT OF BED ARRANGEMENT ON ENERGY-DISPERSIVE X-RAY SPECTROSCOPY OF SPENT CATALYST

8.2 ENERGY-DISPERSIVE X-RAY SPECTROSCOPY AFTER CATALYST STABILITY TESTS

CHAPTER 9

CONCLUSIONS

92

REFERENCES

96

APPENDICES

APPENDIX A

A.1 Chromatograph operating conditions for gas products

B.1.1 TCD calibration of gases

B.1.2 FID calibration of gases

B.2 Chromatograph calibration procedure for liquid products 
D.1 Calculation procedure for gas analysis

CONVERSIONS AND LIQUID WEIGHTS COLLECTED FOR BASE CATALYST, SEPARATE BED, AND MIXED BED ARRANGEMENT

FID GAS REACTION DATA FOR BASE CATALYST, SEPARATE-BED, AND MIXED-BED ARRANGEMENT

ORGANIC AND AQUEOUS PHASE REACTION DATA FOR BASE CATALYST, SEPARATEBED, AND MIXED-BED ARRANGEMENT 


\section{LIST OF FIGURES}

Figure 2.1 Branching probability as a function of carbon number $\mathrm{Nc}$ (of the species to be branched) and time in FT synthesis with iron catalyst (Schulz et al., 2003)

Figure 2.2 Branching probability as a function of carbon number Nc (of the species to be branched) and time in FT synthesis with cobalt catalyst (Schulz et al., 2001)

Figure 2.3 TPR profiles of different Mo-promoted Fe-Cu-K/AC catalysts (Ma et al., 2006)

Figure 2.4 Effect of Mo loading on CO conversion (593K, 300 psig, $3 \mathrm{N1} / \mathrm{gcat} / \mathrm{h}, \mathrm{H} 2 / \mathrm{CO}=0.9)(\mathrm{Ma}$ et al., 2007a)

Figure 2.5 Effect of carbon support type on $\mathrm{CO}$ conversion $\left(593 \mathrm{~K}, 300 \mathrm{psig}, 3 \mathrm{~N} 1 / \mathrm{g}\right.$-cat $/ \mathrm{h}, \mathrm{H}_{2} / \mathrm{CO}=0.9$ ) (Ma et al., 2007a)

Figure 3.1 Equipment setup for Fischer Tropsch process

Figure 4.1 SEM low magnification image of surface of the base catalyst before reaction

Figure 4.2 Magnified SEM image of surface of the base catalyst before reaction

Figure 4.3 EDX analysis of surface of the base catalyst before reaction

Figure 4.4 EDX elemental analysis of fresh ZSM-5

Figure $4.5 \mathrm{XRD}$ of fresh base catalyst

Figure 4.6 XRD of fresh ZSM-5

Figure 4.7 TPR profiles (a) is $50 \mathrm{mg}$ of base catalyst, (b) $33.33 \mathrm{mg}$ of base catalyst and $16.67 \mathrm{mg}$ of ZSM-5 (2:1), (c) $25 \mathrm{mg}$ of base catalyst and $25 \mathrm{mg}$ of ZSM-5 (1:1) (d) 50mg of fresh ZSM-5 36

Figure 6.1 WGS and FTS reaction rates ( $\mathrm{mmol} / \mathrm{min}$ ). Separate-bed catalyst arrangement, $0.5 \mathrm{~g}$ of base catalyst, $\mathrm{Si} / \mathrm{Al}$ ratio in $\mathrm{ZSM}-5=50, \mathrm{H} 2 / \mathrm{CO}$ ratio $=1$, total feed rate $=100 \mathrm{scc} / \mathrm{min}$, reactor temperature $=300^{\circ} \mathrm{C}$, reactor pressure $=300 \mathrm{psi}$, TOS $=24-48 \mathrm{~h}$. 
Figure 6.2 Gas-phase paraffins detected by FID (g carbon/day). Separate-bed catalyst arrangement, $0.5 \mathrm{~g}$ of base catalyst, $\mathrm{Si} / \mathrm{Al}$ ratio in $\mathrm{ZSM}-5=50, \mathrm{H}_{2} / \mathrm{CO}$ ratio $=1$, total feed rate $=100 \mathrm{scc} / \mathrm{min}$, reactor temperature $=300^{\circ} \mathrm{C}$, reactor pressure $=300 \mathrm{psi}, \mathrm{TOS}=24-48 \mathrm{~h}$.

Figure 6.3 FID gases not shown in Figure 6.2 (g carbon/day). Separate-bed catalyst arrangement, $0.5 \mathrm{~g}$ of base catalyst, $\mathrm{Si} / \mathrm{Al}$ ratio in $\mathrm{ZSM}-5=50, \mathrm{H}_{2} / \mathrm{CO}$ ratio $=1$, total feed rate $=100 \mathrm{scc} / \mathrm{min}$, reactor temperature $=300^{\circ} \mathrm{C}$, reactor pressure $=300 \mathrm{psi}$, TOS $=24-48 \mathrm{~h}$.

Figure 6.4 Liquid hydrocarbon and alcohol production rate (g/kg FT cat $/ \mathrm{h})$. Separate-bed catalyst arrangement, $0.5 \mathrm{~g}$ of base catalyst, $\mathrm{Si} / \mathrm{Al}$ ratio in $\mathrm{ZSM}-5=50, \mathrm{H}_{2} / \mathrm{CO}$ ratio $=1$, total feed rate $=100$ $\mathrm{scc} / \mathrm{min}$, reactor temperature $=300^{\circ} \mathrm{C}$, reactor pressure $=300 \mathrm{psi}, \mathrm{TOS}=24-48 \mathrm{~h}$.

Figure 6.5 Liquid n-paraffins (g carbon/day). Separate-bed catalyst arrangement, $0.5 \mathrm{~g}$ of base catalyst, $\mathrm{Si} / \mathrm{Al}$ ratio in ZSM-5 $=50, \mathrm{H}_{2} / \mathrm{CO}$ ratio $=1$, total feed rate $=100 \mathrm{scc} / \mathrm{min}$, reactor temperature $=300^{\circ} \mathrm{C}$, reactor pressure $=300 \mathrm{psi}, \mathrm{TOS}=24-48 \mathrm{~h}$.

Figure 6.6 Liquid i-paraffins (g carbon/day). Separate-bed catalyst arrangement, $0.5 \mathrm{~g}$ of base catalyst, $\mathrm{Si} / \mathrm{Al}$ ratio in ZSM-5 $=50, \mathrm{H}_{2} / \mathrm{CO}$ ratio $=1$, total feed rate $=100 \mathrm{scc} / \mathrm{min}$, reactor temperature $=300^{\circ} \mathrm{C}$, reactor pressure $=300 \mathrm{psi}, \mathrm{TOS}=24-48 \mathrm{~h}$.

Figure 6.7 Aromatic compounds (g carbon/day). Separate-bed catalyst arrangement, $0.5 \mathrm{~g}$ of base catalyst, $\mathrm{Si} / \mathrm{Al}$ ratio in $\mathrm{ZSM}-5=50, \mathrm{H}_{2} / \mathrm{CO}$ ratio $=1$, total feed rate $=100 \mathrm{scc} / \mathrm{min}$, reactor temperature $=$ $300^{\circ} \mathrm{C}$, reactor pressure $=300 \mathrm{psi}, \operatorname{TOS}=24-48 \mathrm{~h}$.

Figure 6.8 Sketch of an overall reaction sequence

Figure 6.9 WGS and FTS reaction rates (mmol/min). Mixed-bed catalyst arrangement, $0.5 \mathrm{~g}$ of base catalyst, $\mathrm{Si} / \mathrm{Al}$ ratio in $\mathrm{ZSM}-5=50, \mathrm{H}_{2} / \mathrm{CO}$ ratio $=1$, total feed rate $=100 \mathrm{scc} / \mathrm{min}$, reactor temperature $=$ $300^{\circ} \mathrm{C}$, reactor pressure $=300 \mathrm{psi}$, TOS $=24-48 \mathrm{~h}$.

Figure 6.10 Gas-phase paraffins detected by FID (g carbon/day). Mixed-bed catalyst arrangement, $0.5 \mathrm{~g}$ of base catalyst, $\mathrm{Si} / \mathrm{Al}$ ratio in $\mathrm{ZSM}-5=50, \mathrm{H}_{2} / \mathrm{CO}$ ratio $=1$, total feed rate $=100 \mathrm{scc} / \mathrm{min}$, reactor temperature $=300^{\circ} \mathrm{C}$, reactor pressure $=300 \mathrm{psi}$, TOS $=24-48 \mathrm{~h}$. 
Figure 6.11 FID gases not shown in Figure 6.9 (g carbon/day). Mixed-bed catalyst arrangement, $0.5 \mathrm{~g}$ of base catalyst, $\mathrm{Si} / \mathrm{Al}$ ratio in $\mathrm{ZSM}-5=50, \mathrm{H}_{2} / \mathrm{CO}$ ratio $=1$, total feed rate $=100 \mathrm{scc} / \mathrm{min}$, reactor temperature $=300^{\circ} \mathrm{C}$, reactor pressure $=300 \mathrm{psi}$, TOS $=24-48 \mathrm{~h}$.

Figure 6.12 Liquid hydrocarbon and alcohol production rate (g/kg FT cat/h). Mixed-bed catalyst arrangement, $0.5 \mathrm{~g}$ of base catalyst, $\mathrm{Si} / \mathrm{Al}$ ratio in $\mathrm{ZSM}-5=50, \mathrm{H}_{2} / \mathrm{CO}$ ratio $=1$, total feed rate $=100$ $\mathrm{scc} / \mathrm{min}$, reactor temperature $=300^{\circ} \mathrm{C}$, reactor pressure $=300 \mathrm{psi}, \mathrm{TOS}=24-48 \mathrm{~h}$.

Figure 6.13 Liquid n-paraffins (g carbon/day). Mixed-bed catalyst arrangement, $0.5 \mathrm{~g}$ of base catalyst, $\mathrm{Si} / \mathrm{Al}$ ratio in $\mathrm{ZSM}-5=50, \mathrm{H}_{2} / \mathrm{CO}$ ratio $=1$, total feed rate $=100 \mathrm{scc} / \mathrm{min}$, reactor temperature $=300^{\circ} \mathrm{C}$, reactor pressure $=300 \mathrm{psi}$, TOS $=24-48 \mathrm{~h}$.

Figure 6.14 Liquid i-paraffins (g carbon/day). Mixed-bed catalyst arrangement, $0.5 \mathrm{~g}$ of base catalyst, $\mathrm{Si} / \mathrm{Al}$ ratio in $\mathrm{ZSM}-5=50, \mathrm{H}_{2} / \mathrm{CO}$ ratio $=1$, total feed rate $=100 \mathrm{scc} / \mathrm{min}$, reactor temperature $=300^{\circ} \mathrm{C}$, reactor pressure $=300 \mathrm{psi}, \mathrm{TOS}=24-48 \mathrm{~h}$.

Figure 6.15 Aromatic compounds (g carbon/day). Mixed-bed catalyst arrangement, $0.5 \mathrm{~g}$ of base catalyst, $\mathrm{Si} / \mathrm{Al}$ ratio in $\mathrm{ZSM}-5=50, \mathrm{H}_{2} / \mathrm{CO}$ ratio $=1$, total feed rate $=100 \mathrm{scc} / \mathrm{min}$, reactor temperature $=$ $300^{\circ} \mathrm{C}$, reactor pressure $=300 \mathrm{psi}$, TOS $=24-48 \mathrm{~h}$.

Figure 7.1 $\mathrm{CO}$ and $\mathrm{H}_{2}$ conversions (\%). Separate-bed catalyst arrangement, $0.5 \mathrm{~g}$ of base catalyst, $0.5 \mathrm{~g}$ of ZSM-5 catalyst, $\mathrm{Si} / \mathrm{Al}$ ratio in $\mathrm{ZSM}-5=50, \mathrm{H}_{2} / \mathrm{CO}$ ratio $=1$, total feed rate $=100 \mathrm{scc} / \mathrm{min}$, reactor temperature $=300^{\circ} \mathrm{C}$, reactor pressure $=300 \mathrm{psi}$, TOS $=0-240 \mathrm{~h}$.

Figure 7.2 $\mathrm{CO}_{2}$ and unreacted $\mathrm{CO}$ (g carbon/day). Separate-bed catalyst arrangement, $0.5 \mathrm{~g}$ of base catalyst, $0.5 \mathrm{~g}$ of ZSM-5 catalyst, $\mathrm{Si} / \mathrm{Al}$ ratio in $\mathrm{ZSM}-5=50, \mathrm{H}_{2} / \mathrm{CO}$ ratio $=1$, total feed rate $=100$ $\mathrm{scc} / \mathrm{min}$, reactor temperature $=300^{\circ} \mathrm{C}$, reactor pressure $=300 \mathrm{psi}, \mathrm{TOS}=0-240 \mathrm{~h}$.

80

Figure 7.3 Gas-phase n-paraffins detected by FID (g carbon/day). Separate-bed catalyst arrangement, 0.5 $\mathrm{g}$ of base catalyst, $0.5 \mathrm{~g}$ of ZSM-5 catalyst, $\mathrm{Si} / \mathrm{Al}$ ratio in $\mathrm{ZSM}-5=50, \mathrm{H}_{2} / \mathrm{CO}$ ratio $=1$, total feed rate $=$ $100 \mathrm{scc} / \mathrm{min}$, reactor temperature $=300^{\circ} \mathrm{C}$, reactor pressure $=300 \mathrm{psi}$, TOS $=0-240 \mathrm{~h}$.

Figure 7.4 FID gases not shown in Figure 7.4 (g carbon/day). Separate-bed catalyst arrangement, $0.5 \mathrm{~g}$ of base catalyst, $0.5 \mathrm{~g}$ of ZSM-5 catalyst, $\mathrm{Si} / \mathrm{Al}$ ratio in $\mathrm{ZSM}-5=50, \mathrm{H}_{2} / \mathrm{CO}$ ratio $=1$, total feed rate $=$ $100 \mathrm{scc} / \mathrm{min}$, reactor temperature $=300^{\circ} \mathrm{C}$, reactor pressure $=300 \mathrm{psi}$, TOS $=0-240 \mathrm{~h}$. 
Figure 7.5 FID gases not shown in Figure 7.4 and Figure 7.5 (g carbon/day). Separate-bed catalyst arrangement, $0.5 \mathrm{~g}$ of base catalyst, $0.5 \mathrm{~g}$ of ZSM-5 catalyst, $\mathrm{Si} / \mathrm{Al}$ ratio in ZSM-5 = 50, $\mathrm{H}_{2} / \mathrm{CO}$ ratio = 1 , total feed rate $=100 \mathrm{scc} / \mathrm{min}$, reactor temperature $=300^{\circ} \mathrm{C}$, reactor pressure $=300 \mathrm{psi}$, TOS $=0-240 \mathrm{~h}$.

Figure 7.6 Liquid hydrocarbon production rate (g/Kg FT cat./h). Separate-bed catalyst arrangement, 0.5 $\mathrm{g}$ of base catalyst, $0.5 \mathrm{~g}$ of ZSM-5 catalyst, $\mathrm{Si} / \mathrm{Al}$ ratio in $\mathrm{ZSM}-5=50, \mathrm{H}_{2} / \mathrm{CO}$ ratio $=1$, total feed rate $=$ $100 \mathrm{scc} / \mathrm{min}$, reactor temperature $=300^{\circ} \mathrm{C}$, reactor pressure $=300 \mathrm{psi}$, TOS $=0-240 \mathrm{~h}$.

Figure 7.7 Aromatics compounds (g carbon/day). Separate-bed catalyst arrangement, $0.5 \mathrm{~g}$ of base catalyst, $0.5 \mathrm{~g}$ of ZSM-5 catalyst, $\mathrm{Si} / \mathrm{Al}$ ratio in $\mathrm{ZSM}-5=50, \mathrm{H}_{2} / \mathrm{CO}$ ratio $=1$, total feed rate $=100$ $\mathrm{scc} / \mathrm{min}$, reactor temperature $=300^{\circ} \mathrm{C}$, reactor pressure $=300 \mathrm{psi}, \mathrm{TOS}=0-240 \mathrm{~h}$.

86

Figure 7.8 Alcohol production rate (g/Kg FT cat./h). Separate-bed catalyst arrangement, $0.5 \mathrm{~g}$ of base catalyst, $0.5 \mathrm{~g}$ of ZSM-5 catalyst, $\mathrm{Si} / \mathrm{Al}$ ratio in $\mathrm{ZSM}-5=50, \mathrm{H}_{2} / \mathrm{CO}$ ratio $=1$, total feed rate $=100$ $\mathrm{scc} / \mathrm{min}$, reactor temperature $=300^{\circ} \mathrm{C}$, reactor pressure $=300 \mathrm{psi}$, TOS $=0-240 \mathrm{~h}$.

Figure 8.1 EDX elemental analysis of spent ZSM-5 after $72 \mathrm{~h}$ (separate-bed catalyst arrangement, $0.5 \mathrm{~g}$ of base catalyst, $0.5 \mathrm{~g}$ of ZSM-5 catalyst, $\mathrm{Si} / \mathrm{Al}$ ratio in ZSM-5 $=50, \mathrm{H}_{2} / \mathrm{CO}$ ratio $=1$, total feed rate $=$ $100 \mathrm{scc} / \mathrm{min}$, reactor temperature $=300^{\circ} \mathrm{C}$, reactor pressure $=300 \mathrm{psi}$, TOS $=0-72 \mathrm{~h}$ )

Figure 8.2 EDX elemental analysis of spent ZSM-5 after $72 \mathrm{~h}$ (mixed-bed catalyst arrangement, $0.5 \mathrm{~g}$ of base catalyst, $0.5 \mathrm{~g}$ of ZSM-5 catalyst, $\mathrm{Si} / \mathrm{Al}$ ratio in $\mathrm{ZSM}-5=50, \mathrm{H}_{2} / \mathrm{CO}$ ratio $=1$, total feed rate $=100$ $\mathrm{scc} / \mathrm{min}$, reactor temperature $=300^{\circ} \mathrm{C}$, reactor pressure $=300 \mathrm{psi}$, TOS $=0-72 \mathrm{~h}$ )

Figure 8.3 EDX elemental analysis of ZSM-5 after $240 \mathrm{~h}$ (separate-bed catalyst arrangement, $0.5 \mathrm{~g}$ of base catalyst, $0.5 \mathrm{~g}$ of ZSM-5 catalyst, $\mathrm{Si} / \mathrm{Al}$ ratio in ZSM-5 $=50, \mathrm{H}_{2} / \mathrm{CO}$ ratio $=1$, total feed rate $=100$ $\mathrm{scc} / \mathrm{min}$, reactor temperature $=300^{\circ} \mathrm{C}$, reactor pressure $=300 \mathrm{psi}, \mathrm{TOS}=0-240 \mathrm{~h}$ )

Figure C.1 MFC calibration curve for He gas

Figure C.2 MFC calibration curve for $\mathrm{H}_{2}$ gas

Figure C.3 MFC calibration curve for syngas mixture gas (45\% CO, $\left.45 \% \mathrm{H}_{2}, 5 \% \mathrm{Ar}, 5 \% \mathrm{He}\right) \quad 114$ 


\section{LIST OF TABLES}

Table 1.1 Commercial Fischer-Tropsch plants

Table 2.1 Iron-based kinetic rate models

Table 2.2 Steady-state performance of $\mathrm{Fe} 2 \mathrm{O} 3-\mathrm{Zn}$ catalysts $(\mathrm{Zn} / \mathrm{Fe}=0.1)$ with different loadings of $\mathrm{K}$ and $\mathrm{Cu}\left(\mathrm{H}_{2} / \mathrm{CO}=2,493 \mathrm{~K}, 464\right.$ psig, $\mathrm{CO}$ conversion 14-18\%) (Li et al., 2001)

Table 2.3 Productivity and Selectivity of Hydrocarbon and Olefin-to-Paraffin ratio over Different MoLoaded Fe-Cu-K supported on activated carbon catalysts $(593 \mathrm{~K}, 3 \mathrm{N1} / \mathrm{g}$-cat/h, 300 psig, H2/CO = 0.9). All catalysts contain 15.7 wt \% Fe, 0.8 wt \% Cu, and 0.9 wt \% K (Ma et al., 2006)

Table 2.4 BET measurement result of activated carbon supports (Ma et al., 2007a)

Table 2.5 Isomerization activity zeolites added to Fe catalyst (Vytnova et al., 2006)

Table 2.6 Average hydrocarbon distribution (\%C) for the base + zeolite hybrid catalysts (Martinez et al., 2007)

Table 4.1 Degree of reduction calculations for different catalysts

Table 5.1 Fischer-Tropsch data for the reactions without base catalyst (syngas flow=100 scc/min, Temperature $=300^{\circ} \mathrm{C}$, Pressure $=300 \mathrm{Psi}, \mathrm{H}_{2} / \mathrm{CO}$ ratio $=1.0$, TOS $=0-48 \mathrm{~h}$ )

Table 6.1 Overall product distribution (separate-bed catalyst arrangement, $0.5 \mathrm{~g}$ of base catalyst, $\mathrm{Si} / \mathrm{Al}$ ratio in $\mathrm{ZSM}-5=50, \mathrm{H}_{2} / \mathrm{CO}$ ratio $=1$, total feed rate $=100 \mathrm{scc} / \mathrm{min}$, reactor temperature $=300^{\circ} \mathrm{C}$, reactor pressure $=300 \mathrm{psi}, \mathrm{TOS}=24-48 \mathrm{~h}$ )

Table 6.2 Aqueous-phase compounds (separate-bed catalyst arrangement, $0.5 \mathrm{~g}$ of base catalyst, $\mathrm{Si} / \mathrm{Al}$ ratio in $\mathrm{ZSM}-5=50, \mathrm{H}_{2} / \mathrm{CO}$ ratio $=1$, total feed rate $=100 \mathrm{scc} / \mathrm{min}$, reactor temperature $=300^{\circ} \mathrm{C}$, reactor pressure $=300 \mathrm{psi}, \mathrm{TOS}=24-48 \mathrm{~h}$ )

Table 6.3 Overall product distribution (mixed-bed catalyst arrangement, $0.5 \mathrm{~g}$ of base catalyst, $\mathrm{Si} / \mathrm{Al}$ ratio in $\mathrm{ZSM}-5=50, \mathrm{H}_{2} / \mathrm{CO}$ ratio $=1$, total feed rate $=100 \mathrm{scc} / \mathrm{min}$, reactor temperature $=300^{\circ} \mathrm{C}$, reactor pressure $=300 \mathrm{psi}, \mathrm{TOS}=24-48 \mathrm{~h}$ ) 
Table 6.4 Aqueous-phase compounds (mixed-bed catalyst arrangement, $0.5 \mathrm{~g}$ of base catalyst, $\mathrm{Si} / \mathrm{Al}$ ratio in $\mathrm{ZSM}-5=50, \mathrm{H}_{2} / \mathrm{CO}$ ratio $=1$, total feed rate $=100 \mathrm{scc} / \mathrm{min}$, reactor temperature $=300^{\circ} \mathrm{C}$, reactor pressure $=300 \mathrm{psi}, \mathrm{TOS}=24-48 \mathrm{~h}$ )

Table 6.5 Delta amounts of overall products ( $0.5 \mathrm{~g}$ of base catalyst, $\mathrm{Si} / \mathrm{Al}$ ratio in $\mathrm{ZSM}-5=50, \mathrm{H}_{2} / \mathrm{CO}$ ratio $=1$, total feed rate $=100 \mathrm{scc} / \mathrm{min}$, reactor temperature $=300^{\circ} \mathrm{C}$, reactor pressure $=300 \mathrm{psi}, \mathrm{TOS}=$ $24-48 \mathrm{~h})$

Table 6.6 Delta amounts of WGS and FTS reaction rates $(0.5 \mathrm{~g}$ of base catalyst, $\mathrm{Si} / \mathrm{Al}$ ratio in ZSM-5 = $50, \mathrm{H}_{2} / \mathrm{CO}$ ratio $=1$, total feed rate $=100 \mathrm{scc} / \mathrm{min}$, reactor temperature $=300^{\circ} \mathrm{C}$, reactor pressure $=300$ Psi, TOS = $24-48$ h)

Table 6.7 Delta amounts of gas products $\left(0.5 \mathrm{~g}\right.$ of base catalyst, $\mathrm{Si} / \mathrm{Al}$ ratio in $\mathrm{ZSM}-5=50, \mathrm{H}_{2} / \mathrm{CO}$ ratio $=1$, total feed rate $=100 \mathrm{scc} / \mathrm{min}$, reactor temperature $=300^{\circ} \mathrm{C}$, reactor pressure $=300$ Psi, $\mathrm{TOS}=24-$ $48 \mathrm{~h})$

Table 6.8 Delta amounts of hydrocarbon and alcohol production rates ( $0.5 \mathrm{~g}$ of base catalyst, $\mathrm{Si} / \mathrm{Al}$ ratio in $\mathrm{ZSM}-5=50, \mathrm{H}_{2} / \mathrm{CO}$ ratio $=1$, total feed rate $=100 \mathrm{scc} / \mathrm{min}$, reactor temperature $=300^{\circ} \mathrm{C}$, reactor pressure $=300 \mathrm{Psi}, \mathrm{TOS}=24-48 \mathrm{~h}$ )

Table 6.9 Delta values of liquid paraffins and aromatic compounds in organic liquid phase ( $0.5 \mathrm{~g}$ of base catalyst, $\mathrm{Si} / \mathrm{Al}$ ratio in $\mathrm{ZSM}-5=50, \mathrm{H}_{2} / \mathrm{CO}$ ratio $=1$, total feed rate $=100 \mathrm{scc} / \mathrm{min}$, reactor temperature $=$ $300^{\circ} \mathrm{C}$, reactor pressure $=300 \mathrm{Psi}$, TOS $=24-48 \mathrm{~h}$ )

Table 6.10 Delta amounts of alcohol products and water in aqueous liquid phase $(0.5 \mathrm{~g}$ of base catalyst, $\mathrm{Si} / \mathrm{Al}$ ratio in $\mathrm{ZSM}-5=50, \mathrm{H}_{2} / \mathrm{CO}$ ratio $=1$, total feed rate $=100 \mathrm{scc} / \mathrm{min}$, reactor temperature $=300^{\circ} \mathrm{C}$, reactor pressure $=300 \mathrm{Psi}, \mathrm{TOS}=24-48 \mathrm{~h}$ )

Table 6.11 Effect of temperature on products from the base catalyst and the separate-bed catalyst arrangement $\left(0.5 \mathrm{~g}\right.$ of base catalyst, $\mathrm{Si} / \mathrm{Al}$ ratio in $\mathrm{ZSM}-5=50, \mathrm{H}_{2} / \mathrm{CO}$ ratio $=1$, total feed rate $=100$ $\mathrm{scc} / \mathrm{min}$, reactor pressure $=300 \mathrm{psi}, \mathrm{TOS}=24-48 \mathrm{~h}$ )

Table 6.12 Effect of temperatures on reaction rates from the base catalyst and separate-bed catalyst arrangement $\left(0.5 \mathrm{~g}\right.$ of base catalyst, $\mathrm{Si} / \mathrm{Al}$ ratio in $\mathrm{ZSM}-5=50, \mathrm{H}_{2} / \mathrm{CO}$ ratio $=1$, total feed rate $=100$ $\mathrm{scc} / \mathrm{min}$, reactor pressure $=300 \mathrm{psi}, \mathrm{TOS}=24-48 \mathrm{~h}$ ) 
Table 6.13 Effect of temperature on gas-phase paraffins from the base catalyst and the separate-bed $(0.5$ $\mathrm{g}$ of base catalyst, $\mathrm{Si} / \mathrm{Al}$ ratio in $\mathrm{ZSM}-5=50, \mathrm{H}_{2} / \mathrm{CO}$ ratio $=1$, total feed rate $=100 \mathrm{scc} / \mathrm{min}$, reactor pressure $=300 \mathrm{psi}$, TOS $=24-48 \mathrm{~h}$ )

Table 6.14 Effect of temperature on liquid production rates from the base catalyst and the separate-bed $\left(0.5 \mathrm{~g}\right.$ of base catalyst, $\mathrm{Si} / \mathrm{Al}$ ratio in $\mathrm{ZSM}-5=50, \mathrm{H}_{2} / \mathrm{CO}$ ratio $=1$, total feed rate $=100 \mathrm{scc} / \mathrm{min}$, reactor pressure $=300 \mathrm{psi}$, TOS $=24-48 \mathrm{~h}$ )

Table 6.15 Effect of temperature on liquid paraffins from the base catalyst and the separate-bed ( $0.5 \mathrm{~g}$ of base catalyst, $\mathrm{Si} / \mathrm{Al}$ ratio in $\mathrm{ZSM}-5=50, \mathrm{H}_{2} / \mathrm{CO}$ ratio $=1$, total feed rate $=100 \mathrm{scc} / \mathrm{min}$, reactor pressure $=300 \mathrm{psi}, \mathrm{TOS}=24-48 \mathrm{~h}$ )

Table 6.16 Effect of temperature on aromatic compounds from the base catalyst and the separate-bed $\left(0.5 \mathrm{~g}\right.$ of base catalyst, $\mathrm{Si} / \mathrm{Al}$ ratio in $\mathrm{ZSM}-5=50, \mathrm{H}_{2} / \mathrm{CO}$ ratio $=1$, total feed rate $=100 \mathrm{scc} / \mathrm{min}$, reactor pressure $=300 \mathrm{psi}$, TOS $=24-48 \mathrm{~h}$ )

Table 6.17 Effect of temperature on weights of alcohols and water from the base catalyst and the separate-bed $\left(0.5 \mathrm{~g}\right.$ of base catalyst, $0.5 \mathrm{~g}$ of $\mathrm{ZSM}-5, \mathrm{Si} / \mathrm{Al}$ ratio in $\mathrm{ZSM}-5=50, \mathrm{H}_{2} / \mathrm{CO}$ ratio $=1$, total feed rate $=100 \mathrm{scc} / \mathrm{min}$, reactor pressure $=300 \mathrm{psi}$, TOS $=24-48 \mathrm{~h}$ )

Table 7.1 WGS and FTS reaction rates (separate-bed catalyst arrangement, $0.5 \mathrm{~g}$ of base catalyst, $0.5 \mathrm{~g}$ of ZSM-5 catalyst, $\mathrm{Si} / \mathrm{Al}$ ratio in $\mathrm{ZSM}-5=50, \mathrm{H}_{2} / \mathrm{CO}$ ratio $=1$, total feed rate $=100 \mathrm{scc} / \mathrm{min}$, reactor temperature $=300^{\circ} \mathrm{C}$, reactor pressure $=300 \mathrm{psi}, \mathrm{N}_{\mathrm{CO}}$, inlet $\left.=2.112 \mathrm{mmole} / \mathrm{min}, \mathrm{TOS}=0-240 \mathrm{~h}\right) 81$

Table 7.2 Hydrocarbons distribution (g carbon/day) (separate-bed catalyst arrangement, $0.5 \mathrm{~g}$ of base catalyst, $0.5 \mathrm{~g}$ of $\mathrm{ZSM}-5$ catalyst, $\mathrm{Si} / \mathrm{Al}$ ratio in $\mathrm{ZSM}-5=50, \mathrm{H}_{2} / \mathrm{CO}$ ratio $=1$, total feed rate $=100$ $\mathrm{scc} / \mathrm{min}$, reactor temperature $=300^{\circ} \mathrm{C}$, reactor pressure $=300 \mathrm{psi}, \mathrm{TOS}=0-240 \mathrm{~h}$ )

Table 7.3 Aqueous-phase compounds (separate-bed catalyst arrangement, $0.5 \mathrm{~g}$ of base catalyst, $0.5 \mathrm{~g}$ of $\mathrm{ZSM}-5$ catalyst, $\mathrm{Si} / \mathrm{Al}$ ratio in $\mathrm{ZSM}-5=50, \mathrm{H}_{2} / \mathrm{CO}$ ratio $=1$, total feed rate $=100 \mathrm{scc} / \mathrm{min}$, reactor temperature $=300^{\circ} \mathrm{C}$, reactor pressure $=300 \mathrm{psi}$, TOS $=0-240 \mathrm{~h}$ )

Table A.1 GC operating conditions for liquid analysis 108

Table B.1 Slope and rRF of TCD gas compounds 109 
Table B.2 Slope and rRF of FID gas compounds

Table B.3 Areas and weights of standard alcohol samples

Table F.1 Conversions and liquid weights collected for base catalyst, separate bed, and mixed bed

Table F.2 WGS and FTS rates

Table F.3 FID gas amounts for base catalyst, separate bed, and mixed bed 


\section{CHAPTER 1}

\section{INTRODUCTION}

The world's fuel need is predominantly dependent on crude oil (Dry, 2002). Oil prices are rising continuously since 1960. Oil reserves are also limited and the demand for fuel is increasing day by day. The negative effect of oil prices on the economy is significant, and should be used to build the business case to invest in alternative energy like coal, methane, and renewable energy (Owen et al., 2010).

Presently known reserves of methane and of coal exceed that of crude oil by factors of about 1.5 and 25 respectively (Dry, 2002). Therefore, production of syngas from methane or coal and conversion of the syngas to a range of fuels and chemicals could be of interest (Dry, 2002). For all these reasons, the Fischer-Tropsch (FT) process is an ideal candidate to fulfill the energy demands. Development should be in areas that decrease the capital costs of use of syngas through the FT process and improve the thermal efficiency of the plant as a whole (Vasloo, 2001).

Application of FT involves complex integrated plants. The plant consists of synthesis gas preparation, FT synthesis and product upgrading. Some advantages of FT hydrocarbons, compared to crude oil, as a feedstock for fuel production are the absence of sulfur, nitrogen or heavy metals, and the low aromatic content (Forghani et al., 2009). The kerosene produced has good combustion properties and high smoke points, and the diesel fuel produced has a high cetane number and can be used in blending purposes (Steynberg, 1999).

Martinez et al. (2005) showed that the chain size of constituents of the FT liquid can be limited beyond the gasoline-range product with the addition of ZSM-5 to form dual-functional FT catalyst. Thus the pore structure of ZSM-5 and its catalytic cracking active sites can limit the size of produced molecules (Pour et al., 2008).

\subsection{FISCHER-TROPSCH PROCESS}

The FT process is a key component of gas-to-liquids (GTL) technology, producing a petroleum substitute, typically from coal, natural gas, or biomass . The FT process is a set of chemical reactions that convert a mixture of carbon monoxide and hydrogen into liquid hydrocarbons. The chemical reactions lead to a series of both desirable products and undesirable byproducts and the 
liberation of a large amount of heat from the highly exothermic synthesis reactions (Stenger et al., 1986; Espinoza et al., 1998; Steynberg et al., 1999). The FT products are olefins, oxygenates, gasoline-, diesel, and kerosene-range paraffins. The products gasoline- and diesel-range paraffins are desirable because these products are already established and proven in the market. Moreover, this project details are mainly concerned on these products. Useful reactions that give alkanes $\mathrm{C}_{n} \mathrm{H}_{(2 n+2)}$, where ' $\mathrm{n}$ ' is a positive integer, are generalized as (Luo et al., 2009):

$(2 \mathrm{n}+1) \mathrm{H}_{2}+\mathrm{nCO} \rightarrow \mathrm{C}_{\mathrm{n}} \mathrm{H}_{(2 \mathrm{n}+2)}+\mathrm{n} \mathrm{H}_{2} \mathrm{O}$

The water-gas-shift reaction (WGS) also occurs in FT process. WGS is expressed as:

$\mathrm{CO}+\mathrm{H}_{2} \mathrm{O} \leftrightarrow \mathrm{CO}_{2}+\mathrm{H}_{2}$

Generally, the FT process is operated in the temperature range of $150-300^{\circ} \mathrm{C}$. Higher temperatures lead to faster reactions and higher conversion rates, but also tend to favor methane production (Schulz et al., 1991). As a result, the temperature is usually maintained in the low to middle part of the range. Increasing the pressure leads to higher conversion rates and also favors formation of long-chain alkanes. Typical pressures range from one to several tens of atmospheres. Even higher pressures would be favorable, but the benefits may not justify the additional costs of high-pressure equipment (Schulz, 2003).

A variety of synthesis-gas compositions can be used. For cobalt-based catalysts, the optimal $\mathrm{H}_{2}$ : $\mathrm{CO}$ ratio is around 1.8-2.1 (Dry, 2002). Iron-based catalysts promote the WGS reaction (Equation 1.2) and thus can tolerate significantly lower ratios. WGS can be important for synthesis gas derived from coal or biomass, which tend to have relatively low $\mathrm{H}_{2}$ : $\mathrm{CO}$ ratios (<1) (Lohitharn et al., 2008).

\subsection{INTEREST IN FISCHER-TROPSCH PROCESS}

Linear long-chain hydrocarbons usually dominate the FT products, which need post-cracking or isomerization to obtain transportation fuels like gasoline, diesel. The use of different zeolites in combination with a FT catalyst has been investigated by Botes et al. (2004). Vytnova et al. (2006) suggests the use of ZSM-5 in the cracking of the long-chain hydrocarbons. Note that zeolites are used in our experiments for FT liquid production. During recent years, the use of FT has gained lot of research interest. Some of the factors that contribute to interest in FT are:

- An increase in the known reserves of natural gas (Owen et al., 2010). 
- Environmental pressures to minimize the flaring of associated gas (Waldner et al., 2001).

\subsection{CHALLENGES IN FISCHER-TROPSCH PROCESS}

The area of concern in FT plants should be to decrease the capital cost of syngas generation and to improve the thermal efficiency of the plant as a whole. The very common way of improving the thermal efficiency of the process is to combine the FT process with a power generation plant. Such a combination will create a more efficient use of the low-pressure steam produced by the FT process (Vosloo, 2001).

Also, in order to reduce the total cost of the catalyst in the FT process, an iron-based catalyst can be used. Note that an iron-based catalyst will be used in our experiments for FT liquid production.

\subsection{COMMERCIAL FISCHER-TROPSCH PLANTS}

There are many companies involved in Fischer Tropsch business. Some are shown in Table 1.1.

Table 1.1 Commercial Fischer-Tropsch plants

\begin{tabular}{|l|c|l|l|l|l|}
\hline Company & Location & $\begin{array}{l}\text { Size } \\
\text { (BPD) }\end{array}$ & Type of Products & $\begin{array}{l}\text { Year of Production } \\
\text { Start }\end{array}$ & References \\
\hline Sasol & $\begin{array}{l}\text { South } \\
\text { Africa }\end{array}$ & 124,000 & $\begin{array}{c}\text { Light olefins and } \\
\text { gasoline }\end{array}$ & Dry (2001) \\
\hline Moss Gas & $\begin{array}{l}\text { South } \\
\text { Africa }\end{array}$ & 22,500 & Gasoline and diesel & 1955 & Knottenbelt \\
& Malaysia & 20,000 & $\begin{array}{r}\text { Waxes, chemicals, } \\
\text { diesel }\end{array}$ & 2002)
\end{tabular}

\subsection{OBJECTIVE OF THIS STUDY}

The idea here is to increase gasoline- and diesel-range hydrocarbons. The present research investigates this as follows: 
- The high-silica ZSM-5 zeolite is evaluated in two process configurations. In one operating mode, Fe catalyst and ZSM-5 are placed in separate zones. In the other operating mode, the Fe catalyst and ZSM-5 are mixed. Here the effect of catalyst bed configuration is checked.

- The effects of reaction conditions (temperature, changes in ZSM-5 weights, TOS) are investigated, and the liquid and gas products formed are analyzed. These conditions are important to compare the iron-based catalyst with the dual-functional catalyst system (Febased + ZSM-5). 


\section{CHAPTER 2}

\section{LITERATURE REVIEW}

The focus of the present research is on Fe-based catalysts because of their high water-gas-shift (WGS) activity in addition to their high FT activity. Fe-based catalysts are also low cost and have low selectivity towards methane ( $\mathrm{Li}$ et al., 2007). In addition, introduction of zeolites into a FT catalyst increases cracking of heavier liquid hydrocarbons (Abramova et al., 2005), and this is also considered here.

\subsection{OVERVIEW}

FT synthesis mainly uses cobalt- (Co) and iron-based catalyst commercially (Yang et al., 2005). There are some disadvantages to using a Co-based catalyst. Cobalt is 1000 times more expensive as iron (Davis, 2003). Cobalt-based catalysts are only used in the Low-Temperature Fischer-Tropsch (LTFT) process, as excess methane is produced at the higher temperatures (Dry, 2002). The Fe-based FT catalyst is able to use low $\mathrm{H}_{2} / \mathrm{CO}$ ratios of synthesis gas from coal gasification, whereas the Co-based FT catalyst needs a higher ratio (Wan et al., 2008).

FT synthesis suffers mainly from two problems. One is that polymerization leads to waxy products. Waxy products are long-chain hydrocarbons (Martinez et al., 2007). Hence, the chain length of hydrocarbons needs to be adjusted so that primary gasoline- and diesel-range products are formed (Ma et al., 2007b). Ma et al. (2007 b) have shown that the chain length of FT liquids could be controlled below $\mathrm{C}_{20}$ over an activated carbon support. Martinez et al. (2007) used zeolite as a cracking catalyst and showed that FT liquids can be cracked to gasoline- and diesel-range products. Therefore we can use zeolite and activated carbon together for tailoring of product hydrocarbon.

\subsection{REACTION INVOLVED IN THE FISCHER TROPSCH PROCESS}

The chemistry in FT process is very complex but can be simplified into the following chemical reactions (Dry, 2004). Methane formation takes place as follows:

$\mathrm{CO}+3 \mathrm{H}_{2} \rightarrow \mathrm{CH}_{4}+\mathrm{H}_{2} \mathrm{O}$ 
Heavier hydrocarbons form as follows:

$\mathrm{n} \mathrm{CO}+2 \mathrm{n} \mathrm{H}_{2} \rightarrow\left(-\mathrm{CH}_{2}-\right)_{\mathrm{n}}+\mathrm{n} \mathrm{H}_{2} \mathrm{O}$

Alcohols are produced by:

$\mathrm{n} \mathrm{CO}+2 \mathrm{n} \mathrm{H}_{2} \rightarrow \mathrm{C}_{\mathrm{n}} \mathrm{H}_{2 \mathrm{n}+2} \mathrm{O}+(\mathrm{n}-1) \mathrm{H}_{2} \mathrm{O}$

The FT process depends on the ratio of consumption of hydrogen and carbon monoxide. From Equation (2.2), this ratio is 2 for hydrocarbons. The WGS reaction, Equation (1.2), which essentially converts excess $\mathrm{CO}$ to $\mathrm{H}_{2}$, is favored by the iron catalyst (Haijun et al., 2008). Hence, we can carry out the FT process using the Fe-based catalyst with feeds having the ratio of $\mathrm{H}_{2}$ to $\mathrm{CO} \leq 1$ (Riedel et al., 1999). A cobalt-based catalyst favors Equation (2.1) which uses $\mathrm{H}_{2}$ to form methane which is an unneeded product, hence the feed ratio of $\mathrm{H}_{2}$ to $\mathrm{CO}$ in case of cobalt catalyst is typically between 2.06 to 2.16 (Dry, 2004).

\subsection{KINETICS OF FISCHER-TROPSCH PROCESS}

There are many rate models reported in the literature. Some are listed in Table 2.1.

\subsection{REACTION MECHANISMS}

The FT synthesis is a polymerization reaction in which monomers are produced from the reactants hydrogen and carbon monoxide. Hence, FT reactions can be divided into the following three sections (Claeys et al., 2004):

1. Generation of the chain initiator

2. Chain growth or propagation

3. Chain termination or desorption

There are several FT mechanisms reported in the literature described below. Here $\mathrm{M}$ is a metal, $\mathrm{R}$ is $\mathrm{CH}_{3}$, etc. 
Table 2.1 Iron-based kinetic rate models

\begin{tabular}{|c|c|c|c|c|c|c|c|}
\hline Rate Model & Catalyst & $\begin{array}{l}\mathrm{T} \\
\left({ }^{\circ} \mathrm{C}\right)\end{array}$ & $\begin{array}{l}k(\mathrm{~mol} / \mathrm{g}- \\
\text { cat } . \mathrm{h} . \\
\mathrm{MPa})\end{array}$ & $\begin{array}{l}\mathrm{P} \\
\text { (psi) }\end{array}$ & $\begin{array}{l}a, b \\
\text { or c }\end{array}$ & Reference & $\begin{array}{l}\mathrm{H}_{2} / \mathrm{CO} \\
\text { ratio }\end{array}$ \\
\hline $\mathrm{r}_{\mathrm{FT}}=\frac{k P_{C O} P_{\mathrm{H}_{2}}}{P_{\mathrm{CO}}+a P_{\mathrm{H} 2 \mathrm{O}}}$ & CCI fused iron & $\begin{array}{l}250 \\
282 \\
315\end{array}$ & $\begin{array}{c}0.0017 \\
0.0049 \\
0.013\end{array}$ & NA & $\begin{array}{l}0.028 \\
0.028 \\
0.028\end{array}$ & $\begin{array}{c}\text { Atwood and } \\
\text { Bennett (1979) }\end{array}$ & NA \\
\hline $\mathrm{r}_{\mathrm{FT}}=\frac{k P_{\mathrm{CO}} P_{\mathrm{H}_{2}}}{P_{\mathrm{CO}}+a P_{\mathrm{H}_{2 O} \mathrm{O}}}$ & $\mathrm{Fe} / \mathrm{Cu} / \mathrm{K}$ & 265 & 0.062 & NA & 0.58 & Kuo (1984) & NA \\
\hline $\mathrm{r}_{\mathrm{FT}}=\frac{k P_{\mathrm{CO}} P_{\mathrm{H}_{2}}}{P_{\mathrm{CO}}+a P_{\mathrm{H} 2 \mathrm{O}}}$ & Precipitated Fe & 270 & 0.018 & NA & 4.51 & $\begin{array}{l}\text { Nettelhoff et al. } \\
(1985)\end{array}$ & NA \\
\hline $\mathrm{r}_{\mathrm{FT}}=\frac{k P_{\mathrm{CO}} P^{2} \mathrm{H}_{2}}{P_{\mathrm{CO}} P_{\mathrm{H}_{2}}+b P_{\mathrm{H} 2 \mathrm{O}}}$ & $\begin{array}{c}\text { C-73 fused } \\
\text { iron } \\
\text { (United } \\
\text { Catalysts Inc.) }\end{array}$ & $\begin{array}{l}232 \\
248 \\
263\end{array}$ & $\begin{array}{l}0.013 \\
0.025 \\
0.042\end{array}$ & NA & $\begin{array}{l}2.56 \\
1.15 \\
0.67\end{array}$ & $\begin{array}{l}\text { Huff and } \\
\text { Satterfield } \\
(1984)\end{array}$ & NA \\
\hline $\mathrm{r}_{\mathrm{FT}}=\frac{k P_{\mathrm{CO}} P_{\mathrm{H}_{2}}}{P_{\mathrm{CO}}+c P_{\mathrm{CO} 2}}$ & $\begin{array}{l}\text { S6-10 fused } \\
\text { iron (BASF) }\end{array}$ & 240 & 0.010 & NA & 0.19 & $\begin{array}{l}\text { Nettelhoff et al. } \\
(1985)\end{array}$ & NA \\
\hline $\mathrm{r}_{\mathrm{FT}}=\frac{k P_{\mathrm{CO}} P_{\mathrm{H}_{2}}}{P_{\mathrm{CO}}+c P_{\mathrm{CO} 2}}$ & $\begin{array}{l}\text { Precipitated } \\
100 \mathrm{Fe} / 1.3 \mathrm{~K}\end{array}$ & $\begin{array}{l}220 \\
240 \\
250 \\
260\end{array}$ & $\begin{array}{c}0.0088 \\
0.025 \\
0.049 \\
0.058\end{array}$ & NA & $\begin{array}{l}0.255 \\
0.210 \\
0.229 \\
0.237\end{array}$ & $\begin{array}{c}\text { Leadakowicz et } \\
\text { al. (1985) }\end{array}$ & NA \\
\hline $\mathrm{r}_{\mathrm{FT}}=k P_{H_{2}}$ & Fused Fe/K & $\begin{array}{l}225- \\
265\end{array}$ & NA & $\begin{array}{l}147- \\
265\end{array}$ & NA & Dry et al.(1972) & $1.2-7.2$ \\
\hline $\mathrm{r}_{\mathrm{FT}}=\frac{k P_{\mathrm{CO}} P_{\mathrm{H}_{2}}}{\left(P_{\mathrm{CO}}+K P_{\mathrm{H} 2 \mathrm{O}}\right)}$ & $\begin{array}{l}\text { Precipitated } \\
\mathrm{Fe} / \mathrm{K} / \mathrm{Cu}\end{array}$ & 250 & NA & $\begin{array}{l}220- \\
441\end{array}$ & NA & $\begin{array}{l}\text { Zimmerman et } \\
\text { al. (1990) }\end{array}$ & $0.6-1.0$ \\
\hline
\end{tabular}

NA - Not Available

\subsubsection{Alkyl mechanism}

The mechanism was originally proposed by Fischer et al. (1926) and Crawford et al. (1939). Chain initiation takes place via dissociative $\mathrm{CO}$ chemisorption and formation of surface carbon. This surface carbon further hydrogenates, giving $\mathrm{CH}, \mathrm{CH}_{2}$ and $\mathrm{CH}_{3}$ surface species. The $\mathrm{CH}_{3}$ surface species is the chain initiator and the $\mathrm{CH}_{2}$ surface species is a monomer. Chain growth takes place by subsequent addition of $\mathrm{CH}_{2}$.

Initiation:

Monomer and chain initiator are formed as shown below: 
$\mathrm{M}=\mathrm{CO} \stackrel{+2 H,-H 2 O}{\longrightarrow} \mathrm{M} \equiv \mathrm{C} \stackrel{+H}{\rightarrow} \mathrm{M} \equiv \mathrm{CH} \stackrel{+H}{\rightarrow} \mathrm{M}=\mathrm{CH}_{2} \stackrel{+H}{\rightarrow} \mathrm{M}-\mathrm{CH}_{3}$

Surface carbon Monomer Chain initiator

Propagation:

The chain initiator and the monomer react by:

$\mathrm{M}-\mathrm{CH}_{3}+\mathrm{M}=\mathrm{CH}_{2} \stackrel{+H}{\rightarrow} \mathrm{M}-\mathrm{CH}_{2}-\mathrm{CH}_{3}+\mathrm{M}-\mathrm{H}$

In subsequent propagation steps, the monomer is added as follows:

$\mathrm{M}-\mathrm{CH}_{2}-\mathrm{R}+\mathrm{M}=\mathrm{CH}_{2} \stackrel{+H}{\rightarrow} \mathrm{M}-\mathrm{CH}_{2}-\mathrm{CH}_{2} \mathrm{R}+\mathrm{M}$

In general, the alkyl M- $\mathrm{CH}_{2}-\mathrm{CH}_{2} \mathrm{R}$ is called the propagation-step intermediate product because it is formed in the propagation step and consumed by the termination step.

Termination:

The polymerization ends when the metal $\mathrm{M}$ is returned to its original state from the propagationstep intermediate product in one of three ways, leading to three primary products as shown below:

$$
\begin{aligned}
& \mathrm{M}-\mathrm{CH}_{2}-\mathrm{CH}_{2} \mathrm{R} \stackrel{-H}{\rightarrow} \mathrm{CH}_{2}=\mathrm{CHR}+\mathrm{M} \quad \alpha \text {-olefin } \\
& \stackrel{+H}{\rightarrow} \mathrm{CH}_{3}-\mathrm{CH}_{2} \mathrm{R}+\mathrm{M}-\mathrm{H} \quad \text { n-paraffin } \\
& \stackrel{+O H}{\longrightarrow} \mathrm{CH}_{2} \mathrm{OH}-\mathrm{CH}_{2} \mathrm{R}+\mathrm{M} \quad \text { n-alcohol }
\end{aligned}
$$

Primary products $\alpha$-olefin and n-paraffins are formed by reactions (2.7) and (2.8) respectively. Note that the alkyl mechanism does not include the formation of branched hydrocarbons. Also, the alkyl mechanism cannot explain the formation of oxygenates in the FT synthesis (Schulz et al., 1988, 1990).

\subsubsection{Alkenyl mechanism}

Maitlis et al. (1996) proposed an alternate reaction pathway to predict the formation of olefins in FT synthesis. 
Initiation:

The monomer is formed similar to Equation (2.10) by:

$\mathrm{M}=\mathrm{CO} \stackrel{+2 H,-H 2 O}{\longrightarrow} \mathrm{M} \equiv \mathrm{C} \stackrel{+H}{\rightarrow} \quad \mathrm{M} \equiv \mathrm{CH} \stackrel{+H}{\rightarrow} \mathrm{M}=\mathrm{CH}_{2}$

Surface carbon $\quad \begin{aligned} & \text { Hydrogenated } \\ & \text { surface carbon }\end{aligned}$

Now the chain initiator is formed by addition of the hydrogenated surface carbon to the monomer.

$\mathrm{M} \equiv \mathrm{CH}+\mathrm{M}=\mathrm{CH}_{2} \rightarrow \mathrm{M}-\mathrm{CH}=\mathrm{CH}_{2}+\mathrm{M}$

Chain initiator

Propagation:

Chain propagation involves the addition of the methylene monomer to the chain initiator to form a surface allyl species. This is followed by an allyl-vinyl isomerization forming a surface alkenyl species:

$\mathrm{M}-\mathrm{CH}=\mathrm{CH}_{2}+\mathrm{M}=\mathrm{CH}_{2} \rightarrow \mathrm{M}-\mathrm{CH}_{2}-\mathrm{CH}=\mathrm{CH}_{2}+\mathrm{M} \rightarrow \mathrm{M}-\mathrm{CH}=\mathrm{CH}-\mathrm{CH}_{3}+\mathrm{M}$

Chain initiator Surface allyl Surface alkenyl

In subsequent propagation steps, the monomer is added to the surface alkenyl to give a higher alkenyl species:

$\mathrm{M}-\mathrm{CH}=\mathrm{CHR}+\mathrm{M}=\mathrm{CH}_{2} \rightarrow \mathrm{M}-\mathrm{CH}_{2}-\mathrm{CH}=\mathrm{CHR}+\mathrm{M} \rightarrow \mathrm{M}-\mathrm{CH}=\mathrm{CH}-\mathrm{CH}_{2} \mathrm{R}+\mathrm{M}$

Termination:

Product desorption involves the hydrogen addition to the alkenyl species giving a $\alpha$-olefin.

$\mathrm{M}-\mathrm{CH}=\mathrm{CH}-\mathrm{R} \stackrel{+H}{\rightarrow} \mathrm{CH}_{2}=\mathrm{CHR}+\mathrm{M}$

$\alpha$-olefin 
Note that this mechanism fails to explain the formation of n-paraffin as a primary product.

\subsubsection{Enol Mechanism}

Storch et al. (1951) proposed an alternate reaction scheme involving oxygen-containing surface species (enols). Two alternate monomers are postulated.

Initiation:

The chain initiator, or the main monomer and the alternate monomer are formed by addition of hydrogen to the carbon monoxide surface species.

$\mathrm{M}=\mathrm{CO} \stackrel{+2 H}{\longrightarrow} \mathrm{M}=\mathrm{C}(\mathrm{H})-\mathrm{OH} \stackrel{+H}{\rightarrow} \mathrm{M}-\mathrm{CH}_{2}-\mathrm{OH} \stackrel{+2 H,-H 2 O}{\longrightarrow} \mathrm{M}-\mathrm{CH}_{3}$

Chain initiator Alternate monomers

In subsequent steps, the monomer $\mathrm{M}-\mathrm{CH}_{3}$ is added to the carbon monoxide surface species as follows:

$\mathrm{M}=\mathrm{CO}+\mathrm{M}-\mathrm{CH}_{3} \stackrel{+H}{\rightarrow} \mathrm{M}=\mathrm{C}\left(\mathrm{CH}_{3}\right)-\mathrm{OH}+\mathrm{M}$

Similarly, $\mathrm{M}=\mathrm{C}(\mathrm{H})-\mathrm{OH}$ can be formed by surface hydrogen:

$\mathrm{M}=\mathrm{CO}+\mathrm{M}-\mathrm{H} \stackrel{+H}{\rightarrow} \mathrm{M}=\mathrm{C}(\mathrm{H})-\mathrm{OH}+\mathrm{M}$

Propagation:

Chain growth occurs between two enol species with elimination of water. The presence of an enol is due to the involvement of a $\mathrm{C}(\mathrm{R})-\mathrm{OH}$ surface species.

$\mathrm{M}=\mathrm{C}(\mathrm{R})-\mathrm{OH}+\mathrm{HO}-(\mathrm{H}) \mathrm{C}=\mathrm{M} \stackrel{+2 H,-H 2 O}{\longrightarrow} \mathrm{M}=\mathrm{C}(\mathrm{OH})-\mathrm{CH}_{2}-\mathrm{R}+\mathrm{M}$

$\mathrm{C}(\mathrm{R})-\mathrm{OH}$ surface species $\quad$ Enol surface species

Termination:

The termination process yields oxygenates and $\alpha$-olefins as primary products. According to this mechanism, n-paraffins are formed secondarily by hydrogenation of $\alpha$-olefins. 


$$
\mathrm{M}=\mathrm{C}(\mathrm{OH})-\mathrm{CH}_{2}-\mathrm{R} \rightarrow \mathrm{RCH}_{2} \mathrm{CHO}+\mathrm{M}
$$

Oxygenate

$$
\stackrel{+2 \mathrm{H}}{\longrightarrow} \mathrm{RCH}_{2} \mathrm{CH}_{2} \mathrm{OH}+\mathrm{M}
$$

Oxygenate

$$
\begin{aligned}
\mathrm{M}=\mathrm{C}(\mathrm{OH})-\mathrm{CH}_{2}-\mathrm{R} \stackrel{+H}{\rightarrow} \mathrm{M}=\mathrm{C}(\mathrm{H})-\mathrm{OH}+\mathrm{R}=\mathrm{CH}_{2} \stackrel{+2 \mathrm{H}}{\longrightarrow} \mathrm{R}-\mathrm{CH}_{3} \\
\text { Oxygenate } \quad \alpha \text {-olefin } \quad \text { n-paraffin }
\end{aligned}
$$

\subsubsection{CO insertion mechanism}

The CO insertion mechanism was originally proposed by Sternberg et al. (1959) and Roginski (1965). The CO insertion mechanism is viewed by many researchers as the main reaction leading to the formation of oxygenates (Anderson et al., 1985).

Initiation:

Chemisorbed $\mathrm{CO}$ is the monomer. The chain initiator, a surface methyl species, is formed through an alcohol intermediate by the addition of the monomer to hydrogen and removal of water:

$\mathrm{M}=\mathrm{CO} \stackrel{+3 H}{\longrightarrow} \mathrm{M}-\mathrm{CH}_{2}-\mathrm{OH} \stackrel{+2 \mathrm{H},-\mathrm{H} 2 \mathrm{O}}{\longrightarrow} \mathrm{M}-\mathrm{CH}_{3}$

Monomer Alcohol intermediate Chain initiator

Propagation:

The propagation step starts with the addition of the chain initiator $\mathrm{M}-\mathrm{CH}_{3}$ to the chemisorbed $\mathrm{CO}$ monomer forming a ketone intermediate surface species, $\mathrm{M}-\mathrm{C}\left(\mathrm{CH}_{3}\right)=\mathrm{O}$. This intermediate hydrogenates to an alcohol intermediate surface species, $\mathrm{M}-\mathrm{CH}(\mathrm{OH})-\mathrm{CH}_{3}$. After removal of water and hydrogenation, the alcohol intermediate surface species yields the chain-growth intermediate surface species, $\mathrm{M}-\mathrm{CH}_{2}-$ $\mathrm{CH}_{3}$. The propagation step continues as:

$\mathrm{M}-\mathrm{R}+\mathrm{M}=\mathrm{CO} \rightarrow \mathrm{M}-\mathrm{C}(\mathrm{R})=\mathrm{O} \stackrel{+2 H}{\longrightarrow} \mathrm{M}-\mathrm{CH}(\mathrm{OH})-\mathrm{R} \stackrel{+2 H,-H 2 O}{\longrightarrow} \mathrm{M}-\mathrm{CH}_{2}-\mathrm{R}$ 
Termination:

The chain-growth intermediate surface species $\mathrm{M}-\mathrm{CH}_{2}-\mathrm{R}$ and the alcohol intermediate surface species $\mathrm{M}-\mathrm{CH}(\mathrm{OH})-\mathrm{R}$ form n-paraffins and n-alcohols respectively on hydrogenation. Along with these products, the two intermediate surface species dehydrogenate to form $\alpha$-olefins and aldehydes respectively.

$$
\begin{array}{ll}
\mathrm{M}-\mathrm{CH}_{2}-\mathrm{R} \stackrel{+H}{\rightarrow} \mathrm{CH}_{3}-\mathrm{R}+\mathrm{M} & \text { n-paraffin } \\
\mathrm{M}-\mathrm{CH}(\mathrm{OH})-\mathrm{R} \stackrel{+H}{\rightarrow} \mathrm{RCH}_{2} \mathrm{OH}+\mathrm{M} & \text { n-alcohol } \\
\mathrm{M}-\mathrm{CH}_{2}-\mathrm{R} \stackrel{-H}{\rightarrow} \mathrm{CH}_{2}=\mathrm{CHR}+\mathrm{M} & \alpha \text {-olefin }
\end{array}
$$

$\mathrm{M}-\mathrm{CH}(\mathrm{OH})-\mathrm{R} \stackrel{-H}{\rightarrow} \mathrm{RCHO}+\mathrm{M} \quad$ Aldehyde

\subsection{IRON-BASED CATALYST COMPARED TO COBALT-BASED CATALYST}

Iron and cobalt catalysts are both used industrially in Fischer-Tropsch synthesis (Pichler et al., 1952). The following features of comparison are used:
a) Methanation
b) Chain growth
c) Chain branching
d) Water-gas shift reaction
e) Costs and catalyst availability
f) Response to temperature
g) Effect of partial pressure of $\mathrm{CO}$

a) Methanation

Methane formation has to be suppressed in FT-synthesis in favor of the formation of higher hydrocarbons. The iron catalyst is stable against excessive methane formation, even at high temperature $\left(350^{\circ} \mathrm{C}\right)$ and low CO partial pressures (Riedel et al., 2003; Steynberg et al., 1999; Schulz et al., 1977).

The cobalt catalyst is strongly dependent on partial pressures of $\mathrm{CO}$ and $\mathrm{H}_{2}$ and temperatures (Schulz et al., 1991; Schulz et al., 1971; Schulz et al., 1977). Methane formation is restricted at low 
temperatures $\left(180-220^{\circ} \mathrm{C}\right)$. Hence, cobalt is suitable for the low-temperature FT process (Schulz et al., 1977).

b) Chain growth

Chain growth increases with increasing partial pressure of carbon monoxide over cobalt catalysts. However, over iron catalysts, chain growth decreases with increasing partial pressure of carbon monoxide (Schulz et al., 2003).

c) Chain branching

For iron catalysts, branching becomes more favorable with time (Schulz et al., 2003). For cobalt catalysts, branching is more dominant at initial times but decreases with time (Schulz et al., 2001). Figure 2.1 (Schulz et al., 2003) shows the branching probability as a function of time and carbon number $\mathrm{N}_{\mathrm{c}}$ (of the species to be branched) in FT synthesis with an iron catalyst. Figure 2.2 (Schulz et al., 2001) shows the branching probability as a function of time and carbon number $\mathrm{N}_{\mathrm{c}}$ (of the species to be branched) in FT synthesis with cobalt catalyst. From Figures 2.1 and 2.2, it is clear that there is an opposite trend of probability of branching with time for iron and cobalt.

d) Water-gas-shift reaction

The water-gas-shift reaction is fast and easy to be seen on iron catalysts, but is difficult to be seen with cobalt catalyst (Teng et al., 2005).

When synthesis gas with a $\mathrm{H}_{2} / \mathrm{CO}$ ratio of 2:1 can be obtained (for example, by autothermal reforming of methane), water-gas-shift activity will not be useful. Thus a cobalt-based catalyst can be suitable (Ma et al., 2006). 


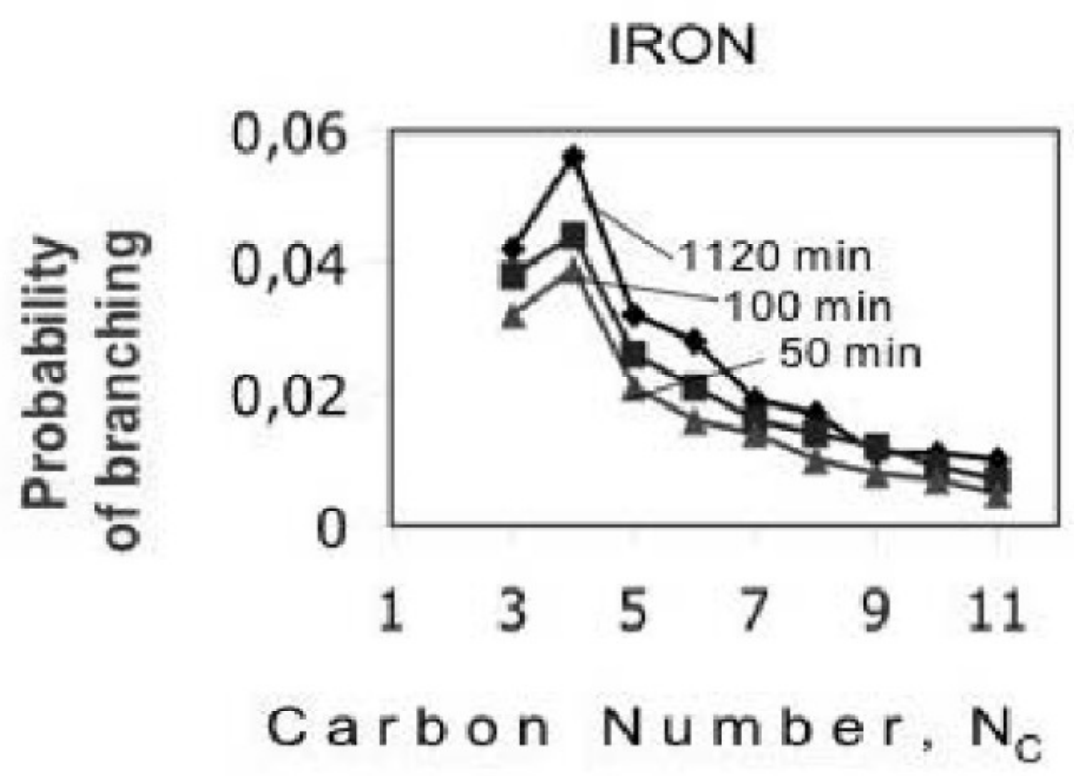

Figure 2.1 Branching probability as a function of carbon number $\mathrm{N}_{\mathrm{c}}$ (of the species to be branched) and time in FT synthesis with iron catalyst (Schulz et al., 2003)

\section{COBALT}

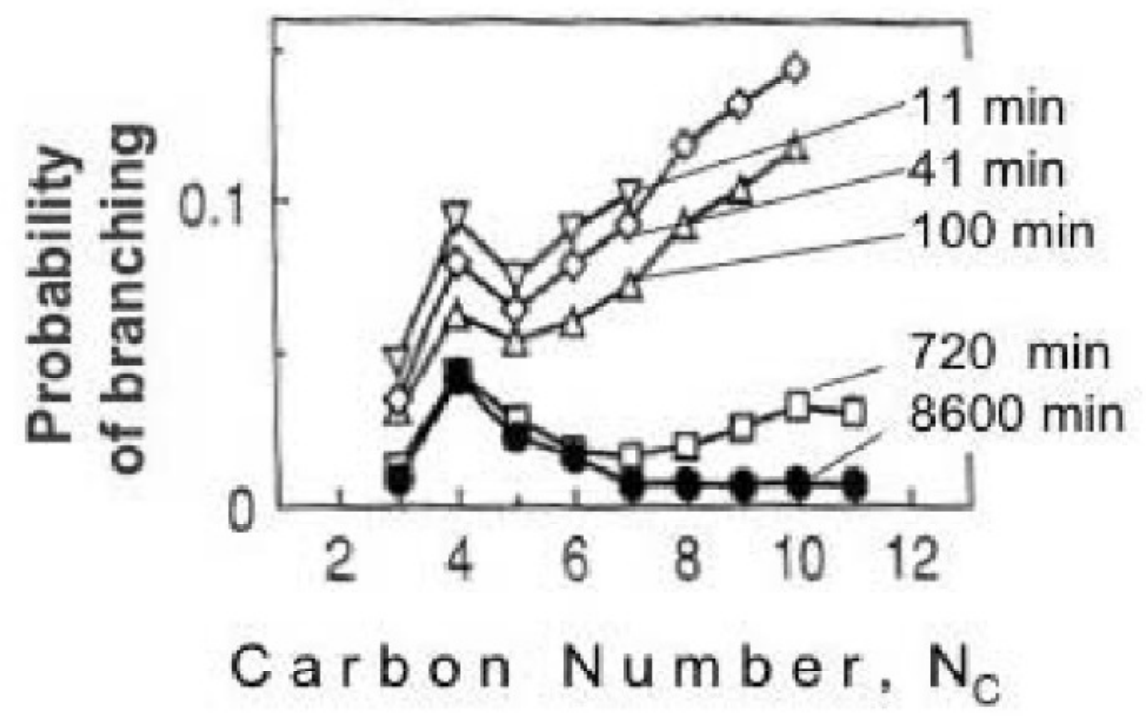

Figure 2.2 Branching probability as a function of carbon number $\mathrm{N}_{\mathrm{c}}$ (of the species to be branched) and time in FT synthesis with cobalt catalyst (Schulz et al., 2001) 


\section{e) Costs of the catalyst}

Only the metals $\mathrm{Fe}, \mathrm{Ni}, \mathrm{Co}$ and $\mathrm{Ru}$ have the required FT activity for commercial application. It has been shown that FT cobalt-based catalyst is effective. However the cost of cobalt-compared to ironbased catalyst is very high (Dry, 2002).

f) Response to temperature

The reaction temperature controls the chain length of the product molecules (Schulz et al., 2001). With an iron-based catalyst, the effect of increasing temperature is to reduce the chain length of the product molecules (Riedel et al., 2003). With a cobalt-based catalyst, the effect of increasing temperature is to reduce the average molecular size of the product. Also in addition to that, methanation and secondary olefin reactions of hydrogenation and isomerization are enhanced (Schulz et al., 1977; Schulz, 2003).

\section{g) Effect of partial pressure of $\mathrm{CO}$ and $\mathrm{H}_{2}$}

With the iron catalyst, $\mathrm{CO}$ partial pressure and $\mathrm{H}_{2}$ partial pressure have no strong influence on product distribution (Schulz, 2003; Schulz et al., 1994). With the cobalt catalyst, the CO partial pressure and $\mathrm{H}_{2}$ partial pressure have strong influences on product distribution (Schulz et al., 1991; Schulz et al., 1971; Schulz et al., 1977).

\subsection{STUDY OF IRON BASED CATALYST ACTIVITY}

\subsubsection{Preparation of the base catalyst}

The incipient-wetness impregnation technique is used to prepare the catalyst supported on activated carbon. Other methods for catalyst preparation are the co-precipitation method and the sol-gel method. The incipient-wetness impregnation method involves mostly surface metal impregnation. But in case of co-precipitation and sol-gel, metal impregnation occurs throughout the pores of support (Liu et al., 2007). Also, the catalyst prepared by incipient-wetness impregnation loses its activity earlier compared to that of other methods (Liu et al., 2007).

\subsubsection{Promotional effect of mixed metals on iron catalyst and selection of metals}

Structural promoters are often added into the iron-based catalyst for the purpose of stabilizing catalyst crystals from sintering and to provide the catalyst with structural stability (Zhao et al., 2001; 
Brien et al., 2001; Bukur et al., 2002). But catalysts containing structural promoters usually suffer from lower FTS activity due to strong metal-support interaction (Bukur et al., 1990; Wielers et al., 1989; Yang et al., 2005; Motjope et al., 2002). Therefore, to improve the performance of iron-based catalysts without sacrificing their activities and selectivities, chemical promoters, such as $\mathrm{K}, \mathrm{Cu}$, Mo etc., are often added into iron-based catalyst (Yang et al., 2004; Zhang et al., 2006; Ma et al., 2006). Cu and K promoters have been proved to improve the adsorption and dissociation of CO and play an important role in the FTS performances. Therefore, a large number of studies were carried out to investigate the relationship between $\mathrm{K}$ or $\mathrm{Cu}$ promoter and FTS performances of iron-based catalyst (Yang et al., 2004; Lohitharn et al., 2008; Wan et al., 2008; Ma et al., 2006).

\subsubsection{Selection of copper $(\mathrm{Cu})$ and potassium $(\mathrm{K})$ as a promoter}

As mentioned earlier, $\mathrm{Cu}$ and $\mathrm{K}$ promoters have been shown to promote both the reduction of iron as well as the adsorption and dissociation of CO (Yang et al., 2004; Li et al., 2002).

$\mathrm{Cu}$ and $\mathrm{K}$ addition studies by Wan et al. (2008) give $\mathrm{H}_{2} / \mathrm{CO}$ usage ratios in FT synthesis. The $\mathrm{H}_{2} / \mathrm{CO}$ usage ratio is the highest for the $\mathrm{Fe} / \mathrm{Cu}$ catalyst and that of $\mathrm{Fe} / \mathrm{Cu} / \mathrm{K}$ catalyst is the lowest.

Similar work for the promotional effects of $\mathrm{Cu}$ and $\mathrm{K}$ on the behavior of Fe-based catalyst was carried out by $\mathrm{Li}$ et al. (2001) with varying $\mathrm{K}(\mathrm{K} / \mathrm{Fe}=0,0.02,0.04)$ and $\mathrm{Cu}(\mathrm{Cu} / \mathrm{Fe}=0,0.01,0.02)$ contents at $493 \mathrm{~K}$ and 464 psig.

From Table 2.2, addition of $\mathrm{Cu}$ to Fe-based catalyst increases $\mathrm{CO}$ conversion from 0.7 to 0.87 mol-CO/h /g-at.Fe. Addition of K similarly increases CO conversion from 0.7 to 1.23 mol-CO/h / g-at. Fe. Also, it is important to note that the addition of $\mathrm{K}$ alone decreases the methane selectivity from 4.8 to $1.8 \%$ and increases the $\mathrm{C}_{5+}$ selectivity from 81.9 to $87.5 \%$. On the other side, the addition of $\mathrm{Cu}$ alone increases methane selectivity from 4.8 to $10.2 \%$, and decreases the $\mathrm{C}_{5+}$ selectivity from 81.9 to $62.1 \%$. But when both $\mathrm{K}$ and $\mathrm{Cu}$ are present, the tendency of $\mathrm{Cu}$ to produce methane nearly vanishes. When $\mathrm{Cu} / \mathrm{Fe}=0.02$ and $\mathrm{K} / \mathrm{Fe}=0.02$, methane selectivity decreases from 4.8 to $2 \%$ and the $\mathrm{C}_{5+}$ selectivity increases from 81.9 to $86.7 \%$, similar to the results of $\mathrm{K} / \mathrm{Fe}=0.02$ with no $\mathrm{Cu}$, but with a higher conversion and hydrocarbon formation rates than the catalyst with $\mathrm{K}$ and no $\mathrm{Cu}$.

Thus addition of $\mathrm{Cu}$ and $\mathrm{K}$ promoter improves the FTS activity and WGS reaction activity. As compared with the addition of $\mathrm{Cu}$ and $\mathrm{K}$ individually, the addition of both $\mathrm{Cu}$ and $\mathrm{K}$ keeps the excellent 
stability and significantly improves the FTS and WGS activities. Due to weaker CO adsorption and stronger $\mathrm{H}_{2}$ adsorption than the catalyst without $\mathrm{Cu}$, chain growth is controlled. However, the addition of $\mathrm{K}$ promoter significantly improves the adsorption of $\mathrm{CO}$ and thus promotes the chain growth reaction.

Table 2.2 Steady-state performance of $\mathrm{Fe}_{2} \mathrm{O}_{3}-\mathrm{Zn}$ catalysts $(\mathrm{Zn} / \mathrm{Fe}=0.1)$ with different loadings of $\mathrm{K}$ and $\mathrm{Cu}\left(\mathrm{H}_{2} / \mathrm{CO}=2,493 \mathrm{~K}, 464\right.$ psig, $\mathrm{CO}$ conversion 14-18\%) (Li et al., 2001)

\begin{tabular}{|l|c|c|c|c|c|c|}
\hline $\mathrm{K} / \mathrm{Fe}$ atomic ratio $(\times 100)$ & 0 & 0 & 2 & 2 & 2 & 4 \\
\hline $\mathrm{Cu} / \mathrm{Fe}$ atomic ratio $(\times 100)$ & 0 & 1 & 0 & 1 & 2 & 1 \\
\hline $\mathrm{CO}$ conversion rate $(\mathrm{mol}-\mathrm{CO} / \mathrm{h} / \mathrm{g}$ at.-Fe) & 0.70 & 0.87 & 1.23 & 2.4 & 2.43 & 2.49 \\
\hline $\mathrm{CO}_{2}$ formation rate $(\mathrm{mol}-\mathrm{CO} / \mathrm{h} / \mathrm{g}$ at.-Fe) & 0.02 & 0.06 & 0.10 & 0.30 & 0.32 & 0.30 \\
\hline $\mathrm{Hydrocarbon}$ formation rate $(\mathrm{mol}-\mathrm{CO} / \mathrm{h} / \mathrm{g}$ at.-Fe) & 0.68 & 0.81 & 1.13 & 2.10 & 2.11 & 2.19 \\
\hline $\mathrm{CO}_{2}$ selectivity $(\%)$ & 2.3 & 6.5 & 8.5 & 12.3 & 12.9 & 12.1 \\
\hline $\mathrm{CH}_{4}$ selectivity $(\%)$ & 4.8 & 10.2 & 1.8 & 1.8 & 2.0 & 2.5 \\
\hline $\mathrm{C}_{5+}$ selectivity $(\%)$ & 81.9 & 62.1 & 87.5 & 87.6 & 86.7 & 85.2 \\
\hline
\end{tabular}

\subsubsection{Selection of Molybdenum (Mo) as a promoter}

Molybdenum has been reported to be moderately active for FTS, but very selective to light hydrocarbons (Schultz et al., 1967). The extent of WGS is high for Mo-based catalysts but decreases with time on stream (Ma et al., 2006). Schultz et al. (1967) first investigated the catalytic performance of molybdenum. They found that molybdenum has moderate activity in $\mathrm{CO}$ hydrogenation.

Ma et al. (2006) carried out a TPR study of Mo-promoted Fe-Cu-K/AC catalysts. The TCD signal response is shown in Figure 2.3 .The first peak $\mathrm{A}$ is assigned to the reduction of $\mathrm{Fe}_{2} \mathrm{O}_{3}$ to $\mathrm{Fe}_{3} \mathrm{O}_{4}$. Peak $\mathrm{B}$ could be identified as due to the subsequent reduction of $\mathrm{Fe}_{3} \mathrm{O}_{4}$ to $\mathrm{FeO}$. Peak $\mathrm{C}$ may be assigned to the reduction of $\mathrm{FeO}$ to metallic Fe. Peak D might be assigned to the reduction of a Mo-Fe oxide species formed at high temperatures during TPR. Peak A and B are much larger for 0\% Mo than for 6\% Mo and 12\% Mo, suggesting that Mo addition significantly inhibits iron reduction. This suggests that a strong interaction exists between Mo and Fe oxides. 


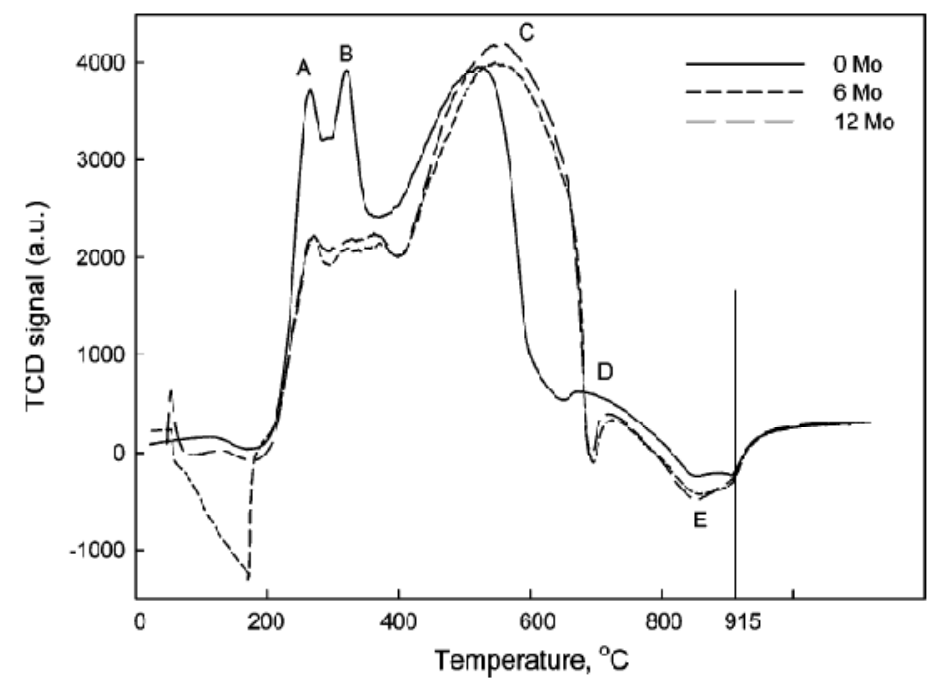

Figure 2.3 TPR profiles of different Mo-promoted Fe-Cu-K/AC catalysts (Ma et al., 2006)

Ma et al. (2007a) also studied the effect of Mo loading on CO conversion for iron-based catalyst. Figure 2.4 shows the important effects of Mo addition. The Mo-based catalyst shows a very slow deactivation rate compared to the Mo-free catalyst, indicating that Mo promoter improves the catalyst stability for longer times. A loading of $12 \%$ Mo decrease the active sites available for the reaction. Thus $6 \%$ Mo is considered to be optimum loading for iron-based catalyst supported on activated carbon (Ma et al., 2007a).

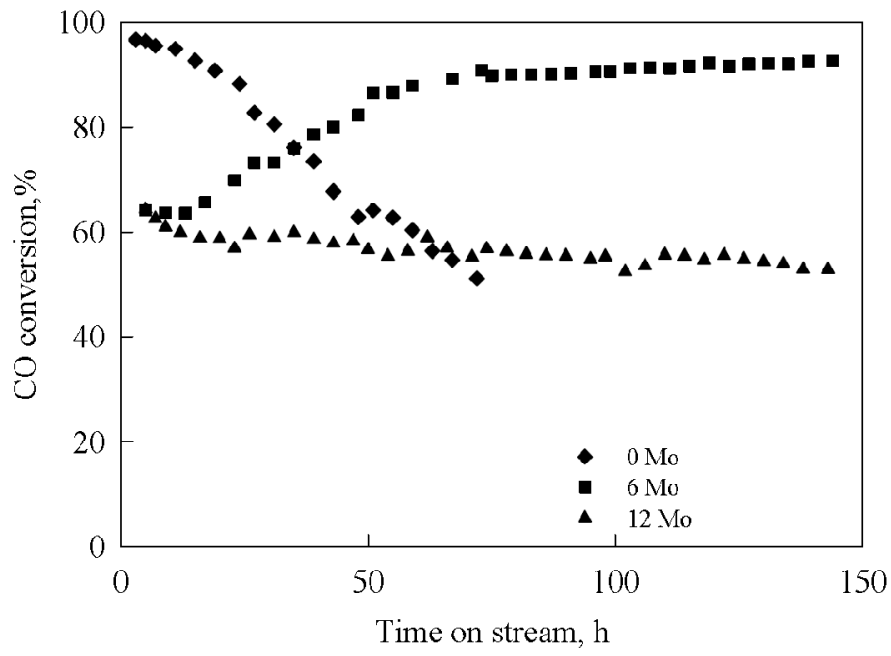

Figure 2.4 Effect of Mo loading on CO conversion (593K, $300 \mathrm{psig}, 3 \mathrm{Nl} / \mathrm{gcat} / \mathrm{h}, \mathrm{H}_{2} / \mathrm{CO}=0.9$ ) (Ma et al., 2007a) 
Ma et al. (2006) also studied the effect of Mo addition on product selectivities. From Table 2.3, the addition of Mo yields more methane and a smaller yield of $\mathrm{C}_{5+}$ hydrocarbons. This is probably due to Mo oxide in the catalyst weakening the $\mathrm{C}-\mathrm{O}$ bond, resulting in a higher concentration of active carbon species on the surface of the Mo-promoted catalyst (Kip et al., 1987).

Table 2.3 Productivity and selectivity of hydrocarbon and Olefin-to-Paraffin ratio over different Moloaded Fe-Cu-K supported on activated carbon catalysts $\left(593 \mathrm{~K}, 3 \mathrm{Nl} / \mathrm{g}\right.$-cat/h, $\left.300 \mathrm{psig}, \mathrm{H}_{2} / \mathrm{CO}=0.9\right)$. All catalysts contain 15.7 wt \% Fe, 0.8 wt \% Cu, and 0.9 wt \% K (Ma et al., 2006)

\begin{tabular}{|l|c|c|c|}
\hline$\%$ Mo & 0 & 6 & 12 \\
\hline Temperature (K) & 593 & 593 & 593 \\
\hline TOS (h) & $25-72$ & $73-144$ & $72-143$ \\
\hline Productivity (g-HC/ g-cat/ h ) & $426-330$ & $495-480$ & $310-290$ \\
\hline $\mathrm{CH}_{4}$ selectivity (\%) & 7.2 & 15 & 14.1 \\
\hline $\mathrm{C}_{2}-\mathrm{C}_{4}$ selectivity (\%) & 39.6 & 45.6 & 40.6 \\
\hline $\mathrm{C}_{5+}$ selectivity (\%) & 51.6 & 39.4 & 45.3 \\
\hline $\mathrm{C}_{2}-\mathrm{C}_{4}$ Olefin/ Paraffin ratio & 6.0 & 2.2 & 2.0 \\
\hline
\end{tabular}

\subsubsection{Effect of catalyst supports}

We need to reduce the size of long-chain hydrocarbons formed in the FT synthesis. Activated carbon (AC) has been found to be a promising catalyst support for restricting hydrocarbon chain length. Some studies with AC-supported iron, cobalt and molybdenum-nickel catalysts indicate that chain length can be limited below $\mathrm{C}_{35}$ over the AC support (Jung et al., 1982; Ma et al., 2005; Kugler et al., 2000). Table 2.4 shows the BET measurement results of different activated carbons. From Table 2.4, peat- and pecan-based activated carbons have smaller micropores compared to wood- and walnut-based AC. This means that peat- and pecan-based AC have greater fraction of mesopore volume.

Table 2.4 BET measurement result of activated carbon supports (Ma et al., 2007a)

\begin{tabular}{|l|c|c|c|}
\hline AC type & $\begin{array}{l}\text { Total Surface area } \\
\left(\mathrm{m}^{2} / \mathrm{g}\right)\end{array}$ & $\begin{array}{l}\text { Total Pore volume } \\
\left(\mathrm{cm}^{3} / \mathrm{g}\right)\end{array}$ & $\begin{array}{l}\text { Fraction of pore volume } \\
\text { present in the micropores }\end{array}$ \\
\hline Peat & 606 & 0.48 & 0.46 \\
\hline Wood & 970 & 0.58 & 0.76 \\
\hline Pecan & 1016 & 0.72 & 0.50 \\
\hline Walnut & 892 & 0.52 & 0.64 \\
\hline
\end{tabular}


From Figure 2.5, catalysts supported on peat- and pecan-based AC show high and steady CO conversion, compared to walnut- and wood-type activated carbons. This can be related to the large fraction of mesopore volume present in peat and pecan. Therefore, we need an AC such that it has a higher fraction of mesoporous volume.

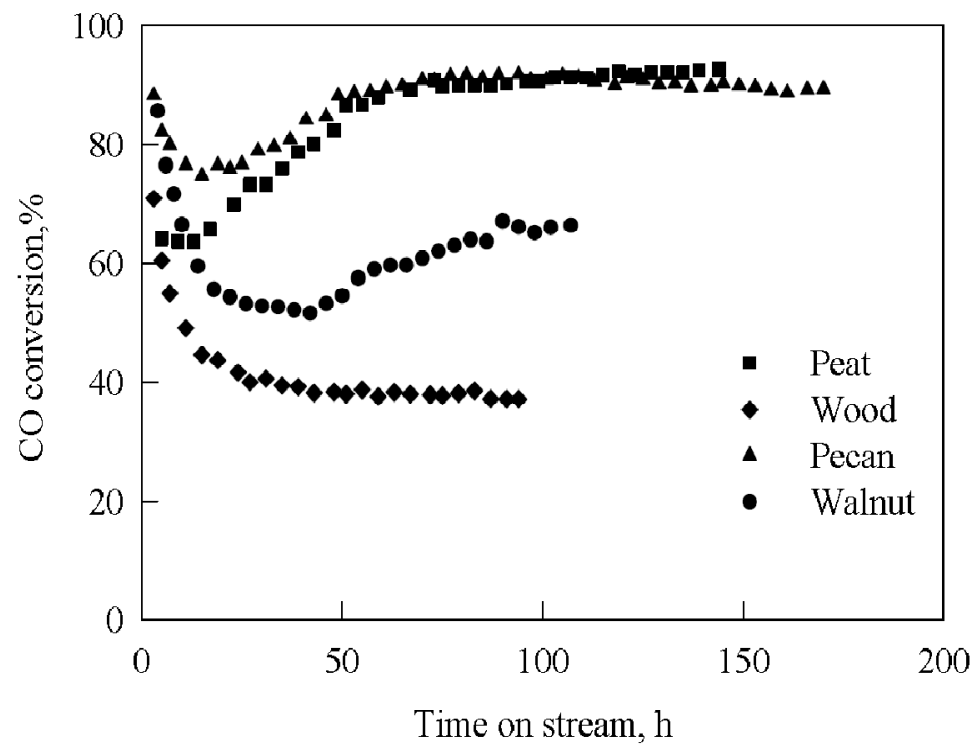

Figure 2.5 Effect of carbon support type on $\mathrm{CO}$ conversion $\left(593 \mathrm{~K}, 300 \mathrm{psig}, 3 \mathrm{N1} / \mathrm{g}\right.$-cat/h, $\left.\mathrm{H}_{2} / \mathrm{CO}=0.9\right)$ (Ma et al., 2007a)

\subsection{ZEOLITE STUDIES IN FISCHER TROPSCH PROCESS}

\subsubsection{Overview}

Zeolites are microporous aluminosilicate minerals commonly used as commercial adsorbents. Zeolites are widely used in industry for water purification (Ellis et al., 1993), as heterogeneous catalysts for petrochemical hydrocracking and hydroisomerization (Usui et al., 2004), and in nuclear reprocessing. Their biggest use is in the production of laundry detergents. They are also used in medicine and in agriculture (Burriesci et al., 1984).

The zeolite chemical formula is $\mathrm{Na}_{n} \mathrm{Al}_{n} \mathrm{Si}_{96-\mathrm{n}} \mathrm{O}_{192} \cdot 16 \mathrm{H}_{2} \mathrm{O}(0<\mathrm{n}<27)$. Zeolites are composed of several pentasil units linked together by oxygen bridges to form pentasil chains. A pentasil unit consists of eight five-membered rings (Garcia et al., 2010). In these rings, the vertices are $\mathrm{Al}$ or Si and an O atom is assumed to be bonded between the vertices. ZSM-5 has a high silicon-to-aluminum ratio, generally 
30-80 molar ratios (Wiley et al., 1988). The microporous molecular structure of ZSM-5 molecules causes changes in their structure and reactivity (William et al., 1999; Rigby et al., 1997).

Shirazi et al. (2008) studied zeolites with different Si/Al ratios and compared the different properties of ZSM-5. BET specific surface areas of the synthesized zeolites increase with increasing $\mathrm{Si} / \mathrm{Al}$ molar ratio. The particle size of the zeolite also increases with the increase in $\mathrm{Si} / \mathrm{Al}$ ratio. Finally, $\mathrm{Si} / \mathrm{Al}$ ratios affect the acidity of the samples and the total acid sites of ZSM-5 decrease with an increase in the $\mathrm{Si} / \mathrm{Al}$ ratio.

The production of liquid fuels by the FT process suffers from two main constraints. One is that the polymerization-type kinetics of the FT reaction results in production of waxy compounds. The second is that the linear structure of the FT hydrocarbons (mostly n-paraffins) results in a fuel of too low quality to be directly blended into the gasoline and diesel pools due to low octane numbers and poor cold flow properties (Martinez et al., 2007). This is because linear aliphatic-chain liquid products (nparaffins), which predominal in FT products, have lower research octane numbers (RONs) than iparaffins (Huo et al., 2010). (The RON is determined by running the fuel in a test engine with a variable compression ratio under controlled conditions, and comparing the results with those from mixtures of i-octane and n-heptane, Nikolaou et al., 2004).

\subsubsection{Effects of zeolite types on Fischer-Tropsch liquid distribution}

The use of different zeolites (mordenite, erionite, ZSM-11, ZSM-12, L, $\Omega$ and $\beta$ ) in combination with an iron-based FT catalyst was studied by Hammer et al. (1994). Martinez et al. (2007) studied USY-500 (CBV500), USY-720 (CBV720), H-Beta (CP811), H-MOR (CBV20A), and HZSM-5 (CBV3020) zeolite types on the cracking of Fischer Tropsch wax.

The isomerization activity of zeolite in FT synthesis can be calculated from proton NMR spectra of the liquid synthetic product. The lower the value of the group ratio $\mathrm{CH}_{2} / \mathrm{CH}_{3}$, the higher is the isomer content (Vytnova et al., 2006). Vytnova et al., (2006) also studied the effect of adding different zeolites on iron-based catalyst. The results are shown in Table 2.5 .

From Table 2.5, it is clear that ZSM-5 zeolites have higher isomerization activity compared to other zeolites. Also, in terms of isomerizing activity under FT conditions, the test zeolites are arranged 
in the order: ZSM-5 (80) $>$ ZSM-5 (50) $>$ ZSM-12 (90) $>$ ZSM-5 (30) $>\beta-75>\beta-25>$ Mn-Si $>\mathrm{Al}_{2} \mathrm{O}_{3}>$ $\mathrm{Ce}-\mathrm{Si}>\beta-\mathrm{Si}$, where the numbers in parentheses refer to the $\mathrm{Si} / \mathrm{Al}$ ratio.

Table 2.5 Isomerization activity zeolites added to Fe catalyst (Vytnova et al., 2006)

\begin{tabular}{|l|c|}
\hline Zeolite types & $\mathrm{CH}_{2} / \mathrm{CH}_{3}$ \\
\hline None $(\mathrm{Base} F$ Fe catalyst $)$ & 4.61 \\
\hline $\mathrm{Al}_{2} \mathrm{O}_{3}$ & 3.41 \\
\hline $\mathrm{ZSM}-5, \mathrm{Si} / \mathrm{Al}=30$ & 1.92 \\
\hline $\mathrm{ZSM}-5, \mathrm{Si} / \mathrm{Al}=50$ & 1.67 \\
\hline $\mathrm{ZSM}-5, \mathrm{Si} / \mathrm{Al}=80$ & 1.58 \\
\hline $\mathrm{ZSM}-12$ & 1.82 \\
\hline$\beta-75$ & 2.20 \\
\hline$\beta-25$ & 2.33 \\
\hline $\mathrm{Ce}-\mathrm{Si}$ & 3.55 \\
\hline $\mathrm{Mn}-\mathrm{Si}$ & 3.03 \\
\hline
\end{tabular}

Another important feature of zeolites is their cracking ability. Zeolites can decrease the longchain waxy hydrocarbons to more useful liquid hydrocarbon such as gasoline and diesel (Zhao et al., 2010). Martinez et al. (2007) studied the activation and deactivation of zeolite with $\mathrm{Co} / \mathrm{SiO}_{2}$ catalyst. The FT liquid distribution over $\mathrm{Co} / \mathrm{SiO}_{2}$-Zeolite catalyst is given in Table 2.6. From Table 2.6, for the ZSM-5 case, high yields of $\mathrm{C}_{5}-\mathrm{C}_{12}$ are obtained. Hence, ZSM-5 has a good cracking ability.

Table 2.6 Average hydrocarbon distribution (\%C) for the base + zeolite hybrid catalysts (Martinez et al., 2007)

\begin{tabular}{|l|c|c|c|c|c|c|}
\hline $\begin{array}{l}\text { Hydrocarbon } \\
\text { fraction }\end{array}$ & Base & $\begin{array}{c}\text { Base }+ \\
\text { USY-500 }\end{array}$ & $\begin{array}{c}\text { Base }+ \\
\text { USY-720 }\end{array}$ & $\begin{array}{c}\text { Base }+ \\
\text { HBeta }\end{array}$ & $\begin{array}{c}\text { Base }+ \\
\text { HMOR }\end{array}$ & $\begin{array}{c}\text { Base }+ \\
\text { ZSM-5 }\end{array}$ \\
\hline $\mathrm{C}_{1}$ & 11.8 & 12.0 & 11.6 & 11.5 & 11.0 & 11.0 \\
\hline $\mathrm{C}_{2}-\mathrm{C}_{4}$ & 10.8 & 12.2 & 13.3 & 13.7 & 14.2 & 14.7 \\
\hline $\mathrm{C}_{5}-\mathrm{C}_{12}$ & 41.0 & 44.4 & 48.6 & 57.3 & 55.8 & 62.2 \\
\hline $\mathrm{C}_{13}-\mathrm{C}_{22}$ & 28.3 & 24.9 & 21.3 & 16.4 & 16.8 & 11.0 \\
\hline $\mathrm{C}_{23+}$ & 8.1 & 6.4 & 5.2 & 1.1 & 2.2 & 1.1 \\
\hline
\end{tabular}

Further, methane formation at high temperatures is decreased when zeolite is added to iron-based FT catalyst (Schulz, 1999; Dry et al., 1981). The shape-selective properties of ZSM-5 limit the formation of hydrocarbons boiling above the gasoline range. The highly acidic nature of ZSM-5 gives 
high activity for oligomerization, cracking, isomerization and aromatization. Finally, ZSM-5 has a medium pore size which makes this zeolite highly resistant to coking and stable under high temperature conditions (Botes et al., 2004). 


\section{CHAPTER 3}

\section{EXPERIMENTAL SETUP AND PROCEDURE}

\subsection{CATALYST PREPARATION PROCEDURE}

\subsubsection{Base catalyst preparation procedure}

The method of catalyst preparation affects the catalyst activity. The following method is described by Ma et al. (2006) and is used in this work.

Activated carbon Norit SX Ultra (Sigma Aldrich) was used as a catalyst support. The activated carbon was stirred and washed twice in hot distilled water at $90^{\circ} \mathrm{C}$ for 2 hours. If Mo was required in the catalyst, then an amount of aqueous ammonium molybdate solution corresponding to 6\% Mo was impregnated on the activated carbon support. The material was then dried in air at $90-100^{\circ} \mathrm{C}$ overnight. An aqueous solution containing ferric nitrate and cupric nitrate, corresponding to final iron and copper contents on the catalyst of $16 \mathrm{wt} \%$ and $0.8 \mathrm{wt} \%$, respectively, was impregnated on the prepared Moactivated carbon sample, again followed by drying in air $90-100^{\circ} \mathrm{C}$ overnight. An aqueous solution of potassium nitrate corresponding to $0.9 \mathrm{wt} \% \mathrm{~K}$ was the last to be put onto the sample, again followed by drying in air $90-100^{\circ} \mathrm{C}$ overnight. The detailed calculations of catalyst preparation are shown in Appendix E.

\subsubsection{ZSM-5 catalyst}

ZSM-5 (CBV 5524-G), was obtained from Zeolyst International. 10 Tons of pressure is applied in the hydraulically operated pelletizer to make ZSM-5 pellets. These pellets are ground on the 40 mesh size sieve and the 20-40 mesh ZSM-5 is then prepared using 20 and 40 mesh sieves. 20-40 mesh ZSM-5 is used throughout the experiments.

\subsection{EQUIPMENT DESCRIPTION}

The experimental setup consists of a reactor assembly, mass flow controllers, gas cylinders, chromatography setups, a computer interface controller and a chiller in a chemical hood. Gaseous compounds are analyzed by an online gas chromatograph (GC). Liquid is collected and analyzed by an offline GC. 
The catalyst testing unit is shown in Figure 3.1 and is very similar to that used by $\mathrm{Ma}$ et al. (2006). The entire system is computer controlled using software InTouch by Wonderware. Most of the operating conditions (furnace temperature, gas flow rates etc.) can be directly set by the computer, except for the reactor pressure. The reactor pressure is manually controlled by the back-pressure regulator (BPR). An auto-injection gas sampler is available for the GC and is controlled from the computer.

The unit has three feeds: hydrogen, helium and syngas. The composition of syngas is $45 \% \mathrm{CO}$, $45 \% \mathrm{H}_{2}, 5 \% \mathrm{He}$ and $5 \%$ Ar. Helium and argon gases in the syngas mixture are used as internal standards. Each inlet line has one inlet isolation ball valve (B1) with a pressure gauge (P). The pressure gauges, in the range of 0-3000 psig, are obtained from Omega Engineering Inc. To protect lines from over- pressurization, each inlet line is connected to an independent pressure safety valve, also not shown in Figure 3.1. The outlets of the pressure safety valves are connected to the common vent manifold, not shown in Figure 3.1. Each feed gas line is further connected to a mass-flow controller (M.F.C.) followed by a regulator $(\mathrm{R})$. The mass flow controllers are controlled by a common computer-interface controller. Each mass-flow controller has an operating range of 0-200 cc/min. The mass-flow controllers are model No. 5850 E, manufactured by Brooks Instruments. The regulator downstream of each mass flow controller helps in adjusting the outlet pressure as indicated by the pressure gauge installed downstream of the regulators. The regulator is followed by a check valve (not shown in Figure 3.1) and a second isolation ball valve (B2). A check valve ensures one-way flow of all the gases and avoids back mixing. The isolation ball valve B2 can be used for isolating one of the gas streams. Downstream of the regulator, each line is connected to a common reactor inlet manifold (shown by $\mathrm{M}$ in Figure 3.1) and then to the reactor inlet three-way bypass valve (TV1). The pressure of the reactor is indicated by a Sensotec pressure transmitter (model \# THE/ 743-01) with an operating range of 0-2000 psig, not shown in Figure 3.1. 


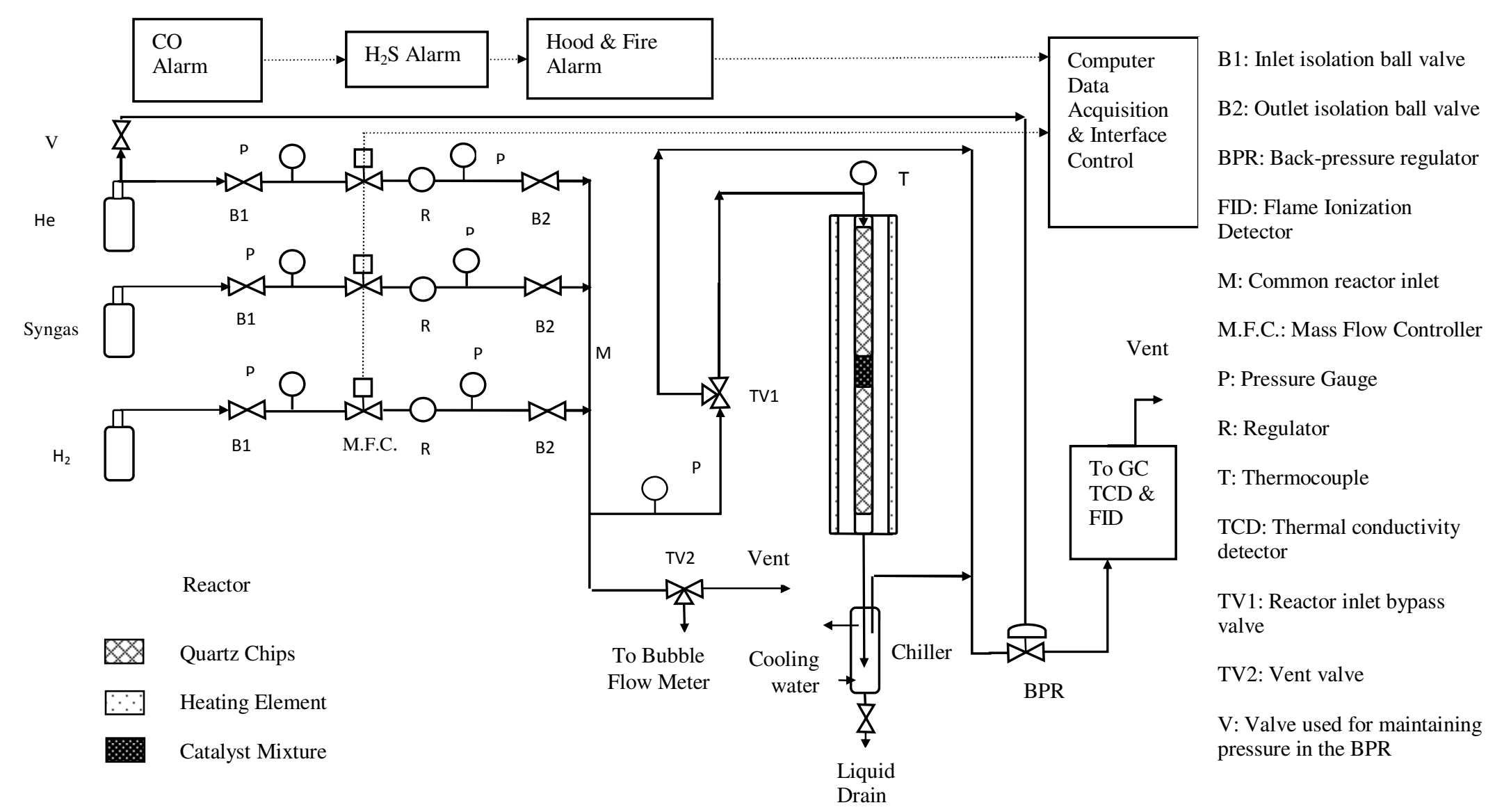

Figure 3.1 Equipment setup for Fischer Tropsch process 
The reactor consists of a stainless-steel tube (SS 304L) of outer diameter of 0.5 in, tube length of 25 in, and wall thickness 0.049 in. Reactor tubes are made by TW Metals. The reactor is heated by a single-zone furnace supplied by Applied Test Systems. An ungrounded K-type thermocouple, (model KQSS-116-18), 1/16" diameter and 18" length with a 304 SS sheath, is used to monitor the catalyst bed temperature. The reactor contains the catalyst mixture in the centre, with the $1 / 16$ " quartz chips placed upstream and downstream in the catalyst bed. See below for details.

The exit gas stream from the reactor is passed through a back-pressure regulator from GO Inc (model P/N 101182) with an operating range 0-2000 psig. Liquids are condensed by a VWR chiller (Model \#117-612) with an operating range from $-20^{\circ} \mathrm{C}$ to $40^{\circ} \mathrm{C}$ and a capacity of $5.41 / \mathrm{min}$. Water is used as the coolant. Liquids condensed are removed by a drain valve (shown in Figure 3.1) and analyzed later in the offline Varian GC.

Gases are analyzed in two types of detectors in the PerkinElmer GC. One is a thermal conductivity detector (TCD), which analyzes for the compounds $\mathrm{H}_{2}, \mathrm{CO}, \mathrm{He}, \mathrm{Ar}, \mathrm{N}_{2}, \mathrm{CH}_{4}$ and $\mathrm{CO}_{2}$. The other is a flame ionization detector (FID), which analyzes hydrocarbons below carbon range $\mathrm{C}_{6}$. Liquids are analyzed separately in an offline Varian GC by a flame ionization detector (FID), which analyzes the $\mathrm{C}_{5+}$ higher alkanes and alcohols.

\subsection{EXPERIMENTAL PROCEDURE}

Initially catalyst and quartz chips are loaded in the reactor. The reactor is pressure tested to avoid any leakages from fittings. Afterwards, the catalyst is pretreated with hydrogen. After the pretreatment, the reaction is started (Ma et al., 2006). See below for details.

\subsubsection{Reactor loading}

The stainless-steel reactor tube is cleaned and dried prior to each loading. Freshly prepared 20-40 mesh ZSM-5 is used for each reaction. $0.5 \mathrm{~g}$ of base catalyst is used in all the runs and three different weights of ZSM-5 $(0.25,0.5$, and $1 \mathrm{~g})$ are used. Two different bed arrangements are used. One is a separate-bed arrangement, in which the base catalyst is followed by the ZSM-5 catalyst. The catalysts are separated by quartz wool. For the case of the separate bed, the reactants pass through the base catalyst first, then through the ZSM-5. The other type of bed arrangement is the mixed bed, in which the base catalyst is intimately mixed with ZSM-5. In each type of bed arrangement, both the catalysts (base catalyst and ZSM-5 catalyst) are diluted 1:4 with 1/32" quartz chips. A thermocouple is carefully inserted in the middle of the catalyst bed. Above and below the catalyst bed and quartz wool, the reactor 
is loaded with 1/16" quartz chips. Fresh quartz chips are used for every run. A Quartz wool plug is placed at the bottom of the reactor and it is then mounted in the furnace enclosure.

The system is then checked for possible leaks by flowing helium at $320 \mathrm{psig}$ and room temperature. Then the reactor system fittings are checked with Snoop solution for any possible leaks. If there is any leak found, the reactor system is depressurized, the fitting is tightened and the test is repeated. The leak check is repeated until no leaks are detected.

In order to check for blank reactor activity, the reactor is loaded as stated above, except that there is no catalyst placed with the $1 / 32$ " quartz chips.

\subsubsection{Pretreatment and reaction}

After the reactor is tested for leaks, the catalyst is pretreated. During pretreatment, $200 \mathrm{cc} / \mathrm{min}$ of hydrogen is used at atmospheric pressure, and the reactor temperature is maintained at $400^{\circ} \mathrm{C}$ for $12 \mathrm{~h}$. The GC is switched on only after ensuring that the carrier gases nitrogen and helium are flowing in the GC.

After the pretreatment, the reaction is started by setting the flows of the feed gases and the required temperature (as mentioned later in the Section 6.2.4) in the computer. The reaction pressure is set manually by means of the back-pressure regulator. The reactor outlet stream is passed through the chiller. The chiller temperature is maintained constant at $9^{\circ} \mathrm{C}$. The chiller collects the compounds (higher alkanes, alcohols, etc.) above $\mathrm{C}_{5+}$ in the form of liquids, to be analyzed separately by the offline GC and auto sampler. The alkanes and olefins below carbon range $\mathrm{C}_{6}$ are detected by the FID. Normally, the auto-injection sampling time for gas analysis is $15 \mathrm{~min}$. The outlet gases from the GC are safely vented in the hood.

The liquid is collected in a $25-\mathrm{ml}$ vial. The collected liquid has two phases, one is organic (oil) and other is aqueous. $3 \mathrm{~h}$ of settling time is given for all the liquid samples. The oil phase, being less dense compared to the aqueous phase, settles on top and the aqueous phase at bottom. The oil phase is carefully removed with an Eppendorf-type pipette, and the weight of both the samples (oil and aqueous phases) is measured. Finally, samples are prepared (as described in Appendix D) in a 2-ml vial, which is placed in the autosampler. The analysis time for the oil sample is fixed as $48 \mathrm{~min}$, and for the aqueous sample as $28 \mathrm{~min}$. Only the $24-48 \mathrm{~h}$ period liquid samples are used for the analysis. The validity of this 
is confirmed by the stability tests to be discussed in Chapter 7. Chromatograph operating conditions for gas and liquid products are given in Appendix A. Gas and liquid calculations are shown in Appendix D.

Experimental results are shown in Chapters 5-7.

\subsection{CHARACTERIZATION EQUIPMENT}

\subsubsection{Scanning Electron Microscopy and Energy-Dispersive X-Ray Spectroscopy}

Scanning Electron Microscopy (SEM) gives information about the surface morphology of a sample, while Energy-Dispersive X-Ray Spectroscopy (EDX) gives information about the elemental composition. The surface morphology of the catalysts was determined by a Hitachi S-4700 scanning electron microscope at an accelerated voltage of $10 \mathrm{kV}$. The samples were prepared on a double-stick adhesive carbon tape mounted on specimen stubs and then sent into the SEM chamber. The SEM is equipped with an energy-dispersive spectrometer. Results before reaction are shown in Chapter 4, and results after reaction are shown in Chapter 8.

\subsubsection{X-Ray Diffraction}

X-Ray Diffraction (XRD) uses X-rays to find the crystalline structure, chemical composition, and physical properties of materials. X-ray diffraction measurements of the base catalyst before the reaction are carried out using PANalytical X'Pert Pro X-ray Diffractometer with $\mathrm{Cu} \mathrm{K} \alpha$ radiation $(1.54184 \AA)$ at room temperature. It is equipped with an X'Celerator Detector System, Theta-Theta goniometer and 45-position sample changer. A software-controlled data acquisition system (X'Pert High Score and X'Pert Quantify) is used for peak ID and profile searches. About $0.5 \mathrm{~g}$ of sample with spacer is taken on the sample holder and placed in the sample stager.

\subsubsection{Temperature-Programmed Reduction}

Temperature-Programmed Reduction (TPR) is used to find the degree of reduction of the catalyst. A U-tube is filled with catalyst, and the air is removed using flowing inert gas. Hydrogen is added by mass flow controllers and a temperature program is initiated. The exit gas is analyzed by TCD detector. When reduction takes place, hydrogen is consumed by the reaction and the change in hydrogen content of the exit stream is picked up by the detector. Using the amount of hydrogen consumed, the degree of reduction (DOR) can be calculated as: 
DOR $=\frac{\text { Actual experimental } \mathrm{H}_{2} \text { consumed }}{\text { Theoretical } \mathrm{H}_{2} \text { consumed }} \times 100$

Total amount of $\mathrm{H}_{2}$ consumed between $200-800^{\circ} \mathrm{C}$ is considered for turn over number calculations. Reactions from (3.2) to (3.4) are occurring on the base catalyst as the temperature is increased in TPR. After stoichiometric balance, Equation (3.5) is used for the calculation of theoretical $\mathrm{H}_{2}$ consumption. Theoretical $\mathrm{H}_{2}$ consumption calculations for the base catalyst TPR are shown in Section 4.3.

$$
\begin{aligned}
& 3 \alpha \mathrm{Fe}_{2} \mathrm{O}_{3}+\mathrm{H}_{2} \rightarrow 2 \mathrm{Fe}_{3} \mathrm{O}_{4}+\mathrm{H}_{2} \mathrm{O} \\
& 2 \mathrm{Fe}_{3} \mathrm{O}_{4}+2 \mathrm{H}_{2} \rightarrow 6 \mathrm{FeO}+2 \mathrm{H}_{2} \mathrm{O} \\
& 6 \mathrm{FeO}+6 \mathrm{H}_{2} \rightarrow 6 \mathrm{Fe}+6 \mathrm{H}_{2} \mathrm{O}
\end{aligned}
$$

$\alpha \mathrm{Fe}_{2} \mathrm{O}_{3}+3 \mathrm{H}_{2} \rightarrow 2 \mathrm{Fe}+3 \mathrm{H}_{2} \mathrm{O}$

\subsubsection{Brunauer, Emmett and Teller surface area}

Brunauer, Emmett and Teller (B.E.T.) surface area is measured with a Micrometrics Accelerated Surface Area and Porosimetry System (ASAP) 2020 to determine the total surface area. A sample of about $0.2 \mathrm{~g}$ is taken in previously weighted sample tube and the total weight is recorded. The sample tube is evacuated to about 100 milliTorr and then backfilled with nitrogen twice using the Micrometrics VacPrep 06. After the second backfill, it is degassed under vacuum at $300^{\circ} \mathrm{C}$ for $1 \mathrm{~h}$ and cooled down to room temperature. The weight of the dried sample weight is recorded. The cooled sample tube is then connected to the ASAP 2020. The ASAP 2021 uses liquid nitrogen to do the absorption tests, and the analysis takes about $16 \mathrm{~h}$.

\subsection{SAFETY REQUIREMENTS}

The process is operated at pressures as high as 400 psig and temperatures as high as $400^{\circ} \mathrm{C}$. Toxic chemical substances such as catalyst, acetone (for cleaning glass wares), liquid hydrocarbons and poisonous carbon monoxide gas are used. For this purpose, personal safety equipment is available. This includes face shields, dust masks, thermal gloves (for handling of high-temperature vessels), safety goggles, an apron, and latex gloves are always worn while handling chemicals or working with equipment. Eye washers are available in the laboratory, to be used in the event of chemical spill in the eyes. Also there are fire extinguishers available in the laboratory, to be used in the event of fire. 
Equipment shutdown switches are available inside the laboratory in case of fire or emergency. Along with the safety equipment, there are safety signs, warnings signs available inside the laboratory to ensure safe work all the time.

The reaction mixture produces hydrocarbon gases, including methane which is highly flammable. The unused hydrogen and carbon monoxide gases in the outlet stream are also flammable. The chemical hood is operated with the exhaust fan on, and this ensures safe discharge of these gases. The hood doors are normally kept closed. There are hood alarms for $\mathrm{CO}$ and $\mathrm{H}_{2} \mathrm{~S}$. The alarms are monitored by the computer. The unit is shut automatically by the computer in the event of hood failure, fire, power failure, $\mathrm{CO}$ detection or $\mathrm{H}_{2} \mathrm{~S}$ detection, or if the flow of any reaction gas or the reaction temperature exceeds the corresponding set value.

The Material Safety Data Sheet file is maintained in the laboratory for all chemicals. A Material Safety Data Sheet (MSDS) contains basic information intended for safety with a material. The MSDS is very useful in the event of chemical poisoning etc., by providing guidelines for antidotes, etc. 


\section{CHAPTER 4}

\section{CATALYST CHARACTERIZATION BEFORE REACTION}

\subsection{SCANNING ELECTRON MICROSCOPY (SEM) AND ENERGY-DISPERSIVE X-RAY SPECTROSCOPY (EDX) ANALYSIS}

Figure 4.1 is a low-magnification micrograph of the surface of the base catalyst before reaction. The lighter areas are richer in metals such as iron, molybdenum, copper, and potassium, while the darker areas are richer in carbon. The area in the white rectangle is further magnified and shown in Figure 4.2. The white rectangles in Figure 4.2 show the metals impregnated on the support.

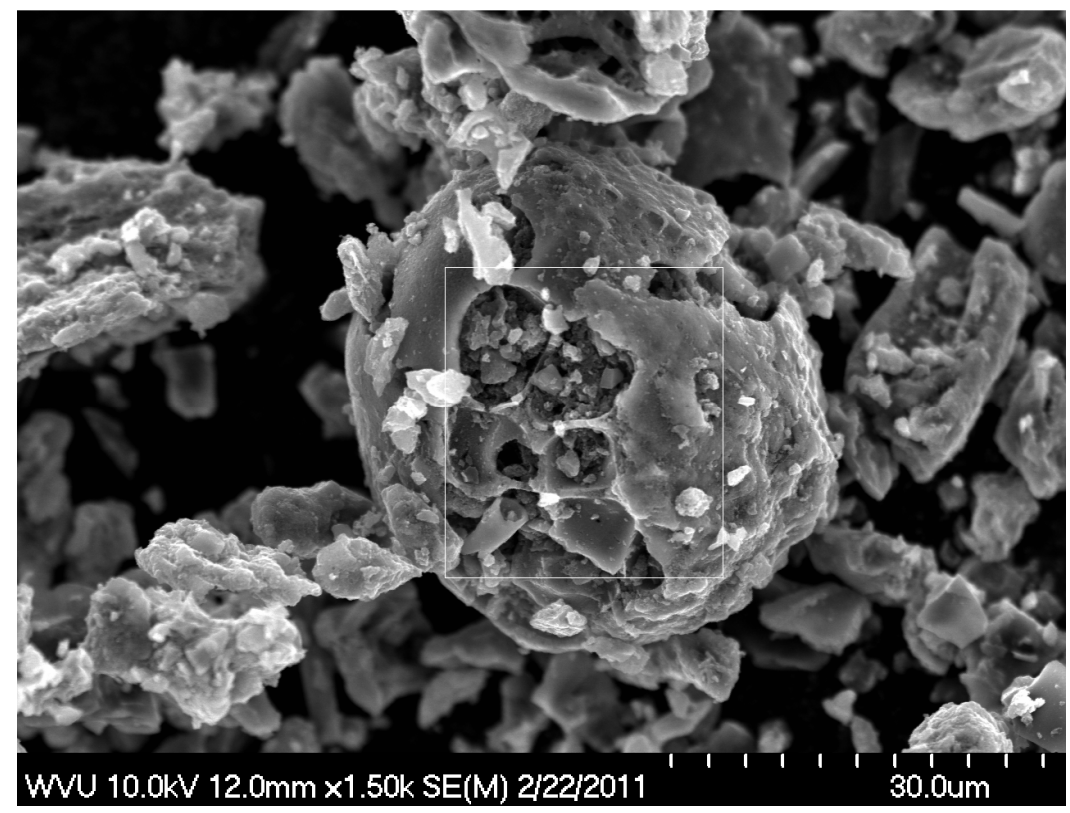

Figure 4.1 SEM low magnification image of surface of the base catalyst before reaction 


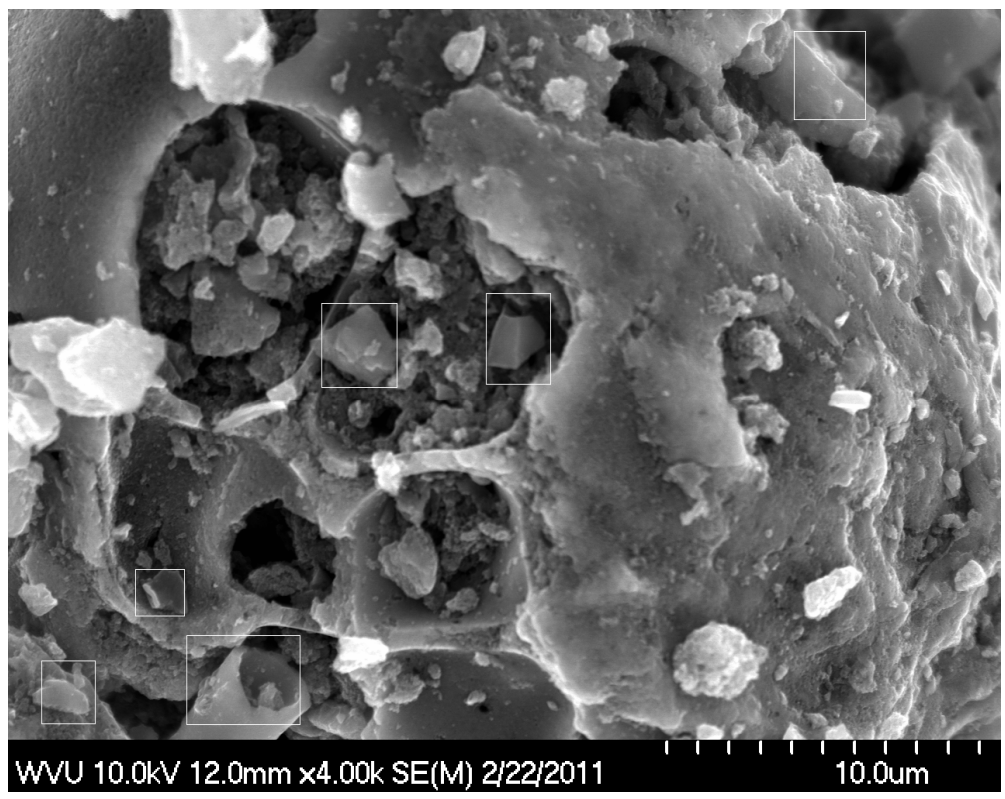

Figure 4.2 Magnified SEM image of surface of the base catalyst before reaction

EDX analysis was carried out to confirm the metals impregnated on support and to find the composition. Figure 4.3 shows the EDX of a portion of the catalyst particle shown by the white reactangle in Figure 4.1. EDX confirms the presence of iron, molybdenum, copper, and potassium metals on support. Notice that the concentrations of copper and potassium are very low because the metal loading for these metals are $0.8 \mathrm{wt} \%$ and $0.9 \mathrm{wt} \%$ respectively on support. Also note that the concentration of iron is higher than molybdenum because the metal loading for iron is 16 wt $\%$ and for molybdenum is $6 \mathrm{wt} \%$. The carbon peak is highest because of the activated carbon support.

Figure 4.4 shows the EDX of the fresh ZSM-5 sample. The presence of Au and Pd is due to the coating material used while in the analysis. EDX of fresh ZSM-5 shows silicon, aluminum, and oxygen. The concentration of $\mathrm{Si}$ is higher due to the high molar ratio of $\mathrm{Si} / \mathrm{Al}(=50)$ in $\mathrm{ZSM}-5$. The oxygen present is in the form of hydrogen aluminum silicate hydrate, as explained in Section 4.2 and Figure 4.6. 


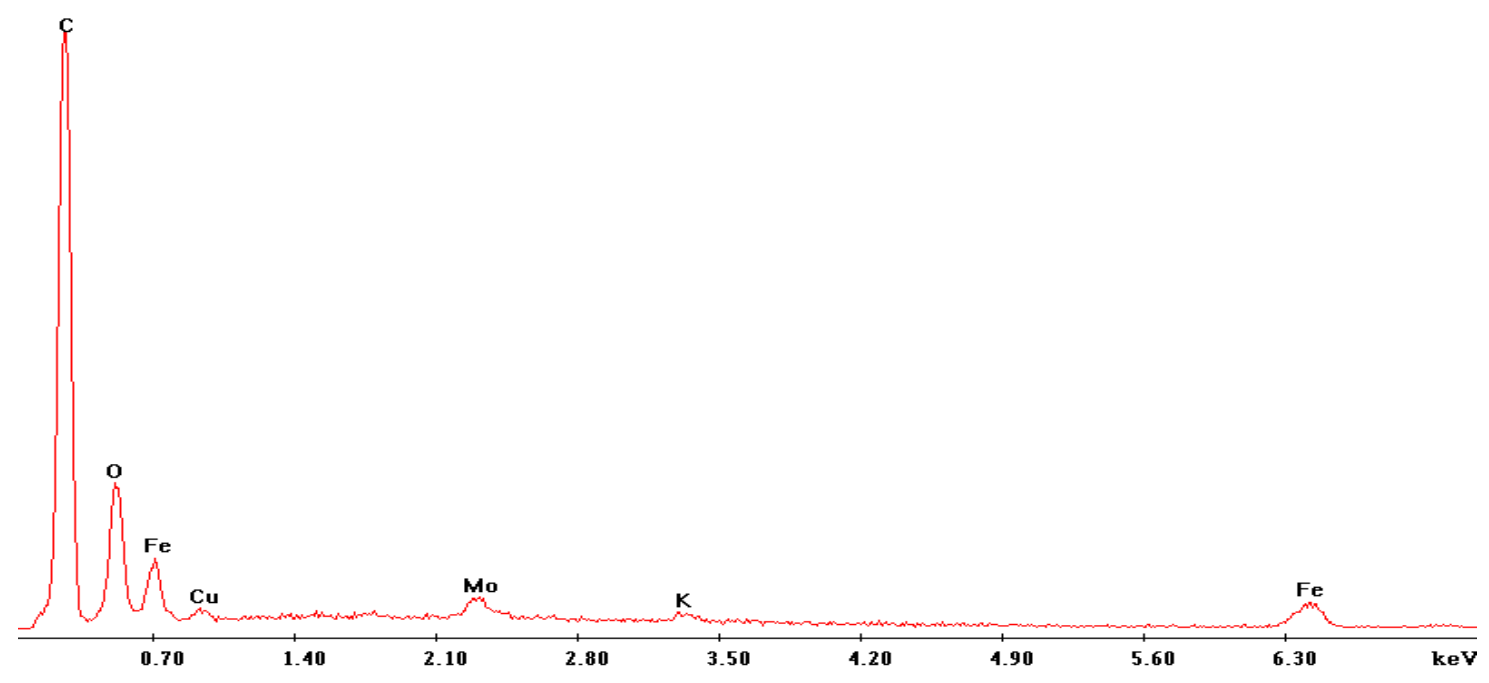

Figure 4.3 EDX analysis of surface of the base catalyst before reaction

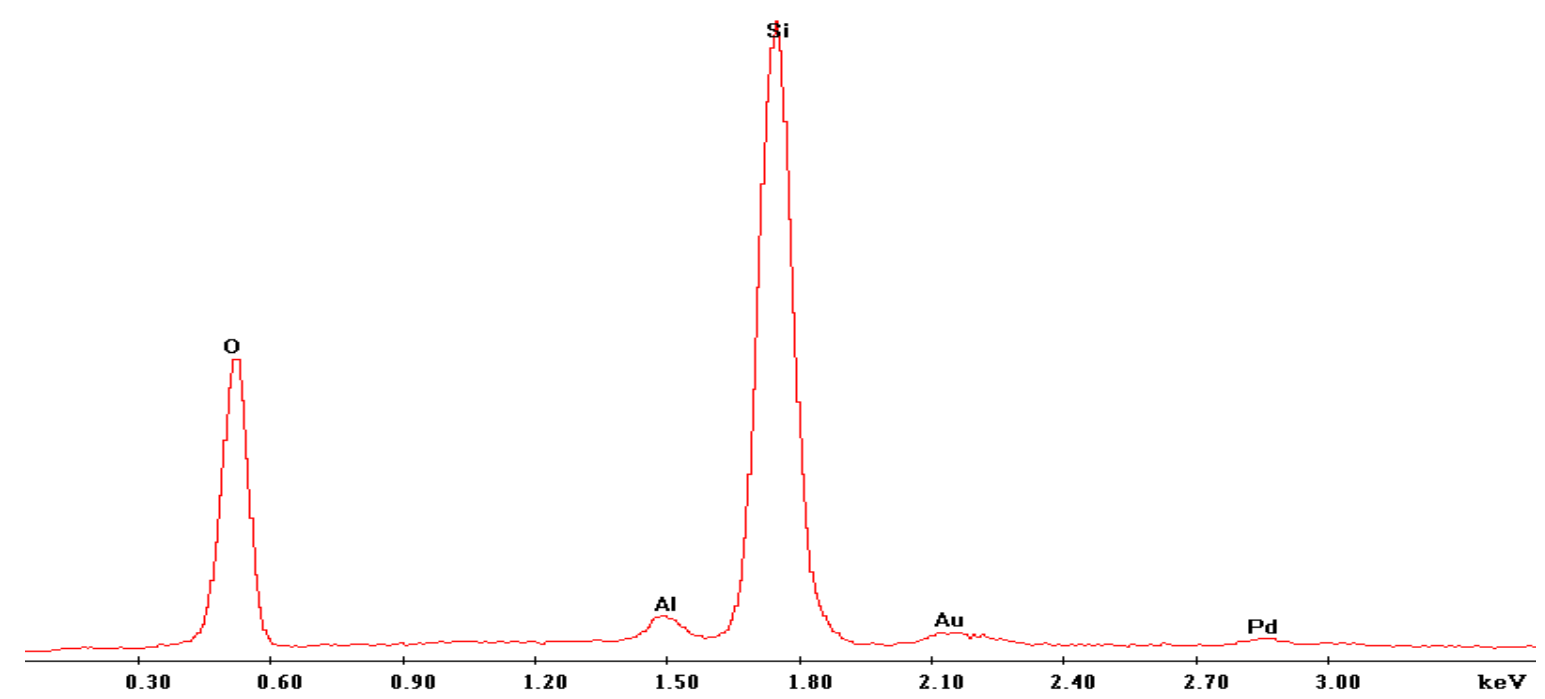

Figure 4.4 EDX elemental analysis of fresh ZSM-5

\subsection{X-RAY DIFFRACTION ANALYSIS}

Figure 4.5 shows the x-ray diffraction (XRD) analysis of fresh base catalyst. The base catalyst is reduced before the XRD under $\mathrm{H}_{2}$ flow of $200 \mathrm{sccm}$, at $400^{\circ} \mathrm{C}$ for $2 \mathrm{~h}$. The base catalyst shows mainly graphite and $\mathrm{Fe}_{3} \mathrm{O}_{4}$ (magnetite phase). The graphite phase is due to the activated carbon, and the magnetite phase is due to reduction of $\alpha-\mathrm{Fe}_{2} \mathrm{O}_{3}$ to $\mathrm{Fe}_{3} \mathrm{O}_{4}$. 


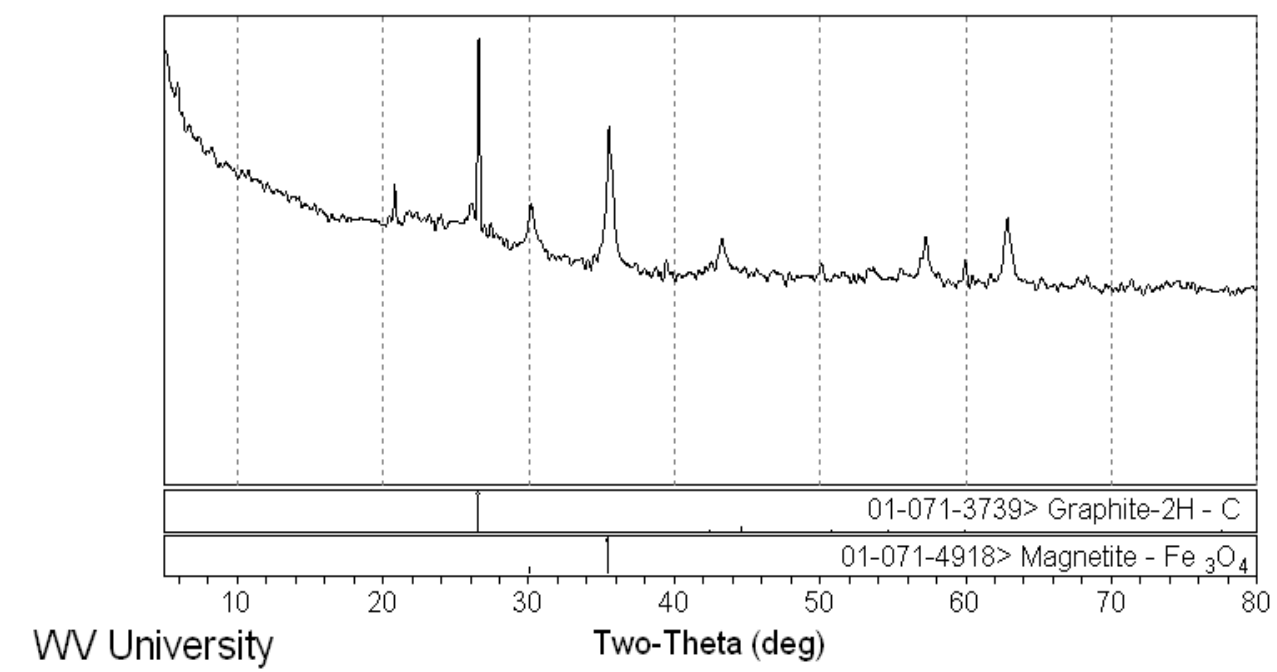

Figure 4.5 XRD of fresh base catalyst

Figure 4.6 shows XRD of fresh ZSM-5. It shows the presence of hydrogen aluminum silicate hydrate phase. This is also reported by Shan et al. (1999).

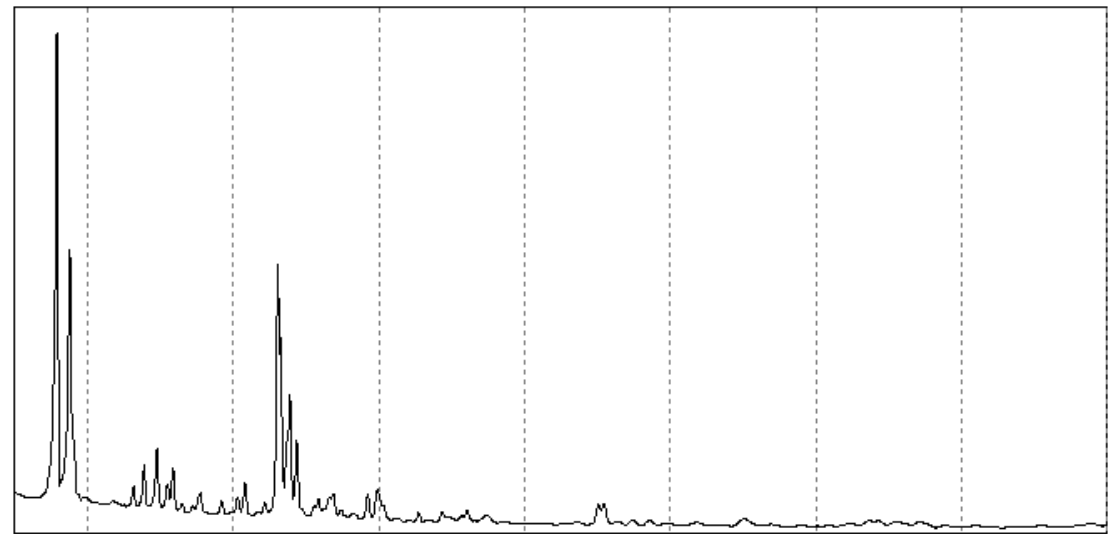

01-079-2401>Hydrogen Aluminum Silicate hydrate - $\mathrm{H}_{1.61}\left(\mathrm{Si}_{94.22} \mathrm{Al}_{1.78} \mathrm{O}_{192}\right)\left(\mathrm{H}_{2} \mathrm{O}\right)$

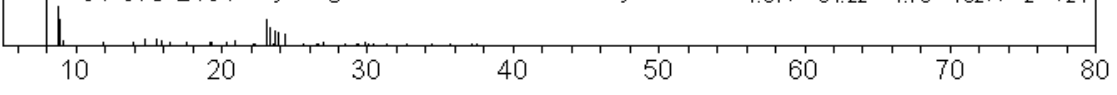

WV University

Two-Theta (deg)

Figure 4.6 XRD of fresh ZSM-5 


\subsection{TEMPERATURE-PROGRAMMED REDUCTION}

Figure 4.7 shows TPR profiles of the base catalyst, 2:1 and 1:1 ratios of the base catalyst to ZSM-5, and fresh ZSM-5. For all the TPR profiles (except ZSM-5), the peak between $200-300^{\circ} \mathrm{C}$ is the reduction of $\alpha-\mathrm{Fe}_{2} \mathrm{O}_{3}$ to $\mathrm{Fe}_{3} \mathrm{O}_{4}$. Also, in this region, $\mathrm{CuO}$ is reduced to $\mathrm{Cu}$ metal. Due to the low concentration of $\mathrm{Cu}$ in the base catalyst compared to $\mathrm{Fe}$, this peak is not seen. From $350-500^{\circ} \mathrm{C}, \mathrm{Fe}_{3} \mathrm{O}_{4}$ is reduced to $\mathrm{FeO}$. In the range of $550-750^{\circ} \mathrm{C}$, there is a broad peak that shows that $\mathrm{FeO}$ is reduced to $\mathrm{Fe}$ metal.

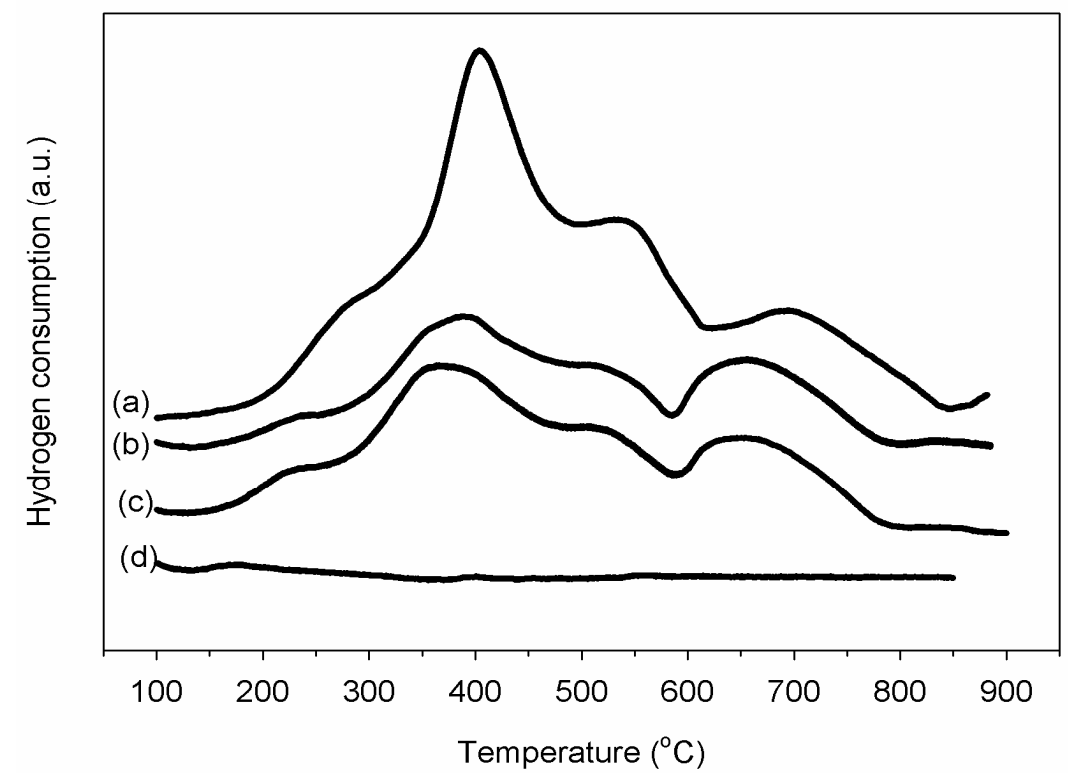

Figure 4.7 TPR profiles (a) $50 \mathrm{mg}$ of base catalyst, (b) $33.33 \mathrm{mg}$ of base catalyst and $16.67 \mathrm{mg}$ of ZSM5 (2:1), (c) $25 \mathrm{mg}$ of base catalyst and $25 \mathrm{mg}$ of ZSM-5 (1:1), (d) $50 \mathrm{mg}$ of ZSM-5

The hydrogen consumption in Figure 4.7 (a) is greater than those in (b) and (c). The higher hydrogen consumption is due to the higher amount of the base catalyst. Table 4.1 shows the weights measured and hydrogen consumed amounts during TPR. Catalyst \# 1 in Table 4.1 shows TPR results from a catalyst identical to the base catalyst but containing no Fe. This catalyst was prepared by Welshans (2011) and the area under that curve corresponds to adsorption on the support and all constituents except Fe and ZSM-5. The amount of experimental hydrogen consumption corresponding to the catalyst \# 1 is subtracted in the calculation of degree of reduction (DOR) for all the catalysts. Note that hydrogen consumption for ZSM-5 is zero. Theoretical $\mathrm{H}_{2}$ consumed is calculated using Equation (3.5) and DOR is calculated using Equation (4.1). Theoretical $\mathrm{H}_{2}$ consumed calculations for catalyst \# 2 are shown below: 
We know that $0.16 \mathrm{~g}$ of $\mathrm{Fe}$ is supported on $1 \mathrm{~g}$ of activated carbon, and similarly for other metals $(0.8 \% \mathrm{Cu}, 0.9 \% \mathrm{~K}$, and $6 \% \mathrm{Mo})$.

So the actual weight $\%$ of $\mathrm{Fe}$ is $=>\frac{0.16 \times 100}{1+0.16+0.008+0.009+0.06}=12.9345 \%$

We know, $56 \mathrm{~g}$ of $\mathrm{Fe}$ is equivalent to $1 \mathrm{~mol}$ of $\mathrm{Fe}$

Therefore, $12.9345 \% \mathrm{Fe}$ of $1 \mathrm{~g}$ of base catalyst is equivalent to $=>\frac{0.129345 \times 1}{56}=0.00231 \mathrm{~mol}=2310$ $\mu \mathrm{mol}$ of Fe.

From Equation (3.5), $2 \mathrm{~mol}$ of Fe need $3 \mathrm{~mol} \mathrm{H}_{2}$

$2310 \mu \mathrm{mol}$ of Fe-at. need $=>2310 \times 3 / 2=3465 \mu \mathrm{mol}$ of $\mathrm{H}_{2}$

Therefore, theoretical $\mathrm{H}_{2}$ consumed on $1 \mathrm{~g}$ of base catalyst $=3465 \mu \mathrm{mol}$ of $\mathrm{H}_{2}$

The amounts of theoretical $\mathrm{H}_{2}$ consumption, actual experimental hydrogen consumption and DOR corresponding to the catalysts in Table 4.1 are found by:

$\mathrm{DOR}=$

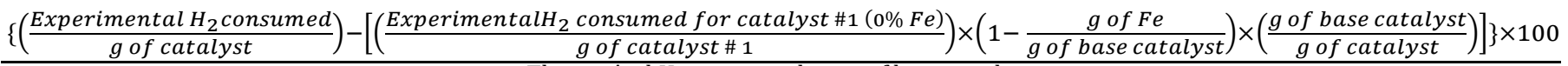
$\left\{\left(\frac{\text { Theoretical H2 consumed }}{\mathrm{g} \text { of base catalyst }}\right) \times\left(\frac{\text { g of base catalyst }}{\mathrm{g} \text { of catalyst }}\right)\right\}$ 
Table 4.1 Degree of reduction calculations for different catalysts

\begin{tabular}{|l|l|l|l|l|c|c|}
\hline $\begin{array}{l}\text { Catalyst } \\
\#\end{array}$ & Catalyst & $\begin{array}{l}\text { Weight } \\
(\mathrm{mg})\end{array}$ & $\begin{array}{l}\text { Experimental } \\
\mathrm{H}_{2} \text { consumed } \\
(\mu \mathrm{mol} / \mathrm{g} \text { of } \\
\text { catalyst }{ }^{*}\end{array}$ & $\begin{array}{l}\text { Theoretical } \\
\mathrm{H}_{2} \\
\text { consumed } \\
(\mu \mathrm{mol} / \mathrm{g} \text { of } \\
\text { catalyst })\end{array}$ & $\begin{array}{l}\text { Actual } \\
\text { experimental } \mathrm{H}_{2} \\
\text { consumed } \\
(\mu \mathrm{mol} / \mathrm{g} \text { of } \\
\text { catalyst) }\end{array}$ & $\begin{array}{l}\text { DOR } \\
(\%)\end{array}$ \\
\hline 1 & $\begin{array}{l}0 \% \mathrm{Fe}, 6 \% \mathrm{Mo}, \\
0.8 \% \mathrm{Cu}, 0.9 \% \mathrm{~K} \text { on } \\
\text { Norit Ultra SX }\end{array}$ & 49.1 & 498 & - & 0 & - \\
\hline $\begin{array}{l}\text { 2 (Base } \\
\text { catalyst) }\end{array}$ & $\begin{array}{l}\text { 16\%Fe, 6\%Mo, } \\
\text { Norit Ultra SX }\end{array}$ & 48.6 & 1353 & 3465 & 909 & 26.5 \\
\hline 3 & $\begin{array}{l}\text { Base catalyst / } \\
\text { ZSM-5 (1:1) }\end{array}$ & 49.0 & 620 & 1732.5 & 403 & 23.3 \\
\hline 4 & $\begin{array}{l}\text { Base catalyst / } \\
\text { ZSM-5 (2:1) }\end{array}$ & 48.0 & 774 & 2310 & 485 & 21.0 \\
\hline 5 & $\begin{array}{l}\text { Fresh ZSM-5 (no } \\
\text { base catalyst) }\end{array}$ & 49.4 & 0 & - & - & - \\
\hline
\end{tabular}

*Total amount of $\mathrm{H}_{2}$ consumed between $200-800^{\circ} \mathrm{C}$ as one peak based $\mathrm{H}_{2}$ consumption by $\mathrm{AgO}$ reference material.

\subsection{BRUNAUER, EMMETT AND TELLER (B.E.T.) SURFACE AREA}

B.E.T. surface area measurement is done for Norit SX Ultra activated carbon and compared with the value found by Ma et al. (2007a).

B.E.T. surface area $=927 \mathrm{~m}^{2} / \mathrm{g}$.
B.E.T. surface area $=1016 \mathrm{~m}^{2} / \mathrm{g}$ (Ma et al., 2007a).

It can be seen that B.E.T. surface area measured for Norit SX Ultra activated carbon is consistent with Ma et al. (2007a). 


\section{CHAPTER 5}

\section{FISCHER-TROPSCH REACTIONS CARRIED OUT WITHOUT BASE CATALYST}

\subsection{INTRODUCTION}

FT reactions are carried out first without any catalyst, to see the activity of the blank reactor, then with the ZSM-5 catalyst, and with the activated carbon (AC) used as the support for the base catalyst. The operating conditions are: syngas flow $=100 \mathrm{scc} / \mathrm{min}$, temperature $=300^{\circ} \mathrm{C}$, pressure $=300$ psig, $\mathrm{H}_{2} / \mathrm{CO}$ ratio $=1.0$.

\subsection{RESULT AND DISCUSSION}

\subsubsection{FISCHER-TROPSCH REACTIONS CARRIED OUT WITHOUT BASE CATALYST}

Table 5.1 shows the reaction data for the reaction carried out without base catalyst. All the reactions show negligible activity towards conversion of $\mathrm{CO}$ and $\mathrm{H}_{2}$. Moreover, there are no FID peaks detected and no liquid products are collected.

This very low conversion of $\mathrm{CO}$ and $\mathrm{H}_{2}$ is due to minor activity of the SS reactor tube, which has $\mathrm{Fe}$, at $300^{\circ} \mathrm{C}$. $\mathrm{CO}$ and $\mathrm{H}_{2}$ conversions reported in the following chapters and in Appendix F.1 are the actual conversions of the particular reaction minus the conversion corresponding to the blank reactor.

Table 5.1 Fischer-Tropsch data for the reactions without base catalyst (syngas flow=100 scc/min, Temperature $=300^{\circ} \mathrm{C}$, Pressure $=300 \mathrm{psi}, \mathrm{H}_{2} / \mathrm{CO}$ ratio $=1.0$, TOS $=0-48 \mathrm{~h}$ )

\begin{tabular}{|l|c|c|c|c|c|}
\hline Reaction details & $\begin{array}{l}\text { Catalyst } \\
\text { weight }(\mathrm{g})\end{array}$ & $\begin{array}{l}\text { CO conversion } \\
(\%)\end{array}$ & $\begin{array}{l}\mathrm{H}_{2} \text { conversion } \\
(\%)\end{array}$ & $\begin{array}{l}\text { Products } \\
\text { in FID }\end{array}$ & $\begin{array}{l}\text { Liquid } \\
\text { product }(\mathrm{g})\end{array}$ \\
\hline $\begin{array}{l}\text { Blank reactor without any } \\
\text { catalyst }\end{array}$ & 0.00 & 0.16 & 2.80 & $\begin{array}{c}\text { No peak } \\
\text { detection } \\
\text { in FID }\end{array}$ & $\begin{array}{c}\text { No liquid } \\
\text { collected }\end{array}$ \\
\hline $\begin{array}{l}\text { Reactor with ZSM-5 only } \\
\text { without base catalyst }\end{array}$ & 0.50 & 0.25 & 1.60 & $\begin{array}{c}\text { No peak } \\
\text { detection } \\
\text { in FID }\end{array}$ & $\begin{array}{l}\text { No liquid } \\
\text { collected }\end{array}$ \\
\hline $\begin{array}{l}\text { Reactor with Norit SX Ultra } \\
\text { AC }\end{array}$ & 0.50 & 0.19 & 1.50 & $\begin{array}{c}\text { No peak } \\
\text { detection } \\
\text { in FID }\end{array}$ & $\begin{array}{c}\text { No liquid } \\
\text { collected }\end{array}$ \\
\hline
\end{tabular}




\section{CHAPTER 6}

FISCHER-TROPSCH REACTIONS CARRIED OUT WITH BASE AND ZSM-5 CATALYST

\subsection{INTRODUCTION}

Operating conditions for these runs (with the base catalyst, with and without ZSM-5) are as before: syngas flow $=100 \mathrm{scc} / \mathrm{min}$, temperature $=300^{\circ} \mathrm{C}$, pressure $=300 \mathrm{psig}, \mathrm{H}_{2} / \mathrm{CO}$ ratio $=1.0$. The effect of ZSM-5 weight change on product selectivities in separate-bed catalyst arrangement and mixedbed catalyst arrangement are analyzed. Products formed in both the arrangements are compared. The effect of temperature change on product selectivities in the separate-bed catalyst arrangement is analyzed.

\subsection{RESULT AND DISCUSSION}

\subsubsection{EFFECT OF ZSM-5 WEIGHT CHANGE ON PRODUCT DISTRIBUTION IN SEPARATE-BED CATALYST ARRANGEMENT}

The quantity of base catalyst is fixed at $0.5 \mathrm{~g}$ for all the reactions. Three different ZSM-5 amounts $(0.25,0.5$, and $1 \mathrm{~g})$ are used in the separate-bed catalyst arrangement. Gas, oil, and aqueous product analyses are carried out. The results are discussed below in detail.

\subsubsection{Overall Products}

The amounts of all hydrocarbons are shown in Table 6.1. The $\mathrm{C}_{5}$-gases from the FID are included as $\mathrm{C}_{5}$ i-paraffins because these gases are not detected as n-paraffins or as olefins. The detailed analysis of products is described in subsequent sections.

From Table 6.1, for the base catalyst alone, the amounts of $\mathrm{C}_{1-4}$ are larger than total $\mathrm{C}_{5+}$. But the product profile shifts towards total $\mathrm{C}_{5+}$ when $0.25 \mathrm{~g}$ of ZSM-5 is added to the base catalyst. This is because ZSM-5 oligomerizes and aromatizes olefinic-gas components coming from the base catalyst, and also ZSM-5 converts alcohols formed by the base catalyst to hydrocarbons. More details on oligomerization of these gas molecules are shown in Section 6.2.1.3. Further addition of ZSM-5 causes cracking, and an increase in amounts of $\mathrm{C}_{1-4}$ can be seen in Table 6.1. The total hydrocarbons (gas and liquid included) increase slightly with ZSM-5 and the amounts of alcohols are nearly zero. This means that the additional ZSM-5 is converting alcohols into hydrocarbons. This is consistent with Bjorgen et 
al. (2007) and Calsavara et al. (2008). ZSM-5 amounts greater than $0.5 \mathrm{~g}$ basically convert all the alcohols to hydrocarbons and water.

Table 6.1 Overall product distribution (separate-bed catalyst arrangement, $0.5 \mathrm{~g}$ of base catalyst, $\mathrm{Si} / \mathrm{Al}$ ratio in $\mathrm{ZSM}-5=50, \mathrm{H}_{2} / \mathrm{CO}$ ratio $=1$, total feed rate $=100 \mathrm{scc} / \mathrm{min}$, reactor temperature $=300^{\circ} \mathrm{C}$, reactor pressure $=300 \mathrm{psi}, \mathrm{TOS}=24-48 \mathrm{~h}$ )

\begin{tabular}{|c|c|c|c|c|}
\hline ZSM-5 weight (g) & 0 & 0.25 & 0.5 & 1 \\
\hline Bed arrangement & Base catalyst & \multicolumn{3}{|c|}{ Separate-bed } \\
\hline Compounds & \multicolumn{4}{|c|}{ g carbon/day } \\
\hline $\mathrm{C}_{1}$ & 2.31 & 1.95 & 2.21 & 2.81 \\
\hline $\mathrm{C}_{2-4}$ & 6.12 & 5.41 & 6.05 & 6.95 \\
\hline Sum of $\mathrm{C}_{1-4}(\mathrm{Gas})$ & 8.43 & 7.36 & 8.26 & 9.76 \\
\hline Total $\mathrm{C}_{5+}(\mathrm{Gas}+$ Liquid $)$ & 6.19 & 8.00 & 8.05 & 7.05 \\
\hline Sum of hydrocarbons (Gas + Liquid) & 14.62 & 15.36 & 16.31 & 16.81 \\
\hline Total alcohols & 0.75 & 0.01 & 0.00 & 0.00 \\
\hline $\mathrm{CO}_{2}$ & 14.39 & 15.56 & 15.10 & 15.50 \\
\hline Unreacted $\mathrm{CO}$ & 6.84 & 5.27 & 4.30 & 5.12 \\
\hline
\end{tabular}

\subsubsection{WGS and FTS reaction activities}

Figure 6.1 shows activities of WGS and FTS reactions in the base catalyst and in the separatebed arrangement. The rates are calculated similar to the procedure followed by Ma et al. (2007b). The calculations are tabulated in Appendix F.2. From Figure 6.1, the rates of the two reactions seem approximately constant with ZSM-5 weight addition. Therefore ZSM-5 is inactive towards FTS and WGS reactions. Mahay et al. (1987) also confirm that ZSM-5 alone cannot show any activity towards WGS. EDX of a spent sample of ZSM-5 is shown in Figure 8.1. This confirms no migration of metals $(\mathrm{Fe}, \mathrm{Cu})$ from the separate bed to ZSM-5, as opposed to results from the mixed-bed configuration, shown later in Chapter 8. 


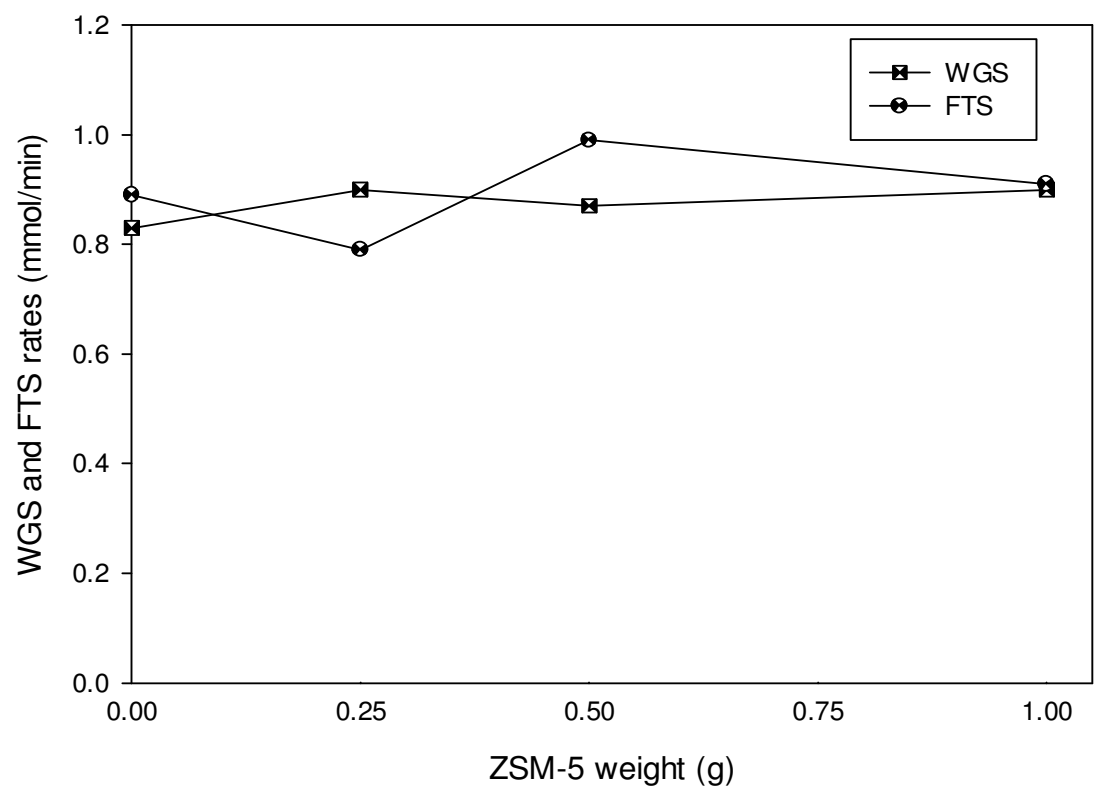

Figure 6.1 WGS and FTS reaction rates $(\mathrm{mmol} / \mathrm{min})$. Separate-bed catalyst arrangement, $0.5 \mathrm{~g}$ of base catalyst, $\mathrm{Si} / \mathrm{Al}$ ratio in $\mathrm{ZSM}-5=50, \mathrm{H}_{2} / \mathrm{CO}$ ratio $=1$, total feed rate $=100 \mathrm{scc} / \mathrm{min}$, reactor temperature $=$ $300^{\circ} \mathrm{C}$, reactor pressure $=300 \mathrm{psi}$, TOS $=24-48 \mathrm{~h}$.

\subsubsection{Gas analysis}

All the data in described in this Section are tabulated in Appendix F.3. Figure 6.2 shows that the amounts of $\mathrm{CH}_{4}, \mathrm{C}_{3} \mathrm{H}_{8}, \mathrm{i}-\mathrm{C}_{4} \mathrm{H}_{10}, \mathrm{n}-\mathrm{C}_{4} \mathrm{H}_{10}, \mathrm{i}-\mathrm{C}_{5} \mathrm{H}_{12}$, and $\mathrm{n}-\mathrm{C}_{5} \mathrm{H}_{12}$ detected by the FID increase with ZSM-5. The additional amounts of ZSM-5 provide more cracking activity sites (Martinez et al., 2005).

From Figure 6.2, the amount of $\mathrm{CH}_{4}$ generated by the separate bed with $0.25 \mathrm{~g} \mathrm{ZSM}-5$ is lower than that of the base catalyst. This is because ZSM-5 forms a $C_{1}$ carbenium ion (Fejes et al., 1984) and this ion further reacts with another carbenium-based molecule to form long-chain hydrocarbons. Larger amounts of ZSM-5 increase the cracking of longer-chain hydrocarbons (Martinez et al., 2005) to form increased amounts of n-paraffins $\mathrm{C}_{3} \mathrm{H}_{8}$, etc. No i- $\mathrm{C}_{4} \mathrm{H}_{10}$ and $\mathrm{i}-\mathrm{C}_{5} \mathrm{H}_{12}$ are found in the products with the base catalyst alone because the base catalyst lacks the acidic active sites responsible for isomerization, but these are available with ZSM-5. The amounts of $\mathrm{i}-\mathrm{C}_{4} \mathrm{H}_{10}$ and $\mathrm{i}-\mathrm{C}_{5} \mathrm{H}_{12}$ increase with ZSM-5 because ZSM-5 provides isomerization active sites (Borges et al., 2007). 


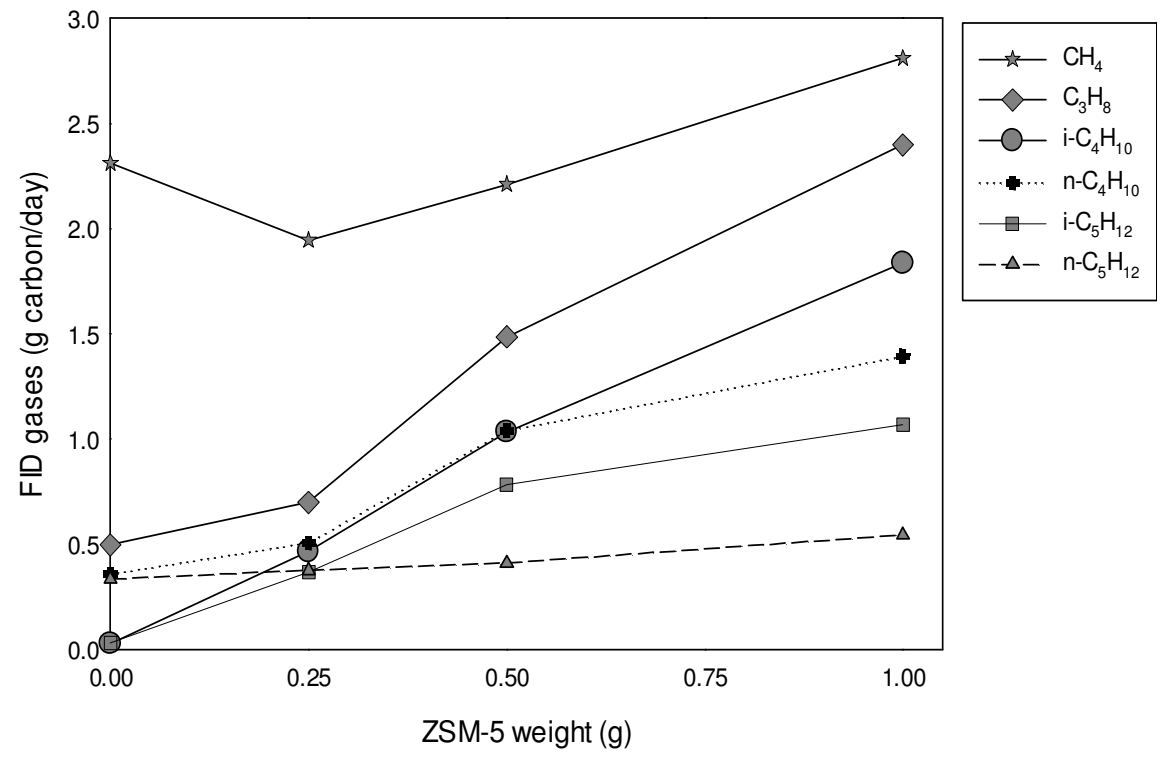

Figure 6.2 Gas-phase paraffins detected by FID (g carbon/day). Separate-bed catalyst arrangement, $0.5 \mathrm{~g}$ of base catalyst, $\mathrm{Si} / \mathrm{Al}$ ratio in $\mathrm{ZSM}-5=50, \mathrm{H}_{2} / \mathrm{CO}$ ratio $=1$, total feed rate $=100 \mathrm{scc} / \mathrm{min}$, reactor temperature $=300^{\circ} \mathrm{C}$, reactor pressure $=300 \mathrm{psi}$, TOS $=24-48 \mathrm{~h}$.

Figure 6.3 shows the effect of ZSM-5 on olefins and other gases that are not shown in Figure 6.2. $\mathrm{C}_{2} \mathrm{H}_{6}$ and $\mathrm{C}_{2} \mathrm{H}_{4}$ are reported together here because both have similar retention times. The production of $\mathrm{C}_{2} \mathrm{H}_{6}+\mathrm{C}_{2} \mathrm{H}_{4}$ is initially flat and then decreases with addition of more ZSM-5. The cracking of longchain hydrocarbons by ZSM-5 may increase the amount of $\mathrm{C}_{2} \mathrm{H}_{6}$ (Martinez et al., 2005). This may be offset by the oligomerization of $\mathrm{C}_{2} \mathrm{H}_{4}$ by ZSM-5 (Knifton et al., 1994). $\mathrm{C}_{2} \mathrm{H}_{4}$ oligomerises because $\mathrm{C}_{2} \mathrm{H}_{4}$ is an unsaturated hydrocarbon and more reactive compared to $\mathrm{C}_{2} \mathrm{H}_{6}$. When relatively large amounts of ZSM-5 are present, oligomerization could be more significant.

From Figure 6.3, the base catalyst with no ZSM-5 produces greater amounts of $\mathrm{C}_{3} \mathrm{H}_{6}, 1-\mathrm{C}_{4} \mathrm{H}_{8}$, and $\mathrm{t}-\mathrm{C}_{4} \mathrm{H}_{8}$ compared to that when ZSM-5 is added. This is because the base catalyst does not have the acidic sites responsible for oligomerization. On the other hand, the acidic sites of ZSM-5 convert $\mathrm{C}_{3} \mathrm{H}_{6}$, 1- $\mathrm{C}_{4} \mathrm{H}_{8}$, and $\mathrm{t}-\mathrm{C}_{4} \mathrm{H}_{8}$ to other products (Knifton et al., 1994; Borges et al., 2007). Gases containing a double bond $\left(\mathrm{C}_{3} \mathrm{H}_{6}, 1-\mathrm{C}_{4} \mathrm{H}_{8} \mathrm{t}-\mathrm{C}_{4} \mathrm{H}_{8}\right)$ are highly reactive and tend to oligomerize on the ZSM-5 active sites (Knifton et al., 1994; Borges et al., 2007). 


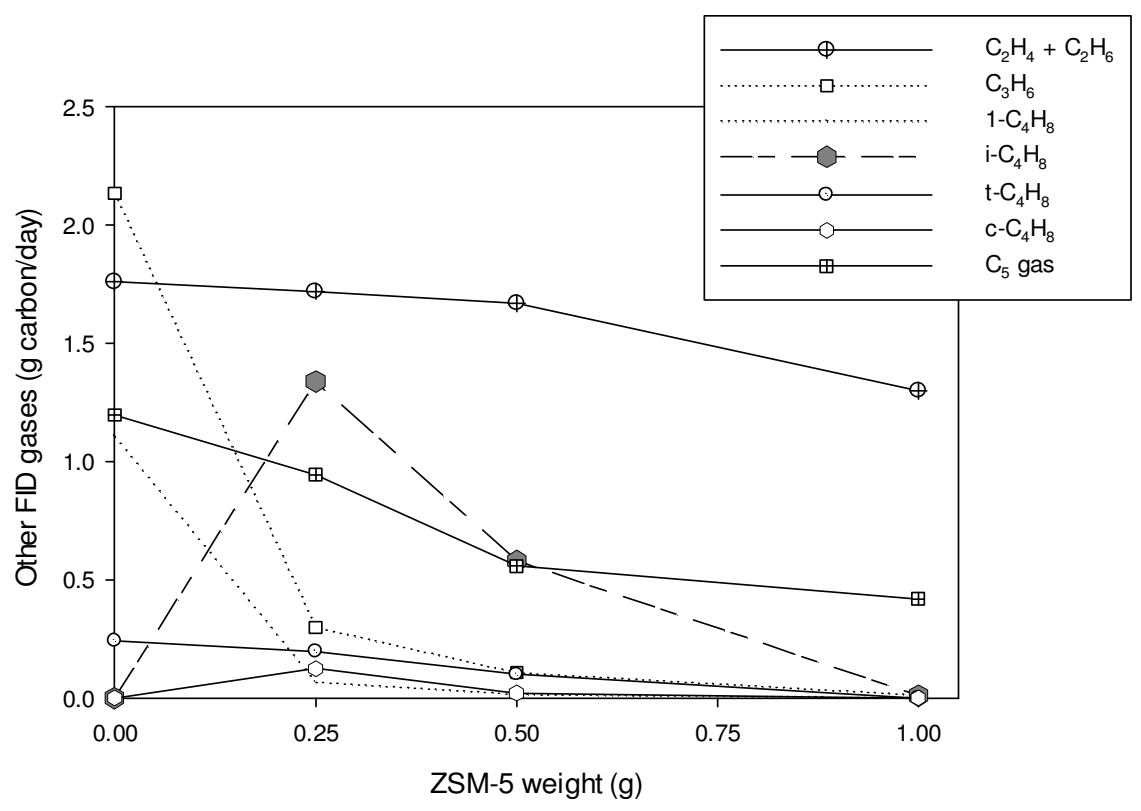

Figure 6.3 FID gases not shown in Figure 6.2 (g carbon/day). Separate-bed catalyst arrangement, $0.5 \mathrm{~g}$ of base catalyst, $\mathrm{Si} / \mathrm{Al}$ ratio in $\mathrm{ZSM}-5=50, \mathrm{H}_{2} / \mathrm{CO}$ ratio $=1$, total feed rate $=100 \mathrm{scc} / \mathrm{min}$, reactor temperature $=300^{\circ} \mathrm{C}$, reactor pressure $=300 \mathrm{psi}$, TOS $=24-48 \mathrm{~h}$.

Also from Figure 6.3, the amounts of $\mathrm{i}-\mathrm{C}_{4} \mathrm{H}_{8}$ and $\mathrm{c}-\mathrm{C}_{4} \mathrm{H}_{8}$ increase for $0.25 \mathrm{~g}$ of ZSM-5 and decrease thereafter. These isomers are not formed with the base catalyst alone because it lacks the acidic active sites needed for isomerization (Borges et al., 2007). The decrease of these species with larger amounts of ZSM-5 can be explained by ZSM-5 causing them, double bonded and highly reactive, to undergo oligomerization. This is consistent with Knifton et al. (1994).

In Figure 6.3, $\mathrm{C}_{5}$ gases are formed when the base catalyst alone is used, but the total amount decreases as ZSM-5 is increased. These $\mathrm{C}_{5}$ gases are not n-alkanes or i-alkanes, and could be alkenes or i-alkenes. The decrease of the $\mathrm{C}_{5}$-olefins could also be due to oligomerization into liquid products (Knifton et al., 1994).

\subsubsection{Overall liquid production rates}

Figure 6.4 shows overall liquid hydrocarbon production rates and overall alcohol production rates. The liquid hydrocarbon appears to go through a maximum around $0.5 \mathrm{~g}$ of ZSM-5. Larger amounts of ZSM-5 provide additional cracking active sites (Martinez et al., 2005) which decrease the 
amount of liquids. This is consistent with the formation of additional gaseous $\mathrm{C}_{1}$ to $\mathrm{C}_{5}$ products, as seen in Figure 6.2.

Small amounts of ZSM-5 convert alcohols formed by the base catalyst to hydrocarbons (Bjorgen et al., 2007; Calsavara et al., 2008). Correspondingly, the production of alcohols decreases to nearly zero in the presence of even small amounts of ZSM-5, as can also be seen in Figure 6.4.

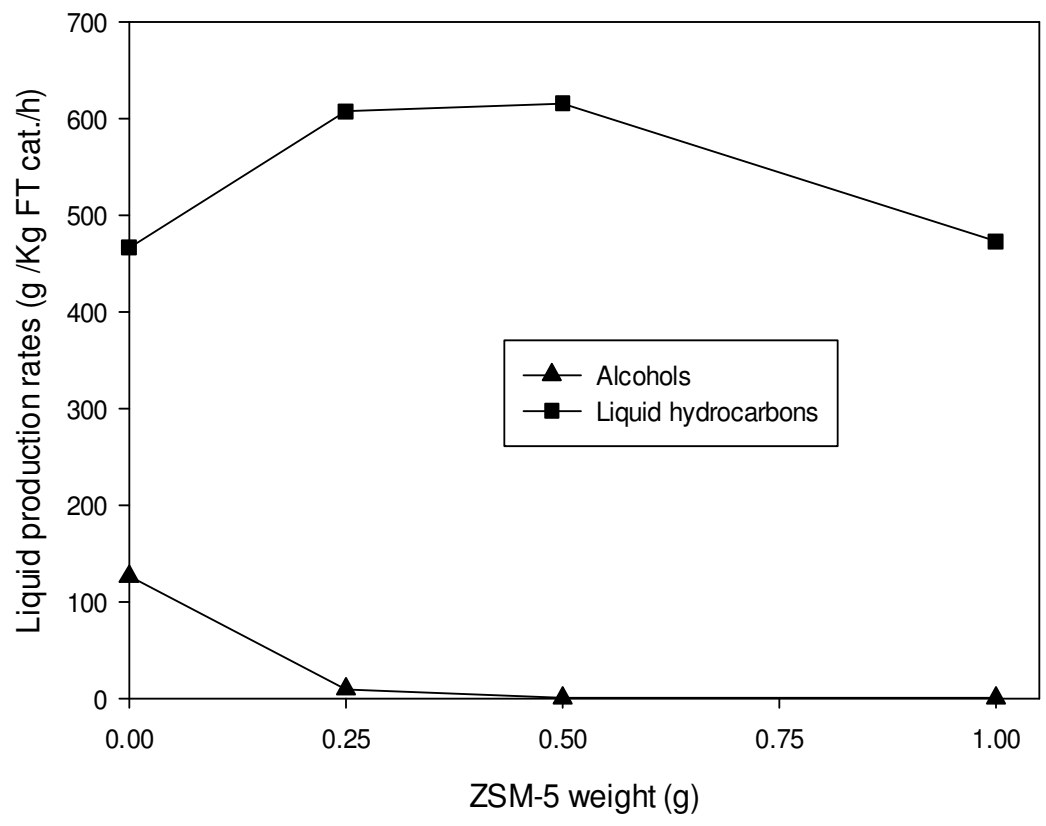

Figure 6.4 Liquid hydrocarbon and alcohol production rate (g/kg FT cat/h). Separate-bed catalyst arrangement, $0.5 \mathrm{~g}$ of base catalyst, $\mathrm{Si} / \mathrm{Al}$ ratio in $\mathrm{ZSM}-5=50, \mathrm{H}_{2} / \mathrm{CO}$ ratio $=1$, total feed rate $=100$ $\mathrm{scc} / \mathrm{min}$, reactor temperature $=300^{\circ} \mathrm{C}$, reactor pressure $=300 \mathrm{psi}, \mathrm{TOS}=24-48 \mathrm{~h}$.

\subsubsection{Hydrocarbons distribution in organic liquid phase}

All the amounts of liquids are shown in Appendix F.4. Figure 6.5 shows the amounts of nparaffins in the organic liquid phase. The amounts of $n-C_{5}$ increase, and the amounts of $n-C_{8}$ to $n-C_{22}$ decrease, with addition of ZSM-5. $n-\mathrm{C}_{6}$ and $\mathrm{n}-\mathrm{C}_{7}$ go through a maximum at $0.25 \mathrm{~g}$ ZSM-5. ZSM-5 provides additional cracking sites (Martinez et al., 2005), and the long-chain paraffins $n-C_{8}$ to $n-C_{22}$ are cracked into smaller-chain hydrocarbon molecules. The amount of $n-C_{5}$ increases with ZSM-5 and can be considered to be a small-chain cracked molecule. The increase in amounts of $n-C_{6}$ and $n-C_{7}$ for a 
small amount of ZSM-5 might be due to rearrangements of small-chain gas molecules. These amounts further decrease because increased ZSM-5 provides cracking and aromatization active sites.

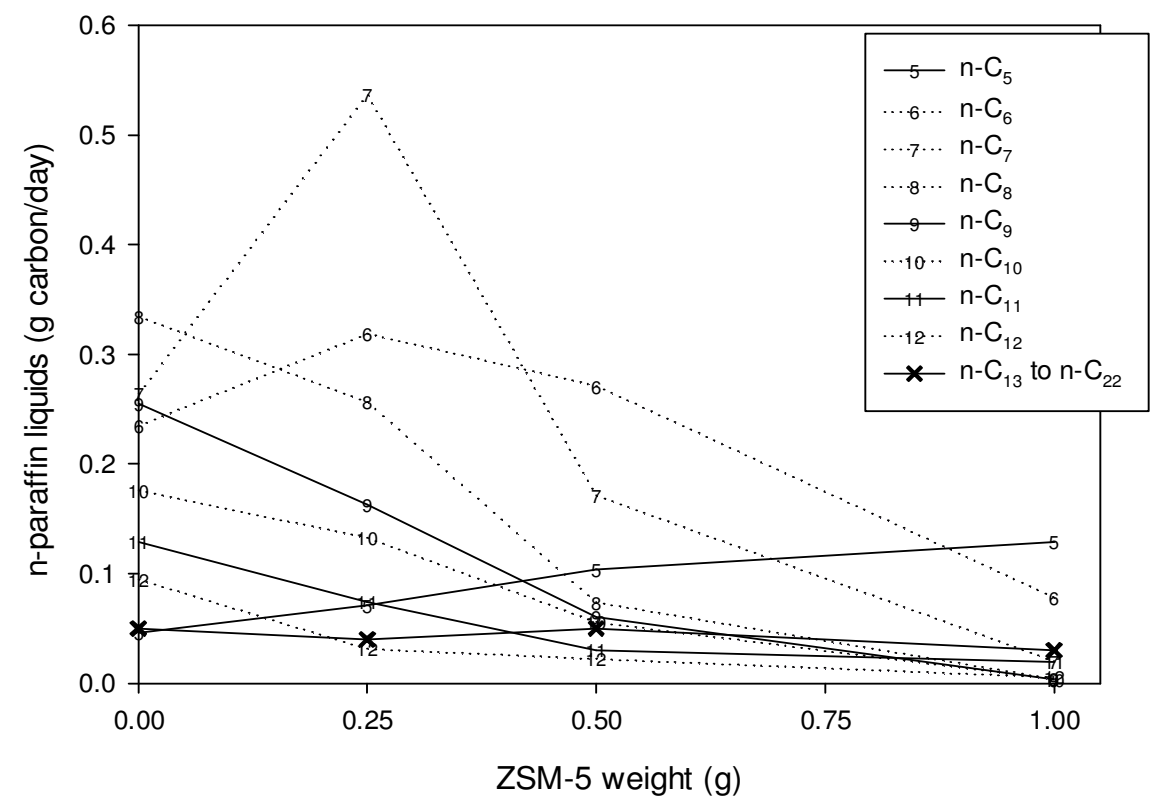

Figure 6.5 Liquid n-paraffins (g carbon/day). Separate-bed catalyst arrangement, $0.5 \mathrm{~g}$ of base catalyst, $\mathrm{Si} / \mathrm{Al}$ ratio in $\mathrm{ZSM}-5=50, \mathrm{H}_{2} / \mathrm{CO}$ ratio $=1$, total feed rate $=100 \mathrm{scc} / \mathrm{min}$, reactor temperature $=300^{\circ} \mathrm{C}$, reactor pressure $=300 \mathrm{psi}$, TOS $=24-48 \mathrm{~h}$.

Figure 6.6 shows the amounts of i-paraffins in the organic liquid phase. The amounts of $\mathrm{i}-\mathrm{C}_{5}$ and $\mathrm{i}-\mathrm{C}_{6}$ increase monotonically with increase in ZSM-5 weight. This is because additional ZSM-5 provides additional cracking active sites (Martinez et al., 2005). $\mathrm{i}-\mathrm{C}_{7}$ through $\mathrm{i}-\mathrm{C}_{12}$ pass through a maximum with ZSM-5 loading between $0.25 \mathrm{~g}$ and $0.5 \mathrm{~g}$. Higher hydrocarbons are present in amounts too small to show significant changes. So the molecules $\mathrm{i}-\mathrm{C}_{7}$ to $\mathrm{i}-\mathrm{C}_{22}$ probably crack to small-chain molecules similar to $\mathrm{i}-$ $\mathrm{C}_{5}$, and consistent with Figure 6.2. The amounts of $\mathrm{C}_{23+}$ are too low to show any significance. 


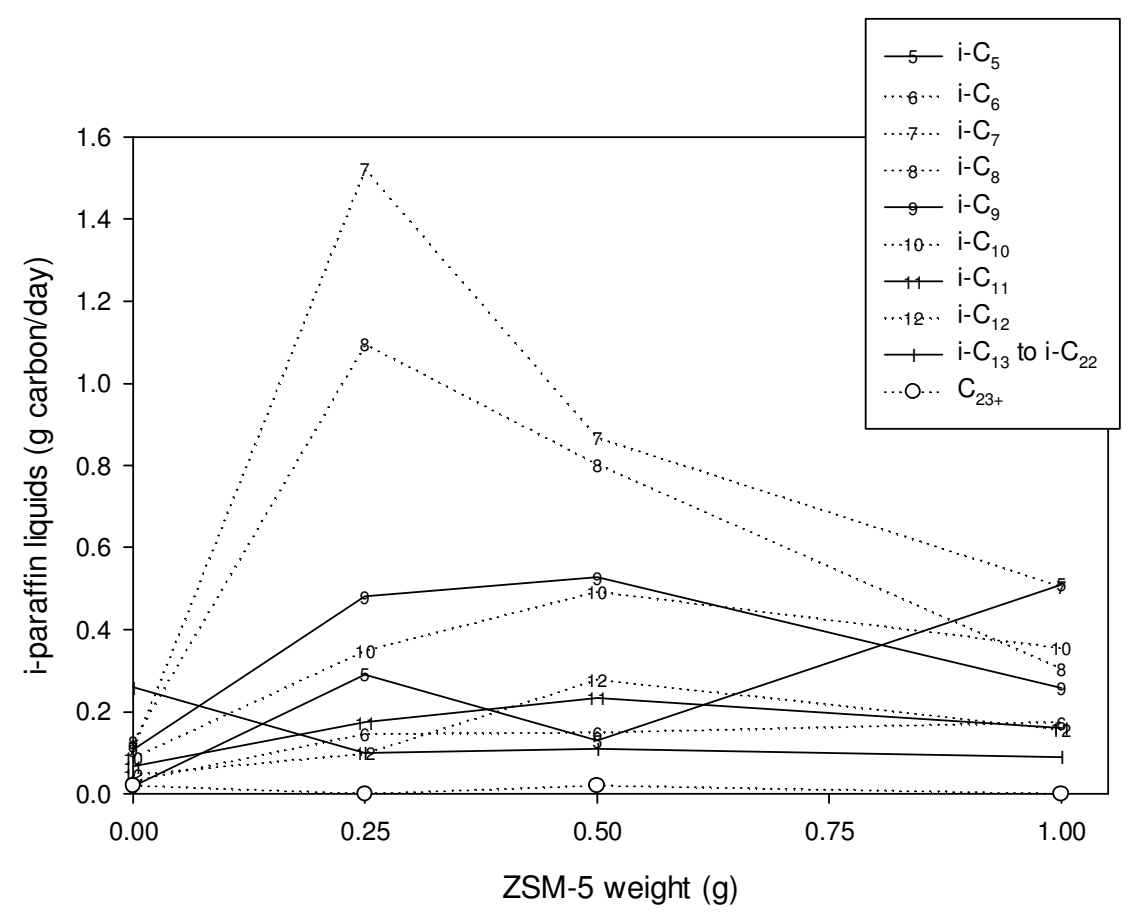

Figure 6.6 Liquid i-paraffins (g carbon/day). Separate-bed catalyst arrangement, $0.5 \mathrm{~g}$ of base catalyst, $\mathrm{Si} / \mathrm{Al}$ ratio in ZSM-5 $=50, \mathrm{H}_{2} / \mathrm{CO}$ ratio $=1$, total feed rate $=100 \mathrm{scc} / \mathrm{min}$, reactor temperature $=300^{\circ} \mathrm{C}$, reactor pressure $=300 \mathrm{psi}, \mathrm{TOS}=24-48 \mathrm{~h}$.

Aromatic ring compounds were not reported by Ma et al. (2006) because the base catalyst lacks acidic active sites for aromatization. However, ZSM-5 oligomerizes and aromatizes small-chain olefin molecules (Zang et al., 2010). The combination of the base catalyst and ZSM-5 produces aromatic products like toluene, p-xylene, propyl-benzene, and butyl-benzene as seen in Figure 6.7. It is important to note that all these aromatic compounds are alkyl-benzenes. This means that ZSM-5 is selective towards alkyl-benzene compounds. ZSM-5 is shape selective (Stocker, 2005) and it allows only certain molecules to flow in and out of the pores relatively easily. This is because steric hindrance of other molecules, such as m-xylene, o-xylene, and 2,3-methyl ethyl-benzene, is higher compared to alkyl benzene. Therefore it is difficult for sterically hindered molecules to desorb from ZSM-5 pores and the converse is also true.

From Figure 6.7, the amounts of toluene and p-xylene increase monotonically with ZSM-5. This is because ZSM-5 provides additional oligomerization active sites and hence a greater tendency towards aromatization (Degnan, 2000). Propyl-benzene and butyl-benzene appear to go through a maximum around 0.5 g ZSM-5. Additional ZSM-5 probably causes cracking of the propyl and butyl chains 
attached to the benzene ring. Also from Figure 6.7, the amounts of butyl-benzene are lower than other aromatics. This can be explained by noting that butyl-benzene is bulky and has more steric hindrance. Thus butyl-benzene is difficult to desorb from ZSM-5 pores.

Production of high amounts of $\mathrm{i}-\mathrm{C}_{5}$ to $\mathrm{i}-\mathrm{C}_{12}$ and aromatics together gives hydrocarbons in the high-octane gasoline range using the separate bed with increasing amounts of ZSM-5. From Appendix F.4, the largest amount of aromatics and isomers for the separate bed is with the base catalyst and ZSM5 in the ratio of 1 .

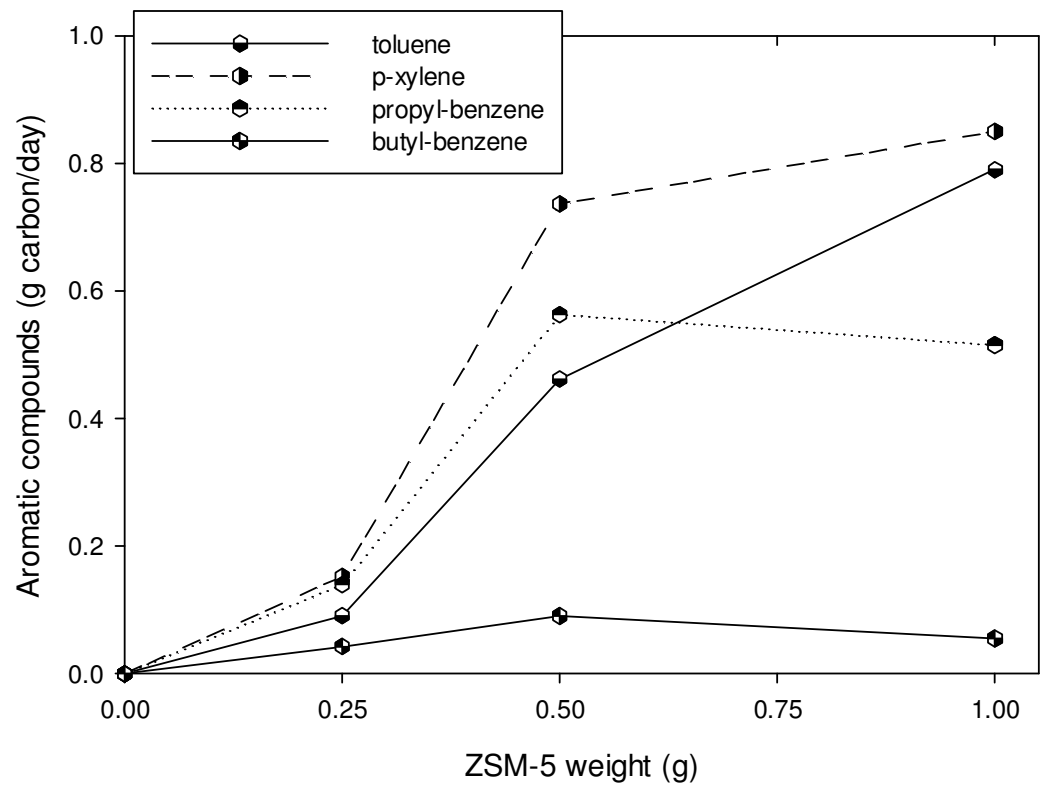

Figure 6.7 Aromatic compounds (g carbon/day). Separate-bed catalyst arrangement, $0.5 \mathrm{~g}$ of base catalyst, $\mathrm{Si} / \mathrm{Al}$ ratio in $\mathrm{ZSM}-5=50, \mathrm{H}_{2} / \mathrm{CO}$ ratio $=1$, total feed rate $=100 \mathrm{scc} / \mathrm{min}$, reactor temperature $=$ $300^{\circ} \mathrm{C}$, reactor pressure $=300 \mathrm{psi}$, TOS $=24-48 \mathrm{~h}$.

\subsubsection{Alcohols and water in aqueous liquid phase}

From Table 6.2, the base catalyst with no ZSM-5 shows the largest amounts of alcohols. Addition of ZSM-5 to the base catalyst shows an increased formation of water. This is because ZSM-5 has activity towards converting alcohols to hydrocarbons and water (Bjorgen et al., 2007; Calsavara et al., 2008). Thus all the alcohol amounts in Table 6.2 are nearly zero. It can also be seen that $0.25 \mathrm{~g}$ of 
ZSM-5 is sufficient to convert nearly all the alcohols into hydrocarbons. The alcohols that are the most resistant to ZSM-5 are 2-propanol and 2-butanol, which can be expected to be bulkier.

Table 6.2 Aqueous-phase compounds (separate-bed catalyst arrangement, $0.5 \mathrm{~g}$ of base catalyst, $\mathrm{Si} / \mathrm{Al}$ ratio in $\mathrm{ZSM}-5=50, \mathrm{H}_{2} / \mathrm{CO}$ ratio $=1$, total feed rate $=100 \mathrm{scc} / \mathrm{min}$, reactor temperature $=300^{\circ} \mathrm{C}$, reactor pressure $=300 \mathrm{psi}, \mathrm{TOS}=24-48 \mathrm{~h}$ )

\begin{tabular}{|l|c|c|c|c|}
\hline ZSM-5 weight $(\mathrm{g})$ & 0 & 0.25 & 0.5 & 1 \\
\hline Bed arrangement & Base catalyst & \multicolumn{3}{|c|}{ Separate-bed } \\
\hline Compounds & \multicolumn{3}{|c|}{ Weights in aqueous phase (mg) } \\
\hline Methanol & 243 & 0 & 0 & 0 \\
\hline Ethanol & 516 & 0 & 2 & 0 \\
\hline 2-Propanol & 92 & 103 & 5 & 3 \\
\hline 1-Propanol & 272 & 0 & 0 & 0 \\
\hline 2-Butanol & 31 & 14 & 0 & 5 \\
\hline 1-Butanol & 205 & 0 & 0 & 0 \\
\hline 2-Pentanol & 0 & 0 & 0 & 0 \\
\hline 1-Pentanol & 157 & 0 & 0 & 8 \\
\hline Sum of alcohols & 1516 & 118 & 7 & 2493 \\
\hline Water & 894 & 2282 & 2295 & 0 \\
\hline
\end{tabular}

Overall reaction (FTS, WGS, cracking, oligomerization, isomerization, aromatization, conversion of alcohols to hydrocarbons, and coke formation) sequence in the separate bed is sketched and shown in Figure 6.8. 


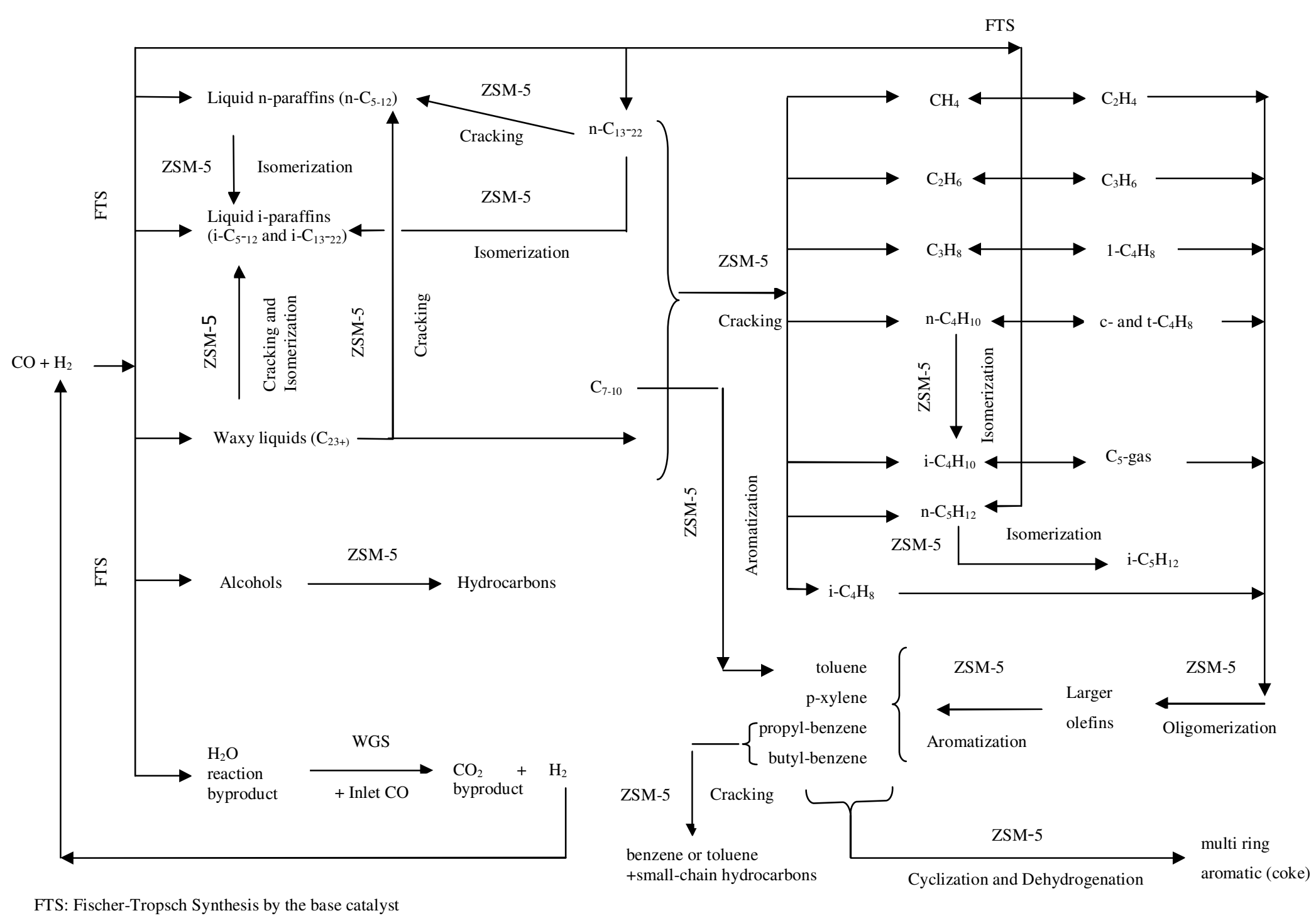

Figure 6.8 Sketch of an overall reaction sequence 


\subsubsection{EFFECT OF ZSM-5 WEIGHT CHANGE ON PRODUCT DISTRIBUTION IN MIXED-BED CATALYST ARRANGEMENT}

As in the separate-bed arrangement, three different ZSM-5 weights $(0.25,0.5$, and $1 \mathrm{~g})$ are used with $0.5 \mathrm{~g}$ base catalyst in the mixed-bed catalyst arrangement. Gas, oil, and aqueous product analyses are carried out. The results are discussed below in detail.

\subsubsection{Overall Products}

Conversion data are shown in Appendix F.1. Table 6.3 shows the amounts of all hydrocarbons. These numbers are compared to those in Table 6.1, corresponding to the separate-bed arrangement, in Section 6.2.3. In this section, we discuss the effect of increasing the amounts of ZSM-5 in the mixed-bed arrangement.

From Table 6.3, the amounts of $\mathrm{C}_{1-4}$ and total $\mathrm{C}_{5+}$ are higher for the base catalyst alone compared to the amounts of these species when ZSM-5 is added in the mixed-bed arrangement. The low activity of physical mixtures of the base catalyst and ZSM-5 is also reported by Botes et al. (2004). The decline in activity in the mixed bed is due to lowering of the alkali content of the iron catalyst due to alkali migration from FT catalyst to ZSM-5 (Botes et al., 2004). Incorporation of $\mathrm{Cu}$ and $\mathrm{K}$ promoters to an iron-based catalyst was found to have significant influences on the adsorption and reduction behaviors, as well as on catalytic performances during FTS (Wan et al., 2008). Hence the changes in $\mathrm{H}_{2}$ adsorption and $\mathrm{CO}$ adsorption significantly affect the FTS performance of the mixed-bed catalyst arrangement. It was attempted to confirm the alkali migration from the FT catalyst to the ZSM-5 by EDX analysis of spent ZSM-5. EDX of a spent sample of ZSM-5, shown in Figure 8.2, confirms alkali migrations of metals. The product distribution of individual hydrocarbons is discussed in Section 6.2.2.3 and Section 6.2.2.5.

The total amount of alcohols over the base catalyst alone is higher than the total alcohols produced in the mixed-bed catalyst arrangement, and the amounts decrease with increasing amounts of ZSM-5. This means that additional ZSM-5 converts alcohols into hydrocarbons and water (Bjorgen et al., 2007; Calsavara et al., 2008).

From Table 6.3, the amount of $\mathrm{CO}_{2}$ formed over the base catalyst is greater than the amounts of $\mathrm{CO}_{2}$ formed when ZSM-5 is added. The amounts of unreacted $\mathrm{CO}$ for all the reactions with ZSM-5 are 
higher than the base catalyst amounts and therefore ZSM-5 affects FTS activity in the mixed bed. As described before, the decline in FT activity in the mixed bed is due to lowering of the alkali content of the iron catalyst because of alkali migration from FT catalyst to ZSM-5 (Botes et al., 2004). The higher amounts of $\mathrm{CO}_{2}$ are also ascribed to the higher $\mathrm{CO}$ conversion in the base catalyst compared to the mixed-bed catalyst arrangement.

Table 6.3 Overall product distribution (mixed-bed catalyst arrangement, $0.5 \mathrm{~g}$ of base catalyst, $\mathrm{Si} / \mathrm{Al}$ ratio in $\mathrm{ZSM}-5=50, \mathrm{H}_{2} / \mathrm{CO}$ ratio $=1$, total feed rate $=100 \mathrm{scc} / \mathrm{min}$, reactor temperature $=300^{\circ} \mathrm{C}$, reactor pressure $=300 \mathrm{psi}$, TOS $=24-48 \mathrm{~h}$ )

\begin{tabular}{|l|c|c|c|c|}
\hline ZSM-5 weight $(\mathrm{g})$ & 0 & 0.25 & 0.5 & 1 \\
\hline Bed arrangement & Base catalyst & \multicolumn{3}{|c|}{ Mixed-bed } \\
\hline Compounds & \multicolumn{4}{|c|}{ g carbon/day } \\
\hline $\mathrm{C}_{1}$ & 2.31 & 1.20 & 1.34 & 2.27 \\
\hline $\mathrm{C}_{2-4}$ & 6.12 & 3.81 & 3.85 & 4.87 \\
\hline Sum of C $1-4(\mathrm{Gas})$ & 8.43 & 5.01 & 5.19 & 7.14 \\
\hline Total C5+ (Gas + Liquid) & 6.19 & 4.64 & 5.15 & 4.34 \\
\hline Sum of hydrocarbons (Gas + Liquid) & 14.62 & 9.65 & 10.34 & 11.48 \\
\hline Total alcohols & 0.75 & 0.35 & 0.22 & 0.10 \\
\hline $\mathrm{CO}_{2}$ & 14.39 & 9.85 & 10.34 & 13.96 \\
\hline Unreacted CO $^{2}$ & 6.84 & 15.83 & 14.98 & 8.58 \\
\hline
\end{tabular}

\subsubsection{WGS and FTS reaction activities}

The activities of WGS and FTS reactions in the base catalyst and the mixed-bed arrangement are calculated similar to the procedure followed by Ma et al. (2007b). The calculations are tabulated in Appendix F.2. From Figure 6.9, the WGS and FTS rates decrease with the addition of a small amount of ZSM-5, and then increase with additional ZSM-5. The initial decrease in WGS and FTS rates for ZSM-5 is probably due to alkali migration from FT catalyst to ZSM-5 (Botes et al., 2004), as mentioned earlier. The further increase in these rates with ZSM-5 is not clearly understood, but these values are relatively lower than the base catalyst alone. So alkali migration definitely reduces the activity of the base catalyst in the mixed bed, as opposed to results from the separate-bed configuration. 


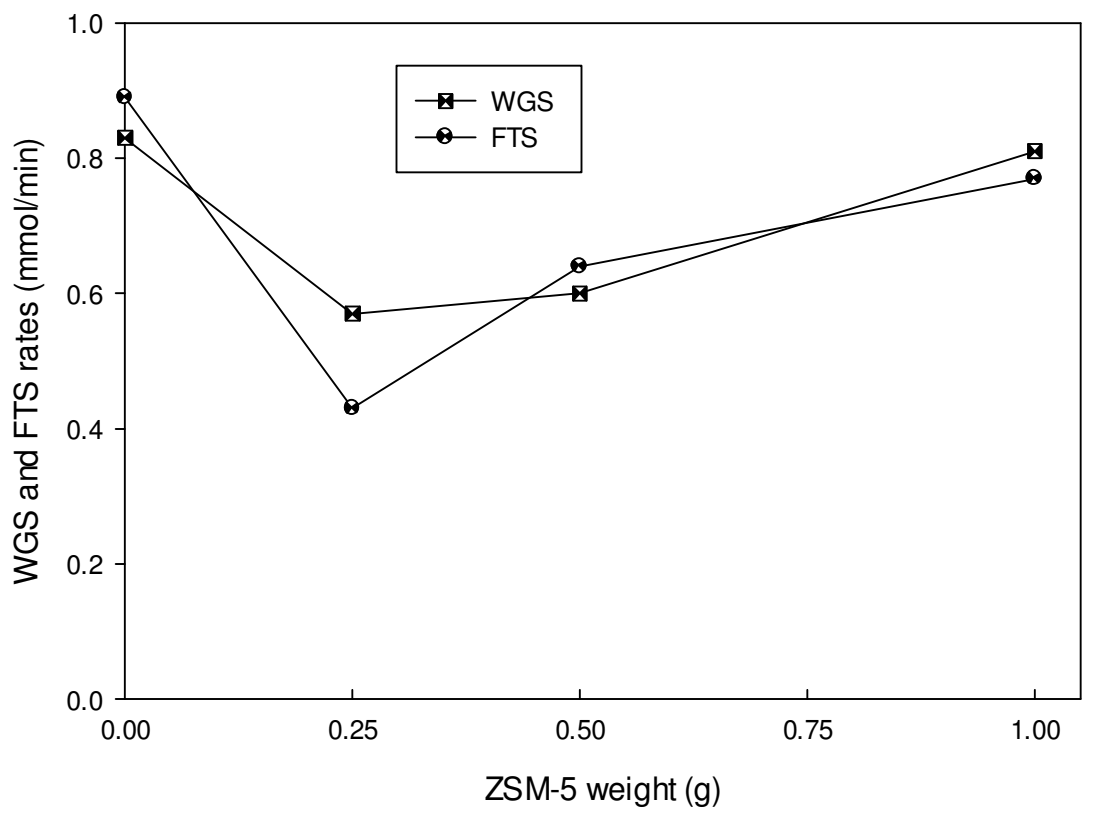

Figure 6.9 WGS and FTS reaction rates (mmol/min). Mixed-bed catalyst arrangement, $0.5 \mathrm{~g}$ of base catalyst, $\mathrm{Si} / \mathrm{Al}$ ratio in $\mathrm{ZSM}-5=50, \mathrm{H}_{2} / \mathrm{CO}$ ratio $=1$, total feed rate $=100 \mathrm{scc} / \mathrm{min}$, reactor temperature $=$ $300^{\circ} \mathrm{C}$, reactor pressure $=300 \mathrm{psi}$, TOS $=24-48 \mathrm{~h}$.

\subsubsection{Gas analysis}

All the data are shown in Appendix F.3. Figure 6.10 shows that the amounts of $\mathrm{CH}_{4}, \mathrm{C}_{3} \mathrm{H}_{8}$, i$\mathrm{C}_{4} \mathrm{H}_{10}, \mathrm{n}-\mathrm{C}_{4} \mathrm{H}_{10}, \mathrm{i}-\mathrm{C}_{5} \mathrm{H}_{12}$, and $\mathrm{n}-\mathrm{C}_{5} \mathrm{H}_{12}$, as detected by the FID, increase with ZSM-5. As in the separatebed case, the amount of $\mathrm{CH}_{4}$ generated by the base catalyst alone is large compared to the mixed bed with 0.25 and $0.5 \mathrm{~g}$ ZSM-5. This is because ZSM-5 forms a $\mathrm{C}_{1}$ carbenium ion (Fejes et al., 1984) and this ion further reacts with another molecule on ZSM-5 to form longer-chain hydrocarbons. Larger amounts of ZSM-5 increase the cracking of long-chain hydrocarbons (Martinez et al., 2005) and this increases the amount of methane formed. $\mathrm{C}_{3} \mathrm{H}_{8}, \mathrm{n}-\mathrm{C}_{4} \mathrm{H}_{10}$, and $\mathrm{n}-\mathrm{C}_{5} \mathrm{H}_{12}$ do not increase appreciably with the addition of ZSM-5. Neither $\mathrm{i}-\mathrm{C}_{4} \mathrm{H}_{10}$ nor $\mathrm{i}-\mathrm{C}_{5} \mathrm{H}_{12}$ is found in the base catalyst alone because the base catalyst lacks the acidic active sites responsible for isomerization. The amounts of $\mathrm{i}-\mathrm{C}_{4} \mathrm{H}_{10}$ and $\mathrm{i}-\mathrm{C}_{5} \mathrm{H}_{12}$ increase with ZSM-5 because it provides isomerization sites (Borges et al., 2007). 


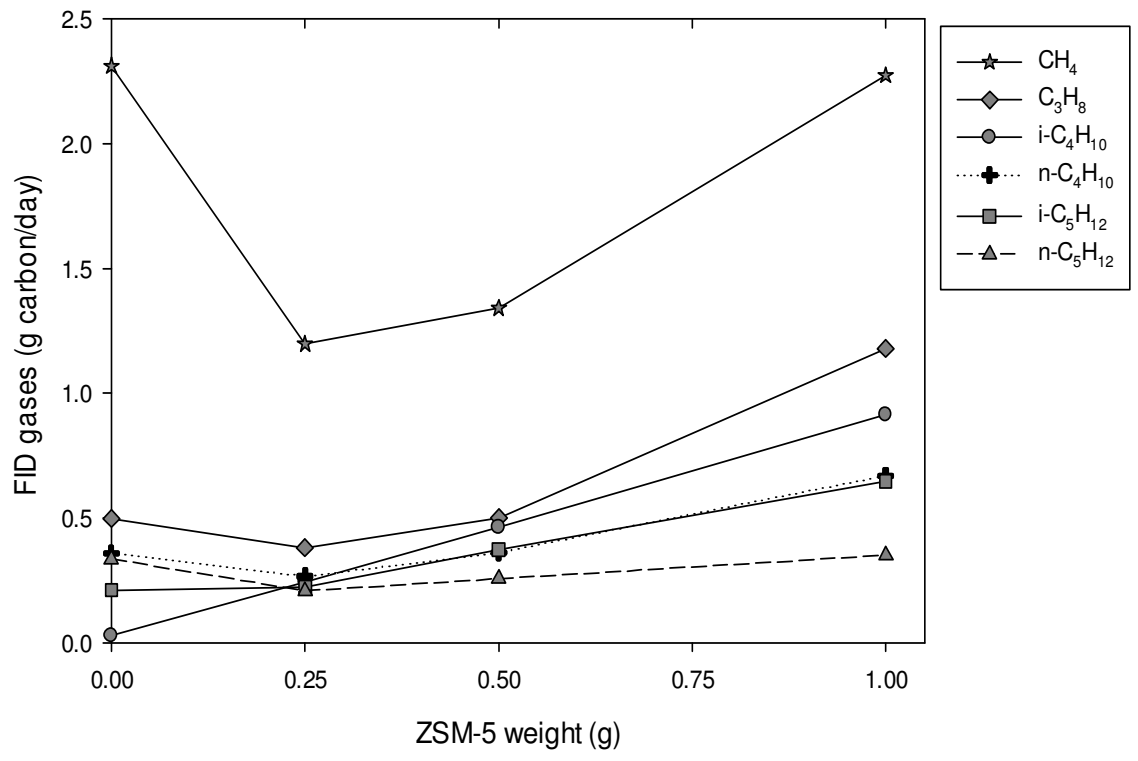

Figure 6.10 Gas-phase paraffins detected by FID (g carbon/day). Mixed-bed catalyst arrangement, $0.5 \mathrm{~g}$ of base catalyst, $\mathrm{Si} / \mathrm{Al}$ ratio in $\mathrm{ZSM}-5=50, \mathrm{H}_{2} / \mathrm{CO}$ ratio $=1$, total feed rate $=100 \mathrm{scc} / \mathrm{min}$, reactor temperature $=300^{\circ} \mathrm{C}$, reactor pressure $=300 \mathrm{psi}$, TOS $=24-48 \mathrm{~h}$.

Figure 6.11 shows the effect of ZSM-5 on olefin and other gases that are not shown in Figure 6.10. As in Figure 6.3, $\mathrm{C}_{2} \mathrm{H}_{6}$ and $\mathrm{C}_{2} \mathrm{H}_{4}$ are reported together here because both have similar retention times. In contrast to Figure 6.3, the production of these gases drops rapidly with addition of $0.25 \mathrm{~g}$ ZSM5 and then levels off. This is partly because of the cracking of long-chain i-paraffins to $\mathrm{C}_{2} \mathrm{H}_{6}$ (Martinez et al., 2005), as can be seen in later in Figure 6.14, and partly because of the oligomerization of $\mathrm{C}_{2} \mathrm{H}_{4}$ (Knifton et al., 1994). Increasing amounts of ZSM-5 provide more active sites for oligomerization (Knifton et al., 1994). Hence $\mathrm{C}_{2} \mathrm{H}_{4}$ oligomerizes because $\mathrm{C}_{2} \mathrm{H}_{4}$ is an unsaturated hydrocarbon and more reactive compared to $\mathrm{C}_{2} \mathrm{H}_{6}$.

From Figure 6.11, the base catalyst with no ZSM-5 produces greater amounts of $\mathrm{C}_{3} \mathrm{H}_{6}, 1-\mathrm{C}_{4} \mathrm{H}_{8}$, and $\mathrm{t}-\mathrm{C}_{4} \mathrm{H}_{8}$ compared to the mixed-bed catalyst arrangement with ZSM-5. This is because the base catalyst does not have the acidic sites responsible for oligomerization. On the other hand, the acidic sites of ZSM-5 convert $\mathrm{C}_{3} \mathrm{H}_{6}, 1-\mathrm{C}_{4} \mathrm{H}_{8}$, and t- $\mathrm{C}_{4} \mathrm{H}_{8}$ to other products (Knifton et al., 1994; Borges et al., 2007). In the absence of $\mathrm{ZSM}-5, \mathrm{c}-\mathrm{C}_{4} \mathrm{H}_{8}$ is not produced. The double-bond-containing gases $\left(\mathrm{C}_{3} \mathrm{H}_{6}, 1-\mathrm{C}_{4} \mathrm{H}_{8} \mathrm{t}-\right.$ 
$\mathrm{C}_{4} \mathrm{H}_{8}$ ) are highly reactive and tend to oligomerize on ZSM-5 active sites (Knifton et al., 1994; Borges et al., 2007).

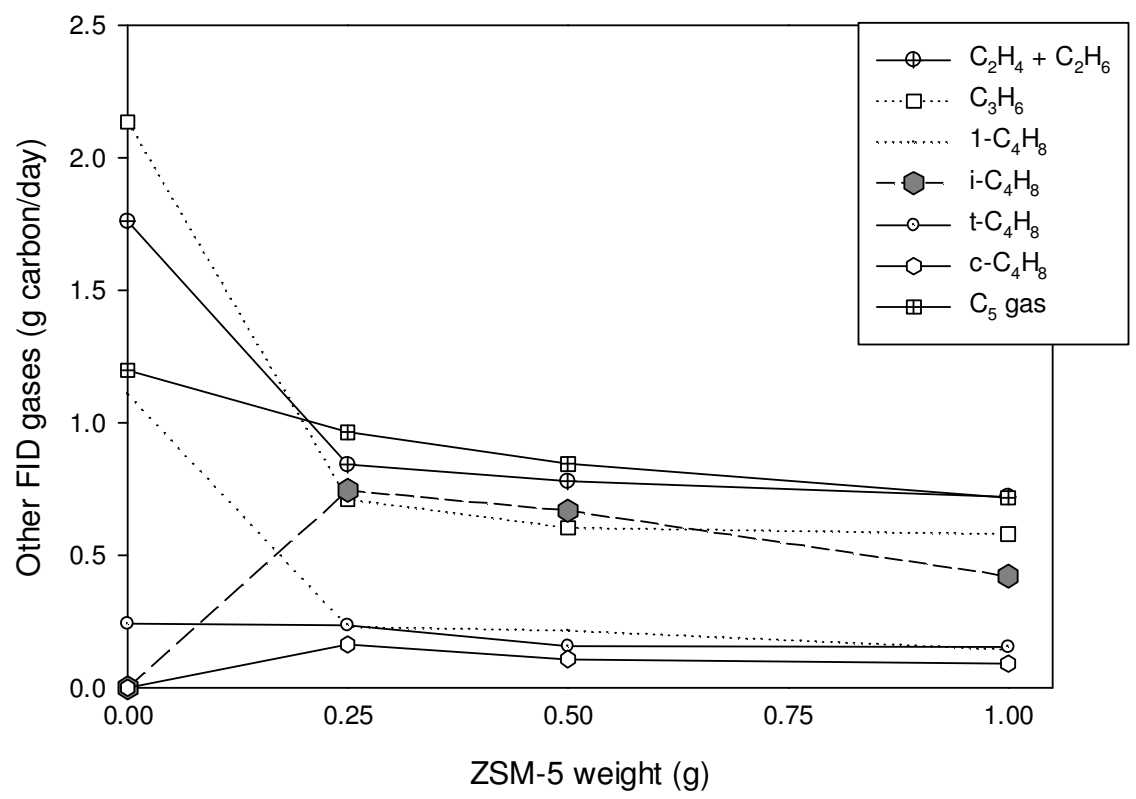

Figure 6.11 FID gases not shown in Figure 6.10 (g carbon/day). Mixed-bed catalyst arrangement, $0.5 \mathrm{~g}$ of base catalyst, $\mathrm{Si} / \mathrm{Al}$ ratio in $\mathrm{ZSM}-5=50, \mathrm{H}_{2} / \mathrm{CO}$ ratio $=1$, total feed rate $=100 \mathrm{scc} / \mathrm{min}$, reactor temperature $=300^{\circ} \mathrm{C}$, reactor pressure $=300 \mathrm{psi}$, TOS $=24-48 \mathrm{~h}$.

As before, $\mathrm{i}-\mathrm{C}_{4} \mathrm{H}_{8}$ is not formed with the base catalyst alone because the base catalyst lacks the acidic active sites needed for isomerization (Borges et al., 2007). As in the separate bed, the amount of i$\mathrm{C}_{4} \mathrm{H}_{8}$ in the mixed bed increases for $0.25 \mathrm{~g}$ of ZSM-5 and decreases thereafter. As before, the decrease of i- $\mathrm{C}_{4} \mathrm{H}_{8}$ with larger amounts of ZSM-5 can be explained by saying that further addition of ZSM-5 causes i- $\mathrm{C}_{4} \mathrm{H}_{8}$, double bonded and highly reactive, to undergo oligomerization (Knifton et al., 1994).

As in Figure 6.3, $\mathrm{C}_{5}$ gases (alkenes or i-alkenes) are formed when the base catalyst alone is used but decrease as ZSM-5 is increased. The decrease of the $\mathrm{C}_{5}$-olefins is also due to oligomerization into liquid products (Knifton et al., 1994).

\subsubsection{Overall liquid production rates}

Figure 6.12 shows overall liquid hydrocarbon and overall alcohol production rates for the base catalyst and the mixed bed. The hydrocarbon production rate drops with ZSM-5 change from 0 to $1 \mathrm{~g}$. 
Also, the production of alcohols decreases for change in ZSM-5 from 0 to $1 \mathrm{~g}$. The decrease in hydrocarbon production is due to alkali migration from the FT catalyst to ZSM-5 and also due to the additional cracking sites available on ZSM-5. Also, ZSM-5 has activity towards converting some of the alcohols formed by the base catalyst to hydrocarbons (Bjorgen et al., 2007; Calsavara et al., 2008).

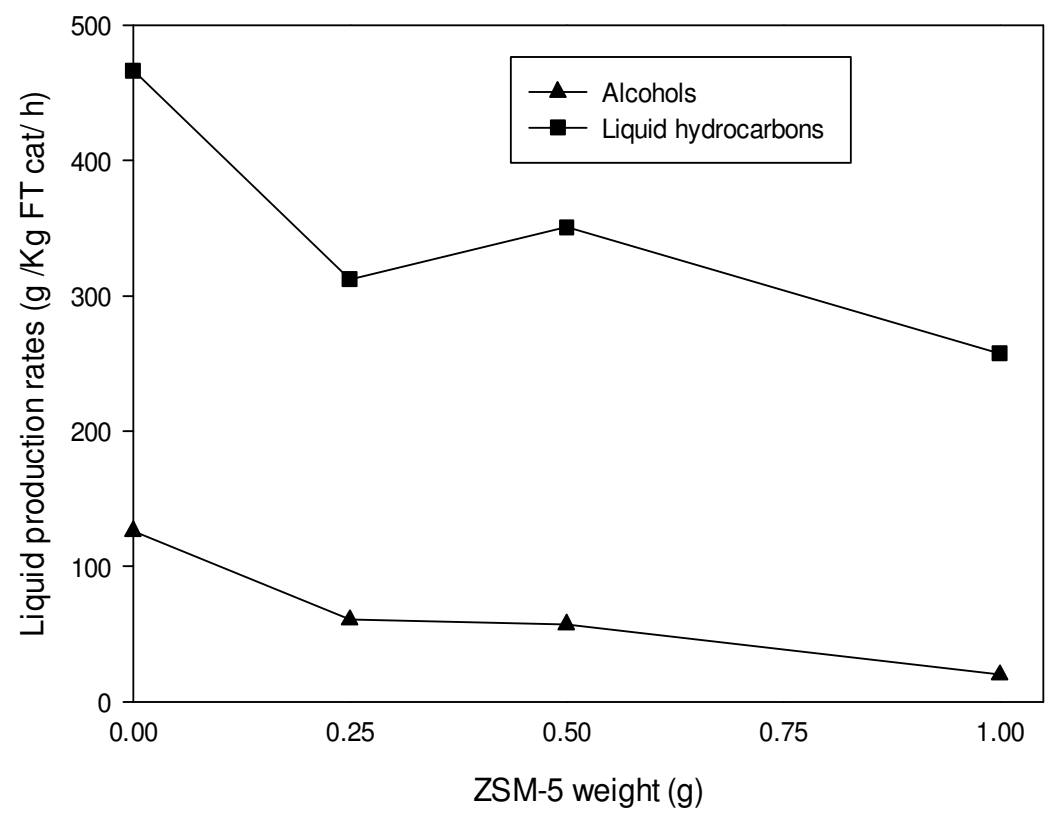

Figure 6.12 Liquid hydrocarbon and alcohol production rate (g/kg FT cat $/ \mathrm{h})$. Mixed-bed catalyst arrangement, $0.5 \mathrm{~g}$ of base catalyst, $\mathrm{Si} / \mathrm{Al}$ ratio in $\mathrm{ZSM}-5=50, \mathrm{H}_{2} / \mathrm{CO}$ ratio $=1$, total feed rate $=100$ scc $/$ min, reactor temperature $=300^{\circ} \mathrm{C}$, reactor pressure $=300 \mathrm{psi}, \mathrm{TOS}=24-48 \mathrm{~h}$.

\subsubsection{Hydrocarbon distribution in organic liquid phase}

Figure 6.13 shows the amounts of individual n-paraffins in the organic liquid phase. The amounts of $\mathrm{n}-\mathrm{C}_{5}$ to $\mathrm{n}-\mathrm{C}_{22}$ paraffins are much higher for the base catalyst compared to the mixed bed with $0.25 \mathrm{~g}$ ZSM-5. This is because the base catalyst follows polymerization kinetics giving high amounts of long-chain hydrocarbons, and the addition of ZSM-5 to the base catalyst causes cracking of these hydrocarbons. The amount of $n-C_{5}$ increases and the amounts of $n-C_{6}$ to $n-C_{22}$ decrease, with increase in ZSM-5 from 0.25 to $1 \mathrm{~g}$. This is because additional ZSM-5 provides additional active sites to crack long-chain paraffins $n-C_{6}$ to $n-C_{22}$ to smaller-chain molecules like $n-C_{5}$. 


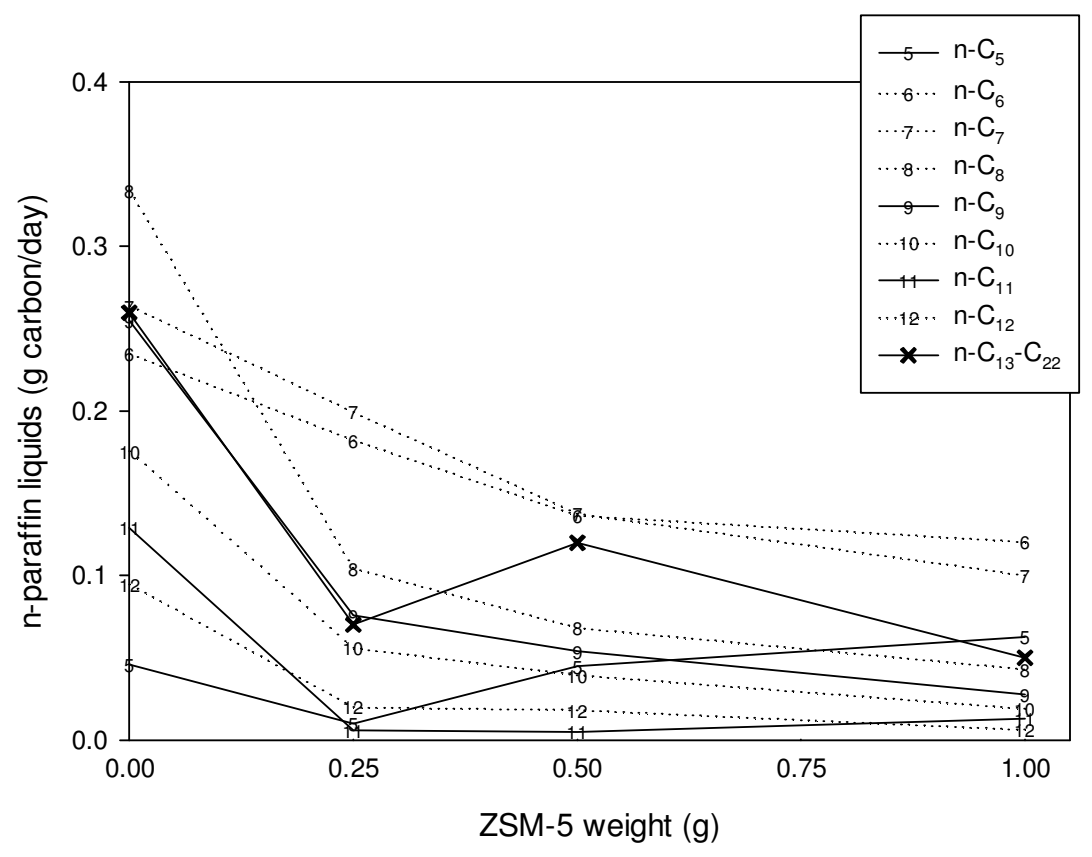

Figure 6.13 Liquid n-paraffins (g carbon/day). Mixed-bed catalyst arrangement, $0.5 \mathrm{~g}$ of base catalyst, $\mathrm{Si} / \mathrm{Al}$ ratio in $\mathrm{ZSM}-5=50, \mathrm{H}_{2} / \mathrm{CO}$ ratio $=1$, total feed rate $=100 \mathrm{scc} / \mathrm{min}$, reactor temperature $=300^{\circ} \mathrm{C}$, reactor pressure $=300 \mathrm{psi}$, TOS $=24-48 \mathrm{~h}$.

Figure 6.14 shows the amounts of individual i-paraffins in the organic liquid phase. The amounts of $\mathrm{i}-\mathrm{C}_{5}$ to $\mathrm{i}-\mathrm{C}_{12}$ paraffins are much lower for the base catalyst compared to the mixed bed with $0.25 \mathrm{~g}$ ZSM-5. This is because the base catalyst does not have isomerization sites. The addition of ZSM-5 to the base catalyst causes isomerization of n-paraffins forming large amounts of gasoline-range isomers. On the other hand, the amounts of $\mathrm{i}-\mathrm{C}_{13+}$ are higher for the base catalyst compared to the mixed bed with $0.25 \mathrm{~g} \mathrm{ZSM-5}$. This is because addition of ZSM-5 to the base catalyst causes cracking of long-chain i$\mathrm{C}_{13+}$ molecules.

From Figure 6.14, with the addition of $0.5 \mathrm{~g}$ ZSM-5 to the base catalyst, the amounts of i- $\mathrm{C}_{5}$ and $\mathrm{i}-\mathrm{C}_{9}$ decrease, while $\mathrm{i}-\mathrm{C}_{6}$ to $\mathrm{i}-\mathrm{C}_{8}$ and $\mathrm{i}-\mathrm{C}_{10-22}$ increase slightly. This is because the addition of $0.5 \mathrm{~g}$ ZSM5 to the base catalyst causes isomerization of n-paraffins (Borges et al., 2007). Further addition of ZSM5 leads to cracking of $\mathrm{i}-\mathrm{C}_{6}$ to $\mathrm{i}-\mathrm{C}_{22}$ compounds. Higher hydrocarbons $\left(\mathrm{C}_{23+}\right)$ are present in amounts too small to show significant changes. 


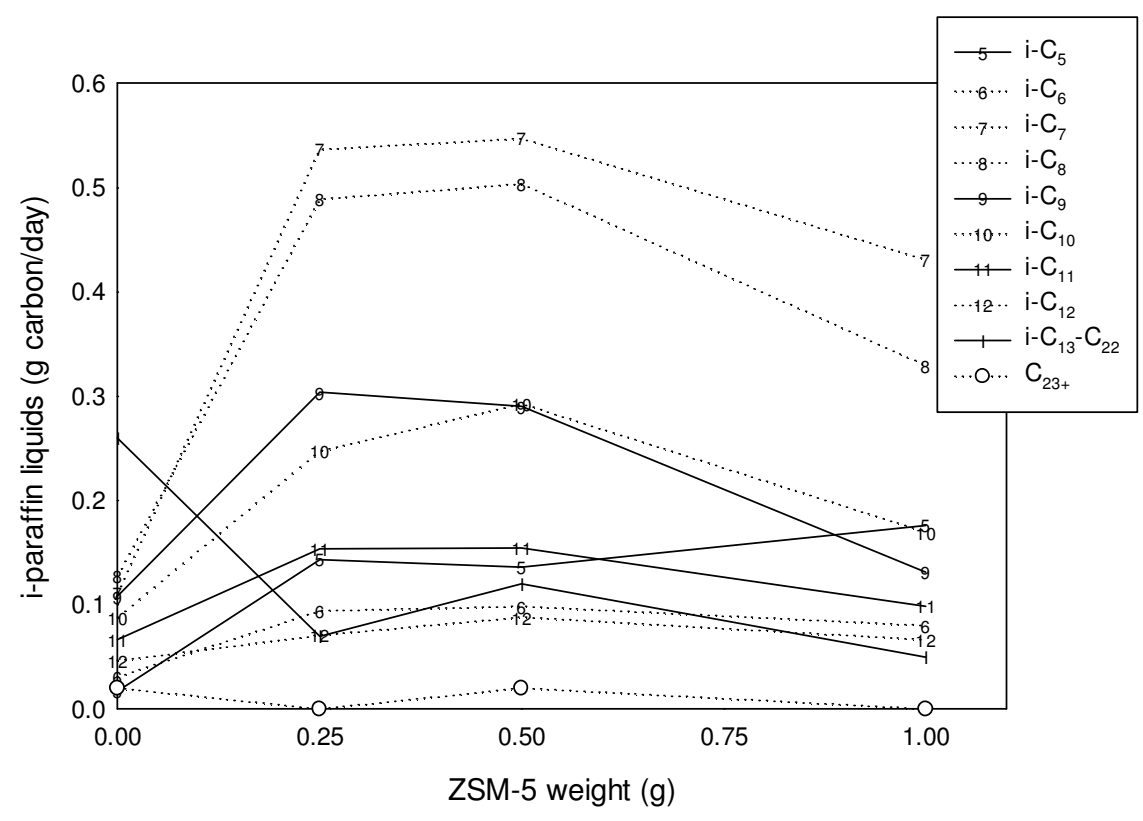

Figure 6.14 Liquid i-paraffins (g carbon/day). Mixed-bed catalyst arrangement, $0.5 \mathrm{~g}$ of base catalyst, $\mathrm{Si} / \mathrm{Al}$ ratio in $\mathrm{ZSM}-5=50, \mathrm{H}_{2} / \mathrm{CO}$ ratio $=1$, total feed rate $=100 \mathrm{scc} / \mathrm{min}$, reactor temperature $=300^{\circ} \mathrm{C}$, reactor pressure $=300 \mathrm{psi}$, TOS $=24-48 \mathrm{~h}$.

As mentioned earlier, aromatic ring compounds were not reported by Ma et al. (2006) because the base catalyst lacks acidic active sites for aromatization. However, ZSM-5 oligomerizes and aromatizes small-chain olefin molecules (Zang et al., 2010). The combination of the base catalyst and ZSM-5 shows aromatic products like toluene, p-xylene, propyl-benzene, and butyl-benzene. Figure 6.15 shows the amounts of different aromatic hydrocarbons for the mixed-bed catalyst arrangement with different amounts of ZSM-5 added to the base catalyst. As in the separate-bed experiments, all these aromatic compounds are alkyl-benzenes.

From Figure 6.15, the amounts of all the aromatics increase when ZSM-5 increases from 0 to 0.5 g, similar to the behavior in the separate bed. This is because ZSM-5 provides additional oligomerization active sites and hence more tendency towards aromatization (Degnan, 2000). Unlike the separate-bed arrangement, further addition of ZSM-5 causes all these species to decrease. This is because additional ZSM-5 provides more cracking active sites, and alkyl chains attached to these aromatic compounds crack to give smaller aromatic species and small-chain paraffins. Again, ZSM-5 favors toluene, p-xylene and propyl-benzene more than butyl-benzene. This can be explained by noting 
that butyl-benzene is bulky and has more steric hindrance. Therefore butyl-benzene is difficult to desorb from ZSM-5 pores.

As in the separate-bed case, production of high amounts of $\mathrm{i}-\mathrm{C}_{5}$ to $\mathrm{i}-\mathrm{C}_{12}$ and aromatics together gives high-octane gasoline-range hydrocarbons in the mixed bed with increasing amounts of ZSM-5. Comparing the amounts of $\mathrm{i}-\mathrm{C}_{5}$ to $\mathrm{i}-\mathrm{C}_{12}$ plus aromatics in the mixed bed, it is seen that the maximum amount is formed in the mixed bed with $0.5 \mathrm{~g}$ ZSM-5. However, this amount is less than that formed in the separate bed with $0.5 \mathrm{~g}$ ZSM-5.

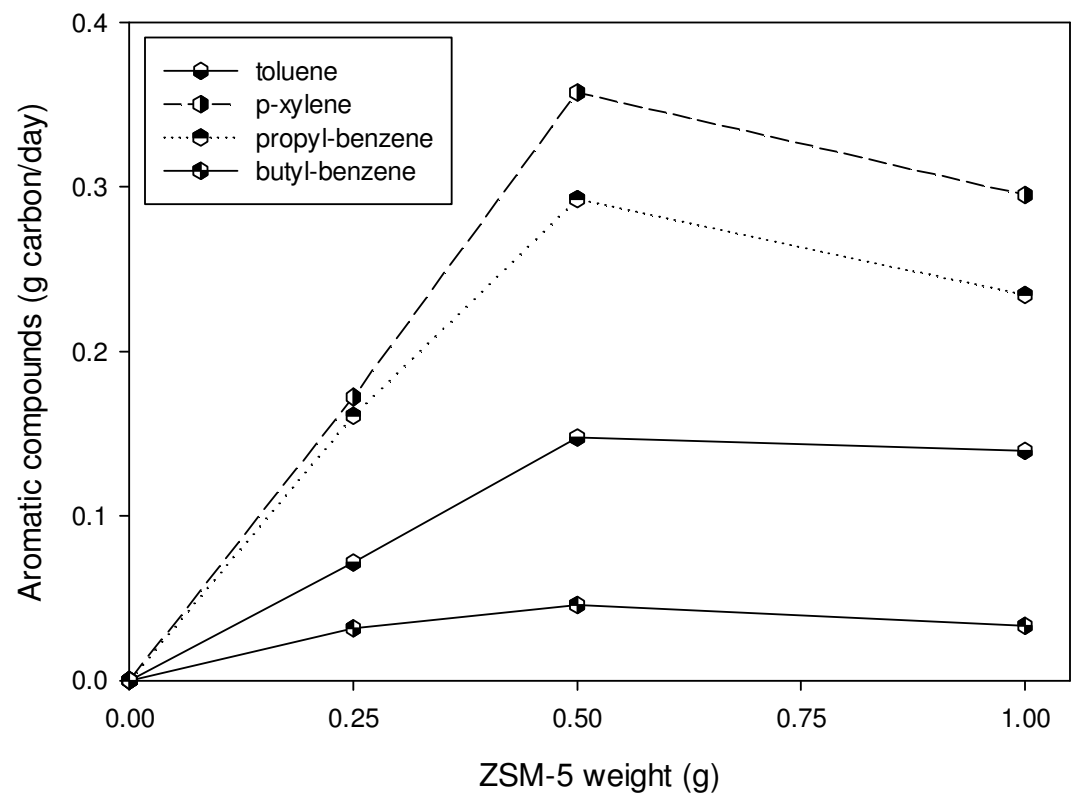

Figure 6.15 Aromatic compounds (g carbon/day). Mixed-bed catalyst arrangement, $0.5 \mathrm{~g}$ of base catalyst, $\mathrm{Si} / \mathrm{Al}$ ratio in $\mathrm{ZSM}-5=50, \mathrm{H}_{2} / \mathrm{CO}$ ratio $=1$, total feed rate $=100 \mathrm{scc} / \mathrm{min}$, reactor temperature $=$ $300^{\circ} \mathrm{C}$, reactor pressure $=300 \mathrm{psi}$, TOS $=24-48 \mathrm{~h}$.

The overall reaction sequence in the mixed bed also follows the similar sequence to the separate bed. The overall reaction sequence is shown in Figure 6.8 .

\subsubsection{Alcohols and water in aqueous liquid phase}

As for the separate bed, the base catalyst shows the highest amounts of alcohols compared to the mixed bed (Table 6.4). This is because ZSM-5 has activity towards converting alcohols to hydrocarbons (Bjorgen et al., 2007; Calsavara et al., 2008). Unlike the separate bed, even $1 \mathrm{~g}$ ZSM-5 is not sufficient 
to convert most of the alcohols. The acidic sites of ZSM-5 are affected by alkali migration from the FT catalyst, similar to the discussion in Section 6.2.2.1. Also from Table 6.4, the water produced increases slightly, because ZSM-5 converts alcohols to hydrocarbons and water.

Table 6.4 Aqueous-phase compounds (mixed-bed catalyst arrangement, $0.5 \mathrm{~g}$ of base catalyst, $\mathrm{Si} / \mathrm{Al}$ ratio in $\mathrm{ZSM}-5=50, \mathrm{H}_{2} / \mathrm{CO}$ ratio $=1$, total feed rate $=100 \mathrm{scc} / \mathrm{min}$, reactor temperature $=300^{\circ} \mathrm{C}$, reactor pressure $=300 \mathrm{psi}, \mathrm{TOS}=24-48 \mathrm{~h}$ )

\begin{tabular}{|l|c|c|c|c|}
\hline ZSM-5 weight $(\mathrm{g})$ & 0 & 0.25 & 0.5 & 1 \\
\hline Bed arrangement & Base catalyst & \multicolumn{3}{|c|}{ Mixed-bed } \\
\hline Compounds & \multicolumn{4}{|c|}{ Weights in aqueous phase (mg) } \\
\hline Methanol & 243 & 126 & 128 & 64 \\
\hline Ethanol & 516 & 247 & 273 & 94 \\
\hline 2-Propanol & 92 & 50 & 44 & 25 \\
\hline 1-Propanol & 272 & 118 & 102 & 30 \\
\hline 2-Butanol & 31 & 17 & 17 & 12 \\
\hline 1-Butanol & 205 & 94 & 93 & 0 \\
\hline 2-Pentanol & 0 & 0 & 0 & 0 \\
\hline 1-Pentanol & 157 & 77 & 687 & 239 \\
\hline Sum of alcohols & 1516 & 728 & 813 & 2061 \\
\hline Water & 894 & 472 & & \\
\hline
\end{tabular}




\subsubsection{QUANTITATIVE COMPARISONS BETWEEN SEPARATE BEDS AND MIXED BEDS}

The distribution of individual products from the separate bed and the mixed bed has already been discussed in Section 6.2.1 and Section 6.2.2 respectively. The purpose of this section is to compare the separate bed and the mixed bed quantitatively, to find out whether there is any improvement in the product distribution if the bed arrangement is changed. To quantify the changes in amounts of gaseous hydrocarbons, liquid hydrocarbons, and aqueous products with changing reactor configuration, we define a delta value as;

$\Delta \mathrm{X}=(\mathrm{X}$ in separate-bed catalyst arrangement $)-(\mathrm{X}$ in the mixed-bed catalyst arrangement $)$

\subsubsection{Delta values of overall products}

Table 6.5 shows the delta amounts of overall products calculated using Equation (6.1). Overall product amounts in both the beds can also be found in Table 6.1 and Table 6.3. The delta values of $\mathrm{C}_{1}$, $\mathrm{C}_{2}-\mathrm{C}_{4}$, and total $\mathrm{C}_{5+}$ are positive for all the ZSM-5 amounts. This implies that higher amounts of these hydrocarbons are formed in the separate bed compared to the mixed bed. The positive values of $\Delta$ are due to the lowering of alkali content of the base catalyst following alkali migration to ZSM-5 in the mixed bed, as mentioned in the discussion of Section 6.2.2.1. There is no improvement in the total hydrocarbon production when the base catalyst and ZSM-5 are mixed.

Also from Table 6.5, the delta amounts of total alcohols are negative for all the ZSM-5 amounts. Lower amounts of alcohols are formed in the separate bed compared to the mixed bed. This is because, in the separate bed, all the alcohols formed by the base catalyst pass over all the ZSM-5 present and all the amounts are converted effectively to hydrocarbons and water. On the contrary, the mixed bed is unable to convert all the alcohols to hydrocarbons and water. This is probably because the acidic sites of ZSM-5 are affected by the alkali migration from FT catalyst, as discussed in Section 6.2.2.6. Hence, the conversion of alcohols to hydrocarbons and water is affected in the mixed bed.

From Table 6.5, the delta amounts of $\mathrm{CO}_{2}$ are positive, and those of unreacted $\mathrm{CO}$ are negative, for all the ZSM-5 amounts. This means that higher amounts of $\mathrm{CO}_{2}$ are formed, and higher amount of $\mathrm{CO}$ are converted, in the separate bed compared to the mixed bed. The higher amounts of $\mathrm{CO}_{2}$ formed are due to higher CO conversion (partly due to FTS reaction and partly due to WGS reaction) in the separate-bed compared to the mixed bed, as shown in Appendix F.1. The lower conversion in the mixed bed is due to lowering of alkali content of the base catalyst due to alkali migration from FT catalyst to 
ZSM-5, as discussed in Section 6.2.2.1. There is no improvement in the CO conversions when the base catalyst and ZSM-5 are mixed.

Table 6.5 Delta amounts of overall products ( $0.5 \mathrm{~g}$ of base catalyst, $\mathrm{Si} / \mathrm{Al}$ ratio in $\mathrm{ZSM}-5=50, \mathrm{H}_{2} / \mathrm{CO}$ ratio $=1$, total feed rate $=100 \mathrm{scc} / \mathrm{min}$, reactor temperature $=300^{\circ} \mathrm{C}$, reactor pressure $=300 \mathrm{psi}$, TOS $=$ $24-48 \mathrm{~h})$

\begin{tabular}{|c|c|c|c|}
\hline ZSM-5 weight (g) & 0.25 & 0.5 & 1 \\
\hline Compounds & \multicolumn{3}{|c|}{$\Delta$ (Compound) g carbon/day } \\
\hline $\mathrm{C}_{1}$ & 0.75 & 0.87 & 0.54 \\
\hline $\mathrm{C}_{2-4}$ & 1.6 & 2.2 & 2.08 \\
\hline Sum of $\mathrm{C}_{1-4}(\mathrm{Gas})$ & 2.35 & 3.07 & 2.62 \\
\hline Total $\mathrm{C}_{5+}(\mathrm{Gas}+$ Liquid $)$ & 3.36 & 2.9 & 2.71 \\
\hline Sum of hydrocarbons (Gas + Liquid) & 5.71 & 5.97 & 5.33 \\
\hline Total alcohols & -0.34 & -0.22 & -0.1 \\
\hline $\mathrm{CO}_{2}$ & 5.71 & 4.76 & 1.54 \\
\hline Unreacted CO & -10.56 & -10.68 & -3.46 \\
\hline
\end{tabular}

\subsubsection{Delta values of WGS and FTS reaction activities}

Table 6.6 shows the delta rates of WGS and FTS calculated using Equation (6.1). The detailed data are shown in Appendix F.2. The delta rates of WGS and FTS are positive for all the ZSM-5 amounts. The activities of WGS and FTS are higher in the separate bed compared to the mixed bed. The lower amounts of WGS and FTS rates in the mixed bed are due to lowering of the alkali content of the base catalyst due to alkali migration from FT catalyst to ZSM-5, as discussed in Section 6.2.2.1. There is no alkali migration in the separate bed, as discussed in Section 8.1. Hence, there is no improvement in the WGS and FTS rates when the base catalyst and ZSM-5 are mixed. 
Table 6.6 Delta amounts of WGS and FTS reaction rates $(0.5 \mathrm{~g}$ of base catalyst, $\mathrm{Si} / \mathrm{Al}$ ratio in ZSM-5 = $50, \mathrm{H}_{2} / \mathrm{CO}$ ratio $=1$, total feed rate $=100 \mathrm{scc} / \mathrm{min}$, reactor temperature $=300^{\circ} \mathrm{C}$, reactor pressure $=300$ Psi, TOS $=24-48$ h)

\begin{tabular}{|l|c|c|c|}
\hline ZSM-5 weight $(\mathrm{g})$ & 0.25 & 0.5 & 1 \\
\hline Rates & \multicolumn{3}{|c|}{$\Delta$ (Rate) $\mathrm{mmol} / \mathrm{min}$} \\
\hline rWGS & 0.33 & 0.27 & 0.09 \\
\hline rFTS & 0.36 & 0.35 & 0.15 \\
\hline
\end{tabular}

\subsubsection{Delta amounts of gas products}

Table 6.7 shows the delta amounts of $\mathrm{CH}_{4}, \mathrm{C}_{2} \mathrm{H}_{6}+\mathrm{C}_{2} \mathrm{H}_{4}, \mathrm{C}_{3} \mathrm{H}_{8}, \mathrm{C}_{3} \mathrm{H}_{6}, \mathrm{i}-\mathrm{C}_{4} \mathrm{H}_{10}, \mathrm{n}-\mathrm{C}_{4} \mathrm{H}_{10}, 1-\mathrm{C}_{4} \mathrm{H}_{8}$, i$\mathrm{C}_{4} \mathrm{H}_{8}, \mathrm{t}-\mathrm{C}_{4} \mathrm{H}_{8}, \mathrm{c}-\mathrm{C}_{4} \mathrm{H}_{8}, \mathrm{i}-\mathrm{C}_{5} \mathrm{H}_{12}, \mathrm{n}-\mathrm{C}_{5} \mathrm{H}_{12}$, and $\mathrm{C}_{5}$-gas hydrocarbons calculated using Equation (6.1). The detailed data for these gas hydrocarbons are shown in Appendix F.3.

Table 6.7 Delta amounts of gas products $\left(0.5 \mathrm{~g}\right.$ of base catalyst, $\mathrm{Si} / \mathrm{Al}$ ratio in $\mathrm{ZSM}-5=50, \mathrm{H}_{2} / \mathrm{CO}$ ratio $=1$, total feed rate $=100 \mathrm{scc} / \mathrm{min}$, reactor temperature $=300^{\circ} \mathrm{C}$, reactor pressure $=300$ Psi, TOS $=24-$ $48 \mathrm{~h})$

\begin{tabular}{|l|c|c|c|}
\hline ZSM-5 weight $(\mathrm{g})$ & 0.25 & 0.5 & 1 \\
\hline Products & \multicolumn{2}{|c|}{$\Delta$ (Product) g carbon/day } \\
\hline $\mathrm{CH}_{4}$ & 0.75 & 0.87 & 0.54 \\
\hline $\mathrm{C}_{2} \mathrm{H}_{6}+\mathrm{C}_{2} \mathrm{H}_{4}$ & 0.88 & 0.89 & 0.58 \\
\hline $\mathrm{C}_{3} \mathrm{H}_{8}$ & 0.32 & 0.99 & 1.22 \\
\hline $\mathrm{C}_{3} \mathrm{H}_{6}$ & -0.41 & -0.50 & -0.57 \\
\hline $\mathrm{i}-\mathrm{C}_{4} \mathrm{H}_{10}$ & 0.22 & 0.57 & 0.92 \\
\hline $\mathrm{n}-\mathrm{C}_{4} \mathrm{H}_{10}$ & 0.24 & 0.68 & 0.73 \\
\hline $1-\mathrm{C}_{4} \mathrm{H}_{8}$ & -0.16 & -0.20 & -0.14 \\
\hline $\mathrm{i}-\mathrm{C}_{4} \mathrm{H}_{8}$ & 0.59 & -0.09 & -0.41 \\
\hline $\mathrm{t}-\mathrm{C}_{4} \mathrm{H}_{8}$ & -0.04 & -0.06 & -0.15 \\
\hline $\mathrm{c}-\mathrm{C}_{4} \mathrm{H}_{8}$ & -0.04 & -0.09 & -0.09 \\
\hline $\mathrm{i}-\mathrm{C}_{5} \mathrm{H}_{12}$ & 0.14 & 0.41 & 0.42 \\
\hline $\mathrm{n}-\mathrm{C}_{5} \mathrm{H}_{12}$ & 0.17 & 0.15 & 0.19 \\
\hline $\mathrm{C}_{5}-\mathrm{gas} \mathrm{g}$ & -0.02 & -0.29 & -0.30 \\
\hline
\end{tabular}

From Table 6.7, the delta amounts of $\mathrm{CH}_{4}, \mathrm{C}_{2} \mathrm{H}_{6}+\mathrm{C}_{2} \mathrm{H}_{4}, \mathrm{C}_{3} \mathrm{H}_{8}, \mathrm{i}-\mathrm{C}_{4} \mathrm{H}_{10}, \mathrm{n}-\mathrm{C}_{4} \mathrm{H}_{10}, \mathrm{i}-\mathrm{C}_{4} \mathrm{H}_{8}, \mathrm{i}-\mathrm{C}_{5} \mathrm{H}_{12}$, and $n-\mathrm{C}_{5} \mathrm{H}_{12}$ are positive. The higher amount of these hydrocarbons in the separate bed is due to 
cracking and isomerization reactions over the ZSM-5. These reactions occur to a lower extent in the mixed bed. The negative delta values for $\mathrm{C}_{3} \mathrm{H}_{6}, 1-\mathrm{C}_{4} \mathrm{H}_{8}, \mathrm{t}-\mathrm{C}_{4} \mathrm{H}_{8}, \mathrm{c}-\mathrm{C}_{4} \mathrm{H}_{8}$, and $\mathrm{C}_{5}$-gas (higher amounts in the mixed bed) are due to the decrease of oligomerization active site on ZSM-5 in that configuration. The decrease in these active sites in the mixed bed is due to alkali migration from the base catalyst to the ZSM-5, as discussed in Section 8.1.

\subsubsection{Delta amounts of overall liquid production rates}

Table 6.8 shows the delta amounts of overall hydrocarbon and overall alcohol production rates calculated using Equation (6.1). The detailed amounts of these production rates are shown in Figure 6.4 and Figure 6.11.

From Table 6.8, the delta amounts of hydrocarbon production are positive for all the ZSM-5 amounts. The activities of WGS and FTS are higher in the separate bed compared to the mixed bed, as discussed in Section 6.2.3.2. Higher WGS and FTS rates give higher hydrocarbon production rates. On the other hand, the delta amounts of alcohol production are negative in the mixed bed. The mixed bed is unable to convert all the alcohols to hydrocarbons and water. This is probably because the acidic sites of ZSM-5 are affected by the alkali migration from FT catalyst, as discussed in Section 6.2.3.1. Hence, there is no improvement in hydrocarbon production rate and the conversion of alcohols to hydrocarbons and water when the base catalyst and ZSM-5 are mixed.

Table 6.8 Delta amounts of hydrocarbon and alcohol production rates $(0.5 \mathrm{~g}$ of base catalyst, $\mathrm{Si} / \mathrm{Al}$ ratio in $\mathrm{ZSM}-5=50, \mathrm{H}_{2} / \mathrm{CO}$ ratio $=1$, total feed rate $=100 \mathrm{scc} / \mathrm{min}$, reactor temperature $=300^{\circ} \mathrm{C}$, reactor pressure $=300 \mathrm{Psi}, \mathrm{TOS}=24-48 \mathrm{~h}$ )

\begin{tabular}{|l|c|c|c|}
\hline ZSM-5 weight $(\mathrm{g})$ & 0.25 & 0.5 & 1 \\
\hline Production rates & \multicolumn{3}{|c|}{$\Delta$ (Rate) g/Kg FT cat./h } \\
\hline Hydrocarbon production & 295.00 & 265.00 & 215.83 \\
\hline Alcohol production & -50.82 & -56.79 & -19.31 \\
\hline
\end{tabular}

6.2.3.5 Delta amounts of hydrocarbons in organic liquid phase

Table 6.9 shows the delta amounts of liquid hydrocarbons calculated using Equation (6.1). The detailed data for these hydrocarbons are shown in Appendix F.4. 
From Table 6.9, the delta amounts of liquid $n-C_{5}$ are positive for all ZSM-5 amounts. This implies that amounts of $n-C_{5}$ are higher in the separate bed, probably because the cracking of long-chain hydrocarbons is greater compared to mixed bed. The cracking activity of ZSM-5 is reduced in the mixed bed due to alkali migration from FT catalyst, as discussed in Section 6.2.3.1. For $n-C_{6}$ to $n-C_{14}$ the values are generally positive for ZSM-5 amounts 0.25 and $0.5 \mathrm{~g}$, and these values are generally negative for higher amount of ZSM-5. The increase in these values in the separate bed for ZSM-5 amounts 0.25 and $0.5 \mathrm{~g}$ is probably because the cracking of long-chain hydrocarbons is greater in the separate bed than the mixed bed. The negative values of $n-C_{6}$ to $n-C_{14}$ species are also due to greater cracking effect in the separate bed, but the amounts of $\mathrm{CH}_{4}, \mathrm{C}_{2} \mathrm{H}_{6}+\mathrm{C}_{2} \mathrm{H}_{4}, \mathrm{C}_{3} \mathrm{H}_{8}, \mathrm{i}-\mathrm{C}_{4} \mathrm{H}_{10}, \mathrm{n}-\mathrm{C}_{4} \mathrm{H}_{10}, \mathrm{i}-\mathrm{C}_{5} \mathrm{H}_{12}$, and n- $\mathrm{C}_{5} \mathrm{H}_{12}$ gases increase, as per the discussion of Table 6.7 in Section 6.2.3.3, at higher ZSM-5 amounts in the separate bed compared to the mixed bed. So at higher ZSM-5 amounts, $\mathrm{n}-\mathrm{C}_{6}$ to $\mathrm{n}-\mathrm{C}_{14}$ species are more cracked to smaller-chain species in the separate bed than the mixed bed. The overall effect is the cracking of longchain hydrocarbons is greater in separate bed than the mixed bed for all ZSM-5 amounts. For n- $\mathrm{C}_{15+}$ the values are generally negative. This implies that the amounts of $n-C_{15+}$ are higher in the mixed bed, probably because cracking activity of ZSM-5 is reduced in the mixed bed due to alkali migration from FT catalyst, as discussed in Section 6.2.3.1. Hence, there is no improvement in cracking of long-chain hydrocarbons when the base catalyst and ZSM-5 are mixed. The delta values of n-paraffins are relatively smaller than the delta values of i-paraffins and aromatics.

From Table 6.9 , the delta amounts of liquid $\mathrm{i}-\mathrm{C}_{5}$ to $\mathrm{C}_{15}$ are generally positive. For $\mathrm{i}-\mathrm{C}_{16+}$ the values are generally negative. The amounts of $\mathrm{i}-\mathrm{C}_{5}$ to $\mathrm{C}_{15}$ are generally higher in the separate bed and the amounts of $\mathrm{i}-\mathrm{C}_{16+}$ are generally higher in the mixed bed. ZSM-5 is active towards the cracking of longchain hydrocarbons and the isomerization of n-paraffins formed by the base catalyst, more so in the separate bed than the mixed bed. Cracking and isomerization activities of ZSM-5 are reduced in the mixed bed due to alkali migration from FT catalyst, as discussed in Section 6.2.3.1. Hence, there is no improvement in isomerized hydrocarbons when the base catalyst and ZSM-5 are mixed. 
Table 6.9 Delta values of liquid paraffins and aromatic compounds in organic liquid phase (separate-bed and mixed-bed catalyst arrangement, $0.5 \mathrm{~g}$ of base catalyst, $\mathrm{Si} / \mathrm{Al}$ ratio in $\mathrm{ZSM}-5=50, \mathrm{H}_{2} / \mathrm{CO}$ ratio $=1$, total feed rate $=100 \mathrm{scc} / \mathrm{min}$, reactor temperature $=300^{\circ} \mathrm{C}$, reactor pressure $=300 \mathrm{Psi}, \mathrm{TOS}=24-48 \mathrm{~h}$ )

\begin{tabular}{|c|c|c|c|}
\hline ZSM-5 weight (g) & 0.25 & 0.5 & 1 \\
\hline n-paraffins & \multicolumn{3}{|c|}{$\Delta$ (n-paraffin) mg carbon/day } \\
\hline $\mathrm{n}-\mathrm{C}_{5}$ & 60.9 & 59 & 66.3 \\
\hline$n-C_{6}$ & 136.4 & 134.8 & -42.3 \\
\hline $\mathrm{n}-\mathrm{C}_{7}$ & 338 & 33.5 & -80.1 \\
\hline$n-C_{8}$ & 152 & 5.5 & -39.1 \\
\hline $\mathrm{n}-\mathrm{C}_{9}$ & 87.3 & 6.4 & -24.7 \\
\hline$n-C_{10}$ & 76.7 & 16.3 & -15.2 \\
\hline $\mathrm{n}-\mathrm{C}_{11}$ & 68.7 & 25.7 & 7.1 \\
\hline$n-C_{12}$ & 11.5 & 3.9 & -0.9 \\
\hline $\mathrm{n}-\mathrm{C}_{13}$ & 3.1 & -4.7 & -2.9 \\
\hline$n-C_{14}$ & 11.9 & 1.8 & 11.2 \\
\hline$n-C_{15}$ & -4.3 & -7.1 & 2.8 \\
\hline$n-C_{16}$ & -7.5 & -7.8 & 2.7 \\
\hline$n-C_{17+}$ & -10.2 & -21.8 & 1.6 \\
\hline i-paraffins & \multicolumn{3}{|c|}{$\Delta$ (i-paraffin) mg carbon/day } \\
\hline $\mathrm{i}-\mathrm{C}_{5}$ & 148 & -6.9 & 333.7 \\
\hline $\mathrm{i}-\mathrm{C}_{6}$ & 52.3 & 50.8 & 95.2 \\
\hline $\mathrm{i}-\mathrm{C}_{7}$ & 985.1 & 320 & 73.8 \\
\hline $\mathrm{i}-\mathrm{C}_{8}$ & 606.7 & 299.1 & -25 \\
\hline $\mathrm{i}-\mathrm{C}_{9}$ & 176.7 & 238.2 & 126.1 \\
\hline $\mathrm{i}-\mathrm{C}_{10}$ & 102 & 200.2 & 185.4 \\
\hline $\mathrm{i}-\mathrm{C}_{11}$ & 21.3 & 79.9 & 62.7 \\
\hline $\mathrm{i}-\mathrm{C}_{12}$ & 27.6 & 190.1 & 90.4 \\
\hline $\mathrm{i}-\mathrm{C}_{13}$ & 8.5 & 90.4 & 83.3 \\
\hline $\mathrm{i}-\mathrm{C}_{14}$ & 6.4 & 48.5 & 65.1 \\
\hline $\mathrm{i}-\mathrm{C}_{15}$ & 4.5 & 12.2 & 30.5 \\
\hline $\mathrm{i}-\mathrm{C}_{16}$ & 9.3 & -0.7 & 18.7 \\
\hline $\mathrm{i}-\mathrm{C}_{17+}$ & -1.9 & -3.9 & 8.3 \\
\hline Aromatics & \multicolumn{3}{|c|}{$\Delta$ (aromatic) mg carbon/day } \\
\hline toluene & 19.2 & 314.2 & 650.4 \\
\hline p-xylene & -20.2 & 379 & 554.8 \\
\hline propyl- benzene & -21.2 & 270.3 & 280.4 \\
\hline butyl-benzene & 11.2 & 44.5 & 22.7 \\
\hline
\end{tabular}

From Table 6.9, the delta amounts of liquid aromatics are generally negative for small amounts of ZSM-5, and positive for 0.5 and $1 \mathrm{~g}$ ZSM-5. The amounts of aromatics are higher in the separate bed. ZSM-5 is active towards aromatization and oligomerization of olefins formed by the base catalyst in the 
separate bed. Aromatization and oligomerization activities of ZSM-5 are reduced in the mixed bed due to alkali migration from FT catalyst, as discussed in Section 6.2.3.1. Hence, there is no improvement in aromatic hydrocarbons when the base catalyst and ZSM-5 are mixed.

The overall reaction sequence in the both the beds are similar. The amounts of all the hydrocarbons in the mixed bed are generally lower than those of the separate bed. This is mainly due to the metal migration in the mixed bed, as mentioned earlier. Hence, the extent of hydrocarbon rearrangement reactions in the separate bed might be higher. The overall reaction sequence for the separate bed is already shown in Figure 6.8.

6.2.3.6 Delta values of alcohol products and water in the aqueous liquid phase

Table 6.10 shows the delta amounts of alcohol products and water in the aqueous liquid phase calculated using Equation (6.1). The detailed data for these aqueous liquid compounds are shown in Appendix F.4.

From Table 6.10, the delta amounts of all alcohol products and water are generally negative for all the ZSM-5 amounts used, except for 2-pentanol. Lower amounts of alcohols are formed in the separate bed compared to the mixed bed. This is because all the alcohols formed by the base catalyst in the separate bed pass over all the ZSM-5 present and all the amounts are converted effectively to hydrocarbons and water. Higher amounts of water are formed in the separate bed due to the higher conversion of alcohols to hydrocarbons. On the other hand, the mixed bed is unable to convert all the alcohols to hydrocarbons and water, probably because the acidic sites of ZSM-5 are affected by alkali migration from the FT catalyst, as discussed in Section 6.2.2.6. Hence, there is no improvement in the conversion of alcohols to hydrocarbons and water when the base catalyst and ZSM-5 are mixed. 
Table 6.10 Delta amounts of alcohol products and water in the aqueous liquid phase (separate-bed and mixed-bed catalyst arrangement, $0.5 \mathrm{~g}$ of base catalyst, $\mathrm{Si} / \mathrm{Al}$ ratio in $\mathrm{ZSM}-5=50, \mathrm{H}_{2} / \mathrm{CO}$ ratio $=1$, total feed rate $=100 \mathrm{scc} / \mathrm{min}$, reactor temperature $=300^{\circ} \mathrm{C}$, reactor pressure $=300 \mathrm{Psi}, \mathrm{TOS}=24-48 \mathrm{~h}$ )

\begin{tabular}{|l|c|c|c|}
\hline ZSM-5 weight (g) & 0.25 & 0.5 & 1 \\
\hline Aqueous product & \multicolumn{2}{|c|}{$\Delta$ (Product) mg carbon/day } \\
\hline Methanol & -47.3 & -47.8 & -24.2 \\
\hline Ethanol & -129 & -141.8 & -49.2 \\
\hline 2-Propanol & 32.3 & -23.8 & -13.9 \\
\hline 1-Propanol & -70.6 & -61.2 & -17.9 \\
\hline 2-Butanol & -1.8 & -10.7 & -4.8 \\
\hline 1-Butanol & -60.7 & -60.3 & -9 \\
\hline 2-Pentanol & 0.1 & 0 & 0 \\
\hline 1-Pentanol & -52.4 & -21.5 & 0 \\
\hline & \multicolumn{3}{|c|}{$\Delta$ (Product) mg/day } \\
\hline Water & 1809.9 & 1294.5 & 45.4 \\
\hline
\end{tabular}




\subsubsection{EFFECT OF TEMPERATURE IN BASE CATALYST AND IN SEPARATE-BED CATALYST}

ARRANGEMENT

The effect of temperature is studied for the base catalyst alone and in the separate bed. The quantities of the base catalyst and the ZSM-5 are fixed in the reactor. Analyses of gas, oil, and aqueous product are carried out. The results are discussed below in detail, using the sketch of the overall reaction sequence in Figure 6.8 as a guide.

\subsubsection{Overall Products}

The detailed amounts of gas and liquid components are given in Appendix F.3 and Appendix F.4 respectively. Table 6.11 gives the overall amounts of reactor outlet compounds. The effect of temperature change on the overall product distribution is discussed here, and more details are provided in subsequent sections.

From Table 6.11, the amounts of $\mathrm{C}_{1-4}$ are higher than total $\mathrm{C}_{5+}$ at a given temperature for the base catalyst and the separate bed. Note that there is a significant decrease in amounts of total $\mathrm{C}_{5+}$ at $320^{\circ} \mathrm{C}$ for the separate bed. The decrease in these amounts in the base catalyst at $320^{\circ} \mathrm{C}$ is not much significant. This means that the rates of reactions involving $\mathrm{C}_{5}$ as a reactant (cracking and isomerization) increase more than the rates of FT reactions forming $\mathrm{C}_{5}$. Therefore $\mathrm{E}_{\text {act }}$ for cracking and isomerization reactions are higher than $\mathrm{E}_{\mathrm{act}}$ for forming $\mathrm{C}_{5}$ (Smit et al., 2008; Bizreh et al., 1984; Wei, 1996). Similarly, there is a sharp increase in total hydrocarbons between $280-300^{\circ} \mathrm{C}$ (especially for the separate bed), then a smaller rise (for the base catalyst) or a small decrease (for the separate bed) between $300-320^{\circ} \mathrm{C}$. The sharp rise in total hydrocarbons in the separate bed between $280-300^{\circ} \mathrm{C}$ is mainly because of conversion of alcohols to hydrocarbons by ZSM-5, and because of oligomerization of small-chain hydrocarbons (formed by the base catalyst) to liquid hydrocarbons on ZSM-5. More details on the increase in the hydrocarbon rate are given in Section 6.2.4.4. The smaller decrease in total hydrocarbons for the separate bed between $300-320^{\circ} \mathrm{C}$ is inconsistent with the smaller rise for the base catalyst, probably due to the small variations in the amount of unreacted CO.

Alcohols increase with increase in temperature using the base catalyst, but no net alcohols are

produced in the separate bed at higher temperatures. So $\mathrm{E}_{\text {act }}$ for hydrocarbon to alcohol is greater than $\mathrm{E}_{\text {act }}$ for hydrocarbon formation (Felmer et al., 1981). 
From Table 6.11, the respective amounts of $\mathrm{CO}_{2}$ and unreacted $\mathrm{CO}$ at a given temperature are nearly the same for both the base catalyst and the separate bed. As expected, ZSM-5 does not participate in the conversion of $\mathrm{CO}$ or in the formation of $\mathrm{CO}_{2}$. Only the base catalyst is active towards conversion of $\mathrm{CO}$ and in formation of $\mathrm{CO}_{2}$. The amounts of $\mathrm{CO}_{2}$ are low at lowest temperature, and these level off to nearly constant higher values at higher temperatures for both the base catalyst and the separate bed. Also, it can be seen that the amounts of unreacted CO are high at lowest temperature, and these level off to nearly constant low values at higher temperatures for both the base catalyst and the separate bed. The decrease in $\mathrm{CO}$ and increase in $\mathrm{CO}_{2}$ amounts with increasing temperatures are because high temperature favors FTS and WGS reactions to occur on the base catalyst.

Table 6.11 Effect of temperature on products from the base catalyst and the separate-bed catalyst arrangement $\left(0.5 \mathrm{~g}\right.$ of base catalyst, $\mathrm{Si} / \mathrm{Al}$ ratio in $\mathrm{ZSM}-5=50, \mathrm{H}_{2} / \mathrm{CO}$ ratio $=1$, total feed rate $=100$ $\mathrm{scc} / \mathrm{min}$, reactor pressure $=300 \mathrm{psi}, \mathrm{TOS}=24-48 \mathrm{~h}$ )

\begin{tabular}{|l|c|c|c|c|c|c|}
\hline Temperature $\left({ }^{\circ} \mathrm{C}\right)$ & \multicolumn{2}{|c|}{280} & \multicolumn{2}{c|}{300} & \multicolumn{2}{c|}{320} \\
\hline Bed arrangement & $\begin{array}{l}\text { Base } \\
\text { catalyst }\end{array}$ & $\begin{array}{l}\text { Separate- } \\
\text { bed }\end{array}$ & $\begin{array}{l}\text { Base } \\
\text { catalyst }\end{array}$ & $\begin{array}{l}\text { Separate- } \\
\text { bed }\end{array}$ & $\begin{array}{l}\text { Base } \\
\text { catalyst }\end{array}$ & $\begin{array}{l}\text { Separate- } \\
\text { bed }\end{array}$ \\
\hline ZSM-5 weight $(\mathrm{g})$ & 0 & 0.5 & 0 & 0.5 & 0 & 0.5 \\
\hline Compounds & \multicolumn{7}{|c|}{ g carbon/day } & \multicolumn{2}{|c|}{0} \\
\hline $\mathrm{C}_{1}$ & 0.72 & 0.89 & 2.31 & 2.21 & 3.23 & 3.79 \\
\hline $\mathrm{C}_{2-4}$ & 2.77 & 2.25 & 6.14 & 6.05 & 7.43 & 7.07 \\
\hline Sum of $\mathrm{C}_{1-4}(\mathrm{Gas})$ & 3.49 & 3.14 & 8.45 & 8.26 & 10.66 & 10.86 \\
\hline Total $\mathrm{C}_{5+}(\mathrm{Gas}+$ Liquid) & 2.68 & 2.57 & 6.19 & 8.05 & 5.05 & 4.41 \\
\hline $\begin{array}{l}\text { Sum of hydrocarbons } \\
(\text { Gas }+ \text { Liquid) }\end{array}$ & 6.17 & 5.71 & 14.62 & 16.31 & 15.71 & 15.26 \\
\hline Total alcohols & 0.25 & 0.03 & 0.75 & 0 & 1.06 & 0 \\
\hline $\mathrm{CO}_{2}$ & 10.2 & 8.81 & 14.39 & 15.1 & 14.2 & 15.12 \\
\hline Unreacted CO & 18.5 & 18.51 & 6.84 & 4.3 & 4.2 & 5.17 \\
\hline
\end{tabular}

\subsubsection{WGS and FTS reaction rates}

From Table 6.12, the respective rates of WGS and FTS at a given temperature are generally the same for both the base catalyst and the separate bed. Only the base catalyst is active towards conversion of $\mathrm{CO}$ (by FTS) and in the formation of $\mathrm{CO}_{2}$ (by WGS). The addition of ZSM-5 has a negligible contribution in FTS and WGS rates with increase in temperatures. The rates of FTS and WGS are low at lowest temperature, and these levels off to generally higher constant values at higher temperatures for 
both the base catalyst and the separate bed. Between $280-300^{\circ} \mathrm{C}$, the FTS rates increase much more than the WGS rates.

Table 6.12 Effect of temperatures on reaction rates from the base catalyst and separate-bed catalyst arrangement $\left(0.5 \mathrm{~g}\right.$ of base catalyst, $\mathrm{Si} / \mathrm{Al}$ ratio in $\mathrm{ZSM}-5=50, \mathrm{H}_{2} / \mathrm{CO}$ ratio $=1$, total feed rate $=100$ $\mathrm{scc} / \mathrm{min}$, reactor pressure $=300 \mathrm{psi}, \mathrm{TOS}=24-48 \mathrm{~h}$ )

\begin{tabular}{|l|c|c|c|c|c|c|}
\hline Temperature $\left({ }^{\circ} \mathrm{C}\right)$ & \multicolumn{2}{|c|}{280} & \multicolumn{2}{c|}{300} & \multicolumn{2}{c|}{320} \\
\hline Bed arrangement & $\begin{array}{l}\text { Base } \\
\text { catalyst } \\
\text { bed }\end{array}$ & $\begin{array}{l}\text { Separate- } \\
\text { Base } \\
\text { catalyst } \\
\text { bed }\end{array}$ & $\begin{array}{l}\text { Separate- } \\
\text { Base } \\
\text { catalyst } \\
\text { bed }\end{array}$ \\
\hline ZSM-5 weight (g) & 0 & 0.5 & 0 & 0.5 & 0 & 0.5 \\
\hline Rates & 0.59 & 0.51 & 0.83 & 0.87 & 0.82 & 0.88 \\
\hline rWGS & 0.26 & 0.36 & 0.89 & 0.99 & 0.88 & 0.77 \\
\hline rFTS
\end{tabular}

\subsubsection{Gas analysis}

Table 6.13 shows the production of all the FID gases with increase in temperature for both the base catalyst and the separate bed. It can be seen that the amount of each hydrocarbon increases when the temperature is increased from 280 to $320^{\circ} \mathrm{C}$.

From Table 6.13, the amounts of $\mathrm{CH}_{4}, \mathrm{C}_{3} \mathrm{H}_{8}, \mathrm{n}-\mathrm{C}_{4} \mathrm{H}_{10}$, and $\mathrm{n}-\mathrm{C}_{5} \mathrm{H}_{12}$ increase with the temperatures in both the base catalyst and the separate bed. The amounts of $\mathrm{CH}_{4}$ increase more than the amounts of $\mathrm{C}_{3} \mathrm{H}_{8}$ with increase in the temperature, and so on with $\mathrm{n}-\mathrm{C}_{4} \mathrm{H}_{10}$, and $\mathrm{n}-\mathrm{C}_{5} \mathrm{H}_{12}$. Hence the activation energy for the formation of species with low carbon number (like $\left.\mathrm{CH}_{4}\right)$ could be higher than that for species with higher carbon number (like $\mathrm{C}_{3} \mathrm{H}_{8}$ ). Further, there might be cracking reactions occurring on long-chain hydrocarbons over the zeolite, and these could further change the product distribution for the separate bed.

From Table 6.13, the amounts of $\mathrm{C}_{2} \mathrm{H}_{6}+\mathrm{C}_{2} \mathrm{H}_{4}$ increase in the base catalyst at higher temperatures, probably due to higher FTS rates. For the separate bed, the increases of $\mathrm{C}_{2} \mathrm{H}_{6}+\mathrm{C}_{2} \mathrm{H}_{4}$ amounts are lower than those of $\mathrm{CH}_{4}$, probably because the activation energy of methane formation is larger $(92 \mathrm{KJ} / \mathrm{mol}$ vs. $84 \mathrm{KJ} / \mathrm{mol}$ [Felmer et al., 1981]). Further, there is increased oligomerization of $\mathrm{C}_{2} \mathrm{H}_{4}$ over ZSM-5 in the separate bed. 
Table 6.13 Effect of temperature on gas-phase paraffins from the base catalyst and the separate-bed $(0.5$ $\mathrm{g}$ of base catalyst, $\mathrm{Si} / \mathrm{Al}$ ratio in $\mathrm{ZSM}-5=50, \mathrm{H}_{2} / \mathrm{CO}$ ratio $=1$, total feed rate $=100 \mathrm{scc} / \mathrm{min}$, reactor pressure $=300 \mathrm{psi}, \mathrm{TOS}=24-48 \mathrm{~h}$ )

\begin{tabular}{|c|c|c|c|c|c|c|}
\hline Temperature $\left({ }^{\circ} \mathrm{C}\right)$ & \multicolumn{2}{|c|}{280} & \multicolumn{2}{|c|}{300} & \multicolumn{2}{|c|}{320} \\
\hline Bed arrangement & Base catalyst & $\begin{array}{l}\text { Separate- } \\
\text { bed }\end{array}$ & Base catalyst & $\begin{array}{l}\text { Separate- } \\
\text { bed }\end{array}$ & Base catalyst & $\begin{array}{l}\text { Separate- } \\
\text { bed }\end{array}$ \\
\hline ZSM-5 weight (g) & 0 & 0.5 & 0 & 0.5 & 0 & 0.5 \\
\hline Compounds & \multicolumn{6}{|c|}{ g carbon/day } \\
\hline $\mathrm{CH}_{4}$ & 0.72 & 0.89 & 2.31 & 2.21 & 3.23 & 3.79 \\
\hline $\mathrm{C}_{2} \mathrm{H}_{6}+\mathrm{C}_{2} \mathrm{H}_{4}$ & 0.65 & 0.45 & 1.76 & 1.67 & 2.21 & 1.92 \\
\hline $\mathrm{C}_{3} \mathrm{H}_{8}$ & 0.21 & 0.46 & 0.50 & 1.49 & 0.56 & 1.61 \\
\hline $\mathrm{C}_{3} \mathrm{H}_{6}$ & 0.64 & 0.10 & 2.14 & 0.11 & 2.64 & 0.21 \\
\hline $\mathrm{i}-\mathrm{C}_{4} \mathrm{H}_{10}$ & 0.00 & 0.29 & 0.03 & 1.03 & 0.03 & 1.12 \\
\hline $\mathrm{n}-\mathrm{C}_{4} \mathrm{H}_{10}$ & 0.18 & 0.32 & 0.36 & 1.04 & 0.37 & 1.11 \\
\hline $1-\mathrm{C}_{4} \mathrm{H}_{8}$ & 0.90 & 0.06 & 1.11 & 0.01 & 1.37 & 0.14 \\
\hline $\mathrm{i}-\mathrm{C}_{4} \mathrm{H}_{8}$ & 0.00 & 0.44 & 0.00 & 0.58 & 0.00 & 0.77 \\
\hline $\mathrm{t}-\mathrm{C}_{4} \mathrm{H}_{8}$ & 0.19 & 0.08 & 0.24 & 0.10 & 0.25 & 0.12 \\
\hline $\mathrm{c}-\mathrm{C}_{4} \mathrm{H}_{8}$ & 0.00 & 0.05 & 0.00 & 0.02 & 0.00 & 0.07 \\
\hline Sum of $\mathrm{C}_{2-4}$ & 2.77 & 2.25 & 6.14 & 6.05 & 7.43 & 7.07 \\
\hline $\mathrm{i}-\mathrm{C}_{5} \mathrm{H}_{12}$ & 0.00 & 0.27 & 0.03 & 0.78 & 0.04 & 0.81 \\
\hline $\mathrm{n}-\mathrm{C}_{5} \mathrm{H}_{12}$ & 0.21 & 0.27 & 0.33 & 0.41 & 0.30 & 0.43 \\
\hline $\mathrm{C}_{5}$-gas & 0.91 & 0.51 & 1.20 & 0.56 & 1.25 & 0.83 \\
\hline Sum of $\mathrm{C}_{5}$ & 1.12 & 1.05 & 1.56 & 1.75 & 1.59 & 2.07 \\
\hline
\end{tabular}

From Table 6.13, the amounts of $\mathrm{i}-\mathrm{C}_{4} \mathrm{H}_{10}$, and $\mathrm{i}-\mathrm{C}_{4} \mathrm{H}_{8}$ are nearly zero for the base catalyst, and increase for the separate bed for all the temperatures. For the base catalyst, these species are not formed in appreciable amounts, compared to $\mathrm{CH}_{4}, \mathrm{C}_{3} \mathrm{H}_{8}$, and $n-\mathrm{C}_{4} \mathrm{H}_{10}$, as mentioned earlier. For the separate bed isomerization reactions on ZSM-5 of these species are expected to increase with increasing temperatures. It is also important to note that the amount of $\mathrm{i}-\mathrm{C}_{4} \mathrm{H}_{10}$ increases more than $\mathrm{i}-\mathrm{C}_{4} \mathrm{H}_{8}$ or $\mathrm{i}-$ $\mathrm{C}_{5} \mathrm{H}_{12}$ with increasing temperatures. This means that the activation energy for $\mathrm{i}-\mathrm{C}_{4} \mathrm{H}_{10}$ isomerization is larger than those of the other two species (Bizerh et al., 1984).

From Table 6.13, the amounts of $\mathrm{C}_{3} \mathrm{H}_{6}, 1-\mathrm{C}_{4} \mathrm{H}_{8}$, and $\mathrm{t}-\mathrm{C}_{4} \mathrm{H}_{8}$ increase in the base catalyst at higher temperatures. For the separate bed, these amounts are lower than those of in the base catalyst, probably because the higher temperatures favor the oligomerization reactions over ZSM-5. This means that the 
activation energies for oligomerization reactions could be larger than those formations of these species (Bizerh et al., 1984).

\subsubsection{Overall liquid production rates}

Table 6.14 shows the overall liquid production rates of hydrocarbons and the alcohols. For the base catalyst and the separate bed, there is an increase in the liquid hydrocarbon production rate when the temperature is increased from 280 to $300^{\circ} \mathrm{C}$, but then drops with a further increase in temperature to $320^{\circ} \mathrm{C}$. For the base catalyst, the increase in the hydrocarbon production rates is because high temperature favors the FTS reaction for production of gasoline-range liquid hydrocarbons, as seen in Section 6.2.4.5. Wei (1996) showed that activation energies of formation for long-chain hydrocarbon species decrease with increase in carbon number $(n=8-14)$. Hence, a further increase in temperature (to $320^{\circ} \mathrm{C}$ ) could favor $\mathrm{C}_{2-4}$ formation reactions (by FTS) which have higher activation energies compared to the formation of long-range liquid hydrocarbons. This is consistent with Table 6.13.

For the separate bed, from 280 to $300^{\circ} \mathrm{C}$, overall liquid production rates of hydrocarbons increase

to a much greater extent than for the base catalyst. Production in the separate bed then drops with a further increase in temperature to $320^{\circ} \mathrm{C}$, also to a much greater extent than for the base catalyst. The increase in the hydrocarbon production rates could be because of an increase in one or more of the following reactions;

a) The FTS reaction for production of liquid hydrocarbons due to the base catalyst.

b) WGS reaction which produces hydrogen necessary for liquid hydrocarbon forming reactions on the base catalyst.

c) Conversion of alcohols formed by the base catalyst to hydrocarbon and water on ZSM-5.

d) Oligomerization of small-chain (less than $\mathrm{C}_{5}$ ) hydrocarbon reactions occurring on ZSM-5.

e) Aromatization and oligomerization of small-chain hydrocarbons together to form aromatic compounds containing reactions occurring on ZSM-5. 
The further increase in temperature to $320^{\circ} \mathrm{C}$ could decrease the production rate of liquid hydrocarbons because of increased cracking of long-chain hydrocarbons, and also because production of $\mathrm{C}_{2-4}$ may be forced by FTS at high temperatures, as mentioned earlier.

Table 6.14 Effect of temperature on overall liquid production rates from the base catalyst and the separate-bed $\left(0.5 \mathrm{~g}\right.$ of base catalyst, $\mathrm{Si} / \mathrm{Al}$ ratio in $\mathrm{ZSM}-5=50, \mathrm{H}_{2} / \mathrm{CO}$ ratio $=1$, total feed rate $=100$ $\mathrm{scc} / \mathrm{min}$, reactor pressure $=300 \mathrm{psi}, \mathrm{TOS}=24-48 \mathrm{~h}$ )

\begin{tabular}{|l|c|c|c|c|c|c|}
\hline Temperature $\left({ }^{\circ} \mathrm{C}\right)$ & \multicolumn{2}{|c|}{280} & \multicolumn{2}{c|}{300} & \multicolumn{2}{c|}{320} \\
\hline Bed arrangement & $\begin{array}{l}\text { Base } \\
\text { catalyst }\end{array}$ & $\begin{array}{l}\text { Separate- } \\
\text { bed }\end{array}$ & $\begin{array}{l}\text { Base } \\
\text { catalyst }\end{array}$ & $\begin{array}{l}\text { Separate- } \\
\text { bed }\end{array}$ & $\begin{array}{l}\text { Base } \\
\text { catalyst }\end{array}$ & $\begin{array}{l}\text { Separate- } \\
\text { bed }\end{array}$ \\
\hline ZSM-5 weight $(\mathrm{g})$ & 0 & 0.5 & 0 & 0.5 & 0 & 0.5 \\
\hline $\begin{array}{l}\text { Hydrocarbon production rate } \\
\text { g/kg FT cat./h) }\end{array}$ & 237.50 & 271.10 & 466.67 & 615.63 & 400.00 & 481.68 \\
\hline $\begin{array}{l}\text { Alcohol production rate } \\
\text { (g/kg FT cat./h) }\end{array}$ & 41.36 & 3.51 & 126.32 & 0.45 & 128.00 & 0.43 \\
\hline
\end{tabular}

From Table 6.14, the alcohol rate for the base catalyst increases with increase in temperature, and the trend is consistent with the results of Ma et al. (2007b). The alcohol rates in the separate bed decrease with increasing temperatures because of the increased reaction rate forming hydrocarbons and water over ZSM-5. Even the lowest temperature is sufficient to convert nearly all the alcohols in the separate bed.

\subsubsection{Hydrocarbons distribution in organic liquid phase}

Table 6.15 shows the amounts of paraffins in the hydrocarbon liquid phase. The amounts of $n-\mathrm{C}_{5}$ to $\mathrm{C}_{12}$ are higher than $\mathrm{n}-\mathrm{C}_{13+}$ for both the base catalyst and the separate bed at all temperatures. This means that the rates of cracking of $\mathrm{n}_{-} \mathrm{C}_{13+}$ (over ZSM-5) and the rates of FT reaction forming these compounds (over the base catalyst) are higher than those for the formation reactions of $n-C_{13+}$. Therefore, $E_{\text {act }}$ for reactions involving $n-C_{13+}$ and $F T$ reaction forming $n-C_{5}$ to $C_{12}$ might be higher than those for forming $\mathrm{n}-\mathrm{C}_{13+}$. 
Table 6.15 Effect of temperature on liquid paraffins from the base catalyst and the separate-bed ( $0.5 \mathrm{~g}$ of base catalyst, $\mathrm{Si} / \mathrm{Al}$ ratio in $\mathrm{ZSM}-5=50, \mathrm{H}_{2} / \mathrm{CO}$ ratio $=1$, total feed rate $=100 \mathrm{scc} / \mathrm{min}$, reactor pressure $=300 \mathrm{psi}$, TOS $=24-48 \mathrm{~h}$ )

\begin{tabular}{|c|c|c|c|c|c|c|}
\hline Temperature $\left({ }^{\circ} \mathrm{C}\right)$ & \multicolumn{2}{|c|}{280} & \multicolumn{2}{|c|}{300} & \multicolumn{2}{|c|}{320} \\
\hline Bed arrangement & $\begin{array}{l}\text { Base } \\
\text { catalyst }\end{array}$ & $\begin{array}{l}\text { Separate- } \\
\text { bed }\end{array}$ & $\begin{array}{l}\text { Base } \\
\text { catalyst }\end{array}$ & $\begin{array}{l}\text { Separate- } \\
\text { bed }\end{array}$ & $\begin{array}{l}\text { Base } \\
\text { catalyst }\end{array}$ & $\begin{array}{l}\text { Separate- } \\
\text { bed }\end{array}$ \\
\hline ZSM-5 weight (g) & 0 & 0.5 & 0 & 0.5 & 0 & 0.5 \\
\hline n-paraffins & \multicolumn{6}{|c|}{ mg carbon/day } \\
\hline $\mathrm{n}-\mathrm{C}_{5}$ & 4 & 27 & 46 & 104 & 7 & 867 \\
\hline$n-C_{6}$ & 20 & 155 & 235 & 271 & 50 & 2036 \\
\hline $\mathrm{n}-\mathrm{C}_{7}$ & 55 & 165 & 264 & 171 & 90 & 1745 \\
\hline $\mathrm{n}-\mathrm{C}_{8}$ & 65 & 85 & 334 & 73 & 125 & 674 \\
\hline $\mathrm{n}-\mathrm{C}_{9}$ & 13 & 71 & 255 & 60 & 114 & 345 \\
\hline$n-C_{10}$ & 49 & 56 & 176 & 56 & 94 & 556 \\
\hline $\mathrm{n}-\mathrm{C}_{11}$ & 43 & 15 & 129 & 30 & 82 & 344 \\
\hline$n-C_{12}$ & 39 & 9 & 94 & 22 & 73 & 102 \\
\hline Sum of $n-C_{5}$ to $n-C_{12}$ & 288 & 583 & 1533 & 787 & 635 & 6699 \\
\hline$n-C_{13-22}$ & 30 & 19 & 318 & 50 & 180 & 160 \\
\hline i-paraffins & \multicolumn{6}{|c|}{ mg carbon/day } \\
\hline $\mathrm{i}-\mathrm{C}_{5}$ & 61 & 101 & 606 & 129 & 147 & 87 \\
\hline $\mathrm{i}-\mathrm{C}_{6}$ & 76 & 49 & 193 & 149 & 168 & 204 \\
\hline $\mathrm{i}-\mathrm{C}_{7}$ & 238 & 460 & 538 & 867 & 407 & 175 \\
\hline $\mathrm{i}-\mathrm{C}_{8}$ & 287 & 508 & 608 & 803 & 461 & 67 \\
\hline $\mathrm{i}-\mathrm{C}_{9}$ & 304 & 339 & 337 & 528 & 374 & 34 \\
\hline$\overline{\mathrm{i}-\mathrm{C}_{10}}$ & 179 & 238 & 225 & 493 & 301 & 56 \\
\hline$\overline{\mathrm{i}-\mathrm{C}_{11}}$ & 149 & 136 & 151 & 234 & 240 & 34 \\
\hline $\mathrm{i}-\mathrm{C}_{12}$ & 114 & 80 & 100 & 278 & 184 & 10 \\
\hline Sum of $\mathrm{i}-\mathrm{C}_{5}$ to $\mathrm{i}-\mathrm{C}_{12}$ & 1408 & 1911 & 2758 & 3481 & 2282 & 667 \\
\hline $\mathrm{i}-\mathrm{C}_{13-22}$ & 150 & 56 & 355 & 110 & 200 & 17 \\
\hline $\mathrm{C}_{23+}$ & 180 & 5 & 40 & 20 & 60 & 12 \\
\hline
\end{tabular}

Between $280-300^{\circ} \mathrm{C}$, the amount of $\mathrm{n}-\mathrm{C}_{5-12}$ increases by a factor of approximately 5 in the base catalyst but increases by only a factor of approximately 1.5 in the separate bed. The rates of reactions involving cracking of $n-C_{5-12}$ (to small-chain species) over ZSM-5 increase more than the rates of FT reactions forming these species. Therefore, the activation energies for cracking reactions involving $n-C_{5}$ ${ }_{12}$ over ZSM-5 are higher than those for the formation reactions for these species. The amount of $n-C_{13-22}$ 
increases by a factor of approximately 10 in the base catalyst but increases by only approximately 2.5 in the separate bed. The greater extent of increases in the base catalyst is due to higher FTS activity at higher temperatures. The rates of reactions involving cracking of $n-C_{13-22}$ over ZSM-5 increase more than the rates of FT reactions forming these species. Therefore, the activation energies for cracking reactions involving $n-C_{13-22}$ over ZSM-5 are higher than those for the formation reactions of these species. The amount of $\mathrm{i}-\mathrm{C}_{5-12}$ increases by a factor of approximately 2 in the base catalyst and increases by approximately 1.5 in the separate bed. Also, the amount of $\mathrm{i}-\mathrm{C}_{13-22}$ increases by a factor of approximately 2.5 in the base catalyst and increases by approximately 2 in the separate bed. The lower extent of increase in the separate bed is because ZSM-5 rearranges all these species to form smallerchain and aromatic molecules through cracking and aromatization reactions respectively. Therefore, the activation energies for cracking and aromatization reactions involving i- $\mathrm{C}_{5-22}$ over ZSM-5 are higher than those for the formation reactions of these species.

Between $300-320^{\circ} \mathrm{C}$, the amounts of $\mathrm{n}-\mathrm{C}_{5-12}$ and $\mathrm{i}-\mathrm{C}_{13-22}$ both drop by a factor of approximately 0.5 in the base catalyst. The lower extent of drop in the base catalyst is due to shift in the product spectrum towards small-chain molecules at higher temperature, as mentioned earlier. In the separate bed, the amount of $n-\mathrm{C}_{5-12}$ increases by a factor of 10 and the amount of $\mathrm{i}-\mathrm{C}_{5-12}$ decreases by a factor of 0.2. The relatively greater extent of increase of n-paraffins in the separate bed is because the rates of cracking reactions involving $\mathrm{i}-\mathrm{C}_{5-12}$ over ZSM-5 are higher than those for the formation reactions of n$\mathrm{C}_{5-12}$ over the base catalyst (isomers are more reactive than $\mathrm{n}$-paraffins). Therefore, the activation energies for cracking reactions involving i-C $\mathrm{C}_{5-12}$ over ZSM-5 are higher than those for the formation reactions of $n-C_{5-12}$. The amounts of $\mathrm{i}-\mathrm{C}_{5-12}$ are nearly the same in the base catalyst, and there is not much effect on rates of formation of these species. Also, the amount of $\mathrm{i}-\mathrm{C}_{13-22}$ between $300-320^{\circ} \mathrm{C}$ drops by factor of approximately 0.5 in the base catalyst and drops by a factor of approximately 0.1 in the separate bed. Note that these drops are not consistent with those of trends between $280-300^{\circ} \mathrm{C}$. The amounts of $\mathrm{C}_{23+}$ are relatively small compared to the amounts of all the other products.

Table 6.16 shows the distribution of the aromatic components with change in temperature. The amounts for the base catalyst are zero at all temperatures, because FTS provides no aromatics. But this is not true with the separate bed, where ZSM-5 provides the sites necessary for aromatic compound formation. The amounts of all aromatic compounds increase from 280 to $300^{\circ} \mathrm{C}$. The increase is greater for toluene and least for butyl benzene, probably due to steric hindrance. A further increase in 
temperature causes these amounts to decrease, probably because of coke deposition on ZSM-5 (Guanjie et al., 2010) reducing the aromatization activity of ZSM-5.The decrease is the least for butyl benzene and the greatest for toluene.

Table 6.16 Effect of temperature on aromatic compounds from the base catalyst and the separate-bed $\left(0.5 \mathrm{~g}\right.$ of base catalyst, $\mathrm{Si} / \mathrm{Al}$ ratio in $\mathrm{ZSM}-5=50, \mathrm{H}_{2} / \mathrm{CO}$ ratio $=1$, total feed rate $=100 \mathrm{scc} / \mathrm{min}$, reactor pressure $=300 \mathrm{psi}$, TOS $=24-48 \mathrm{~h}$ )

\begin{tabular}{|l|c|c|c|c|c|c|}
\hline $\begin{array}{l}\text { Temperature } \\
\left({ }^{\circ} \mathrm{C}\right)\end{array}$ & \multicolumn{2}{|c|}{280} & \multicolumn{2}{c|}{300} & \multicolumn{2}{c|}{320} \\
\hline Bed arrangement & $\begin{array}{l}\text { Base } \\
\text { catalyst }\end{array}$ & $\begin{array}{l}\text { Separate- } \\
\text { bed }\end{array}$ & $\begin{array}{l}\text { Base } \\
\text { catalyst }\end{array}$ & $\begin{array}{l}\text { Separate- } \\
\text { bed }\end{array}$ & $\begin{array}{l}\text { Base } \\
\text { catalyst }\end{array}$ & $\begin{array}{l}\text { Separate- } \\
\text { bed }\end{array}$ \\
\hline $\begin{array}{l}\text { ZSM-5 weight } \\
(\mathrm{g})\end{array}$ & 0 & 0.5 & 0 & 0.5 & 0 & 0.5 \\
\hline Compounds & \multicolumn{7}{|c|}{ mg carbon/day } & 0 & 162 \\
\hline toluene & 0 & 31 & 0 & 462 & 0 & 367 \\
\hline p-xylene & 0 & 99 & 0 & 737 & 0 & 306 \\
\hline propyl benzene & 0 & 99 & 0 & 563 & 0 & 70 \\
\hline butyl benzene & 0 & 33 & 0 & 90 & 0 & 0 \\
\hline
\end{tabular}

\subsubsection{Alcohols and water in aqueous liquid phase}

From Table 6.17, the total amount of alcohols for the base catalyst increases with increase in the temperature and the trend is consistent with the results of Ma et al. (2007b). Between $280-300^{\circ} \mathrm{C}$, the total alcohol production increases by a factor of 3. Individually, ethanol, which is present in the largest amounts, increases by a relatively small amount, a factor of approximately 2.5. 1-pentanol, present in very small amount, increases by a factor of approximately 4 . Between $300-320^{\circ} \mathrm{C}$, the increases are much lower, probably due to deactivation.

From Table 6.17, the total alcohol amounts in the separate bed are vanishingly low compared to the base catalyst. ZSM-5 has the ability to convert almost all the alcohols formed by the base catalyst to hydrocarbon and water, and the alcohol amount decreases with increase in the temperature. At all temperatures, 2-propanol is the most abundant species. This means that the activation energies for the conversion of alcohol to hydrocarbon and water on ZSM-5 are higher than those for alcohols formation on the base catalyst. It can also be seen that even the lowest temperature is sufficient to convert nearly all the alcohol in the separate bed. 
Table 6.17 Effect of temperature on weights of alcohols and water from the base catalyst and the separate-bed $\left(0.5 \mathrm{~g}\right.$ of base catalyst, $0.5 \mathrm{~g}$ of $\mathrm{ZSM}-5, \mathrm{Si} / \mathrm{Al}$ ratio in $\mathrm{ZSM}-5=50, \mathrm{H}_{2} / \mathrm{CO}$ ratio $=1$, total feed rate $=100 \mathrm{scc} / \mathrm{min}$, reactor pressure $=300 \mathrm{psi}$, TOS $=24-48 \mathrm{~h}$ )

\begin{tabular}{|c|c|c|c|c|c|c|}
\hline Temperature $\left({ }^{\circ} \mathrm{C}\right)$ & \multicolumn{2}{|c|}{280} & \multicolumn{2}{|c|}{300} & \multicolumn{2}{|c|}{320} \\
\hline Bed arrangement & $\begin{array}{l}\text { Base } \\
\text { catalyst }\end{array}$ & $\begin{array}{l}\text { Separate- } \\
\text { bed }\end{array}$ & $\begin{array}{l}\text { Base } \\
\text { catalyst }\end{array}$ & $\begin{array}{l}\text { Separate- } \\
\text { bed }\end{array}$ & $\begin{array}{l}\text { Base } \\
\text { catalyst }\end{array}$ & $\begin{array}{l}\text { Separate- } \\
\text { bed }\end{array}$ \\
\hline ZSM-5 weight (g) & 0 & 0.5 & 0 & 0.5 & 0 & 0.5 \\
\hline Compounds & \multicolumn{6}{|c|}{ Weights in aqueous phase (mg) } \\
\hline methanol & 73 & 2 & 243 & 0 & 307 & 0 \\
\hline ethanol & 192 & 5 & 516 & 2 & 595 & 0 \\
\hline 2-Propanol & 36 & 35 & 92 & 5 & 115 & 5 \\
\hline 1-Propanol & 89 & 0 & 272 & 0 & 275 & 0 \\
\hline 2-Butanol & 14 & 2 & 31 & 0 & 26 & 0 \\
\hline 1-Butanol & 58 & 0 & 205 & 0 & 134 & 0 \\
\hline 2-Pentanol & 0 & 0 & 0 & 0 & 0 & 0 \\
\hline 1-Pentanol & 35 & 0 & 157 & 0 & 83 & 0 \\
\hline Total alcohols & 496 & 42 & 1516 & 7 & 1536 & 5 \\
\hline Water & 354 & 1458 & 894 & 2295 & 1664 & 1496 \\
\hline
\end{tabular}




\section{CHAPTER 7}

\section{CATALYST STABILITY TESTS}

\subsection{Conversions}

Stability tests of the base catalyst along with $0.5 \mathrm{~g}$ of ZSM-5 have been carried out for $240 \mathrm{~h}$ time on stream (TOS) in the separate-bed catalyst arrangement. Figure 7.1 shows the $\mathrm{CO}$ and $\mathrm{H}_{2}$ conversions. The $\mathrm{CO}$ and $\mathrm{H}_{2}$ conversions start with low values, and then reach their maximum values in approximately $28 \mathrm{~h}$. The catalyst seems stable up to $115 \mathrm{~h}$, and then starts losing its activity slowly up to the end of the run, at $240 \mathrm{~h}$. This general behavior confirms the use of the products obtained in the period from $24-48 \mathrm{~h}$ TOS to characterize the performance of the various catalysts and bed arrangements.

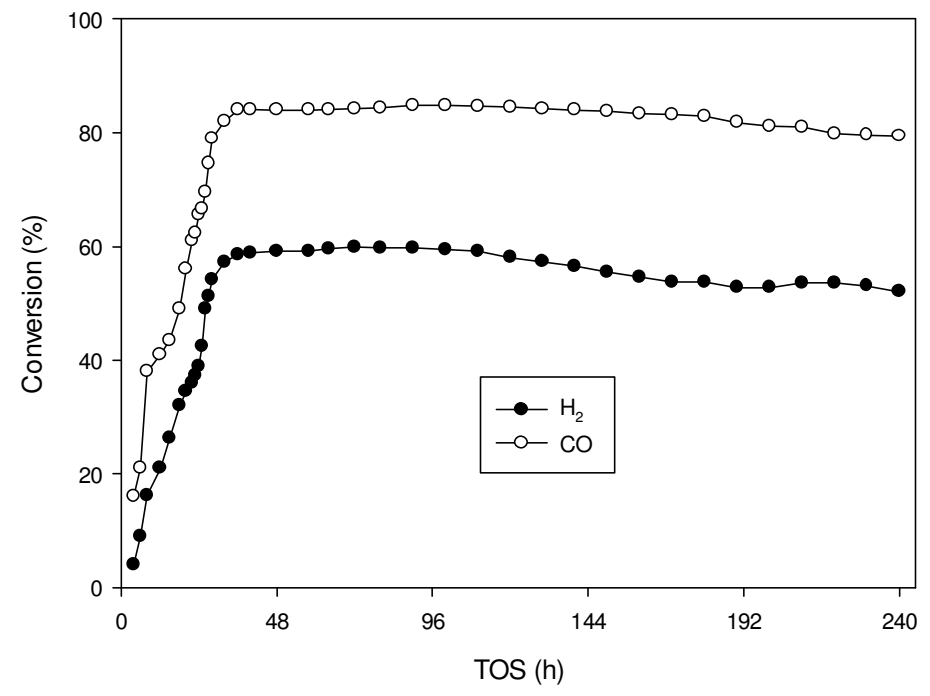

Figure 7.1 $\mathrm{CO}$ and $\mathrm{H}_{2}$ conversions (\%) with time on stream (TOS, h). Separate-bed catalyst arrangement, $0.5 \mathrm{~g}$ of base catalyst, $0.5 \mathrm{~g}$ of ZSM-5 catalyst, $\mathrm{Si} / \mathrm{Al}$ ratio in ZSM-5 = 50, $\mathrm{H}_{2} / \mathrm{CO}$ ratio = 1 , total feed rate $=100 \mathrm{scc} / \mathrm{min}$, reactor temperature $=300^{\circ} \mathrm{C}$, reactor pressure $=300 \mathrm{psi}$, TOS $=0-240 \mathrm{~h}$.

The decrease in catalytic activity can be explained as follows. As discussed in Section 4.3, the base catalyst has $\mathrm{FeO}$ and $\mathrm{Fe}_{3} \mathrm{O}_{4}$ before starting the reaction. After starting the reaction, there might be rapid phase transformation of the iron oxide to the iron carbide, and the fraction of the iron carbide could increase rapidly in the initial reaction period. According to Davis (2009), the iron carbide shows 
greater activity towards FT reactions. This could account for the rapid increase in the conversions in Figure 7.1 from 0 to $28 \mathrm{~h}$. Davis (2009) also suggests that there is a decline in the iron-carbide phase with greater operating time. So the slow decline in the conversions in Figure 7.1 after 28 h may be due to a decline in the iron-carbide phase. ZSM-5 has no role in the conversion of syngas.

Figure 7.2 gives the amounts of $\mathrm{CO}_{2}$ formed and $\mathrm{CO}$ unreacted with reaction time. There is not much change in $\mathrm{CO}_{2}$ formed after $48 \mathrm{~h}$ TOS. This means that the combined effect of the base catalyst and ZSM-5 in the separate-bed catalyst arrangement is nearly constant. The slight increase in unreacted $\mathrm{CO}$ is due to the slow drop in $\mathrm{CO}$ conversion after $48 \mathrm{~h}$, as also seen in Figure 7.1.

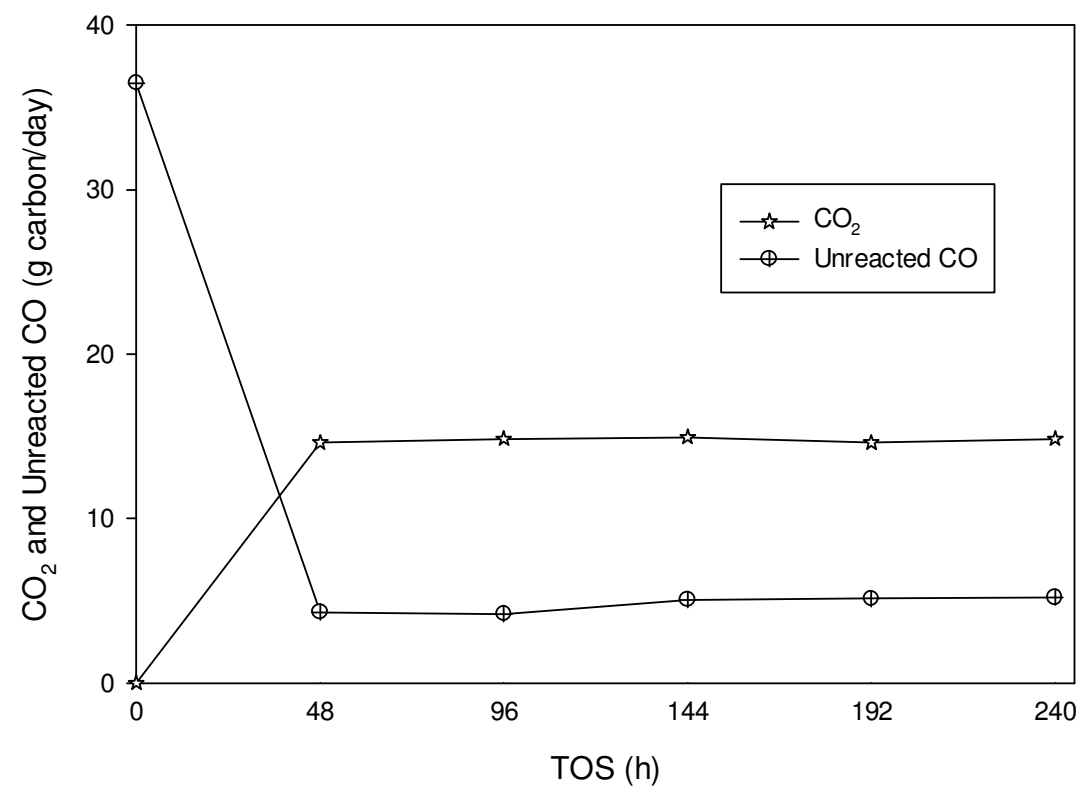

Figure 7.2 $\mathrm{CO}_{2}$ and unreacted $\mathrm{CO}$ (g carbon/day) with time on stream (TOS, h). Separate-bed catalyst arrangement, $0.5 \mathrm{~g}$ of base catalyst, $0.5 \mathrm{~g}$ of ZSM-5 catalyst, $\mathrm{Si} / \mathrm{Al}$ ratio in $\mathrm{ZSM}-5=50, \mathrm{H}_{2} / \mathrm{CO}$ ratio $=1$, total feed rate $=100 \mathrm{scc} / \mathrm{min}$, reactor temperature $=300^{\circ} \mathrm{C}$, reactor pressure $=300 \mathrm{psi}, \mathrm{TOS}=0-240 \mathrm{~h}$.

\subsection{WGS and FTS reaction rates}

The WGS and FTS rates are shown in Table 7.1. There is not much variation in WGS reaction activity. Therefore addition of ZSM-5 to the base catalyst in the separate-bed arrangement is inactive towards WGS reaction. Mahay et al. (1987) also confirm that ZSM-5 zeolite alone cannot show any activity towards WGS reaction. The FTS rate decrease slowly with time. This is because of the slow decline in FTS activity of the base catalyst, as explained in Section 7.1. 
Table 7.1 WGS and FTS reaction rates with time on stream (TOS, h) (separate-bed catalyst arrangement, $0.5 \mathrm{~g}$ of base catalyst, $0.5 \mathrm{~g}$ of ZSM-5 catalyst, $\mathrm{Si} / \mathrm{Al}$ ratio in $\mathrm{ZSM}-5=50, \mathrm{H}_{2} / \mathrm{CO}$ ratio $=1$, total feed rate $=100 \mathrm{scc} / \mathrm{min}$, reactor temperature $=300^{\circ} \mathrm{C}$, reactor pressure $=300 \mathrm{psi}, \mathrm{N}_{\mathrm{CO}}$, inlet $=2.112$ $\mathrm{mmole} / \mathrm{min}, \mathrm{TOS}=0-240 \mathrm{~h}$ )

\begin{tabular}{|l|c|c|c|c|c|}
\hline TOS $(\mathrm{h})$ & $24-48$ & $48-96$ & $96-144$ & $144-192$ & $192-240$ \\
\hline Rates & \multicolumn{5}{|c|}{ mmole/min } \\
\hline rWGS $=\mathrm{rCO}_{2}$ & 0.84 & 0.86 & 0.86 & 0.84 & 0.86 \\
\hline rFTS = -rCO - rWGS & 1.02 & 1.01 & 0.95 & 0.97 & 0.95 \\
\hline
\end{tabular}

\subsection{Gas analysis}

From Figure 7.3, the amounts of all the gases are relatively constant after around $48 \mathrm{~h}$, except for a spike at $240 \mathrm{~h}$ for $\mathrm{C}_{3} \mathrm{H}_{8}$. The increases are mainly due to a progressive shift in the product spectrum of the base catalyst towards lighter compounds (Botes et al., 2004), assuming that the cracking ability of the ZSM-5 catalyst is unchanged with time on stream.

From Figure 7.4, the amounts of $\mathrm{C}_{3} \mathrm{H}_{6}, 1-\mathrm{C}_{4} \mathrm{H}_{8}, \mathrm{t}-\mathrm{C}_{4} \mathrm{H}_{8} \quad \mathrm{c}-\mathrm{C}_{4} \mathrm{H}_{8}$, and $\mathrm{C}_{5}$-olefins increase with reaction time. ZSM-5 has the ability to oligomerize these compounds (Borges et al., 2007; Knifton et al., 1994). The increase may be due to a decrease in oligomerization sites on ZSM-5, as well as a progressive shift in the product spectrum of the base catalyst towards lighter compounds (Botes et al., 2004). 


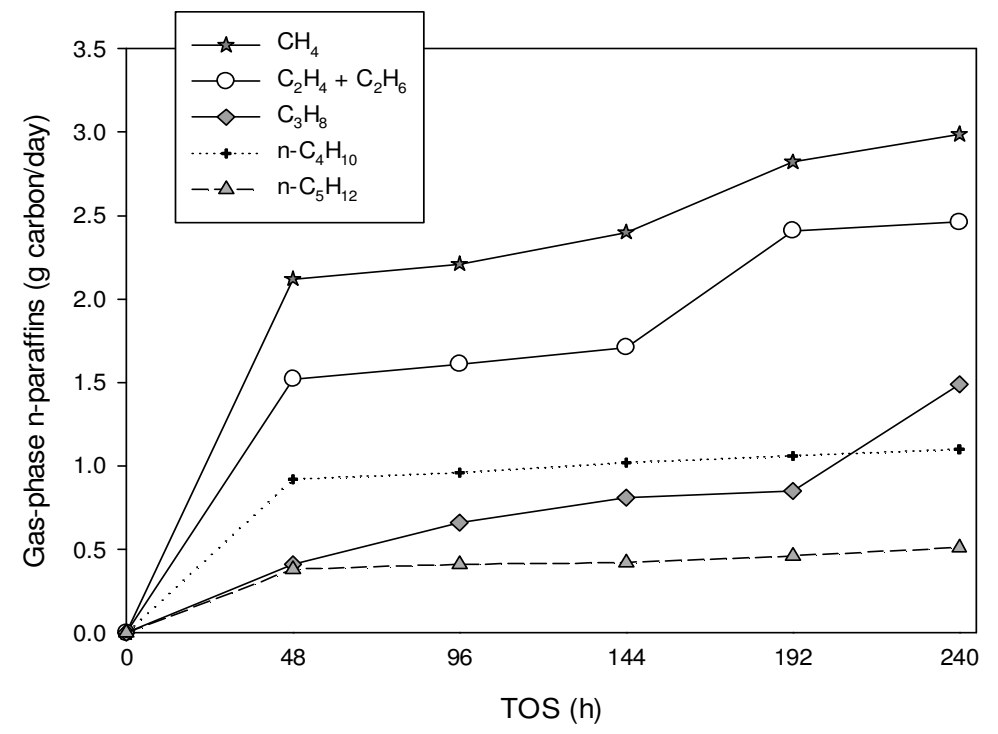

Figure 7.3 Gas-phase n-paraffins detected by FID (g carbon/day) with time on stream (TOS, h). Separate-bed catalyst arrangement, $0.5 \mathrm{~g}$ of base catalyst, $0.5 \mathrm{~g}$ of ZSM-5 catalyst, Si/Al ratio in ZSM-5 $=50, \mathrm{H}_{2} / \mathrm{CO}$ ratio $=1$, total feed rate $=100 \mathrm{scc} / \mathrm{min}$, reactor temperature $=300^{\circ} \mathrm{C}$, reactor pressure $=300$ psi, TOS $=0-240 \mathrm{~h}$.

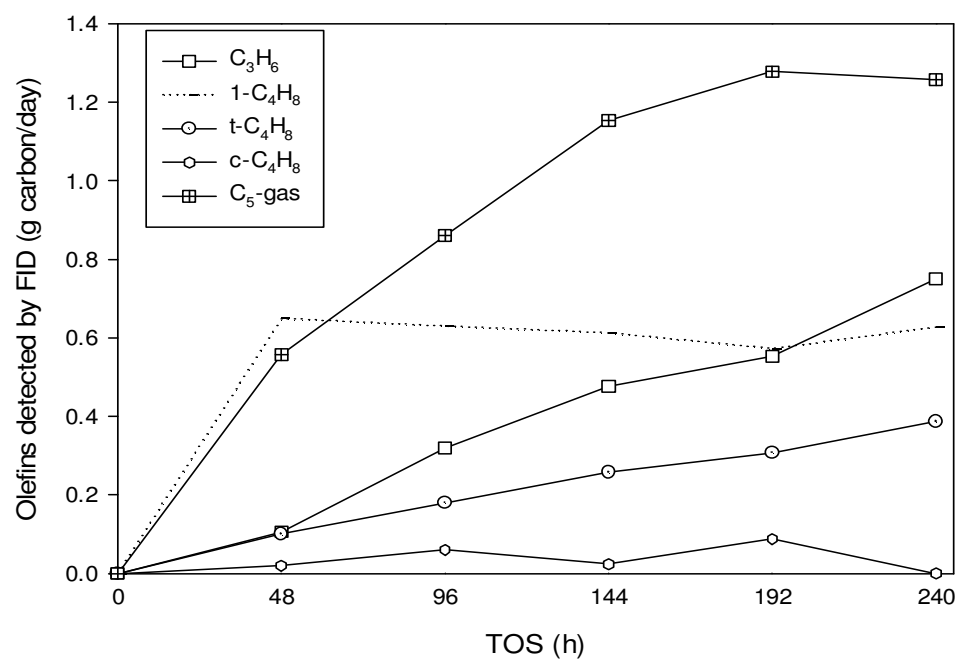

Figure 7.4 FID gases not shown in Figure 7.3 (g carbon/day) with time on stream (TOS, h). Separatebed catalyst arrangement, $0.5 \mathrm{~g}$ of base catalyst, $0.5 \mathrm{~g}$ of ZSM-5 catalyst, Si/Al ratio in ZSM-5 = 50, $\mathrm{H}_{2} / \mathrm{CO}$ ratio $=1$, total feed rate $=100 \mathrm{scc} / \mathrm{min}$, reactor temperature $=300^{\circ} \mathrm{C}$, reactor pressure $=300 \mathrm{psi}$, TOS $=0-240 \mathrm{~h}$. 
From Figure 7.5, the amounts of $\mathrm{i}-\mathrm{C}_{4} \mathrm{H}_{10}, \mathrm{i}-\mathrm{C}_{4} \mathrm{H}_{8}$, and $\mathrm{i}-\mathrm{C}_{5} \mathrm{H}_{12}$ initially increase, then decrease with reaction time. It may be that there is a decrease in the number of isomerization sites on ZSM-5, due to coke deposition. Coke deposition on ZSM-5 could also account for (a portion of) the increase in Figure 7.3 and 7.4, along with the shift on the product spectrum of the FT catalyst. The presence of coke on ZSM-5 is further confirmed by EDX analysis of ZSM-5, as shown in Section 8.2.

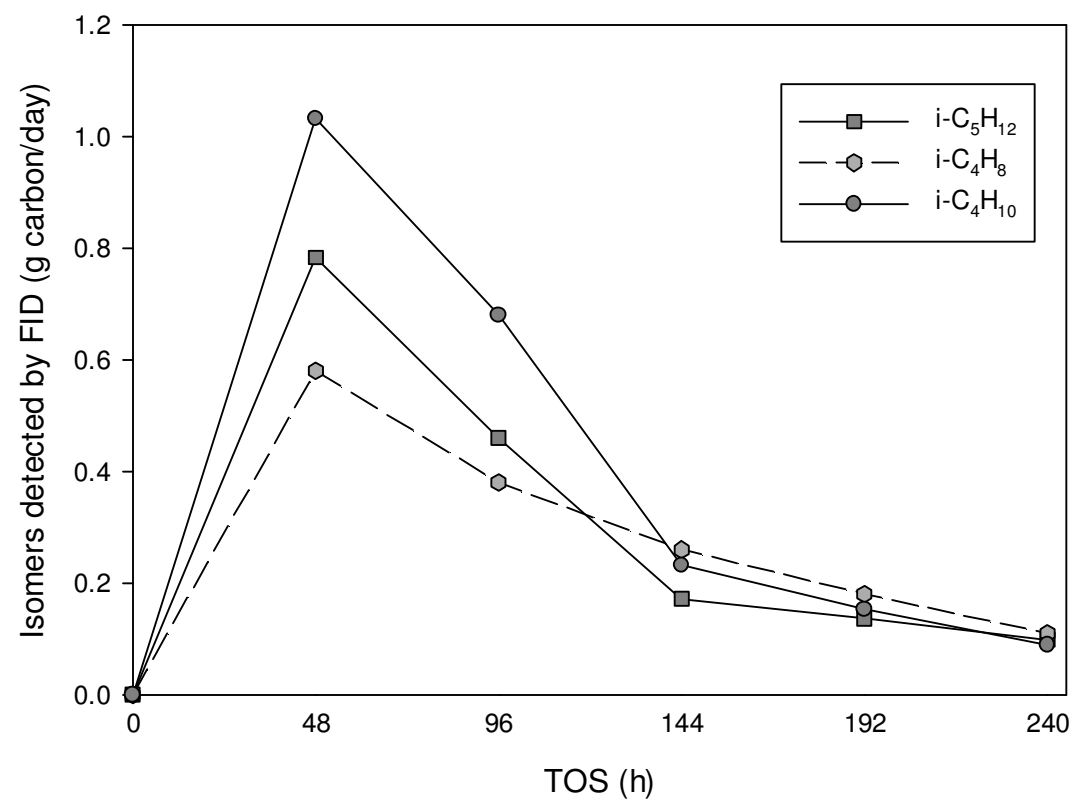

Figure 7.5 FID gases not shown in Figure 7.3 and Figure 7.4 (g carbon/day) with time on stream (TOS, h). Separate-bed catalyst arrangement, $0.5 \mathrm{~g}$ of base catalyst, $0.5 \mathrm{~g}$ of ZSM-5 catalyst, Si/Al ratio in $\mathrm{ZSM}-5=50, \mathrm{H}_{2} / \mathrm{CO}$ ratio $=1$, total feed rate $=100 \mathrm{scc} / \mathrm{min}$, reactor temperature $=300^{\circ} \mathrm{C}$, reactor pressure $=300 \mathrm{psi}$, TOS $=0-240 \mathrm{~h}$.

\subsection{Overall liquid hydrocarbon production rates}

Overall liquid hydrocarbon production rates are shown in Figure 7.6. There is a slow decrease in production from $96 \mathrm{~h}$ onwards. The decrease in production can be explained by the increase in gas-phase light hydrocarbons by a shift in the product spectrum of the FT catalyst (Botes et al., 2004). 


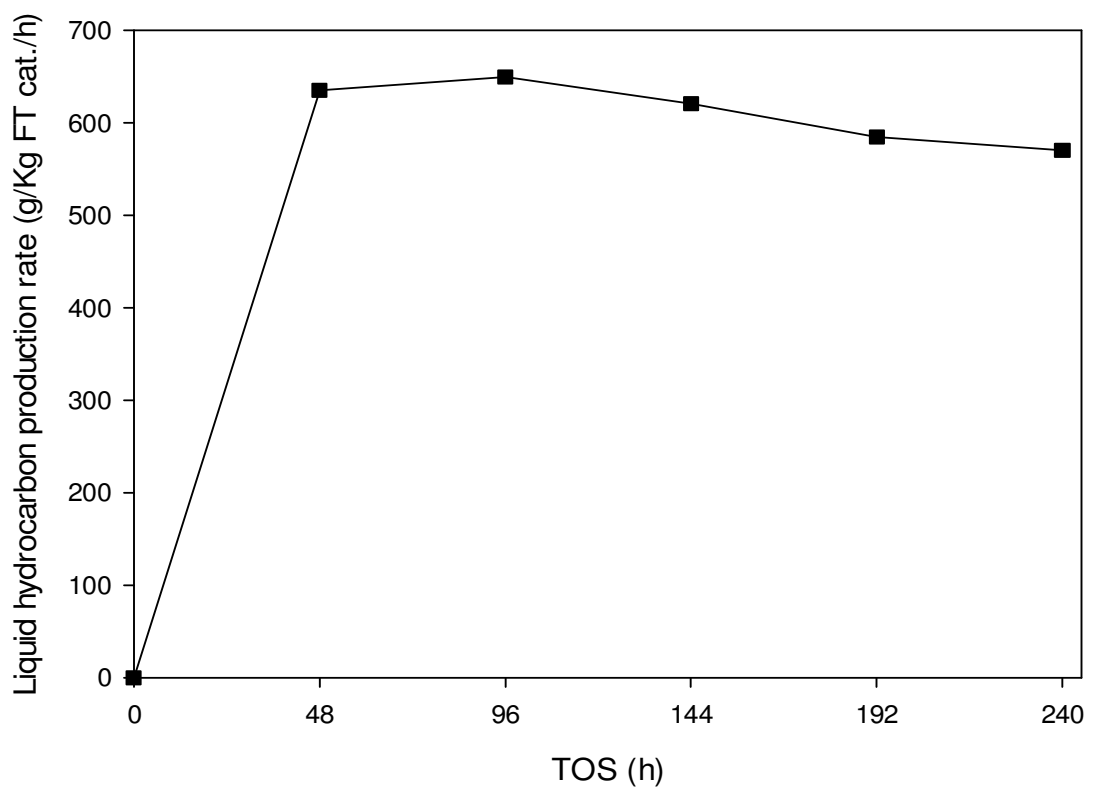

Figure 7.6 Liquid hydrocarbon production rate (g/Kg FT cat./h) with time on stream (TOS, h). Separatebed catalyst arrangement, $0.5 \mathrm{~g}$ of base catalyst, $0.5 \mathrm{~g}$ of ZSM-5 catalyst, Si/Al ratio in ZSM-5 = 50, $\mathrm{H}_{2} / \mathrm{CO}$ ratio $=1$, total feed rate $=100 \mathrm{scc} / \mathrm{min}$, reactor temperature $=300^{\circ} \mathrm{C}$, reactor pressure $=300 \mathrm{psi}$, TOS $=0-240 \mathrm{~h}$.

7.5 Hydrocarbons distribution in organic liquid phase

Detailed liquid distribution of the hydrocarbons is shown in Appendix F.4. Table 7.2 gives information about the amounts of hydrocarbons distributed in the organic liquid phase. The amounts of $\mathrm{n}-\mathrm{C}_{5-12}$ increase with reaction time, while $\mathrm{i}-\mathrm{C}_{5-12}$ has a maximum at $96-144 \mathrm{~h}$. The amounts of $\mathrm{i}-\mathrm{C}_{5-12}$ drop probably because of the reduced isomerization ability of ZSM-5 due to formation of coke with time. The amounts of $\mathrm{C}_{7-10}$ aromatics, $\mathrm{n}-\mathrm{C}_{13+}$, and $\mathrm{i}-\mathrm{C}_{13+}$ decrease with reaction time. The decrease in amounts of $\mathrm{C}_{13+}$, both $\mathrm{n}$ - and $\mathrm{i}-$, is also explained by the increase in gas-phase light hydrocarbons due to a shift in the product spectrum of the base catalyst. The decrease in the amounts of $\mathrm{C}_{7-10}$ aromatics can be explained by coke deposition on the ZSM-5. 
Table 7.2 Hydrocarbons distribution (g carbon/day) with time on stream (TOS, h) (separate-bed catalyst arrangement, $0.5 \mathrm{~g}$ of base catalyst, $0.5 \mathrm{~g}$ of ZSM-5 catalyst, $\mathrm{Si} / \mathrm{Al}$ ratio in ZSM-5 = 50, $\mathrm{H}_{2} / \mathrm{CO}$ ratio = 1, total feed rate $=100 \mathrm{scc} / \mathrm{min}$, reactor temperature $=300^{\circ} \mathrm{C}$, reactor pressure $=300 \mathrm{psi}, \mathrm{TOS}=0-240 \mathrm{~h}$ )

\begin{tabular}{|c|c|c|c|c|c|}
\hline TOS (h) & $24-48$ & $48-96$ & $96-144$ & $144-192$ & $192-240$ \\
\hline Products & \multicolumn{4}{|c|}{ g carbon / day } & \\
\hline$n-C_{5-12}$ & 1.19 & 1.48 & 1.63 & 1.67 & 1.86 \\
\hline $\mathrm{i}-\mathrm{C}_{5-12}$ & 4.93 & 5.77 & 6.27 & 5.91 & 5.65 \\
\hline $\mathrm{C}_{7-10}$ Aromatics & 1.91 & 1.21 & 0.53 & 0.39 & 0.34 \\
\hline Sum of $\mathrm{C}_{5-12}$ & 8.03 & 8.46 & 8.43 & 7.97 & 7.85 \\
\hline$n-C_{13+}$ & 0.06 & 0.02 & 0.01 & 0.01 & 0.01 \\
\hline $\mathrm{i}-\mathrm{C}_{13+}$ & 0.28 & 0.12 & 0.09 & 0.08 & 0.05 \\
\hline Sum $C_{13+}$ & 0.34 & 0.14 & 0.10 & 0.09 & 0.06 \\
\hline
\end{tabular}

Figure 7.7 shows the amounts of individual aromatic compounds with increase in reaction time. The amounts of all the aromatic compounds increase for the first $48 \mathrm{~h}$, decrease thereafter and level off after $144 \mathrm{~h}$. ZSM-5 might be active for aromatization in the first $48 \mathrm{~h}$. Coke deposition on the ZSM-5 pores causes the amounts of all the aromatic compounds to decrease with reaction time after $48 \mathrm{~h}$. 


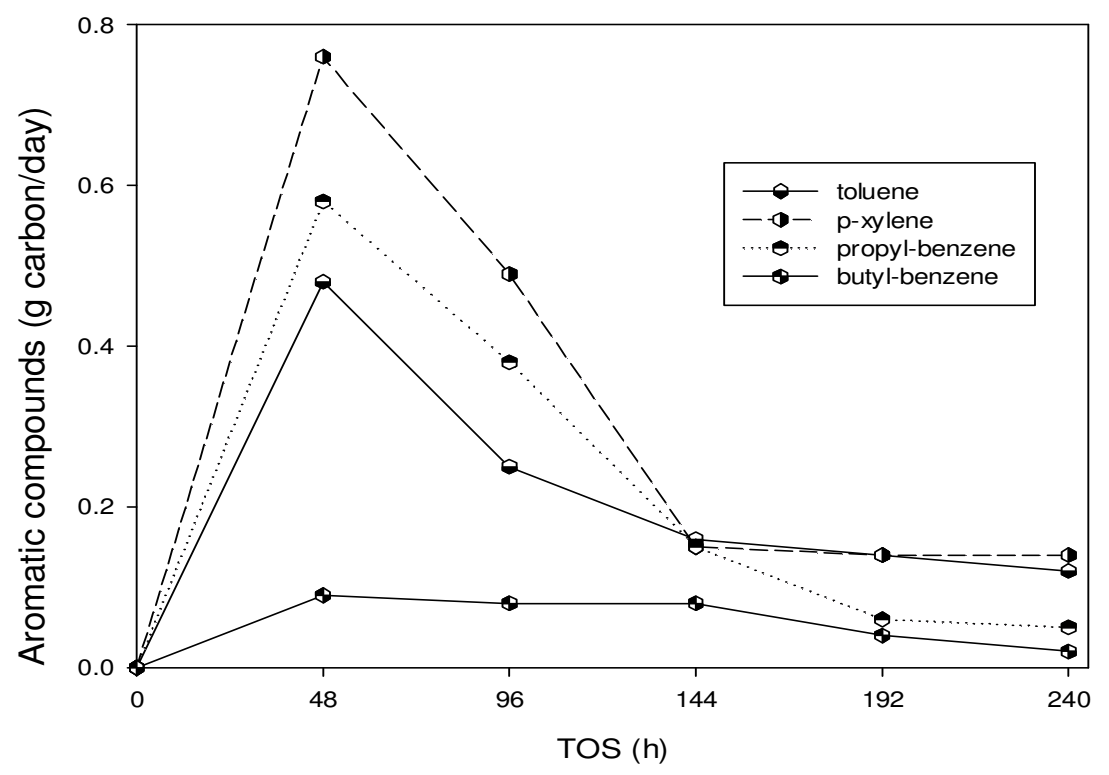

Figure 7.7 Aromatics compounds (g carbon/day) with time on stream (TOS, h). Separate-bed catalyst arrangement, $0.5 \mathrm{~g}$ of base catalyst, $0.5 \mathrm{~g}$ of ZSM- 5 catalyst, $\mathrm{Si} / \mathrm{Al}$ ratio in ZSM- $5=50, \mathrm{H}_{2} / \mathrm{CO}$ ratio $=1$, total feed rate $=100 \mathrm{scc} / \mathrm{min}$, reactor temperature $=300^{\circ} \mathrm{C}$, reactor pressure $=300 \mathrm{psi}, \mathrm{TOS}=0-240 \mathrm{~h}$.

7.6 Overall alcohol production rates

From Figure 7.8, the overall alcohol production rate drops somewhat till $96 \mathrm{~h}$ and increases slowly thereafter. The decrease in production is due to the ability of ZSM-5 to convert alcohols to hydrocarbons initially. Coke deposition probably reduces the ability of ZSM-5 to convert alcohols to hydrocarbons eventually, and hence alcohol production rate increases after $96 \mathrm{~h}$. 


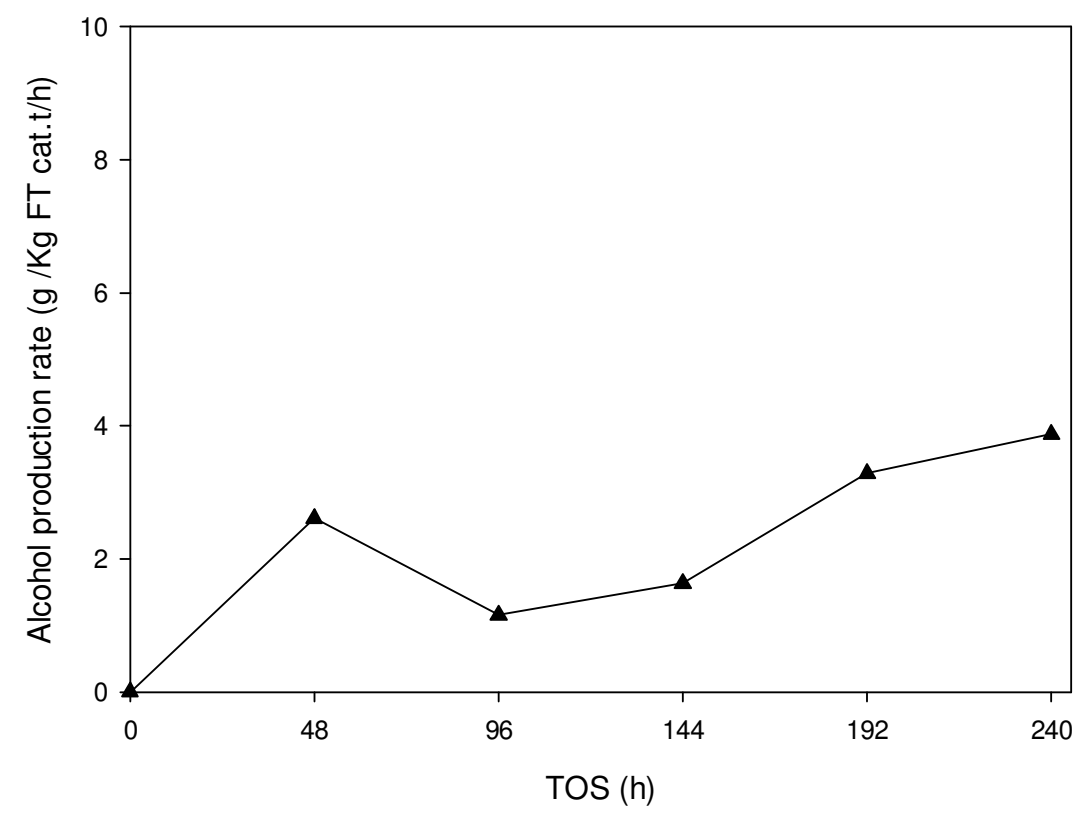

Figure 7.8 Alcohol production rate (g/Kg FT cat./h) with time on stream (TOS, h). Separate-bed catalyst arrangement, $0.5 \mathrm{~g}$ of base catalyst, $0.5 \mathrm{~g}$ of ZSM-5 catalyst, $\mathrm{Si} / \mathrm{Al}$ ratio in ZSM-5 = 50, $\mathrm{H}_{2} / \mathrm{CO}$ ratio = 1 , total feed rate $=100 \mathrm{scc} / \mathrm{min}$, reactor temperature $=300^{\circ} \mathrm{C}$, reactor pressure $=300 \mathrm{psi}$, TOS $=0-240 \mathrm{~h}$.

7.7 Alcohol distribution in the aqueous liquid phase

Table 7.3 shows the amounts of different alcohols for the separate-bed catalyst arrangement for reaction time until $240 \mathrm{~h}$. The total amount for all the alcohols is small. Initially, 1-propanol is the most abundant species. At the largest TOS values, 1-butanol and 1-pentanol are the most abundant. But all the numbers are small and subject to error. 
Table 7.3 Aqueous-phase compounds with time on stream (TOS, h) (separate-bed catalyst arrangement, $0.5 \mathrm{~g}$ of base catalyst, $0.5 \mathrm{~g}$ of ZSM-5 catalyst, $\mathrm{Si} / \mathrm{Al}$ ratio in ZSM-5 $=50, \mathrm{H}_{2} / \mathrm{CO}$ ratio $=1$, total feed rate $=100 \mathrm{scc} / \mathrm{min}$, reactor temperature $=300^{\circ} \mathrm{C}$, reactor pressure $=300 \mathrm{psi}, \mathrm{TOS}=0-240 \mathrm{~h}$ )

\begin{tabular}{|l|c|c|c|c|c|}
\hline TOS $(\mathrm{h})$ & $24-48$ & $48-96$ & $96-144$ & $144-192$ & $192-240$ \\
\hline Compounds & \multicolumn{5}{|c|}{ Weights in aqueous phase (mg) } \\
\hline Methanol & 0 & 3 & 6 & 8 & 2 \\
\hline Ethanol & 1 & 2 & 2 & 16 & 0 \\
\hline 2-Propanol & 5 & 5 & 0 & 2 & 3 \\
\hline 1-Propanol & 12 & 2 & 0 & 0 & 6 \\
\hline 2-Butanol & 7 & 2 & 5 & 4 & 2 \\
\hline 1-Butanol & 0 & 0 & 0 & 0 & 12 \\
\hline 2-Pentanol & 5 & 0 & 5 & 6 & 10 \\
\hline 1-Pentanol & 2 & 0 & 2 & 2 & 12 \\
\hline Sum of Alcohols & 31 & 14 & 20 & 39 & 46 \\
\hline Water & 2269 & 2306 & 2230 & 2081 & 1914 \\
\hline
\end{tabular}

The overall reaction sequence for the separate bed with TOS does not seem change with reaction time except that the coke deposition reduces ability of cracking, oligomerization, isomerization, and conversion of alcohols to hydrocarbons reactions on ZSM-5. The overall reaction sequence is also can be seen in Figure 6.8. 


\section{CHAPTER 8}

\section{CATALYST CHARACTERIZATION AFTER REACTION}

\subsection{EFFECT OF BED ARRANGEMENT ON ENERGY-DISPERSIVE X-RAY SPECTROSCOPY OF SPENT CATALYST}

It was difficult to separate out ZSM-5 particles from quartz chips, and so Energy Dispersive X-Ray Spectroscopy (EDX) of only the spent ZSM-5 with $0.5 \mathrm{~g}$ ZSM-5 was done. Samples from both the separate-bed and mixed-bed arrangements were used.

Figure 8.1 shows EDX analysis of spent ZSM-5 in the separate bed after $72 \mathrm{~h}$. As mentioned for Figure 4.4, $\mathrm{Au}$ and $\mathrm{Pd}$ are the coating metals used for EDX analysis and have nothing to do with our reaction data analysis. As previously discussed for Figure 4.4, the concentration of carbon (in the form of coke) for the unused ZSM-5 sample is zero. Figure 8.1 confirms the presence of carbon in the form of coke. This coke might be due to heavy and waxy hydrocarbon from the base catalyst. Note that the ZSM-5 sample after $72 \mathrm{~h}$ does not contain $\mathrm{Fe}$ and $\mathrm{Cu}$ metals. Hence there is no metal migration from the base catalyst in the separate bed.

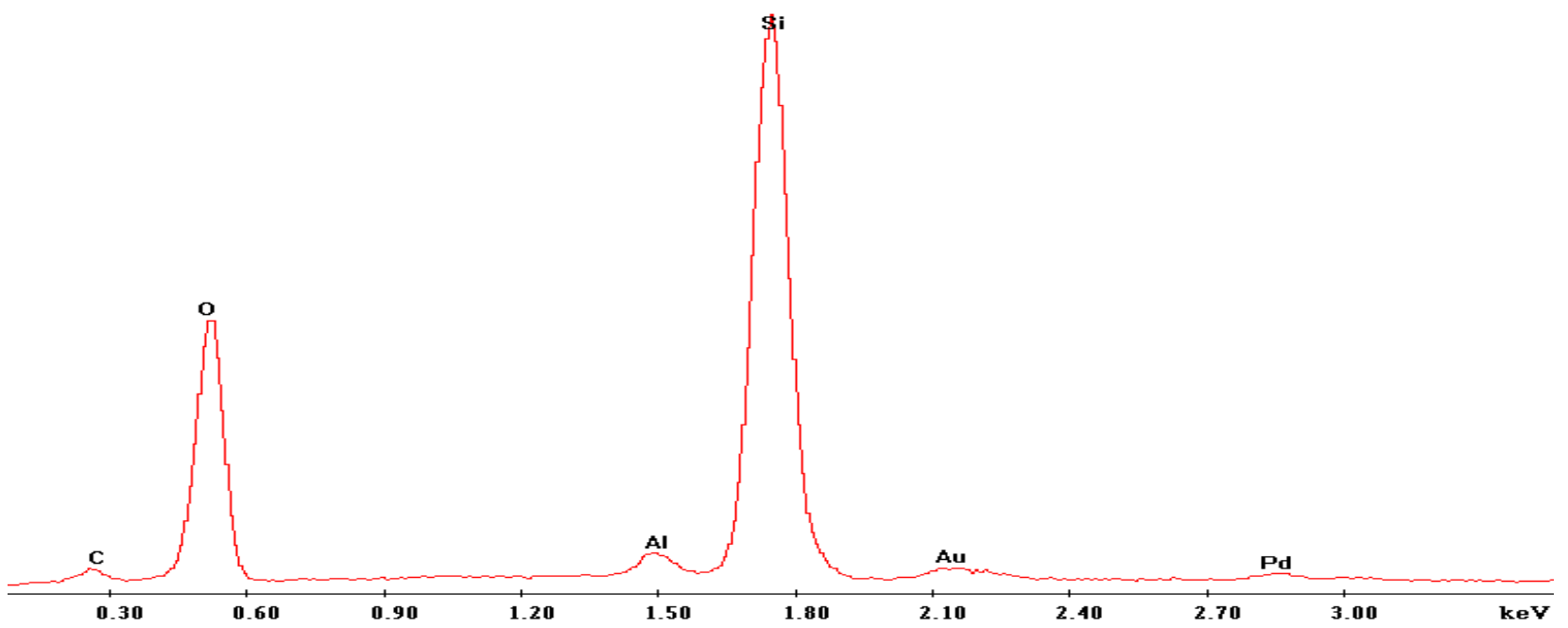

Figure 8.1 EDX elemental analysis of spent ZSM-5 after $72 \mathrm{~h}$ (separate-bed catalyst arrangement, $0.5 \mathrm{~g}$ of base catalyst, $0.5 \mathrm{~g}$ of ZSM-5 catalyst, $\mathrm{Si} / \mathrm{Al}$ ratio in $\mathrm{ZSM}-5=50, \mathrm{H}_{2} / \mathrm{CO}$ ratio $=1$, total feed rate = $100 \mathrm{scc} / \mathrm{min}$, reactor temperature $=300^{\circ} \mathrm{C}$, reactor pressure $=300 \mathrm{psi}$, TOS $=0-72 \mathrm{~h}$ ) 
Figure 8.2 shows EDX analysis of spent ZSM-5 in the mixed bed after 72 h. Figure 8.2 confirms the presence of carbon as well as $\mathrm{Fe}$ and $\mathrm{Cu}$ metals. The higher concentration of carbon relative to Figure 8.1 signifies a greater amount of coke deposition. The presence of metals in ZSM-5 suggests that metal migrates from FT catalyst to ZSM-5. Hence the base catalyst probably shows a declining activity towards reactions in the mixed bed, as discussed in Section 6.2.2.2.

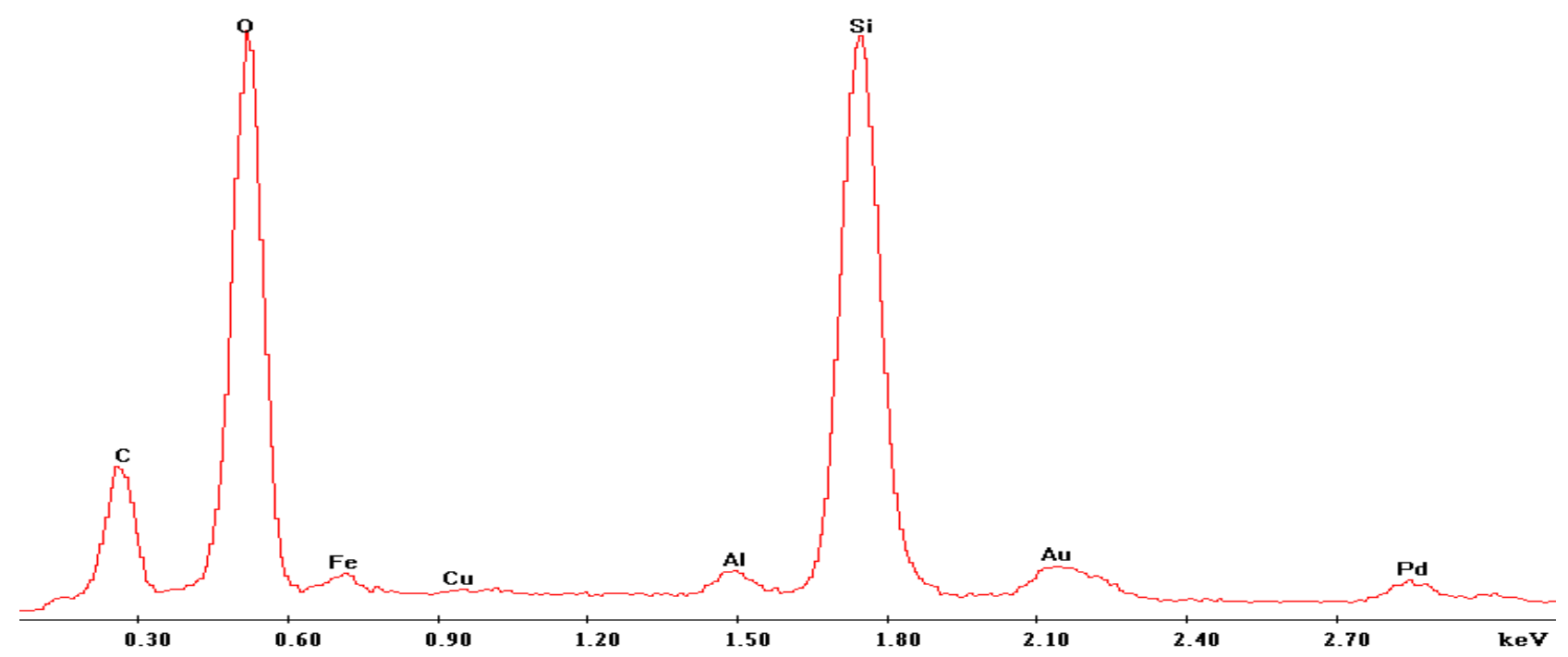

Figure 8.2 EDX elemental analysis of spent ZSM-5 after $72 \mathrm{~h}$ (mixed-bed catalyst arrangement, $0.5 \mathrm{~g}$ of base catalyst, $0.5 \mathrm{~g}$ of ZSM-5 catalyst, $\mathrm{Si} / \mathrm{Al}$ ratio in $\mathrm{ZSM}-5=50, \mathrm{H}_{2} / \mathrm{CO}$ ratio $=1$, total feed rate $=100$ $\mathrm{scc} / \mathrm{min}$, reactor temperature $=300^{\circ} \mathrm{C}$, reactor pressure $=300 \mathrm{psi}$, TOS $=0-72 \mathrm{~h}$ )

\subsection{ENERGY-DISPERSIVE X-RAY SPECTROSCOPY AFTER CATALYST STABILITY TESTS}

Only the ZSM-5 sample in the separate-bed arrangement using $0.5 \mathrm{~g}$ ZSM-5 was used. The EDX analysis of the spent ZSM-5 sample after $240 \mathrm{~h}$ of reaction is shown in Figure 8.3. Figure 8.3 shows the presence of carbon for ZSM-5 sample. As the reaction time increases, coke deposits on the ZSM-5 surface and ZSM-5 activity for isomerization declines. Note that the ZSM-5 sample after $240 \mathrm{~h}$ does not contain $\mathrm{Fe}$ and $\mathrm{Cu}$ metals, and hence there is no metal migration from the base catalyst in the separate bed. 


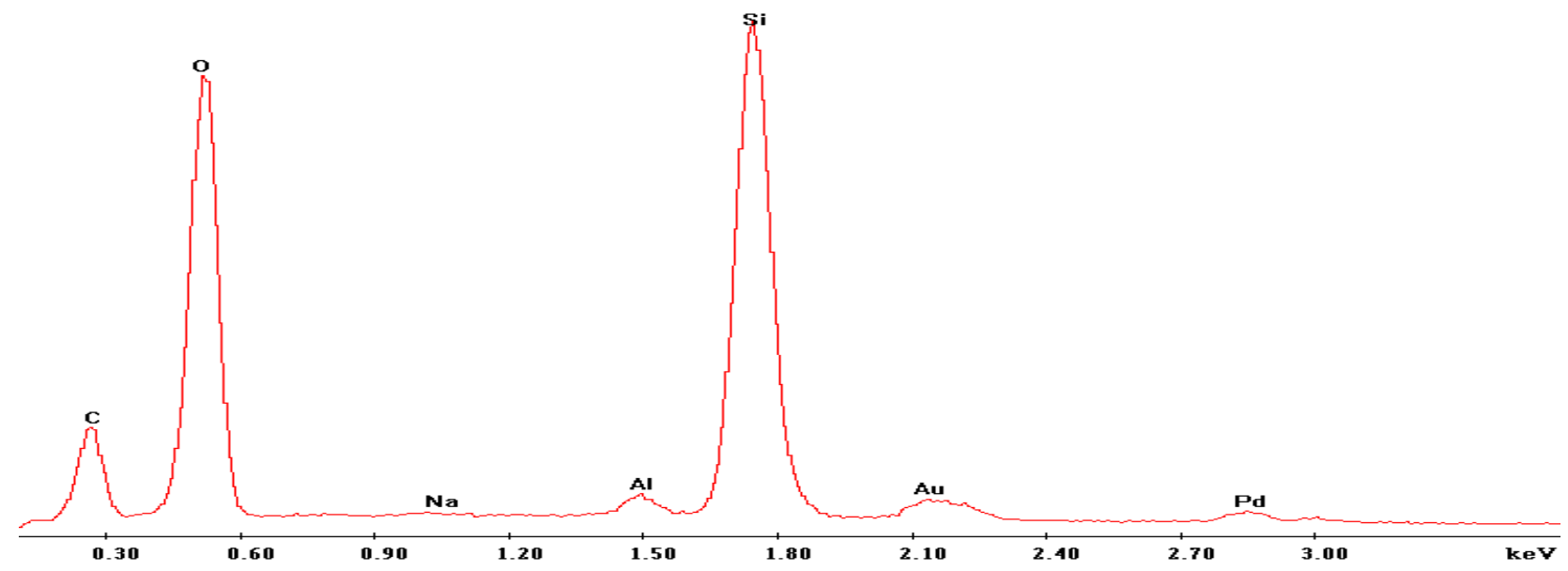

Figure 8.3 EDX elemental analysis of ZSM-5 after $240 \mathrm{~h}$ (separate-bed catalyst arrangement, $0.5 \mathrm{~g}$ of base catalyst, $0.5 \mathrm{~g}$ of ZSM-5 catalyst, $\mathrm{Si} / \mathrm{Al}$ ratio in $\mathrm{ZSM}-5=50, \mathrm{H}_{2} / \mathrm{CO}$ ratio $=1$, total feed rate $=100$ $\mathrm{scc} / \mathrm{min}$, reactor temperature $=300^{\circ} \mathrm{C}$, reactor pressure $=300 \mathrm{psi}, \mathrm{TOS}=0-240 \mathrm{~h}$ )

\subsection{COMPARISON OF SPENT SAMPLES}

EDX samples discussed in Section 8.1 and Section 8.2 are compared here. If we compare Figure 8.1 and Figure 8.2, the concentrations of Si are same, but the concentrations of carbon and oxygen in the mixed bed are significantly higher than in the separate bed. The significant amount of carbon in the mixed bed might be due to the coke deposition on ZSM-5. The higher concentration of oxygen in the mixed bed is probably due to disintegration of the ZSM-5 pentasil unit framework in this configuration, and it might attract more water molecules.

From Figure 8.1 and Figure 8.3, the concentrations of Si are same. The concentrations of carbon and oxygen in the separate bed with $240 \mathrm{~h}$ TOS are significantly higher than in the separate bed with $72 \mathrm{~h}$ TOS. Hence, coke deposition on the ZSM-5 surface increases with time. The higher concentration of oxygen in the ZSM-5 sample of the separate bed with $240 \mathrm{~h}$ TOS is probably due to the increased disintegration of the pentasil unit framework with time.

As seen from Figure 8.1 and Figure 8.2, the ZSM-5 sample of the separate bed after $72 \mathrm{~h}$ TOS does not contain $\mathrm{Fe}$ and $\mathrm{Cu}$ metals, as opposed to the sample from the mixed bed. Hence there is metal migration from the base catalyst in the mixed bed. 


\section{CHAPTER 9}

\section{CONCLUSIONS}

The conclusions that can be drawn on the data obtained are as follows.

1. Addition of ZSM-5 to the iron-based FT catalyst alters the product distribution towards the formation of gasoline-range i-paraffins and aromatics through the cracking of long-chain hydrocarbons and isomerization of n-paraffins, oligomerization of olefins and the formation of aromatics through aromatization reactions occurring on the ZSM-5 active sites.

2. The separate bed shows high activity towards FTS, and gives higher conversions and larger amounts of high-octane gasoline-range hydrocarbons. WGS and FTS rates are constant for increasing ZSM-5 in the separate-bed arrangement, probably because ZSM-5 is inactive towards CO consumption. The mixed-bed arrangement shows lower activity towards FTS and WGS compared to the separate bed. This may be due to lowering of the alkali content of the iron catalyst because of alkali migration to ZSM-5. EDX analysis of the spent ZSM-5 after $72 \mathrm{~h}$ shows metal migration from the base catalyst to ZSM-5 in the mixed bed, but not in the separate bed. Both the separate bed and the mixed bed show conversion of alcohols to hydrocarbons and water. The extent of conversion of alcohols is higher in the separate bed compared to the mixed bed. This is possibly because all alcohols pass over all the ZSM-5 in the separate bed, and so more amounts are reacted.

3. For the separate bed, the amounts of gas n- and i-paraffins increase with an increase in ZSM-5, probably because of enhanced cracking reactions. The amounts of olefins in the gas generally decrease with an increase in ZSM-5, probably because of an increase in the oligomerization reactions on ZSM-5. Liquid hydrocarbon production rates increase for small amounts of ZSM-5 because it converts alcohols formed by the base catalyst to hydrocarbons. Larger amounts of ZSM-5 provide additional cracking sites to give larger amounts of gas species. The production of alcohols decreases to nearly zero in the presence of even small amounts of ZSM-5. Heavierchain hydrocarbon molecules $\left(\mathrm{C}_{13+}\right)$ formed by the base catalyst are effectively cracked and isomerized on the ZSM-5 catalyst surface. The base catalyst shows no selectivity towards aromatic compounds, but addition of ZSM-5 forms alkyl-benzene aromatic compounds $\left(\mathrm{C}_{7-10}\right)$. 
p-xylene yields are highest, probably because of low steric hindrance compared to other aromatic compounds. $0.25 \mathrm{~g}$ ZSM-5 is sufficient to crack long-chain hydrocarbons, but not enough to give high yields of aromatic compounds.

4. For the mixed bed, FTS and WGS rates decrease with the addition of a small amount of ZSM-5, but then increase with an increase in ZSM-5, but these values are lower than those of the base catalyst. The amounts of gas n- and i-paraffins increase with an increase in ZSM-5, probably because of enhanced cracking reactions. The amounts of olefins in the gas generally decrease with a small amount of ZSM-5, probably because of an increase in the oligomerization reactions on ZSM-5. Further addition of ZSM-5 does not seem to contribute much towards oligomerization reactions. Liquid hydrocarbon production rates decrease with an increase in ZSM-5, possibly due to metal migration from the FT catalyst to ZSM-5. The low activity of physical mixtures of the base catalyst and ZSM-5 is also reported by Botes et al. (2004). As in the separate bed, ZSM-5 converts alcohols formed by the base catalyst to hydrocarbons, and larger amounts of ZSM-5 provide additional cracking sites to give larger amounts of gas species. However, for the mixed bed, the maximum amount of ZSM-5 is not sufficient to convert all the alcohols produced by the base catalyst. Heavier-chain hydrocarbon molecules $\left(\mathrm{C}_{13+}\right)$ formed by the base catalyst are effectively cracked and isomerized on the ZSM-5 catalyst surface. As in the separate bed, the base catalyst shows no selectivity towards aromatic compounds, but addition of ZSM-5 forms alkyl-benzene aromatic compounds $\left(\mathrm{C}_{7-10}\right)$. The aromatic yield shows a maximum at $0.5 \mathrm{~g}$ ZSM-5, and higher amounts of ZSM-5 decrease the yield. $0.25 \mathrm{~g}$ ZSM-5 is sufficient to crack long-chain hydrocarbons but not enough to give high yields of aromatic compounds.

5. When comparing both the beds, it is seen that the maximum amount of $\mathrm{i}-\mathrm{C}_{5-12}$ plus aromatics (high-octane gasoline-range hydrocarbons) is formed in the separate bed with $0.5 \mathrm{~g}$ ZSM-5.

6. The separate bed and mixed bed are quantitatively compared for increasing ZSM-5 using a delta terminology. There is no improvement (i.e., delta is negative) in the CO conversions, the WGS and FTS rates, the hydrocarbon production rate, i-paraffins production, and aromatic hydrocarbons production when the base catalyst and ZSM-5 are mixed, compared to separatebed case. The conversion of alcohols to hydrocarbons and water is not complete in the mixed bed, as opposed to the separate bed. 
7. The effect of increasing temperature on the product distribution is studied on the base catalyst and the separate bed. WGS and FTS rates are increased at $300^{\circ} \mathrm{C}$, but higher temperatures do not seem to enhance these rates. The addition of ZSM-5 has a negligible contribution to FTS and WGS rates with increase in temperature. Production of small-chain hydrocarbons $\left(\mathrm{C}_{1-5}\right)$ increases with increase in temperature in the base catalyst because of higher FTS rates. In the gas phase, it is observed that the amounts of species with low carbon number (like $\mathrm{CH}_{4}$ ) increase more than those with higher carbon number (like $n-\mathrm{C}_{5} \mathrm{H}_{12}$ ), probably because of higher activation energy for the formation of species with low carbon number. The increase in the amounts of these species (except gas olefins in general, which undergo oligomerization over ZSM-5) with temperature in the separate bed is because of combinations of reactions like higher FTS rates (due to the base catalyst), cracking (of long-chain molecules), and isomerization reactions. There is a greater increase of overall hydrocarbon liquid production rates between $280-300^{\circ} \mathrm{C}$ in the separate bed, compared to the base catalyst. This is because combinations of the reactions occurring on the both the base catalyst and ZSM-5 (FTS and WGS on the base catalyst, and conversion of alcohols to hydrocarbon, oligomerization, and aromatization occurring on ZSM-5). A further increase in temperature to $320^{\circ} \mathrm{C}$ could decrease the production rate because of increased cracking of long-chain hydrocarbons, and also because production of $\mathrm{C}_{1-4}$ may be dominated by FTS at high temperature. Between $280-300^{\circ} \mathrm{C}$, it is found that the activation energies for cracking and aromatization reactions involving n- and $\mathrm{i}-\mathrm{C}_{5-22}$ over ZSM-5 are greater than those for the formation reactions of these species. Further increase in temperature generally causes these species to crack to small-chain molecules. Aromatic yields are found to decrease, probably due to coke formation at $320^{\circ} \mathrm{C}$. The total amount of alcohols for the base catalyst increases with increase in the temperature, and the trend is consistent with the results of Ma et al. (2007b). The extent of conversion of alcohols to hydrocarbons is not much changed with temperatures, and $280^{\circ} \mathrm{C}$ is sufficient for ZSM-5 to convert all the alcohols formed by the base catalyst.

8. A progressive loss of the activities of the base catalyst and the ZSM-5 occurs with increasing time on stream (TOS). The slow decline in activity of the base catalyst with TOS could be due to a decrease in iron carbide. EDX of spent ZSM-5 confirms that coke has deposited with TOS. A loss of ZSM-5 activity is because of the decline in the active sites due to coke formation. 
Martinez et al. (2005) show similar results. The decline in liquid hydrocarbon production rate is partly due to increase in gas-phase hydrocarbons by a shift in the product spectrum of the FT catalyst and partly due to coke deposition on ZSM-5. The coke deposition of ZSM-5 decreases the formation of aromatic species due to declining aromatization sites. Coke deposition on ZSM5 has a negligible effect on the ability of ZSM-5 to convert alcohols to hydrocarbons and water. 


\section{REFERENCES}

Abramova, A.V., Panin, A.A., Kliger, G.A., "Production of synthetic fuels from alternative petroleum raw material by method of Fischer-Tropsch on zeolite catalysts”, Kulikova, E.A., Slivinsky, E.V., Studies in Surface Science and Catalysis 158, 1709-1716 (2005)

Anderson, K.G., Ekerdt, J.G., "Study of Fischer-Tropsch synthesis over Fe/SiO2: Effect of diethylamine on hydrocarbon and alcohol production”, Journal of Catalysis 95, 602-604 (1985)

Atwood, H. E., Bennett, C., "Kinetics of the Fischer-Tropsch reaction over iron", Industrial and Engineering Chemistry Process Design and Development 18, 163-170 (1979)

Auerbach, S.M., Carrado, K.A., Dutta, P.K., Handbook of Zeolite Science and Technology 16, 591-720, Marcel Dekker Inc, New York (2003)

Bizreh, Y.W., Gates, B.C., "Butane cracking catalyzed by the zeolite H-ZSM-5", Journal of Catalysis $88,240-243$ (1984)

Bjorgen, M., Svelle, S., Joensen, F., Nerlov, J., Kolboe, S., Bonino, F., Palumbo, L., Bordiga, S., Olsbye, U., "Conversion of methanol to hydrocarbons over zeolite H-ZSM-5: on the origin of the olefinic species", Journal of Catalysis 249,195-207 (2007)

Borges, P., Pinto,R., Lemos, M., Lemos, F.,, Vedrine, J., Derouane, E., Ribeiro, F., "Light olefin transformation over ZSM-5 zeolites: A kinetic model for olefin consumption", Applied Catalysis A: General 324, 20-29 (2007)

Botes, F.G., Bohringer, W., "The addition of HZSM-5 to the Fischer-Tropsch process for improved gasoline production”, Applied Catalysis A: General 267, 217-225 (2004)

Botes, F.G., "Water-gas-shift kinetics in the iron-based low-temperature Fischer-Tropsch synthesis", Applied Catalysis A: General 328, 237-242 (2007)

Brien, R.J., Xu, L., Bao, S., Raje, A., Davis, B.H., “Activity, selectivity and attrition characteristics of supported iron Fischer-Tropsch catalysts”, Applied Catalysis A: General 196, 173-178 (2000)

Buchanan, J.S., Adewuyi, Y.G., "Effects of high temperature and high ZSM-5 additive level on FCC olefins yields and gasoline composition”, Applied catalysis A: General 134, 247-262 (1996) 
Bukur, D.B., Sivaraj, C., "Supported iron catalysts for slurry phase Fischer-Tropsch synthesis”, Applied Catalysis A: General 231, 201-214 (2002)

Burriesci, N., Valente, S., Zipelli, C., Bart, J. C. J., "Studies on zeolites in agriculture. Effect on crop growth ofPrunus persica and Vifis vinifera", Zeolites 4, 373-376 (1984)

Bunker, D.B., Nowichi, L., Lang, X., "Fischer-Tropsch synthesis in a stirred tank slurry reactor", Chemical Engineering Science 49, 4615-4625 (1994)

Calsavara, V., Baesso, M., Regina, N., Machado, C., "Transformation of ethanol into hydrocarbons on ZSM-5 zeolites modified with iron in different ways", Fuel 87, 1628-1636 (2008)

Claeys, M., Van Steen, E., "Basic studies”, Studies in Surface Science and Catalysis 152, Chapter 8 (2004)

Collins, J.P., Joep, J.H.M., Freide, F., Nay, B., “A history of Fischer-Tropsch wax upgrading at BPfrom catalyst screening studies to full scale demonstration in Alaska", Journal of Natural Gas Chemistry $15,1-10(2006)$

Craxford, S.R., Rideal, E., "Fischer-Tropsch synthesis of hydrocarbons and some related reactions", Brennstoff-Chem. 20, 263-270 (1939)

Crisfield, M.A., Non-Linear Finite Element Analysis of Solids and Structures 2, John Wiley and Sons, Chichester (1997)

Davis,B.H., "Fischer-Tropsch synthesis: relationship between iron catalyst composition and process variables", Catalysis Today 84, 83-98 (2003)

Davis, B.H., "Fischer-Tropsch Synthesis: Reaction mechanisms for iron catalysts", Catalysis Today $141,25-33$ (2009)

Degnan, T., “Applications of zeolites in petroleum refining”, Topics in Catalysis 13, 349-356 (2000)

Dictor, R.A., Bell, A.T., "Fischer-Tropsch synthesis over reduced and unreduced iron oxide catalysts", Journal of Catalysis 97, 121-136 (1986)

Dry, M.E., “The Fischer-Tropsch process - commercial aspects”, Catalysis Today 6, 183-206 (1990) 
Dry, M.E., “The Fischer-Tropsch process: 1950-2000”, Catalysis Today 71, 227-241 (2002)

Dry, M.E., Anderson, J.R., Boudart, M., Catalysis Science and Technology 1, Chapter 4 (1981)

Dry, M.E., Shingles, T., Boshoff, L.J., "Rate of the Fischer-Tropsch reaction over iron catalysts", Journal of Catalysis 25, 99-104 (1972)

Ellis, J., Korth, W., "Removal of geosmin and methylisoborneol from drinking water by adsorption on ultrastable zeolite-Y”, Water Research 27, 535-539 (1993)

Espinoza, R. L., Steynberg, A. P., Jager, B., Vosloo, A. C., "Low temperature Fischer-Tropsch synthesis from a Sasol perspective”, Applied Catalysis A: General 186, 13-26 (1999)

Farzin, Y.H., "The impact of oil price on additions to US proven reserves", Resource and Energy Economics 23, 271-292 (2001)

Felmer, J.L., Silveston, P.L., Hudgins, R.R., "Steady-state study of the Fischer-Tropsch reaction", Industrial and Engineering Chemistry Product Research and Development 20, 609-615 (1981)

Fejes, P., Forster, H., Kiricsi, I., Seebode, J., "Carbocation formation in zeolites. Uv-Vis-Nir spectroscopic investigations on mordenites", Studies in Surface Science and Catalysis 18, 91-98 (1984)

Fischer, F., Tropsch, H., "The synthesis of petroleum at atmospheric pressures from gasification products of coal", Brennstoff-Chem 7, 97-104 (1926)

Forghani, A.A., Elekaei, H., Rahimpour, M.R., "Enhancement of gasoline production in a novel hydrogen-permselective membrane reactor in Fischer-Tropsch synthesis of GTL technology", International Journal of Hydrogen Energy 34, 3965-3976 (2009)

Garcia, R., Hortiguela, L.G., Blasco, T., Pariente, J.P., "Layering of ferrierite sheets by using large costructure directing agents: Zeolite synthesis using 1-benzyl-1-methylpyrrolidinium and tetraethylammonium", Microporous and Mesoporous Materials 132, 375-383 (2010)

Gawade, P., Mirkelamogly, B., Tan, B., Ozkan, U., "Cr-free Fe-based water-gas-shift catalysts prepared through propylene oxide-assisted sol-gel technique", Journal of Molecular Catalysis A: Chemical 321, $61-70(2010)$ 
Guanjie, M.,Jianwei, L., Dong, Q., Biaohua, C., "Kinetics of coke formation on a Fe-ZSM-5 zeolite catalyst in the one-step oxidation of benzene to phenol with $\mathrm{N}_{2} \mathrm{O}$ ”, Chinese Journal of Catalysis 31, $547-551(2010)$

Hammer, H., Joisten, M., Lungen, S., Winkler, D., "The use of different zeolites (mordenite, erionite, ZSM-11, ZSM-12, L, $\Omega$ and $\beta$ ) in combination with an iron-based FT catalyst” Int. J. Energy Res. 18, 223-231 (1994)

Herranz, T., Rojas, S., Perez-Alonso, F.J., Ojeda, M.,Terreros, P., Luis, J., Fierro, G., “Genesis of iron carbides and their role in the synthesis of hydrocarbons from synthesis gas", Journal of Catalysis 243, 199-211( 2006)

Huff, G. A., Satterfield, C. N., "Intrinsic kinetics of Fischer-Tropsch synthesis on reduced fusedmagnetite catalyst", Industrial and Engineering Chemistry Process Design and Development 23, 696705 (1984)

Huo, Q., Dou, T., Zhao, Z., Pan, H., "Synthesis and application of a novel mesoporous zeolite L in the catalyst for the HDS of FCC gasoline”, Applied Catalysis A: General 381, 101-108 (2010)

John, W., "Nonlinear finite element analysis of solids and structures", European Journal of Mechanics A/Solids 17, 1041-1042(1998)

Jung, H.J., Vannice, M.A., Mulay, L.N., Stanfield, R.M., Delgass, W.N., "The characterization of carbon-supported iron catalysts: Chemisorption, magnetization, and Mossbauer spectroscopy", Journal of Catalysis 76, 208-224 (1982)

Kip, B.J., Smeets, P.A.T., Grondelle, J.V., Prins, R., "Hydrogenation of carbon monoxide over vanadium oxide-promoted rhodium catalysts", Applied Catalysis 33, 181-208 (1987)

Knifton, J., Sanderson, J., “Olefin oligomerization via zeolite catalysis”, Catalysis Letters 28, 223-230 (1994)

Knottenbelt, C., "Mossgas "gas-to-liquid" diesel fuels - an environmentally friendly option", Catalysis Today 71, 437-445 (2002) 
Kugler, E.L., Feng, L., Li, X., Dadyburjor, D.B., "Effect of Ni on K-doped molybdenum-on-carbon catalysts: Temperature-programmed reduction and reactivity to higher-alcohol formation", Studies in Surface Science and Catalysis 130, 299-304 (2000)

Li, S., Li, A., Krishnamoorthy, S., Iglesia, E., Effects of $\mathrm{Zn}, \mathrm{Cu}$, and $\mathrm{K}$ promoters on the structure and on the reduction, carburization, and catalytic behavior of iron-based Fischer-Tropsch synthesis", Catalysts Catalysis Letters 77,197-205 (2001)

Li, S., Krisyhnamoorthy, S., Li, A., Meitzner, G.D., Iglesia, E., "Promoted iron-based catalysts for the Fischer-Tropsch synthesis: design, synthesis, site densities, and catalytic properties", Journal of Catalysis 206, 202-217 (2002)

Li, T., Yang, Y., Zhang, C., Tao, Z., Wan, H., An, X., Xiang, H., Li, Y., "Effect of manganese incorporation manner on an iron-based catalyst for Fischer-Tropsch Synthesis", Journal of Natural Gas Chemistry 16, 244-251 (2007)

Li, X., Li, C., Zhang, J., Yang, C., Shan, H., "Effects of temperature and catalyst to oil weight ratio on the catalytic conversion of heavy oil to propylene using ZSM-5 and USY catalysts", Journal of Natural Gas Chemistry 16, 92-99 (2007)

Liu, F., Xu, S., Cao, L., Chi, Y., Zhang, T., Xue, D., “A comparison of $\mathrm{NiMo} \mathrm{Al}_{2} \mathrm{O}_{3}$ catalysts prepared by impregnation and coprecipitation methods for hydrodesulfurization of dibenzothiophene", Journal of Physical Chemistry C 111, 7396-7402 (2007)

Lohitharn, N., Goodwin, J.G., "Effect of K promotion of Fe and FeMn Fischer-Tropsch synthesis catalysts: analysis at the site level using SSITKA", Journal of Catalysis 260, 7-16 (2008)

Luo, M., Hamdeh, H., Davis, B.H., "Fischer-Tropsch synthesis: catalyst activation of low alpha iron catalyst”, Catalysis Today 140, 127-134 (2009)

Ma, W.P., Ding, Y.J., Lin, L.W., "Fischer-Tropsch synthesis over activated-carbon-supported cobalt catalysts: effect of Co loading and promoters on catalyst performance", Industrial Engineering and Chemistry Research 43, 2391-2398 (2004) 
Ma, W., Kugler, E.L., Dadyburjor, D.B., "Effect of Mo loading and support type on hydrocarbons and oxygenates produced over Fe-Mo-Cu-K catalysts supported on activated carbons", Studies in Surface Science and Catalysis 163, 125-140 (2007a)

Ma W., Kugler E.L., Dadyburjor D.B., "Potassium effects on activated-carbon-supported iron catalysts for Fischer-Tropsch synthesis”, Energy \& Fuels 21, 1832-1842 (2007b)

Ma, W., Kugler, E.L., Wright, J., Dadyburjor, D.B., "Mo-Fe catalysts supported on activated carbon for synthesis of liquid fuels by the Fischer-Tropsch process: effect of Mo addition on reducibility, activity, and hydrocarbon selectivity", Energy \& Fuels 20, 2299-2307 (2006)

Mahay, A., Simard, F., Lemay, G., Adnot, A., Kaliaguine, S., "Deoxygenation of methanol with carbon monoxide over ZSM-5-supported Fe, Ru, Pd and Rh Catalysts”, Applied catalysis 33, 55-71 (1987)

Maitlis, P.M., “A new view of the Fischer-Tropsch polymerization reaction”, Pure Appl.Chem. 61, 1747-1754 (1989)

Martinez, A., Lopez, C., "The influence of ZSM-5 zeolite composition and crystal size on the in situ conversion of Fischer-Tropsch products over hybrid catalysts”, Applied Catalysis A: General 294, 251$259(2005)$

Martinez, A., Rollan, J., Arribas, M.A., Cerqueira, H.S., Costa, A.F., Aguiar, E.F.S., “A detailed study of the activity and deactivation of zeolites in hybrid $\mathrm{Co} / \mathrm{SiO} 2-z e o l i t e$ Fischer-Tropsch catalysts", Journal of Catalysis 249, 162-173(2007)

Motjope, T. R., Dlamini, H. T., Hearne, G. R., Coville, N. J., “Application of in situ mossbauer spectroscopy to investigate the effect of precipitating agents on precipitated iron Fischer-Tropsch catalysts", Catalysis Today 71, 335-341 (2002)

Nettelhoff, H., Kokuun, R.., Ledakowicz, S. , Deckwer, W.D., "Studies on the kinetics of iron catalysts in Fischer-Tropsch synthesis in slurry phase", German Chemical Engineering 8, 177-185 (1985)

Nikolaoua, N., Papadopoulosa, C.E., Gagliasb, I.A., Pitarakisc, K.G., "A new non-linear calculation method of isomerisation gasoline research octane number based on gas chromatographic data", Fuel 83, $517-523(2004)$ 
Owen, N. A., Inderwildi, O.R., King, D.A., "The status of conventional world oil reserves-hype or cause for concern?", Energy Policy 38, 4743-4749 (2010)

Park, J.Y., Lee, Y. J., Jun, K.W., Bae, J.W., Vishwanadham, N., Kim, Y.H., "Direct conversion of synthesis gas to light olefins using dual bed reactor", Journal of Industrial and Engineering Chemistry $15,847-853$ (2009)

Pichler, H., Frankenburg, W., Rideal, E., Komarewsky, V., "Twenty-five years of synthesis of gasoline by catalytic conversion of carbon monoxide and hydrogen", Advances in Catalysis 4, 271-341 (1952)

Pour, A.N., Zamani, Y., Tavasoli, A., Shahri, S.K., Taheri, S.A., "Study on products distribution of iron and iron-zeolite catalysts in Fischer-Tropsch synthesis”, Fuels 87, 2004-2012 (2008)

Riedel, T., Claeys, M., Schulz, H., Schaub, G., Nam, S., Jun, K., Choi, M., Kishan, G., Lee, K., "Comparative study of Fischer-Tropsch synthesis with $\mathrm{H}_{2} / \mathrm{CO}$ and $\mathrm{H}_{2} / \mathrm{CO}_{2}$ syngas using Fe- and Cobased catalysts", Applied Catalysis A: General 186, 201-213 (1999)

Riedel, T., Schulz, H., Schaub, G., Jun, K., Hwang, J., Lee, K., "Fischer-Tropsch on iron with $\mathrm{H}_{2} / \mathrm{CO}$ and $\mathrm{H}_{2} / \mathrm{CO}_{2}$ as synthesis gases: The episodes of formation of the Fischer-Tropsch regime and construction of the catalyst: Fischer-Tropsch catalysis-science and practice", Topics in Catalysis 26, 4154 (2003)

Rigby, M., Frash, M. V., "Ab initio calculations on the mechanisms of hydrocarbon conversion in zeolites: Skeletal isomerisation and olefin chemisorption", Journal of Molecular Catalysis A: Chemical 126, 61-72 (1997)

Shan, X., L., Guan, N., J., Zeng, X., Xiang, S., H., "In-situ synthesis of ZSM-5 with different Si/Al ratios on honeycomb-shaped cordierite and their behavior on NO decomposition", Chinese Chemical Letters 10, 885-888 (1999)

Schulz, H., "Short history and present trends of Fischer-Tropsch synthesis", Applied Catalysis A 186, 3-12 (1999)

Schulz, H., "Major and minor reactions in Fischer-Tropsch synthesis on cobalt", Catalysts Topics in Catalysis 26, 73-85 (2003) 
Schulz, H., Achtsnit, H., Quimica, “Olefin reactions during the Fischer-Tropsch synthesis", Revista Portuguesa de Quimica 19, 317-322 (1977)

Schulz, H., Beck, K., Erich, E., Proc. 9th Int. Congr. On Catalyis, the Chemical Institute of Canada, Ottawa 2,829 (1988)

Schulz, H., Erich, E., Gorre, H., Steen, E., "Regularities of selectivity as a key for discriminating FTsurface reactions and formation of the dynamic system", Catalysis Letter 7, 157-167 (1990)

Schulz, H., Claeys, M., "Reactions of $\alpha$-olefins of different chain length added during Fischer-Tropsch synthesis on a cobalt catalyst in a slurry reactor", Applied Catalysis A: General 186, 71-90 (1999)

Schultz, J.F., Karn, F.S., Anderson, R.B., U.S. Bureau of Mines Report 6974 (1967)

Schulz, H., Niederberger, H.L., Kneip, M., Weil, F., "Synthesis gas conversion on Fischer-Tropsch iron/HZSM-5 composite catalysts”, Studies in Surface Science Catalysis 61, 313-323 (1991)

Shirazi, L., Jamshidi, E., Ghasemi, M. R., "The effect of Si/Al ratio of ZSM-5 zeolite on its morphology, acidity and crystal size”, Crystal Research and Technology 43, 1300-1306 (2008)

Smit, E.D., Wechhuysen, B.M., "The renaissance of iron-based Fischer-Tropsch synthesis: on the multifaceted catalyst deactivation behavior", Chemical Society Reviews 37, 2758-2781 (2008)

Stenger, H.G., Askonas, C.F., "Thermodynamic product distributions for the Fischer-Tropsch synthesis", Industrial and Engineering Chemistry Fundamentals 25, 410-413 (1986)

Steynberg, A., Espinoza, R., Jager, B., Vosloo, A., "High temperature Fischer-Tropsch synthesis in commercial practice”, Applied Catalysis A: General 186, 41-54 (1999)

Stocker, M., "Gas phase catalysis by zeolites”, Microporous and Mesoporous Materials 82, 257-292 (2005)

Storch, H.H., Golumbic, N., Anderson, R.B, The Fischer-Tropsch and Related Synthesis, John Wiley and Sons, New York (1951)

Teng, B., Chang, J., Yang, J., Wang, G., Zhang, C., Xu, Y., Xiang, H., Li, Y., "Water-gas-shift reaction kinetics in Fischer-Tropsch synthesis over an industrial Fe-Mn catalyst”, Fuel 84, 917-926 (2005) 
Usui, K., Kidena, K., Murata, S., Nomura, M., Trisunaryanti, W., "Catalytic hydrocracking of petroleum-derived asphaltenes by transition metal-loaded zeolite catalysts”, Fuel, 83, 1899-1906 (2004)

Vosloo, A.C., "Fischer-Tropsch: a futuristic view”, Fuel Processing Technology 71, 149-155 (2001)

Vytnova, L. A., Bogolepova, E. I., Shuikin, A. N., Kurkin, V. I., Marchevskaya, E. V., Kliger, G. A., "Influence of zeolite type on activity of Fischer-Tropsch iron catalysts", Neftekhimiya 46, 324-331, (2006)

Waldner, C. L., Ribble, C. S., Janzen, E. D., J. R., Campbell, “Associations between oil- and gas-well Sites, processing facilities, flaring, and beef cattle reproduction and calf mortality in western Canada", Preventive Veterinary Medicine 50, 1-17 (2001)

Wan, H., Wu B., Zhang, C., Xiang, H., Li Y., "Promotional effects of Cu and K on precipitated ironbased catalysts for Fischer-Tropsch synthesis”, Journal of Molecular Catalysis A: Chemical 283, 33-42 (2008)

Wan, H.J., Wu, B.S., Zhang, C.H., Xiang, H.W., Li, Y.W., Xu, B.F., Yi, F., "Study on Fe$\mathrm{Al}_{2} \mathrm{O}_{3}$ interaction over precipitated iron catalyst for Fischer-Tropsch synthesis", Catalysis Communications 8, 1538-1545 (2007)

Wang, Y., Ma W., Lu, Y., Yang, J., Xu, Y., Xiang, H., Li, Y., Zhao, Y., Zhang, B., "Kinetics modelling of Fischer-Tropsch synthesis over an industrial Fe-Cu-K catalyst”, Fuel 82,195-213 (2003)

Wei, J., “Adsorption and cracking of n-alkanes over ZSM-5: negative activation energy of reaction”, Chemical Engineering Science 51, 2995 -2999 (1996)

Wielers, A. F. H., Kock, A. J. H. M., Hop, C. E. C. A., Geus, J. W., Van Der Kraan, A. M. , “The reduction behavior of silica-supported and alumina-supported iron catalysts: A Mössbauer and infrared spectroscopic study", Journal of Catalysis 117, 1-18 (1989)

Williams, B. A., Babitz, S. M., Miller, J. T., Snurr, R. Q., Kung, H. H., “The roles of acid strength and pore diffusion in the enhanced cracking activity of steamed Y zeolites", Applied Catalysis A: General 177, 161-175 (1999) 
Yang, Y., Xiang, H.W., Xu, Y.Y., Bai, L., Li, Y.W., "Effect of potassium promoter on precipitated ironmanganese catalyst for Fischer-Tropsch synthesis”, Applied Catalysis A: General, 266, 181-194 (2004)

Yang, Y., Xiang, H., Tian, L., Wang, H., Zhang, C., Tao, Z., Xu, Y., Zhong, B., Li, Y., "Structure and Fischer-Tropsch performance of iron-manganese catalyst incorporated with $\mathrm{SiO}_{2}$ ”, Applied Catalysis A: General 284, 105-122 (2005)

Zhang, L., Liu, H., Li, X., Xie,S., Wang, Y., Xin, W., Liu,S., Xu,L., “Study of an iron-manganese Fischer-Tropsch synthesis catalyst promoted with copper”, Fuel Processing Technology 91 , 449-455 (2010)

Zhang, C.H., Yang, Y., Teng, B.T., Li, T.Z., Zheng, H.Y., Xiang, H.W., Li, Y.W., "Study of an ironmanganese Fischer-Tropsch synthesis catalyst promoted with copper", Journal of Catalysis 237, 405415 (2006)

Zhao, R., Goodwin, J.G., Jothimurugesan, K., Gangwal, S.K., Spivey, J.J., "Spray-dried iron FischerTropsch catalysts. 1. Effect of structure on the attrition resistance of the catalysts in the calcined state", Industrial Engineering Chemistry 40, 1065-1075 (2001)

Zhao, J., Guo, W., Liu, G., Zhang, X., Wang, L., "Cracking of n-dodecane during supercritical state on HZSM-5 membranes”, Fuel Processing Technology 91, 1090-1097 (2010)

Zimmerman W.H., Bukur D.B., "Reaction Kinetics over iron catalysts used for the Fischer Tropsch synthesis", Journal of Chemical Engineering 68, 292-301 (1990) 


\section{APPENDICES}




\section{APPENDIX A}

\section{CHROMATOGRAPH OPERATING CONDITIONS FOR GAS AND LIQUID PRODUCTS}

A.1 Chromatograph operating conditions for gas products

Gas chromatograph model: The PerkinElmer GC

Detector used: Thermal-conductivity detector (TCD) and Flame-ionization detector (FID)

Detector temperature TCD: $200{ }^{\circ} \mathrm{C}$, Detector temperature FID: $250{ }^{\circ} \mathrm{C}$

Carrier gas TCD: $\mathrm{He}$, Carrier gas FID: $\mathrm{N}_{2}$

Carrier gas inlet pressure: He: 33 psig, $\quad \mathrm{N}_{2}$ : $14.1 \mathrm{psig}$

Carrier gas flow rate He: $40 \mathrm{ml} / \mathrm{min}$

Carrier gas flow rate $\mathrm{N}_{2}: \quad 30 \mathrm{ml} / \mathrm{min}$

$\mathrm{H}_{2}$ flow: $45 \mathrm{ml} / \mathrm{min}$

Air flow: $450 \mathrm{ml} / \mathrm{min}$

Columns used:

$18 "$ RGAP, $1 / 8 " \mathrm{Sf}$

17' RGA20, 1/8" Sf

7' RGAP 1/8" Sf

7" RGA, 1/8" Sf

7' HayeSep N 1/8" Sf

9' Molecular Sieve 13x 1/8" Sf

9' Molecular Sieve, 1/8" Sf

4' HayeSep T, 1/8" Sf

Oven temperature: $60^{\circ} \mathrm{C}$

Period of analysis: $15 \mathrm{~min}$ 
A.2 Chromatograph operating conditions for liquid products

Varian $3400 \mathrm{GC}$ is used for liquid analysis. GC is equipped with auto injection setup which is operated by 30 Psig air.

Column used for hydrocarbon liquid analysis: J and W scientific DB 1 capillary column, length: $30 \mathrm{~m}$, film thickness: $1.5 \mu \mathrm{m}$.

Column used for aqueous liquid analysis: Restek packed column, TX-TA 80/100, length: $6 \mathrm{ft}$, ID: 2.00 mm, OD: 1/8 in, SILCO VAR 3400 PRECOND OC INV: 2 in, OUTV: 1.5 in

Table A.1 GC operating conditions for liquid analysis

\begin{tabular}{|c|c|c|}
\hline Conditions & $\begin{array}{l}\text { Hydrocarbon GC operating } \\
\text { conditions (FID A) }\end{array}$ & $\begin{array}{l}\text { Aqueous GC operating } \\
\text { conditions (FID B) }\end{array}$ \\
\hline Carrier gas used & Nitrogen & Nitrogen \\
\hline Carrier gas inlet pressure (psig) & 6 & 82 \\
\hline Period of analysis (min) & 48 & 28 \\
\hline \multicolumn{3}{|l|}{ Column } \\
\hline Initial column Temperature $\left({ }^{\circ} \mathrm{C}\right)$ & 50 & 50 \\
\hline Final column Temperature $\left({ }^{\circ} \mathrm{C}\right)$ & 290 & 300 \\
\hline Column initial hold time (min) & 0 & 0 \\
\hline Column temperature rate $\left({ }^{\circ} \mathrm{C} / \mathrm{min}\right)$ & 5 & 10 \\
\hline \multicolumn{3}{|l|}{ Injector } \\
\hline Initial injection Temperature $\left({ }^{\circ} \mathrm{C}\right)$ & 200 & 200 \\
\hline Final injection Temperature $\left({ }^{\circ} \mathrm{C}\right)$ & 250 & 250 \\
\hline Injection hold time (min) & 1 & 0 \\
\hline Injection temperature rate $\left({ }^{\circ} \mathrm{C} / \mathrm{min}\right)$ & 10 & 10 \\
\hline \multicolumn{3}{|l|}{ Detector } \\
\hline Detector temperature $\left({ }^{\circ} \mathrm{C}\right)$ & 300 & 300 \\
\hline
\end{tabular}




\section{APPENDIX B}

\section{CHROMATOGRAPH CALIBRATION PROCEDURE FOR GAS AND LIQUID PRODUCTS}

B.1 Chromatograph calibration procedure for gas products

\section{B.1.1 TCD calibration of gases}

A slope of different compounds is calculated by plotting moles of compounds in 1 c.c. loop verses GC area. Relative response factor (rRF) is calculated based on the Equation (B.1). In Equation (B.1), slope ${ }_{X}$ is refers to slope of unknown component listed in Table B.1. Internal standard as helium gas is used for Helium, Hydrogen, and carbon dioxide gas compounds. Internal standard as argon gas is used for argon, nitrogen, methane, and carbon monoxide gas compounds. In Equation (B.1), slope He, Ar refers to slopes of Helium or Argon depending on the internal standard definition for a particular gas component. Slopes and rRF values for TCD gases are given in Table B.1.

Definition of relative response factor with TCD: peak area of component: A; concentration: C

relative Response Factor of gas component $X,(r R F)_{X}=\left(\frac{\frac{A_{X}}{C_{X}}}{\frac{A_{H e, A r}}{C_{H e, A r}}}\right)=\frac{\text { slope }_{X}}{\text { slope }_{\mathrm{He}, A r}}$

Table B.1 Slope and rRF of TCD gas compounds

\begin{tabular}{|l|c|c|}
\hline Component & Slopes (Area/moles in 1 c.c.) & rRF \\
\hline $\mathrm{H}_{2}$ & $3.18353 \mathrm{E}+11$ & 1.222068 \\
\hline $\mathrm{CO}$ & $3.43655 \mathrm{E}+11$ & 0.950770 \\
\hline $\mathrm{He}$ & $2.60503 \mathrm{E}+11$ & 1.000000 \\
\hline $\mathrm{Ar}$ & $3.61449 \mathrm{E}+11$ & 1.000000 \\
\hline $\mathrm{N} 2$ & $3.21642 \mathrm{E}+11$ & 0.889867 \\
\hline $\mathrm{CO}_{2}$ & $4.08774 \mathrm{E}+11$ & 1.569168 \\
\hline $\mathrm{CH}_{4}$ & $2.77742 \mathrm{E}+11$ & 0.768411 \\
\hline
\end{tabular}

\section{B.1.2 FID calibration of gases}

A slope of different compounds is calculated by plotting moles of compounds in 1 c.c. loop verses GC area. Relative response factor is calculated based on the Equation (B.2).In Equation (B.2), slope $_{X}$ is refers to slope of unknown component listed in Table B.2. In Equation (B.2), slope CH4 $_{4}$ refers to slopes of methane gas. Slopes and rRF values for FID gases are given in Table B.2. 
Definition of relative response factor with FID: peak area of component: A; concentration: C

relative Response Factor of gas component $X,(r R F)_{X}=\left(\frac{\frac{A_{X}}{C_{C H 4}}}{\frac{A_{C H 4}}{C_{X}}}\right)=\frac{\text { slope }_{X}}{\text { slope }_{C H 4}}$

Table B.2 Slope and rRF of FID gas compounds

\begin{tabular}{|l|c|c|}
\hline Compounds & Slopes & rRF \\
\hline $\mathrm{CH}_{4}$ & $1.68 \mathrm{E}+07$ & 1.000000 \\
\hline $\mathrm{C}_{2} \mathrm{H}_{6}$ & $3.17 \mathrm{E}+07$ & 1.886435 \\
\hline $\mathrm{C}_{2} \mathrm{H}_{4}$ & $3.17 \mathrm{E}+07$ & 1.886435 \\
\hline $\mathrm{C}_{3} \mathrm{H}_{8}$ & $4.71 \mathrm{E}+07$ & 2.805648 \\
\hline $\mathrm{C}_{3} \mathrm{H}_{6}$ & $4.55 \mathrm{E}+07$ & 2.7124589 \\
\hline $\mathrm{C}_{3} \mathrm{H}_{4}$ & $3.62 \mathrm{E}+07$ & 2.1574558 \\
\hline $\mathrm{i}-\mathrm{C}_{4} \mathrm{H}_{10}$ & $6.09 \mathrm{E}+07$ & 3.6304886 \\
\hline $\mathrm{n}-\mathrm{C}_{4} \mathrm{H}_{10}$ & $6.39 \mathrm{E}+07$ & 3.8101614 \\
\hline $1-\mathrm{C}_{4} \mathrm{H}_{8}$ & $6.02 \mathrm{E}+07$ & 3.5872479 \\
\hline $\mathrm{i}-\mathrm{C}_{4} \mathrm{H}_{8}$ & $2.02 \mathrm{E}+07$ & 1.2040752 \\
\hline $\mathrm{t}-\mathrm{C}_{4} \mathrm{H}_{8}$ & $5.72 \mathrm{E}+07$ & 3.4097923 \\
\hline $\mathrm{c}-\mathrm{C}_{4} \mathrm{H}_{8}$ & $6.42 \mathrm{E}+07$ & 3.8251059 \\
\hline $1,3 \mathrm{C}_{4} \mathrm{H}_{6}$ & $5.97 \mathrm{E}+07$ & 3.5566422 \\
\hline $\mathrm{i}-\mathrm{C}_{5} \mathrm{H}_{12}$ & $6.71 \mathrm{E}+07$ & 3.9991299 \\
\hline $\mathrm{n}-\mathrm{C}_{5} \mathrm{H}_{12}$ & $4.97 \mathrm{E}+07$ & 2.9605052 \\
\hline $\mathrm{C}_{5+}(\mathrm{Gas})$ & $9.96 \mathrm{E}+07$ & 5.9329234 \\
\hline
\end{tabular}

B.2 Chromatograph calibration procedure for liquid products

B.2.1 Chromatograph calibration procedure for organic liquid (oil) phase products

$\mathrm{CS}_{2}$ is used as the solvent for oil product sample preparation. The straight-chain paraffins are identified by comparing retention times to standard D-2887 obtained from Restek. Branched paraffins are assumed to elute before the straight-chain paraffin with the same carbon number. A few other large peaks eluting between known paraffins were identified as toluene, $p$-xylene, n-propyl benzene and nbutyl benzene by using standard D-3710 obtained from Restek. However, this was the only aromatic standard we could obtain from Restek. Since the product is expected to contain other di-methyl benzenes and trimethyl benzenes, these were not identified and would have been counted as i-paraffins. Also the response factors for all the liquid hydrocarbons assumed to be linear and constant. 
B.2.2 Chromatograph calculation procedure for aqueous phase products

Cyclohexanol as an internal standard and deionized-water as solvent are used for aqueous phase sample preparation. Retention times of alcohols were identified using Accustandard standard sample (PS-111 C Alcohols $\mathrm{C}_{1}-\mathrm{C}_{5}$ kit). Then each standard sample, for example methanol, is added to preknown quantity of cyclohexanol and water. Then this prepared sample is injected in the GC and areas are noted. Table B.3 represents areas and weights of standard samples. This table is useful in quantification of aqueous compounds. Quantification of aqueous compounds is described in section D.

Table B.3 Areas and weights of standard alcohol samples

\begin{tabular}{|l|c|c|c|c|}
\hline Standard $(\mathrm{x})$ & $\mathrm{A}_{\mathrm{x}, \text { standard }}$ & $\mathrm{A}_{\text {cyclohexanol, standard }}$ & $\begin{array}{c}\mathrm{Wt}_{\text {cyclohexanol, }} \\
\text { standard }(\mu \mathrm{g})\end{array}$ & $\mathrm{Wt}_{\mathrm{x}, \text { standard }}(\mu \mathrm{g})$ \\
\hline Methanol & 84286 & 19451 & 22.2 & 383.7 \\
\hline Ethanol & 82843 & 16693 & 18.3 & 225.6 \\
\hline 2-Propanol & 12534417 & 290032 & 5.8 & 816.1 \\
\hline 1-Propanol & 78959 & 16539 & 19.5 & 305.1 \\
\hline 2-Butanol & 31995228 & 1832669 & 34.2 & 796.5 \\
\hline 1-Butanol & 82482 & 18344 & 18.1 & 391.4 \\
\hline 2-Pentanol & 41499452 & 135882 & 21 & 783.9 \\
\hline 1-Pentanol & 77869 & 19888 & 18.8 & 388.3 \\
\hline
\end{tabular}




\section{APPENDIX C}

\section{MASS FLOW CONTROLLER CALIBRATION}

The experimental setup, as shown Figure 3.1, has three lines for feed gas and each being controlled individually by a Brook's mass-flow controller (MFC). Calibration procedure of these MFC's is described below. Calibration for all these MFC's (hydrogen, helium and syngas mixture gases) follows the similar procedure. The gas flow rate is preset to minimum set value on the MFC and the system is allowed to attain steady state. The volumetric flow rate at the outlet is measured using bubble flow meter. Steady state of the system is assumed when constant outlet volumetric flow rates were achieved. The room temperature and pressure is also noted. The readings are then repeated similarly for other MFC set values and calibration curve is plotted. The calculations are given below.

Measured volumetric flow rate of gas $=\mathrm{V}_{1} \mathrm{cc} / \mathrm{min}$

Measured ambient temperature $=\mathrm{T}_{1} \mathrm{~K}$

Measured ambient pressure $=\mathrm{P}_{1} \mathrm{~mm} \mathrm{Hg}$

Assuming ideal gas law holds for all the gas species. According to ideal gas law,

$V_{2}=\left(\frac{P_{1}}{P_{2}}\right) \times\left(\frac{T_{2}}{T_{1}}\right) \times V_{1}(c c / m i n)$

Where,

$$
\begin{aligned}
& \mathrm{V}_{2}=\text { volume of the species in the loop at STP conditions } \\
& \mathrm{P}_{2}=\text { pressure at STP conditions, } 760 \mathrm{~mm} \mathrm{Hg} \\
& \mathrm{T}_{2}=\text { temperature at STP conditions, } 273 \mathrm{~K}
\end{aligned}
$$




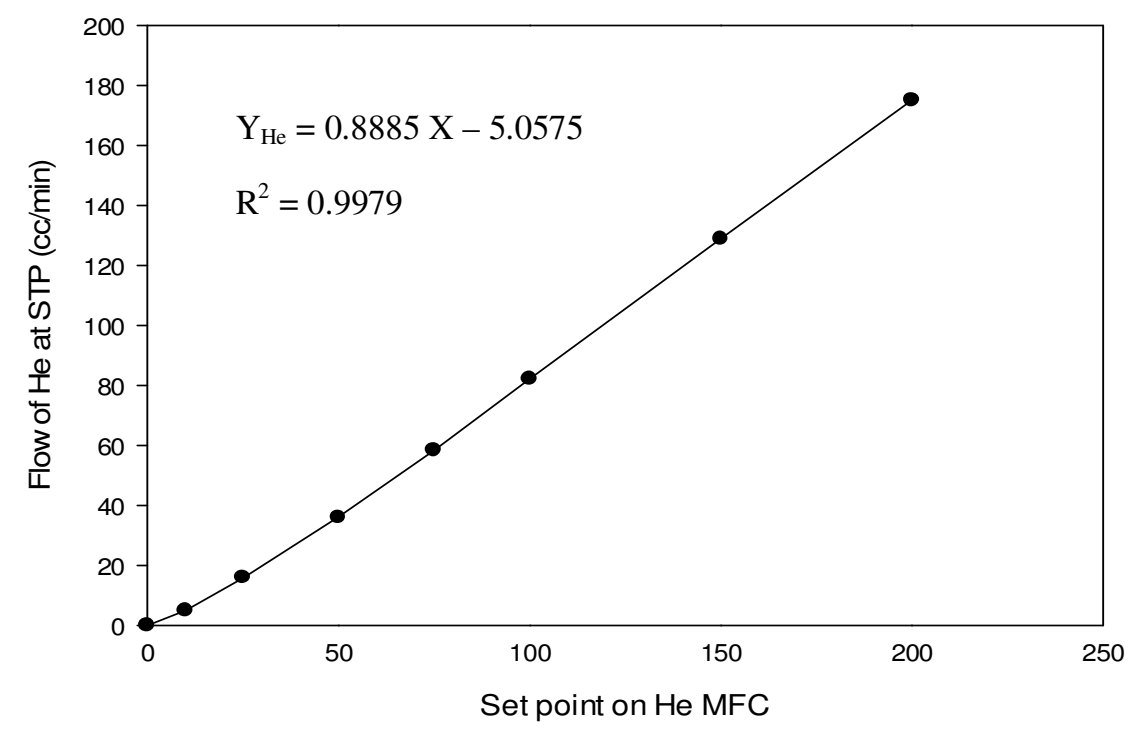

Figure C.1 MFC calibration curve for He gas

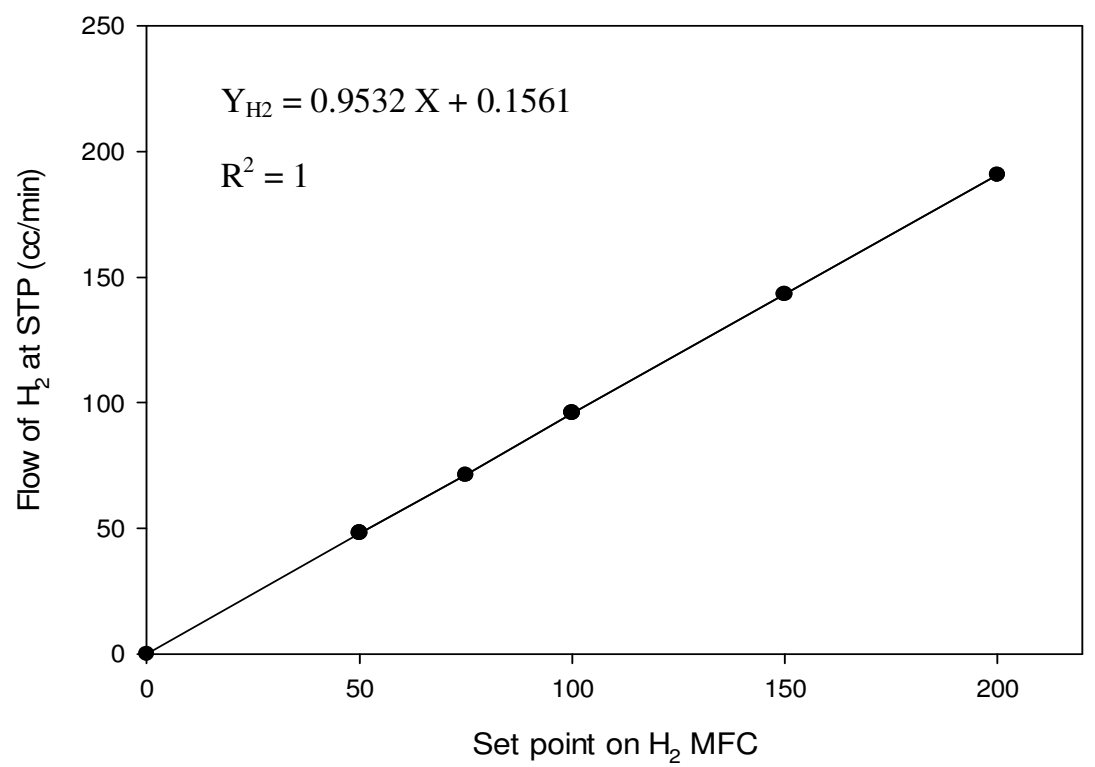

Figure C.2 MFC calibration curve for $\mathrm{H}_{2}$ gas 


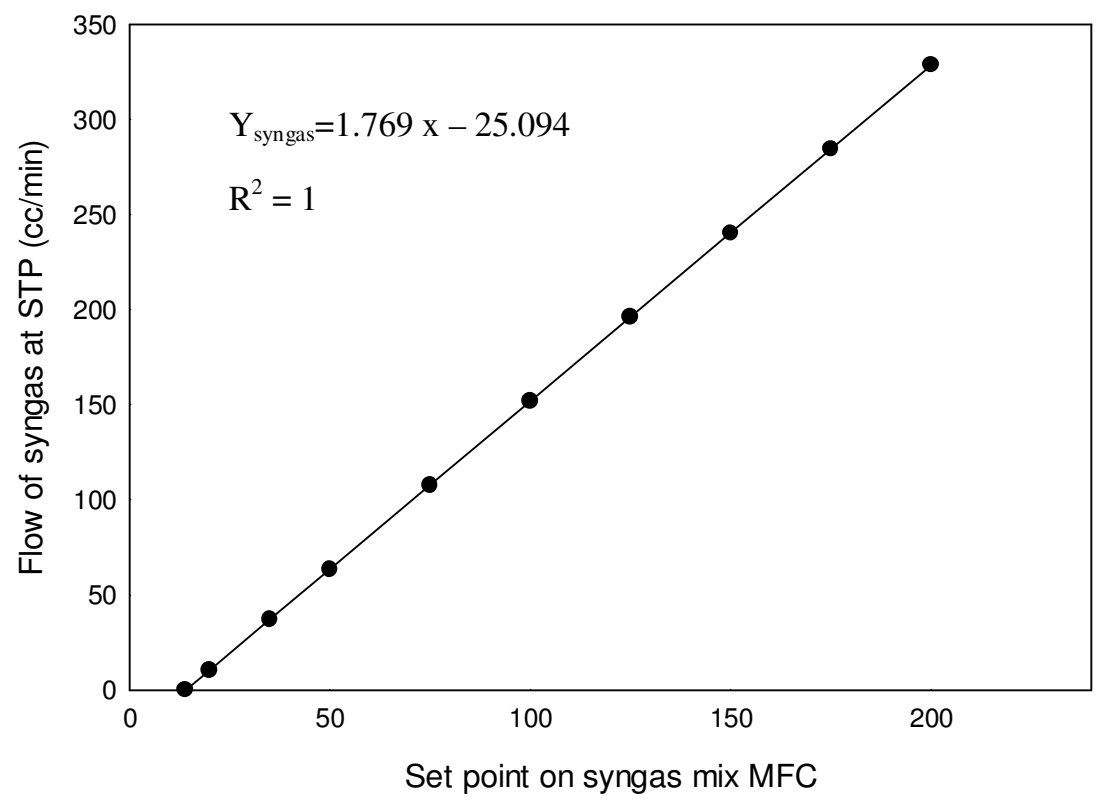

Figure C. $3 \mathrm{MFC}$ calibration curve for syngas mixture gas $\left(45 \% \mathrm{CO}, 45 \% \mathrm{H}_{2}, 5 \% \mathrm{Ar}, 5 \% \mathrm{He}\right)$ 


\section{APPENDIX D}

\section{CALCULATIONS FOR RESULTS WITH BASE CASE CATALYST AND ZSM-5 CATALYST}

D.1 Calculation procedure for gas analysis

D.1.1 Calculation procedure for TCD gas analysis

Feed flow (mol/min) with TCD can be calculated as,

$$
F_{X, \text { out }}\left(\frac{\text { mol }}{\min }\right)=\frac{\left(A_{X, o u t}\right)}{\left(A_{H e, A r, o u t}\right) \times(r R F x)} \times F_{H e, A r, \text { in }}\left(\frac{\text { mol }}{\min }\right)
$$

Internal standard as helium is used for helium, hydrogen, and carbon dioxide gas compounds. Internal standard as argon gas is used for argon, nitrogen, methane, and carbon monoxide gas compounds.

The conversions are calculated as,

CO conversions $(\%)=100 \times \frac{\text { mole rate of Co consumption }}{\text { mole rate of } \text { CO inlet }}$

$H_{2}$ conversions $(\%)=100 \times \frac{\text { mole rate of } \mathrm{H}_{2} \text { consumption }}{\text { mole rate of } \mathrm{H}_{2} \text { inlet }}$

D.2.2 Calculation procedure for FID gas analysis

Feed flow ( $\mathrm{mol} / \mathrm{min}$ ) with FID can be calculated as,

$$
F_{X, \text { out }}\left(\frac{\mathrm{mol}}{\min }\right)=\frac{\left(A_{X, \text { out }}\right)}{\left(A_{C H 4, \text { out }}\right) \times(r R F x)} \times F_{C H 4, \text { out }, T C D}\left(\frac{m o l}{\min }\right)
$$

\section{D.2 Calculation procedure for liquid analysis}

\section{D.2.1 Calculation procedure for oil phase analysis}

GC sample is prepared using $\mathrm{CS}_{2}$ as a solvent. $200 \mu \mathrm{l}$ of $\mathrm{CS}_{2}$ and $800 \mu$ of FT hydrocarbon liquid phase is taken in a 1-ml GC sample vial. Similarly other oil samples are prepared, and GC auto sampler injects $1 \mu l$ per injection. 
The response factors of the liquid hydrocarbons assuming to be linear and constant. Therefore we can calculate weight percentage of liquid hydrocarbons directly from GC areas.

weight percentage of liquid hydrocarbon $x\left(w t_{x} \%\right)=100 \times \frac{\text { Area of hydrocabon } x}{\text { Total area-Area ofCS }} \ldots$

Actual weight of liquid hydrocarbon $x(g)=w t_{x} \%$ of hydrocarbons $\times$ oil weight collected (g) $/ 100$

D.2.2 Calculation procedure for aqueous phase analysis

The internal standard is used to correct for sample volume variations. So we have to correct for sample volume variations by taking the ratio of all peak areas to the internal standard in both the sample and the standard. Since the internal standard has a known concentration in both the sample and the standard, it can be used to correct for variations. Since the concentrations of alcohols responsible for the standard peaks are known, this comparison will allow you to calculate a concentration from the sample peak areas.

Let's pick Methanol as an example:

In order to relate the Area of Methanol in sample to the area of Methanol in the standard, we must first correct for sample variations to arrive at a corrected area of Methanol.

$A_{\text {corrected,Methanol }}=A_{\text {Methanol,sample }} \frac{\left(A_{\text {cyclohexanol,standard }}\right)}{\left(A_{\text {cyclohexanol,sample })}\right.} \times \frac{w t_{\text {cyclohexanol,sample }}}{w t_{\text {cyclohexanol,standard }}}$

Now, we can calculate weight of methanol in GC vial from this corrected area of methanol.

$w t_{\text {Methanol,in GC vial }}=A_{\text {corrected,Methanol }} \times \frac{w t_{\text {Methanol,standard }}}{A_{\text {Methanol,standard }}}$

$\mathrm{A}_{\text {Methanol, standard }} \mathrm{A}_{\text {cyclohexanol, standard }} \mathrm{wt}_{\mathrm{cyclohexanol,} \mathrm{standard}}(\mu \mathrm{g}) \mathrm{wt}_{\text {Methanol, standard }}(\mu \mathrm{g})$ are provided in Table B.3. The subscript 'sample' in equation (D.7) refers to GC vial sample.

Similar procedure is followed for other alcohols and weights of alcohols can be calculated. Now we know the weights of all the alcohols (g) in the GC vial. The weight of methanol in actual fishcer-tropsch aqueous sample can be calculated as, 
Methanol weight in Fischer-Tropsch aqueous sample = Weight of Aqueous weight collected in FT reaction $(g) \times \frac{w t_{\text {Methanol, in GC vial }}}{\text { GC vial sample weight }(g)}$

GC vial sample weight $(g)$ is the sample weight in GC vial without cyclohexanol and water.

Similarly, weight of other alcohols in Fischer-Tropsch aqueous sample can be calculated and sum of alcohols weight calculated in Fischer-Tropsch aqueous sample $(g)$ can be obtained. Water amount in Fischer-Tropsch aqueous sample can be calculated as,

Water in Fischer-Tropsch sample $(g)=$ Weight of Aqueous weight collected in FT reaction $(g)$ sum of alcohols weight calculated in Fischer-Tropsch aqueous sample (g) 


\section{APPENDIX E}

\section{CATALYST PREPARATION CALCULATION PROCEDURE}

The catalyst preparation calculation procedure is given below.

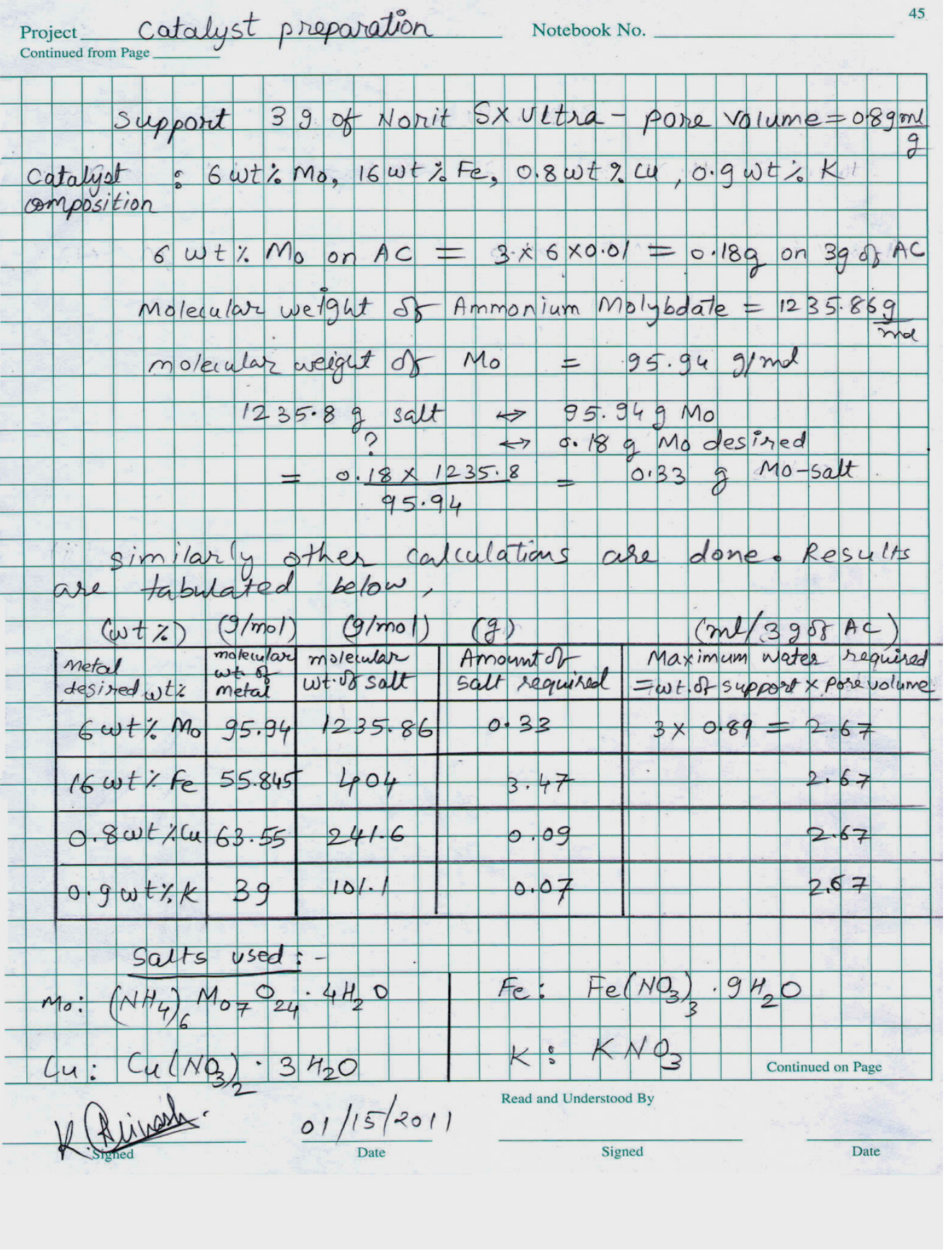




\section{APPENDIX F.1}

CONVERSIONS AND LIQUID WEIGHTS COLLECTED FOR BASE CATALYST, SEPARATE BED, AND MIXED BED ARRANGEMENT

Table F.1 Conversions and liquid weights collected for base catalyst, separate bed, and mixed bed

\begin{tabular}{|c|c|c|c|c|c|c|c|c|c|c|c|c|c|c|c|c|}
\hline \multirow{2}{*}{$\begin{array}{l}\text { Bed arrangement } \\
\text { ZSM-5 weight (g) }\end{array}$} & \multicolumn{3}{|c|}{ Base catalyst } & \multicolumn{5}{|c|}{ Separate-bed } & \multicolumn{5}{|c|}{ Separate-bed and catalyst testing TOS (h) } & \multicolumn{3}{|c|}{ Mixed-bed } \\
\hline & 0 & 0 & 0 & 0.25 & 0.5 & 1 & 0.5 & 0.5 & 0.5 & 0.5 & 0.5 & 0.5 & 0.5 & 0.25 & 0.5 & 1 \\
\hline $\begin{array}{l}\text { Base catalyst } \\
\text { weight }(\mathrm{g})\end{array}$ & 0.5 & 0.5 & 0.5 & 0.5 & 0.5 & 0.5 & 0.5 & 0.5 & 0.5 & 0.5 & 0.5 & 0.5 & 0.5 & 0.5 & 0.5 & 0.5 \\
\hline TOS (h) & $24-48$ & $24-48$ & $24-48$ & $24-48$ & $24-48$ & $24-48$ & $24-48$ & $24-48$ & $24-48$ & $48-96$ & $96-144$ & $\begin{array}{c}144- \\
192\end{array}$ & $\begin{array}{l}192- \\
240\end{array}$ & $24-48$ & $24-48$ & $24-48$ \\
\hline $\mathrm{T}\left({ }^{\circ} \mathrm{C}\right)$ & 280 & 300 & 320 & 300 & 300 & 300 & 320 & 280 & 300 & 300 & 300 & 300 & 300 & 300 & 300 & 300 \\
\hline $\begin{array}{l}\mathrm{CO} \text { conversions } \\
(\%)\end{array}$ & 42.2 & 81.3 & 88 & 85.8 & 88.2 & 85.9 & 84.6 & 44.7 & 81.3 & 84.3 & 84.4 & 83.2 & 80.2 & 52.2 & 58.9 & 76 \\
\hline $\begin{array}{l}\mathrm{H}_{2} \text { conversions } \\
(\%)\end{array}$ & 32.1 & 54.9 & 63 & 56.5 & 65.6 & 60.7 & 60.6 & 28.8 & 56.6 & 59.5 & 58.1 & 54.5 & 53 & 33.9 & 36.4 & 49.3 \\
\hline $\begin{array}{l}\text { Error in carbon } \\
\text { balance }(\%)\end{array}$ & -8.4 & -1.3 & -5.7 & -4.9 & 1.7 & -3.1 & -5.9 & -2.4 & 4.75 & 3.06 & 0.4 & -0.9 & -4.2 & -7.6 & 1.3 & 4.5 \\
\hline $\begin{array}{l}\text { Hydrocarbon } \\
\text { organic liquid } \\
\text { weight }(\mathrm{g})\end{array}$ & 2.85 & 5.6 & 4.8 & 7.29 & 7.39 & 5.68 & 5.78 & 3.25 & 7.62 & 15.6 & 14.9 & 14.04 & 13.68 & 3.75 & 4.21 & 3.09 \\
\hline $\begin{array}{l}\text { Aqueous weight } \\
\text { (g) }\end{array}$ & 0.85 & 2.41 & 3.2 & 2.40 & 2.30 & 2.50 & 1.50 & 1.50 & 2.3 & 4.64 & 4.5 & 4.24 & 3.92 & 1.20 & 1.50 & 2.30 \\
\hline
\end{tabular}


APPENDIX F.2

WGS AND FTS REACTION RATES FOR ALL REACTIONS 


\section{Table F.2 WGS and FTS rates}

\begin{tabular}{|c|c|c|c|c|c|c|c|c|c|c|c|c|c|c|c|c|}
\hline \multirow{2}{*}{$\frac{\text { Bed arrangement }}{\text { ZSM-5 weight }(\mathrm{g})}$} & \multicolumn{3}{|c|}{ Base catalyst } & \multicolumn{5}{|c|}{ Separate-bed } & \multicolumn{5}{|c|}{ Catalyst stability testing in separate-bed } & \multicolumn{3}{|c|}{ Mixed-bed } \\
\hline & 0 & 0 & 0 & 0.25 & 0.5 & 1 & 0.5 & 0.5 & 0.5 & 0.5 & 0.5 & 0.5 & 0.5 & 0.25 & 0.5 & 1 \\
\hline Base catalyst weight $(\mathrm{g})$ & 0.5 & 0.5 & 0.5 & 0.5 & 0.5 & 0.5 & 0.5 & 0.5 & 0.5 & 0.5 & 0.5 & 0.5 & 0.5 & 0.5 & 0.5 & 0.5 \\
\hline Temperature $\left({ }^{\circ} \mathrm{C}\right)$ & 280 & 300 & 320 & 300 & 300 & 300 & 320 & 280 & 300 & 300 & 300 & 300 & 300 & 300 & 300 & 300 \\
\hline TOS (h) & $24-48$ & $24-48$ & $24-48$ & $24-48$ & $24-48$ & $24-48$ & $24-48$ & $24-48$ & $24-48$ & $\begin{array}{l}48- \\
96\end{array}$ & $96-144$ & $\begin{array}{l}144- \\
192 \\
\end{array}$ & $\begin{array}{l}192- \\
240\end{array}$ & $\begin{array}{c}24- \\
48\end{array}$ & $24-48$ & $24-48$ \\
\hline & \multicolumn{16}{|c|}{$\mathrm{g}$ carbon /day } \\
\hline $\mathrm{CO}_{2}$ & 10.2 & 14.39 & 14.2 & 15.56 & 15.1 & 15.5 & 15.12 & 8.81 & 14.6 & 14.84 & 14.94 & 14.6 & 14.84 & 9.85 & 10.34 & 13.96 \\
\hline Unreacted CO & 18.5 & 6.84 & 4.2 & 5.27 & 4.3 & 5.12 & 5.17 & 18.51 & 4.3 & 4.2 & 5.06 & 5.12 & 5.2 & $\begin{array}{c}15.8 \\
3\end{array}$ & 14.98 & 8.58 \\
\hline Rates & \multicolumn{16}{|c|}{$\mathrm{mmol} / \mathrm{min}$} \\
\hline $\mathrm{N}_{\mathrm{CO} \text {,inlet }}$ & 1.92 & 2.11 & 1.94 & 2 & 2.11 & 2.11 & 1.94 & 1.94 & 2.11 & 2.11 & 2.11 & 2.11 & 2.11 & 1.92 & 2.11 & 2.07 \\
\hline $\mathrm{N}_{\mathrm{CO}, \text { unreacted }}$ & 1.07 & 0.40 & 0.24 & 0.30 & 0.25 & 0.30 & 0.30 & 1.07 & 0.25 & 0.24 & 0.29 & 0.30 & 0.30 & 0.92 & 0.87 & 0.50 \\
\hline $\mathrm{rCO}_{2}=\mathrm{rWGS}=\mathrm{N}_{\mathrm{CO} 2}$ & 0.59 & 0.83 & 0.82 & 0.90 & 0.87 & 0.90 & 0.88 & 0.51 & 0.84 & 0.86 & 0.86 & 0.84 & 0.86 & 0.57 & 0.60 & 0.81 \\
\hline $\begin{array}{l}(-\mathrm{rCO})=\mathrm{rFTS}+\mathrm{rWGS}= \\
\mathrm{N}_{\mathrm{CO} \text {,inlet }}-\mathrm{N}_{\mathrm{CO} \text {,unreacted }}\end{array}$ & 0.85 & 1.72 & 1.70 & 1.70 & 1.86 & 1.81 & 1.64 & 0.87 & 1.86 & 1.87 & 1.82 & 1.81 & 1.81 & 1.00 & 1.24 & 1.57 \\
\hline $\mathrm{rFTS}=(-\mathrm{rCO})-\mathrm{rWGS}$ & 0.26 & 0.89 & 0.88 & 0.79 & 0.99 & 0.92 & 0.77 & 0.36 & 1.02 & 1.01 & 0.95 & 0.97 & 0.95 & 0.43 & 0.64 & 0.77 \\
\hline
\end{tabular}


APPENDIX F.3

FID GAS REACTION DATA FOR BASE CATALYST, SEPARATE-BED, AND MIXED-BED ARRANGEMENT 
Table F.3 FID gas amounts for base catalyst, separate bed, and mixed bed

\begin{tabular}{|c|c|c|c|c|c|c|c|c|c|c|c|c|c|c|c|c|}
\hline \multirow{2}{*}{$\begin{array}{r}\text { Bed arrangement } \\
\text { ZSM-5 weight }(\mathrm{g})\end{array}$} & \multicolumn{3}{|c|}{ Base catalyst } & \multicolumn{5}{|c|}{ Separate-bed } & \multicolumn{5}{|c|}{ Catalyst stability testing in separate-bed } & \multicolumn{3}{|c|}{ Mixed-bed } \\
\hline & 0 & 0 & 0 & 0.25 & 0.5 & 1 & 0.5 & 0.5 & 0.5 & 0.5 & 0.5 & 0.5 & 0.5 & 0.25 & 0.5 & 1 \\
\hline Base catalyst weight $(\mathrm{g})$ & 0.5 & 0.5 & 0.5 & 0.5 & 0.5 & 0.5 & 0.5 & 0.5 & 0.5 & 0.5 & 0.5 & 0.5 & 0.5 & 0.5 & 0.5 & 0.5 \\
\hline $\mathrm{T}\left({ }^{\circ} \mathrm{C}\right)$ & 280 & 300 & 320 & 300 & 300 & 300 & 320 & 280 & 300 & 300 & 300 & 300 & 300 & 300 & 300 & 300 \\
\hline TOS (h) & $24-48$ & $24-48$ & $24-48$ & $24-48$ & $24-48$ & $24-48$ & $24-48$ & $24-48$ & $24-48$ & $48-96$ & $96-144$ & 144-192 & $192-240$ & $24-48$ & $24-48$ & $24-48$ \\
\hline Compounds & & & & & & & & $\mathrm{g} \mathrm{ca}$ & on/day & & & & & & & \\
\hline $\mathrm{CH}_{4}$ & 0.7200 & 2.3114 & 3.2254 & 1.9456 & 2.2100 & 2.8100 & 3.7913 & 0.8887 & 2.1200 & 2.2100 & 2.4000 & 2.8200 & 2.9800 & 1.1975 & 1.3400 & 2.2739 \\
\hline $\mathrm{C}_{2} \mathrm{H}_{6}+\mathrm{C}_{2} \mathrm{H}_{4}$ & 0.6500 & 1.7593 & 2.2115 & 1.7200 & 1.6700 & 1.2992 & 1.9219 & 0.4534 & 1.5200 & 1.6100 & 1.7100 & 2.4100 & 2.4600 & 0.8414 & 0.7784 & 0.7200 \\
\hline $\mathrm{C}_{3} \mathrm{H}_{8}$ & 0.2100 & 0.4963 & 0.5619 & 0.6985 & 1.4868 & 2.3983 & 1.6100 & 0.4566 & 0.9200 & 0.9600 & 1.0200 & 1.0600 & 1.1000 & 0.3789 & 0.5004 & 1.1788 \\
\hline $\mathrm{C}_{3} \mathrm{H}_{6}$ & 0.6400 & 2.1351 & 2.6364 & 0.2974 & 0.1059 & 0.0107 & 0.2058 & 0.0999 & 0.3800 & 0.4100 & 0.4200 & 0.4600 & 0.5100 & 0.7105 & 0.6038 & 0.5800 \\
\hline $\mathrm{i}-\mathrm{C}_{4} \mathrm{H}_{10}$ & 0.0000 & 0.0263 & 0.0319 & 0.4649 & 1.0322 & 1.8350 & 1.1200 & 0.2943 & 0.1100 & 0.3200 & 0.4760 & 0.5500 & 0.7500 & 0.2430 & 0.4626 & 0.9126 \\
\hline $\mathrm{n}-\mathrm{C}_{4} \mathrm{H}_{10}$ & 0.1800 & 0.3571 & 0.3696 & 0.5051 & 1.0385 & 1.3937 & 1.1100 & 0.3196 & 0.4100 & 0.6600 & 0.8100 & 0.8500 & 1.4900 & 0.2653 & 0.3599 & 0.6686 \\
\hline 1- $\mathrm{C}_{4} \mathrm{H}_{8}$ & 0.9000 & 1.1064 & 1.3653 & 0.0670 & 0.0142 & 0.0000 & 0.1356 & 0.0596 & 0.6500 & 0.6300 & 0.6100 & 0.5700 & 0.6300 & 0.2300 & 0.2152 & 0.1438 \\
\hline i- $\mathrm{C}_{4} \mathrm{H}_{8}$ & 0.0000 & 0.0000 & 0.0000 & 1.3390 & 0.5800 & 0.0099 & 0.7678 & 0.4431 & 0.1000 & 0.1800 & 0.2600 & 0.3100 & 0.3900 & 0.7450 & 0.6678 & 0.4211 \\
\hline $\mathrm{t}-\mathrm{C}_{4} \mathrm{H}_{8}$ & 0.1900 & 0.2415 & 0.2456 & 0.1974 & 0.1000 & 0.0000 & 0.1166 & 0.0810 & 0.0200 & 0.0600 & 0.0240 & 0.0900 & 0.0000 & 0.2371 & 0.1566 & 0.1540 \\
\hline $\mathrm{c}-\mathrm{C}_{4} \mathrm{H}_{8}$ & 0.0000 & 0.0000 & 0.0000 & 0.1238 & 0.0198 & 0.0000 & 0.0745 & 0.0480 & 0.5600 & 0.8600 & 1.1500 & 1.2800 & 1.2600 & 0.1628 & 0.1084 & 0.0900 \\
\hline $\mathrm{i}-\mathrm{C}_{5} \mathrm{H}_{12}$ & 0.0000 & 0.0321 & 0.0373 & 0.3658 & 0.7832 & 1.0683 & 0.8100 & 0.2652 & 0.5800 & 0.3800 & 0.2600 & 0.1800 & 0.1100 & 0.2223 & 0.3731 & 0.6460 \\
\hline $\mathrm{n}-\mathrm{C}_{5} \mathrm{H}_{12}$ & 0.2100 & 0.3342 & 0.2964 & 0.3754 & 0.4100 & 0.5444 & 0.4300 & 0.2652 & 1.0300 & 0.6800 & 0.2300 & 0.1500 & 0.0900 & 0.2074 & 0.2551 & 0.3495 \\
\hline $\mathrm{C}_{5}$-gas & 0.9100 & 1.1972 & 1.2505 & 0.9441 & 0.5568 & 0.4186 & 0.8300 & 0.5100 & 0.7800 & 0.4600 & 0.1700 & 0.1400 & 0.1000 & 0.9646 & 0.8444 & 0.7167 \\
\hline
\end{tabular}


APPENDIX F.4

ORGANIC AND AQUEOUS PHASE REACTION DATA FOR BASE CATALYST, SEPARATE-BED, AND MIXED-BED ARRANGEMENT 


\begin{tabular}{|c|c|c|c|c|c|c|c|}
\hline \multicolumn{8}{|c|}{$\begin{array}{l}\text { Base catalyst weight }=0.5 \mathrm{~g}, \mathrm{ZSM}-5 \text { weight }=0 \mathrm{~g}, \mathrm{H}_{2} / \mathrm{CO} \text { ratio }=1, \\
\text { total feed rate }=100 \mathrm{scc} / \mathrm{min} \text {, reactor pressure }=300 \mathrm{psi}, \mathrm{TOS}=24-48 \mathrm{~h} \text {, Organic phase wt }=2.85 \mathrm{~g}, \text { Aqueous phase wt }=0.85 \mathrm{~g}\end{array}$} \\
\hline Aromatics & $\begin{array}{l}\text { wt } \% \text { in } \\
\text { Hydrocarbon } \\
\text { liquid phase } \\
\end{array}$ & $\begin{array}{l}\text { weight } \\
\text { (g/day) }\end{array}$ & $\begin{array}{l}\text { Carbon } \\
\text { number }\end{array}$ & $\begin{array}{l}\text { Molecular } \\
\text { weight } \mathrm{g} / \mathrm{mol}\end{array}$ & mol/day & $\mathrm{mmol} / \mathrm{min}$ & g carbon /day \\
\hline toluene & 0 & 0 & 7 & 92 & 0 & 0 & 0 \\
\hline p-xylene & 0 & 0 & 8 & 106 & 0 & 0 & 0 \\
\hline $\begin{array}{l}\text { propyl- } \\
\text { benzene }\end{array}$ & 0 & 0 & 9 & 120 & 0 & 0 & 0 \\
\hline \multirow[t]{2}{*}{ butyl-benzene } & 0 & 0 & 10 & 134 & 0 & 0 & 0 \\
\hline & & & & & & sum & 0 \\
\hline n-praffins & $\begin{array}{l}\text { wt \% in } \\
\text { Hydrocarbon } \\
\text { liquid phase }\end{array}$ & $\begin{array}{l}\text { weight } \\
\text { (g/day) }\end{array}$ & $\begin{array}{l}\text { Carbon } \\
\text { number }\end{array}$ & $\begin{array}{l}\text { Molecular } \\
\text { weight } \mathrm{g} / \mathrm{mol}\end{array}$ & $\mathrm{mol} /$ day & $\mathrm{mmol} / \mathrm{min}$ & g carbon /day \\
\hline $\mathrm{n}-\mathrm{C}_{5}$ & 0.1085 & 0.0031 & 5 & 44 & 0.0001 & 0.0000 & 0.0042 \\
\hline $\mathrm{n}-\mathrm{C}_{6}$ & 0.8366 & 0.0238 & 6 & 86 & 0.0003 & 0.0002 & 0.0200 \\
\hline $\mathrm{n}-\mathrm{C}_{7}$ & 2.3155 & 0.0660 & 7 & 100 & 0.0007 & 0.0005 & 0.0554 \\
\hline $\mathrm{n}-\mathrm{C}_{8}$ & 2.7204 & 0.0775 & 8 & 114 & 0.0007 & 0.0005 & 0.0653 \\
\hline $\mathrm{n}-\mathrm{C}_{9}$ & 0.5511 & 0.0157 & 9 & 128 & 0.0001 & 0.0001 & 0.0133 \\
\hline $\mathrm{n}-\mathrm{C}_{10}$ & 2.0517 & 0.0585 & 10 & 142 & 0.0004 & 0.0003 & 0.0494 \\
\hline $\mathrm{n}-\mathrm{C}_{11}$ & 1.8003 & 0.0513 & 11 & 156 & 0.0003 & 0.0002 & 0.0434 \\
\hline $\mathrm{n}-\mathrm{C}_{12}$ & 1.6135 & 0.0460 & 12 & 170 & 0.0003 & 0.0002 & 0.0390 \\
\hline $\mathrm{n}-\mathrm{C}_{13}$ & 1.4729 & 0.0420 & 13 & 184 & 0.0002 & 0.0002 & 0.0356 \\
\hline $\mathrm{n}-\mathrm{C}_{14}$ & 0.3435 & 0.0098 & 14 & 198 & 0.0000 & 0.0000 & 0.0083 \\
\hline$n-C_{15}$ & 1.2709 & 0.0362 & 15 & 212 & 0.0002 & 0.0001 & 0.0308 \\
\hline $\mathrm{n}-\mathrm{C}_{16}$ & 1.1789 & 0.0336 & 16 & 226 & 0.0001 & 0.0001 & 0.0285 \\
\hline \multirow[t]{2}{*}{$\mathrm{n}-\mathrm{C}_{17+}$} & 7.2391 & 0.2063 & 17 & 240 & 0.0009 & 0.0006 & 0.1754 \\
\hline & & & & & & Sum in oil & 0.5686 \\
\hline i-paraffins & $\begin{array}{l}\text { wt \% in } \\
\text { Hydrocarbon } \\
\text { liquid phase } \\
\end{array}$ & $\begin{array}{l}\text { weight } \\
\text { (g/day) }\end{array}$ & $\begin{array}{l}\text { Carbon } \\
\text { number }\end{array}$ & $\begin{array}{l}\text { Molecular } \\
\text { weight } \mathrm{g} / \mathrm{mol}\end{array}$ & $\mathrm{mol} / \mathrm{day}$ & $\mathrm{mmol} / \mathrm{min}$ & g carbon /day \\
\hline $\mathrm{i}-\mathrm{C}_{5}$ & 1.5742 & 0.0449 & 5 & 44 & 0.0010 & 0.0007 & 0.0612 \\
\hline $\mathrm{i}-\mathrm{C}_{6}$ & 3.2011 & 0.0912 & 6 & 86 & 0.0011 & 0.0007 & 0.0764 \\
\hline $\mathrm{i}-\mathrm{C}_{7}$ & 9.9438 & 0.2834 & 7 & 100 & 0.0028 & 0.0020 & 0.2381 \\
\hline $\mathrm{i}-\mathrm{C}_{8}$ & 11.9565 & 0.3408 & 8 & 114 & 0.0030 & 0.0021 & 0.2870 \\
\hline i-C 9 & 12.6515 & 0.3606 & 9 & 128 & 0.0028 & 0.0020 & 0.3042 \\
\hline $\mathrm{i}-\mathrm{C}_{10}$ & 7.4179 & 0.2114 & 10 & 142 & 0.0015 & 0.0010 & 0.1787 \\
\hline $\mathrm{i}-\mathrm{C}_{11}$ & 6.1832 & 0.1762 & 11 & 156 & 0.0011 & 0.0008 & 0.1491 \\
\hline $\mathrm{i}-\mathrm{C}_{12}$ & 4.7213 & 0.1346 & 12 & 170 & 0.0008 & 0.0005 & 0.1140 \\
\hline $\mathrm{i}-\mathrm{C}_{13}$ & 3.6265 & 0.1034 & 13 & 184 & 0.0006 & 0.0004 & 0.0876 \\
\hline $\mathrm{i}-\mathrm{C}_{14}$ & 4.1313 & 0.1177 & 14 & 198 & 0.0006 & 0.0004 & 0.0999 \\
\hline $\mathrm{i}-\mathrm{C}_{15}$ & 1.7895 & 0.0510 & 15 & 212 & 0.0002 & 0.0002 & 0.0433 \\
\hline $\mathrm{i}-\mathrm{C}_{16}$ & 1.3616 & 0.0388 & 16 & 226 & 0.0002 & 0.0001 & 0.0330 \\
\hline \multirow[t]{2}{*}{$\mathrm{i}-\mathrm{C}_{17+}$} & 7.5755 & 0.2159 & 17 & 240 & 0.0009 & 0.0006 & 0.1835 \\
\hline & & & & & & Total in oil & 2.4243 \\
\hline Alcohols & $\begin{array}{l}\text { wt \% in } \\
\text { aqueous liquid } \\
\text { phase }\end{array}$ & $\begin{array}{l}\text { weight } \\
\text { (g/day) }\end{array}$ & $\begin{array}{l}\text { Carbon } \\
\text { number }\end{array}$ & $\begin{array}{l}\text { Molecular } \\
\text { weight } \mathrm{g} / \mathrm{mol}\end{array}$ & $\mathrm{mol} / \mathrm{day}$ & $\mathrm{mmol} / \mathrm{min}$ & g carbon /day \\
\hline Methanol & 8.6000 & 0.0731 & 1 & 32 & 0.0023 & 0.0016 & 0.0274 \\
\hline Ethanol & 22.6000 & 0.1921 & 2 & 46 & 0.0042 & 0.0029 & 0.1002 \\
\hline 2-Propanol & 4.2000 & 0.0357 & 3 & 60 & 0.0006 & 0.0004 & 0.0214 \\
\hline 1-Propanol & 10.5000 & 0.0893 & 3 & 60 & 0.0015 & 0.0010 & 0.0536 \\
\hline 2-Butanol & 1.6000 & 0.0136 & 4 & 74 & 0.0002 & 0.0001 & 0.0088 \\
\hline 1-Butanol & 6.8000 & 0.0578 & 4 & 74 & 0.0008 & 0.0005 & 0.0375 \\
\hline 2-Pentanol & 0.0000 & 0.0000 & 5 & 88 & 0.0000 & 0.0000 & 0.0000 \\
\hline 1-Pentanol & 4.1000 & 0.0349 & 5 & 88 & 0.0004 & 0.0003 & 0.0238 \\
\hline \multirow[t]{2}{*}{ Water } & 41.6000 & 0.3536 & 0 & 18 & 0.0196 & 0.0136 & 0.0000 \\
\hline & & & & & & Total in Aqueous & 0.2453 \\
\hline \multicolumn{3}{|c|}{ Total carbon due to oil and Aqueous phase } & \multicolumn{2}{|r|}{ carbon /day } & & & \\
\hline
\end{tabular}




\begin{tabular}{|c|c|c|c|c|c|c|c|}
\hline \multicolumn{8}{|c|}{$\begin{array}{l}\text { Base case catalyst at } \mathrm{T}=300^{\circ} \mathrm{C} \\
\text { Base catalyst weight }=0.5 \mathrm{~g}, \mathrm{ZSM}\end{array}$} \\
\hline Aromatics & $\begin{array}{l}\text { wt } \% \text { in } \\
\text { Hydrocarbon } \\
\text { liquid phase }\end{array}$ & $\begin{array}{l}\text { weight } \\
\text { (g/day) }\end{array}$ & $\begin{array}{l}\text { Carbon } \\
\text { number }\end{array}$ & $\begin{array}{l}\text { Molecular } \\
\text { weight } \mathrm{g} / \mathrm{mol}\end{array}$ & $\mathrm{mol} /$ day & $\mathrm{mmol} / \mathrm{min}$ & g carbon /day \\
\hline toluene & 0 & 0 & 7 & 92 & 0 & 0 & 0 \\
\hline p-xylene & 0 & 0 & 8 & 106 & 0 & 0 & 0 \\
\hline $\begin{array}{l}\text { propyl- } \\
\text { benzene }\end{array}$ & 0 & 0 & 9 & 120 & 0 & 0 & 0 \\
\hline \multirow[t]{2}{*}{ butyl-benzene } & 0 & 0 & 10 & 134 & 0 & 0 & 0 \\
\hline & & 0 & & & & & \\
\hline n-praffins & $\begin{array}{l}\mathrm{wt} \% \text { in } \\
\text { Hydrocarbon } \\
\text { liquid phase }\end{array}$ & $\begin{array}{l}\text { weight } \\
\text { (g/day) }\end{array}$ & $\begin{array}{l}\text { Carbon } \\
\text { number }\end{array}$ & $\begin{array}{l}\text { Molecular } \\
\text { weight } \mathrm{g} / \mathrm{mol}\end{array}$ & $\mathrm{mol} /$ day & $\mathrm{mmol} / \mathrm{min}$ & g carbon /day \\
\hline $\mathrm{n}-\mathrm{C}_{5}$ & 0.5997 & 0.0336 & 5 & 44 & 0.0008 & 0.0005 & 0.0458 \\
\hline $\mathrm{n}-\mathrm{C}_{6}$ & 5.0062 & 0.2803 & 6 & 86 & 0.0033 & 0.0023 & 0.2347 \\
\hline $\mathrm{n}-\mathrm{C}_{7}$ & 5.6074 & 0.3140 & 7 & 100 & 0.0031 & 0.0022 & 0.2638 \\
\hline $\mathrm{n}-\mathrm{C}_{8}$ & 7.0865 & 0.3968 & 8 & 114 & 0.0035 & 0.0024 & 0.3342 \\
\hline $\mathrm{n}-\mathrm{C}_{9}$ & 5.3976 & 0.3023 & 9 & 128 & 0.0024 & 0.0016 & 0.2550 \\
\hline $\mathrm{n}-\mathrm{C}_{10}$ & 3.7127 & 0.2079 & 10 & 142 & 0.0015 & 0.0010 & 0.1757 \\
\hline $\mathrm{n}-\mathrm{C}_{11}$ & 2.7239 & 0.1525 & 11 & 156 & 0.0010 & 0.0007 & 0.1291 \\
\hline $\mathrm{n}-\mathrm{C}_{12}$ & 1.9904 & 0.1115 & 12 & 170 & 0.0007 & 0.0005 & 0.0944 \\
\hline $\mathrm{n}-\mathrm{C}_{13}$ & 1.4874 & 0.0833 & 13 & 184 & 0.0005 & 0.0003 & 0.0706 \\
\hline $\mathrm{n}-\mathrm{C}_{14}$ & 1.1287 & 0.0632 & 14 & 198 & 0.0003 & 0.0002 & 0.0536 \\
\hline $\mathrm{n}-\mathrm{C}_{15}$ & 0.8212 & 0.0460 & 15 & 212 & 0.0002 & 0.0002 & 0.0390 \\
\hline $\mathrm{n}-\mathrm{C}_{16}$ & 0.7018 & 0.0393 & 16 & 226 & 0.0002 & 0.0001 & 0.0334 \\
\hline $\mathrm{n}-\mathrm{C}_{17+}$ & 2.5458 & 0.1426 & 17 & 240 & 0.0006 & 0.0004 & 0.1212 \\
\hline i-paraffins & $\begin{array}{l}\text { wt\% in } \\
\text { Hydrocarbon } \\
\text { liquid phase }\end{array}$ & $\begin{array}{l}\text { weight } \\
\text { (g/day) }\end{array}$ & $\begin{array}{l}\text { Carbon } \\
\text { number }\end{array}$ & $\begin{array}{l}\text { Molecular } \\
\text { weight } \mathrm{g} / \mathrm{mol}\end{array}$ & mol/day & $\mathrm{mmol} / \mathrm{min}$ & g carbon /day \\
\hline $\mathrm{i}-\mathrm{C}_{5}$ & 7.9348 & 0.4443 & 5 & 44 & 0.0101 & 0.0070 & 0.6059 \\
\hline${\mathrm{i}-\mathrm{C}_{6}}_{\mathrm{f}}$ & 4.1100 & 0.2302 & 6 & 86 & 0.0027 & 0.0019 & 0.1927 \\
\hline $\mathrm{i}-\mathrm{C}_{7}$ & 11.4422 & 0.6408 & 7 & 100 & 0.0064 & 0.0044 & 0.5382 \\
\hline $\mathrm{i}-\mathrm{C}_{8}$ & 12.8977 & 0.7223 & 8 & 114 & 0.0063 & 0.0044 & 0.6082 \\
\hline $\mathrm{i}-\mathrm{C}_{9}$ & 7.1375 & 0.3997 & 9 & 128 & 0.0031 & 0.0022 & 0.3372 \\
\hline $\mathrm{i}-\mathrm{C}_{10}$ & 4.7582 & 0.2665 & 10 & 142 & 0.0019 & 0.0013 & 0.2252 \\
\hline $\mathrm{i}-\mathrm{C}_{11}$ & 3.1895 & 0.1786 & 11 & 156 & 0.0011 & 0.0008 & 0.1511 \\
\hline $\mathrm{i}-\mathrm{C}_{12}$ & 2.1156 & 0.1185 & 12 & 170 & 0.0007 & 0.0005 & 0.1004 \\
\hline $\mathrm{i}-\mathrm{C}_{13}$ & 1.4761 & 0.0827 & 13 & 184 & 0.0004 & 0.0003 & 0.0701 \\
\hline $\mathrm{i}-\mathrm{C}_{14}$ & 1.0062 & 0.0563 & 14 & 198 & 0.0003 & 0.0002 & 0.0478 \\
\hline $\mathrm{i}-\mathrm{C}_{15}$ & 1.1970 & 0.0670 & 15 & 212 & 0.0003 & 0.0002 & 0.0569 \\
\hline $\mathrm{i}-\mathrm{C}_{16}$ & 0.5966 & 0.0334 & 16 & 226 & 0.0001 & 0.0001 & 0.0284 \\
\hline \multirow[t]{2}{*}{$\mathrm{i}-\mathrm{C}_{17+}$} & 3.1790 & 0.1780 & 17 & 240 & 0.0007 & 0.0005 & 0.1513 \\
\hline & & & & & & Total in oil & 4.9641 \\
\hline Alcohols & $\begin{array}{l}\text { wt } \% \text { in } \\
\text { aqueous liquid } \\
\text { phase }\end{array}$ & $\begin{array}{l}\text { weight } \\
\text { (g/day) }\end{array}$ & $\begin{array}{l}\text { Carbon } \\
\text { number }\end{array}$ & $\begin{array}{l}\text { Molecular } \\
\text { weight } \mathrm{g} / \mathrm{mol}\end{array}$ & $\mathrm{mol} / \mathrm{day}$ & $\mathrm{mmol} / \mathrm{min}$ & g carbon /day \\
\hline Methanol & 10.1000 & 0.2434 & 1 & 32 & 0.0076 & 0.0053 & 0.0913 \\
\hline Ethanol & 21.3948 & 0.5156 & 2 & 46 & 0.0112 & 0.0078 & 0.2690 \\
\hline 2-Propanol & 3.8000 & 0.0916 & 3 & 60 & 0.0015 & 0.0011 & 0.0549 \\
\hline 1-Propanol & 11.3000 & 0.2723 & 3 & 60 & 0.0045 & 0.0032 & 0.1634 \\
\hline 2-Butanol & 1.3000 & 0.0313 & 4 & 74 & 0.0004 & 0.0003 & 0.0203 \\
\hline 1-Butanol & 8.5000 & 0.2049 & 4 & 74 & 0.0028 & 0.0019 & 0.1329 \\
\hline 2-Pentanol & 0.0000 & 0.0000 & 5 & 88 & 0.0000 & 0.0000 & 0.0000 \\
\hline 1-Pentanol & 6.5000 & 0.1567 & 5 & 88 & 0.0018 & 0.0012 & 0.1068 \\
\hline \multirow[t]{2}{*}{ Water } & 37.1000 & 0.8941 & 0 & 18 & 0.0497 & 0.0345 & 0.0000 \\
\hline & & & & & & Total in aqueous & 0.7474 \\
\hline \multicolumn{3}{|c|}{ Total carbon due to oil and aqueous phase } & \multicolumn{2}{|c|}{$5.7114 \mathrm{~g}$ carbon /day } & & & \\
\hline
\end{tabular}




\begin{tabular}{|c|c|c|c|c|c|c|c|}
\hline \multicolumn{8}{|c|}{$\begin{array}{l}\text { Base catalyst weight }=0.5 \mathrm{~g}, \mathrm{ZSM}-5 \text { weight }=0 \mathrm{~g}, \mathrm{H}_{2} / \mathrm{CO} \text { ratio }=1, \\
\text { total feed rate }=100 \mathrm{scc} / \mathrm{min} \text {, reactor pressure }=300 \mathrm{psi}, \mathrm{TOS}=24-48 \mathrm{~h} \text {, Organic phase } \mathrm{wt}=4.8 \mathrm{~g} \text {, Aqueous phase wt }=3.2 \mathrm{~g}\end{array}$} \\
\hline Aromatics & $\begin{array}{l}\text { wt } \% \text { in } \\
\text { Hydrocarbon } \\
\text { liquid phase }\end{array}$ & $\begin{array}{l}\text { weight } \\
\text { (g/day) }\end{array}$ & $\begin{array}{l}\text { Carbon } \\
\text { number }\end{array}$ & $\begin{array}{l}\text { Molecular weight } \\
\mathrm{g} / \mathrm{mol}\end{array}$ & $\mathrm{mol} /$ day & $\mathrm{mmol} / \mathrm{min}$ & $\begin{array}{l}\text { g carbon } \\
\text { /day }\end{array}$ \\
\hline toluene & 0.0000 & 0.0000 & 7 & 92 & 0.0000 & 0.0000 & 0.0000 \\
\hline p-xylene & 0.0000 & 0.0000 & 8 & 106 & 0.0000 & 0.0000 & 0.0000 \\
\hline $\begin{array}{l}\text { propyl- } \\
\text { benzene }\end{array}$ & 0.0000 & 0.0000 & 9 & 120 & 0.0000 & 0.0000 & 0.0000 \\
\hline butyl-benzene & 0.0000 & 0.0000 & 10 & 134 & 0.0000 & 0.0000 & 0.0000 \\
\hline n-praffins & $\begin{array}{l}\text { wt } \% \text { in } \\
\text { Hydrocarbon } \\
\text { liquid phase }\end{array}$ & $\begin{array}{l}\text { weight } \\
\text { (g/day) }\end{array}$ & $\begin{array}{l}\text { Carbon } \\
\text { number }\end{array}$ & $\begin{array}{l}\text { Molecular weight } \\
\mathrm{g} / \mathrm{mol}\end{array}$ & $\mathrm{mol} /$ day & $\mathrm{mmol} / \mathrm{min}$ & $\begin{array}{l}\text { g carbon } \\
\text { /day }\end{array}$ \\
\hline $\mathrm{n}-\mathrm{C}_{5}$ & 0.1048 & 0.0050 & 5 & 44 & 0.0001 & 0.0001 & 0.0069 \\
\hline $\mathrm{n}-\mathrm{C}_{6}$ & 1.2406 & 0.0595 & 6 & 86 & 0.0007 & 0.0005 & 0.0499 \\
\hline $\mathrm{n}-\mathrm{C}_{7}$ & 2.2444 & 0.1077 & 7 & 100 & 0.0011 & 0.0007 & 0.0905 \\
\hline $\mathrm{n}-\mathrm{C}_{8}$ & 3.0958 & 0.1486 & 8 & 114 & 0.0013 & 0.0009 & 0.1251 \\
\hline $\mathrm{n}-\mathrm{C}_{9}$ & 2.8261 & 0.1357 & 9 & 128 & 0.0011 & 0.0007 & 0.1145 \\
\hline $\mathrm{n}-\mathrm{C}_{10}$ & 2.3262 & 0.1117 & 10 & 142 & 0.0008 & 0.0005 & 0.0944 \\
\hline$n-C_{11}$ & 2.0307 & 0.0975 & 11 & 156 & 0.0006 & 0.0004 & 0.0825 \\
\hline $\mathrm{n}-\mathrm{C}_{12}$ & 1.8018 & 0.0865 & 12 & 170 & 0.0005 & 0.0004 & 0.0733 \\
\hline$n-C_{13}$ & 1.6289 & 0.0782 & 13 & 184 & 0.0004 & 0.0003 & 0.0663 \\
\hline $\mathrm{n}-\mathrm{C}_{14}$ & 1.4888 & 0.0715 & 14 & 198 & 0.0004 & 0.0003 & 0.0606 \\
\hline $\mathrm{n}-\mathrm{C}_{15}$ & 1.3495 & 0.0648 & 15 & 212 & 0.0003 & 0.0002 & 0.0550 \\
\hline$n-C_{16}$ & 1.2316 & 0.0591 & 16 & 226 & 0.0003 & 0.0002 & 0.0502 \\
\hline $\mathrm{n}-\mathrm{C}_{17+}$ & 7.0452 & 0.3382 & 17 & 240 & 0.0014 & 0.0010 & 0.2874 \\
\hline i-paraffins & $\begin{array}{l}\text { wt\% in } \\
\text { Hydrocarbon } \\
\text { liquid phase }\end{array}$ & $\begin{array}{l}\text { weight } \\
\text { (g/day) }\end{array}$ & $\begin{array}{l}\text { Carbon } \\
\text { number }\end{array}$ & $\begin{array}{l}\text { Molecular weight } \\
\mathrm{g} / \mathrm{mol}\end{array}$ & $\mathrm{mol} /$ day & $\mathrm{mmol} / \mathrm{min}$ & $\begin{array}{l}\text { g carbon } \\
\text { /day }\end{array}$ \\
\hline $\mathrm{i}-\mathrm{C}_{5}$ & 2.2486 & 0.1079 & 5 & 44 & 0.0025 & 0.0017 & 0.1472 \\
\hline $\mathrm{i}-\mathrm{C}_{6}$ & 4.1912 & 0.2012 & 6 & 86 & 0.0023 & 0.0016 & 0.1684 \\
\hline $\mathrm{i}-\mathrm{C}_{7}$ & 10.1042 & 0.4850 & 7 & 100 & 0.0049 & 0.0034 & 0.4074 \\
\hline $\mathrm{i}-\mathrm{C}_{8}$ & 11.4157 & 0.5480 & 8 & 114 & 0.0048 & 0.0033 & 0.4614 \\
\hline $\mathrm{i}-\mathrm{C}_{9}$ & 9.2423 & 0.4436 & 9 & 128 & 0.0035 & 0.0024 & 0.3743 \\
\hline $\mathrm{i}-\mathrm{C}_{10}$ & 7.4218 & 0.3562 & 10 & 142 & 0.0025 & 0.0017 & 0.3011 \\
\hline $\mathrm{i}-\mathrm{C}_{11}$ & 5.9118 & 0.2838 & 11 & 156 & 0.0018 & 0.0013 & 0.2401 \\
\hline $\mathrm{i}-\mathrm{C}_{12}$ & 4.5354 & 0.2177 & 12 & 170 & 0.0013 & 0.0009 & 0.1844 \\
\hline $\mathrm{i}-\mathrm{C}_{13}$ & 3.5116 & 0.1686 & 13 & 184 & 0.0009 & 0.0006 & 0.1429 \\
\hline $\mathrm{i}-\mathrm{C}_{14}$ & 2.7191 & 0.1305 & 14 & 198 & 0.0007 & 0.0005 & 0.1107 \\
\hline $\mathrm{i}-\mathrm{C}_{15}$ & 2.1167 & 0.1016 & 15 & 212 & 0.0005 & 0.0003 & 0.0863 \\
\hline $\mathrm{i}-\mathrm{C}_{16}$ & 1.6376 & 0.0786 & 16 & 226 & 0.0003 & 0.0002 & 0.0668 \\
\hline \multirow[t]{2}{*}{$\mathrm{i}-\mathrm{C}_{17+}$} & 6.5297 & 0.3134 & 17 & 240 & 0.0013 & 0.0009 & 0.2664 \\
\hline & & & & & & Total in oil & 4.1139 \\
\hline Alcohols & $\begin{array}{l}\text { wt } \% \text { in aqueous } \\
\text { liquid phase }\end{array}$ & $\begin{array}{l}\text { weight } \\
\text { (g/day) }\end{array}$ & $\begin{array}{l}\text { Carbon } \\
\text { number }\end{array}$ & $\begin{array}{l}\text { Molecular weight } \\
\mathrm{g} / \mathrm{mol}\end{array}$ & $\mathrm{mol} /$ day & $\mathrm{mmol} / \mathrm{min}$ & $\begin{array}{l}\text { g carbon } \\
\text { /day }\end{array}$ \\
\hline Methanol & 9.6000 & 0.3072 & 1 & 32 & 0.0096 & 0.0067 & 0.1152 \\
\hline Ethanol & 18.6000 & 0.5952 & 2 & 46 & 0.0129 & 0.0090 & 0.3105 \\
\hline 2-Propanol & 3.6000 & 0.1152 & 3 & 60 & 0.0019 & 0.0013 & 0.0691 \\
\hline 1-Propanol & 8.6000 & 0.2752 & 3 & 60 & 0.0046 & 0.0032 & 0.1651 \\
\hline 2-Butanol & 0.8000 & 0.0256 & 4 & 74 & 0.0003 & 0.0002 & 0.0166 \\
\hline 1-Butanol & 4.2000 & 0.1344 & 4 & 74 & 0.0018 & 0.0013 & 0.0872 \\
\hline 2-Pentanol & 0.0000 & 0.0000 & 5 & 88 & 0.0000 & 0.0000 & 0.0000 \\
\hline 1-Pentanol & 2.6000 & 0.0832 & 5 & 88 & 0.0009 & 0.0007 & 0.0567 \\
\hline \multirow[t]{2}{*}{ Water } & 52.0000 & 1.6640 & 0 & 18 & 0.0924 & 0.0642 & 0.0000 \\
\hline & & & & & & Total in aqueous & 0.7053 \\
\hline \multicolumn{3}{|c|}{ Total carbon due to oil and aqueous phase } & \multicolumn{2}{|c|}{4.8192 g carbon /day } & & & \\
\hline
\end{tabular}




\begin{tabular}{|c|c|c|c|c|c|c|c|}
\hline \multicolumn{8}{|c|}{$\begin{array}{l}\text { Separate-bed catalyst arrangement, ZSM- } 5 \text { weight }=0.25 \mathrm{~g} \\
\text { Base catalyst weight }=0.5 \mathrm{~g}, \mathrm{~T}=300^{\circ} \mathrm{C}, \mathrm{H}_{2} / \mathrm{CO} \text { ratio }=1, \\
\text { total feed rate }=100 \mathrm{scc} / \mathrm{min} \text {, reactor pressure }=300 \mathrm{psi}, \mathrm{TOS}=24-48 \mathrm{~h} \text {, Organic phase wt }=7.2902 \mathrm{~g}, \text { Aqueous phase wt }=2.4 \mathrm{~g}\end{array}$} \\
\hline Aromatics & $\begin{array}{l}\text { wt } \% \text { in } \\
\text { Hydrocarbon } \\
\text { liquid phase }\end{array}$ & $\begin{array}{l}\text { weight } \\
\text { (g/day) }\end{array}$ & $\begin{array}{l}\text { Carbon } \\
\text { number }\end{array}$ & $\begin{array}{l}\text { Molecular } \\
\text { weight } \\
\text { g/mol }\end{array}$ & $\mathrm{mol} /$ day & $\mathrm{mmol} / \mathrm{min}$ & $\begin{array}{l}\text { g carbon } \\
\text { /day }\end{array}$ \\
\hline Toluene & 1.3638 & 0.0994 & 7 & 92 & 0.0011 & 0.0008 & 0.0908 \\
\hline p-xylene & 2.3034 & 0.1679 & 8 & 106 & 0.0016 & 0.0011 & 0.1521 \\
\hline $\begin{array}{l}\text { propyl- } \\
\text { benzene }\end{array}$ & 2.1294 & 0.1552 & 9 & 120 & 0.0013 & 0.0009 & 0.1397 \\
\hline butyl-benzene & 0.6555 & 0.0478 & 10 & 134 & 0.0004 & 0.0002 & 0.0428 \\
\hline n-praffins & $\begin{array}{l}\text { wt } \% \text { in } \\
\text { Hydrocarbon } \\
\text { liquid phase }\end{array}$ & $\begin{array}{l}\text { weight } \\
\text { (g/day) }\end{array}$ & $\begin{array}{l}\text { Carbon } \\
\text { number }\end{array}$ & $\begin{array}{l}\text { Molecular } \\
\text { weight } \\
\text { g/mol }\end{array}$ & mol/day & $\mathrm{mmol} / \mathrm{min}$ & $\begin{array}{l}\text { g carbon } \\
\text { /day }\end{array}$ \\
\hline $\mathrm{n}-\mathrm{C}_{5}$ & 0.7134 & 0.0520 & 5 & 44 & 0.0012 & 0.0008 & 0.0709 \\
\hline $\mathrm{n}-\mathrm{C}_{6}$ & 5.2186 & 0.3804 & 6 & 86 & 0.0044 & 0.0031 & 0.3185 \\
\hline $\mathrm{n}-\mathrm{C}_{7}$ & 8.7701 & 0.6394 & 7 & 100 & 0.0064 & 0.0044 & 0.5371 \\
\hline $\mathrm{n}-\mathrm{C}_{8}$ & 4.1738 & 0.3043 & 8 & 114 & 0.0027 & 0.0019 & 0.2562 \\
\hline $\mathrm{n}-\mathrm{C}_{9}$ & 2.6472 & 0.1930 & 9 & 128 & 0.0015 & 0.0010 & 0.1628 \\
\hline $\mathrm{n}-\mathrm{C}_{10}$ & 2.1503 & 0.1568 & 10 & 142 & 0.0011 & 0.0008 & 0.1325 \\
\hline$n-C_{11}$ & 1.2047 & 0.0878 & 11 & 156 & 0.0006 & 0.0004 & 0.0743 \\
\hline$n-C_{12}$ & 0.5045 & 0.0368 & 12 & 170 & 0.0002 & 0.0002 & 0.0312 \\
\hline$n-C_{13}$ & 0.3033 & 0.0221 & 13 & 184 & 0.0001 & 0.0001 & 0.0187 \\
\hline$n-C_{14}$ & 0.2147 & 0.0157 & 14 & 198 & 0.0001 & 0.0001 & 0.0133 \\
\hline $\mathrm{n}-\mathrm{C}_{15}$ & 0.0907 & 0.0066 & 15 & 212 & 0.0000 & 0.0000 & 0.0056 \\
\hline$n-C_{16}$ & 0.0143 & 0.0010 & 16 & 226 & 0.0000 & 0.0000 & 0.0009 \\
\hline $\mathrm{n}-\mathrm{C}_{17+}$ & 0.0490 & 0.0036 & 17 & 240 & 0.0000 & 0.0000 & 0.0030 \\
\hline i-paraffins & $\begin{array}{l}\text { wt } \% \text { in } \\
\text { Hydrocarbon } \\
\text { liquid phase }\end{array}$ & $\begin{array}{l}\text { weight } \\
\text { (g/day) }\end{array}$ & $\begin{array}{l}\text { Carbon } \\
\text { number }\end{array}$ & $\begin{array}{l}\text { Molecular } \\
\text { weight } \\
\text { g/mol }\end{array}$ & $\mathrm{mol} /$ day & $\mathrm{mmol} / \mathrm{min}$ & $\begin{array}{l}\text { g carbon } \\
\text { /day }\end{array}$ \\
\hline $\mathrm{i}-\mathrm{C}_{5}$ & 2.9301 & 0.2136 & 5 & 44 & 0.0049 & 0.0034 & 0.2913 \\
\hline $\mathrm{i}-\mathrm{C}_{6}$ & 2.3980 & 0.1748 & 6 & 86 & 0.0020 & 0.0014 & 0.1464 \\
\hline $\mathrm{i}-\mathrm{C}_{7}$ & 24.8467 & 1.8114 & 7 & 100 & 0.0181 & 0.0126 & 1.5216 \\
\hline $\mathrm{i}-\mathrm{C}_{8}$ & 17.8412 & 1.3007 & 8 & 114 & 0.0114 & 0.0079 & 1.0953 \\
\hline i-C 9 & 7.8106 & 0.5694 & 9 & 128 & 0.0044 & 0.0031 & 0.4804 \\
\hline $\mathrm{i}-\mathrm{C}_{10}$ & 5.6662 & 0.4131 & 10 & 142 & 0.0029 & 0.0020 & 0.3491 \\
\hline $\mathrm{i}-\mathrm{C}_{11}$ & 2.8323 & 0.2065 & 11 & 156 & 0.0013 & 0.0009 & 0.1747 \\
\hline $\mathrm{i}-\mathrm{C}_{12}$ & 1.5930 & 0.1161 & 12 & 170 & 0.0007 & 0.0005 & 0.0984 \\
\hline $\mathrm{i}-\mathrm{C}_{13}$ & 0.5345 & 0.0390 & 13 & 184 & 0.0002 & 0.0001 & 0.0330 \\
\hline $\mathrm{i}-\mathrm{C}_{14}$ & 0.4944 & 0.0360 & 14 & 198 & 0.0002 & 0.0001 & 0.0306 \\
\hline $\mathrm{i}-\mathrm{C}_{15}$ & 0.1682 & 0.0123 & 15 & 212 & 0.0001 & 0.0000 & 0.0104 \\
\hline $\mathrm{i}-\mathrm{C}_{16}$ & 0.2408 & 0.0176 & 16 & 226 & 0.0001 & 0.0001 & 0.0149 \\
\hline \multirow[t]{2}{*}{$\mathrm{i}-\mathrm{C}_{17+}$} & 0.1374 & 0.0100 & 17 & 240 & 0.0000 & 0.0000 & 0.0085 \\
\hline & & & & & & Total in oil & 6.3050 \\
\hline Alcohols & $\begin{array}{l}\text { wt } \% \text { in } \\
\text { aqueous liquid } \\
\text { phase }\end{array}$ & $\begin{array}{l}\text { weight } \\
\text { (g/day) }\end{array}$ & $\begin{array}{l}\text { Carbon } \\
\text { number }\end{array}$ & $\begin{array}{l}\text { Molecular } \\
\text { weight } \\
\text { g/mol }\end{array}$ & $\mathrm{mol} /$ day & $\mathrm{mmol} / \mathrm{min}$ & $\begin{array}{l}\text { g carbon } \\
\text { /day }\end{array}$ \\
\hline Methanol & 0.0047 & 0.0001 & 1 & 32 & 0.0000 & 0.0000 & 0.0000 \\
\hline Ethanol & 0.0011 & 0.0000 & 2 & 46 & 0.0000 & 0.0000 & 0.0000 \\
\hline 2-Propanol & 4.3418 & 0.1042 & 3 & 60 & 0.0017 & 0.0012 & 0.0625 \\
\hline 1-Propanol & 0.0000 & 0.0000 & 3 & 60 & 0.0000 & 0.0000 & 0.0000 \\
\hline 2-Butanol & 0.5820 & 0.0140 & 4 & 74 & 0.0002 & 0.0001 & 0.0091 \\
\hline 1-Butanol & 0.0000 & 0.0000 & 4 & 74 & 0.0000 & 0.0000 & 0.0000 \\
\hline 2-Pentanol & 0.0083 & 0.0002 & 5 & 88 & 0.0000 & 0.0000 & 0.0001 \\
\hline 1-Pentanol & 0.0000 & 0.0000 & 5 & 88 & 0.0000 & 0.0000 & 0.0000 \\
\hline \multirow[t]{2}{*}{ water } & 95.0621 & 2.2815 & 0 & 18 & 0.1267 & 0.0880 & 0.0000 \\
\hline & & & & & & Total in aqueous & 0.0717 \\
\hline \multicolumn{3}{|c|}{ Total carbon due to oil and aqueous phase } & \multicolumn{2}{|c|}{6.3767 g carbon /day } & & & \\
\hline
\end{tabular}




\begin{tabular}{|c|c|c|c|c|c|c|c|}
\hline \multicolumn{8}{|c|}{$\begin{array}{l}\text { Separate-bed catalyst arrangement, ZSM- } 5 \text { weight }=0.5 \mathrm{~g} \\
\text { Base catalyst weight }=0.5 \mathrm{~g}, \mathrm{~T}=300^{\circ} \mathrm{C}, \mathrm{H}_{2} / \mathrm{CO} \text { ratio }=1, \\
\text { total feed rate }=100 \mathrm{scc} / \mathrm{min}, \text { reactor pressure }=300 \mathrm{psi}, \mathrm{T}\end{array}$} \\
\hline Aromatics & $\begin{array}{l}\text { wt \% in Hydrocarbon } \\
\text { liquid phase }\end{array}$ & $\begin{array}{l}\text { weight } \\
\text { (g/day) }\end{array}$ & $\begin{array}{l}\text { Carbon } \\
\text { number }\end{array}$ & $\begin{array}{l}\text { Molecular weight } \\
\mathrm{g} / \mathrm{mol}\end{array}$ & $\mathrm{mol} / \mathrm{day}$ & $\mathrm{mmol} / \mathrm{min}$ & $\begin{array}{l}\text { g carbon } \\
\text { /day }\end{array}$ \\
\hline toluene & 6.8455 & 0.5057 & 7 & 92 & 0.0055 & 0.0038 & 0.4617 \\
\hline p-xylene & 11.0089 & 0.8133 & 8 & 106 & 0.0077 & 0.0053 & 0.7366 \\
\hline $\begin{array}{l}\text { propyl- } \\
\text { benzene }\end{array}$ & 8.4654 & 0.6254 & 9 & 120 & 0.0052 & 0.0036 & 0.5628 \\
\hline $\begin{array}{l}\text { butyl- } \\
\text { benzene }\end{array}$ & 1.3622 & 0.1006 & 10 & 134 & 0.0008 & 0.0005 & 0.0901 \\
\hline n-praffins & $\begin{array}{l}\text { wt\% in Hydrocarbon } \\
\text { liquid phase }\end{array}$ & $\begin{array}{l}\text { weight } \\
\text { (g/day) }\end{array}$ & $\begin{array}{l}\text { Carbon } \\
\text { number }\end{array}$ & $\begin{array}{l}\text { Molecular weight } \\
\mathrm{g} / \mathrm{mol}\end{array}$ & $\mathrm{mol} /$ day & $\mathrm{mmol} / \mathrm{min}$ & $\begin{array}{l}\text { g carbon } \\
\text { /day }\end{array}$ \\
\hline $\mathrm{n}-\mathrm{C}_{5}$ & 1.0289 & 0.0760 & 5 & 44 & 0.0017 & 0.0012 & 0.1036 \\
\hline$n-C_{6}$ & 4.3825 & 0.3238 & 6 & 86 & 0.0038 & 0.0026 & 0.2711 \\
\hline $\mathrm{n}-\mathrm{C}_{7}$ & 2.7556 & 0.2036 & 7 & 100 & 0.0020 & 0.0014 & 0.1710 \\
\hline $\mathrm{n}-\mathrm{C}_{8}$ & 1.1798 & 0.0872 & 8 & 114 & 0.0008 & 0.0005 & 0.0734 \\
\hline $\mathrm{n}-\mathrm{C}_{9}$ & 0.9667 & 0.0714 & 9 & 128 & 0.0006 & 0.0004 & 0.0603 \\
\hline $\mathrm{n}-\mathrm{C}_{10}$ & 0.8891 & 0.0657 & 10 & 142 & 0.0005 & 0.0003 & 0.0555 \\
\hline $\mathrm{n}-\mathrm{C}_{11}$ & 0.4850 & 0.0358 & 11 & 156 & 0.0002 & 0.0002 & 0.0303 \\
\hline$n-C_{12}$ & 0.3497 & 0.0258 & 12 & 170 & 0.0002 & 0.0001 & 0.0219 \\
\hline$n-C_{13}$ & 0.2169 & 0.0160 & 13 & 184 & 0.0001 & 0.0001 & 0.0136 \\
\hline$n-C_{14}$ & 0.3071 & 0.0227 & 14 & 198 & 0.0001 & 0.0001 & 0.0193 \\
\hline$n-C_{15}$ & 0.0596 & 0.0044 & 15 & 212 & 0.0000 & 0.0000 & 0.0037 \\
\hline$n-C_{16}$ & 0.0373 & 0.0028 & 16 & 226 & 0.0000 & 0.0000 & 0.0023 \\
\hline $\mathrm{n}-\mathrm{C}_{17+}$ & 0.2703 & 0.0200 & 17 & 240 & 0.0001 & 0.0001 & 0.0170 \\
\hline i-paraffins & $\begin{array}{l}\text { wt\% in Hydrocarbon } \\
\text { liquid phase }\end{array}$ & $\begin{array}{l}\text { weight } \\
\text { (g/day) }\end{array}$ & $\begin{array}{l}\text { Carbon } \\
\text { number }\end{array}$ & $\begin{array}{l}\text { Molecular weight } \\
\mathrm{g} / \mathrm{mol}\end{array}$ & $\mathrm{mol} / \mathrm{day}$ & $\mathrm{mmol} / \mathrm{min}$ & $\begin{array}{l}\text { g carbon } \\
\text { /day }\end{array}$ \\
\hline $\mathrm{i}-\mathrm{C}_{5}$ & 1.2832 & 0.0948 & 5 & 44 & 0.0022 & 0.0015 & 0.1293 \\
\hline $\mathrm{i}-\mathrm{C}_{6}$ & 2.4117 & 0.1782 & 6 & 86 & 0.0021 & 0.0014 & 0.1492 \\
\hline $\mathrm{i}-\mathrm{C}_{7}$ & 13.9700 & 1.0320 & 7 & 100 & 0.0103 & 0.0072 & 0.8669 \\
\hline $\mathrm{i}-\mathrm{C}_{8}$ & 12.9020 & 0.9531 & 8 & 114 & 0.0084 & 0.0058 & 0.8026 \\
\hline $\mathrm{i}-\mathrm{C}_{9}$ & 8.4753 & 0.6261 & 9 & 128 & 0.0049 & 0.0034 & 0.5283 \\
\hline $\mathrm{i}-\mathrm{C}_{10}$ & 7.8914 & 0.5830 & 10 & 142 & 0.0041 & 0.0029 & 0.4927 \\
\hline $\mathrm{i}-\mathrm{C}_{11}$ & 3.7504 & 0.2771 & 11 & 156 & 0.0018 & 0.0012 & 0.2344 \\
\hline $\mathrm{i}-\mathrm{C}_{12}$ & 4.4465 & 0.3285 & 12 & 170 & 0.0019 & 0.0013 & 0.2782 \\
\hline $\mathrm{i}-\mathrm{C}_{13}$ & 2.2063 & 0.1630 & 13 & 184 & 0.0009 & 0.0006 & 0.1382 \\
\hline $\mathrm{i}-\mathrm{C}_{14}$ & 1.3136 & 0.0970 & 14 & 198 & 0.0005 & 0.0003 & 0.0823 \\
\hline $\mathrm{i}-\mathrm{C}_{15}$ & 0.3917 & 0.0289 & 15 & 212 & 0.0001 & 0.0001 & 0.0246 \\
\hline $\mathrm{i}-\mathrm{C}_{16}$ & 0.1660 & 0.0123 & 16 & 226 & 0.0001 & 0.0000 & 0.0104 \\
\hline \multirow[t]{2}{*}{$\mathrm{i}-\mathrm{C}_{17+}$} & 0.2266 & 0.0167 & 17 & 240 & 0.0001 & 0.0000 & 0.0142 \\
\hline & & & & & & Sum in oil & 6.4456 \\
\hline Alcohols & $\begin{array}{l}\text { wt } \% \text { in aqueous liquid } \\
\text { phase }\end{array}$ & $\begin{array}{l}\text { weight } \\
\text { (g/day) }\end{array}$ & $\begin{array}{l}\text { Carbon } \\
\text { number }\end{array}$ & $\begin{array}{l}\text { Molecular weight } \\
\mathrm{g} / \mathrm{mol}\end{array}$ & $\mathrm{mol} / \mathrm{day}$ & $\mathrm{mmol} / \mathrm{min}$ & $\begin{array}{l}\text { g carbon } \\
\text { /day }\end{array}$ \\
\hline Methanol & 0.0000 & 0.0000 & 1 & 32 & 0.0000 & 0.0000 & 0.0000 \\
\hline Ethanol & 0.0558 & 0.0012 & 2 & 46 & 0.0000 & 0.0000 & 0.0006 \\
\hline 2-Propanol & 0.1807 & 0.0038 & 3 & 60 & 0.0001 & 0.0000 & 0.0023 \\
\hline 1-Propanol & 0.0000 & 0.0000 & 3 & 60 & 0.0000 & 0.0000 & 0.0000 \\
\hline 2-Butanol & 0.0000 & 0.0000 & 4 & 74 & 0.0000 & 0.0000 & 0.0000 \\
\hline 1-Butanol & 0.0000 & 0.0000 & 4 & 74 & 0.0000 & 0.0000 & 0.0000 \\
\hline 2-Pentanol & 0.0000 & 0.0000 & 5 & 88 & 0.0000 & 0.0000 & 0.0000 \\
\hline 1-Pentanol & 0.0000 & 0.0000 & 5 & 88 & 0.0000 & 0.0000 & 0.0000 \\
\hline \multirow[t]{2}{*}{ Water } & 99.7634 & 2.1075 & 0 & 18 & 0.1171 & 0.0813 & 0.0000 \\
\hline & & & & & & $\begin{array}{l}\text { Total in } \\
\text { aqueous }\end{array}$ & 0.0029 \\
\hline \multicolumn{3}{|c|}{ Total carbon due to oil and aqueous phase } & \multicolumn{2}{|c|}{6.4485 g carbon /day } & & & \\
\hline
\end{tabular}




\begin{tabular}{|c|c|c|c|c|c|c|c|}
\hline \multicolumn{8}{|c|}{$\begin{array}{l}\text { Separate-bed catalyst arrangement, ZSM- } 5 \text { weight }=1 \mathrm{~g} \\
\text { Base catalyst weight }=0.5 \mathrm{~g}, \mathrm{~T}=300^{\circ} \mathrm{C}, \mathrm{H}_{2} / \mathrm{CO} \text { ratio }=1, \\
\text { total feed rate }=100 \mathrm{scc} / \mathrm{min} \text {, reactor pressure }=300 \mathrm{psi}, \mathrm{TOS}=24-48 \mathrm{~h} \text {, Organic phase wt }=5.6756 \mathrm{~g} \text {, Aqueous phase wt }=2.5 \mathrm{~g}\end{array}$} \\
\hline Aromatics & $\begin{array}{l}\text { wt\% in Hydrocarbon } \\
\text { liquid phase }\end{array}$ & $\begin{array}{l}\text { weight } \\
\text { (g/day) }\end{array}$ & $\begin{array}{l}\text { Carbon } \\
\text { number }\end{array}$ & $\begin{array}{l}\text { Molecular weight } \\
\mathrm{g} / \mathrm{mol}\end{array}$ & $\mathrm{mol} / \mathrm{day}$ & $\mathrm{mmol} / \mathrm{min}$ & $\begin{array}{l}\text { g carbon } \\
\text { /day }\end{array}$ \\
\hline toluene & 15.2457 & 0.8653 & 7 & 92 & 0.0094 & 0.0065 & 0.7900 \\
\hline p-xylene & 16.5359 & 0.9385 & 8 & 106 & 0.0089 & 0.0061 & 0.8500 \\
\hline $\begin{array}{l}\text { propyl- } \\
\text { benzene }\end{array}$ & 10.0745 & 0.5718 & 9 & 120 & 0.0048 & 0.0033 & 0.5146 \\
\hline $\begin{array}{l}\text { butyl- } \\
\text { benzene }\end{array}$ & 1.0935 & 0.0621 & 10 & 134 & 0.0005 & 0.0003 & 0.0556 \\
\hline n-praffins & $\begin{array}{l}\text { wt\% in Hydrocarbon } \\
\text { liquid phase }\end{array}$ & $\begin{array}{l}\text { weight } \\
\text { (g/day) }\end{array}$ & $\begin{array}{l}\text { Carbon } \\
\text { number }\end{array}$ & $\begin{array}{l}\text { Molecular weight } \\
\mathrm{g} / \mathrm{mol}\end{array}$ & $\mathrm{mol} / \mathrm{day}$ & $\mathrm{mmol} / \mathrm{min}$ & $\begin{array}{l}\text { g carbon } \\
\text { /day }\end{array}$ \\
\hline $\mathrm{n}-\mathrm{C}_{5}$ & 1.6643 & 0.0945 & 5 & 44 & 0.0021 & 0.0015 & 0.1288 \\
\hline$n-C_{6}$ & 1.6399 & 0.0931 & 6 & 86 & 0.0011 & 0.0008 & 0.0779 \\
\hline$n-C_{7}$ & 0.4166 & 0.0236 & 7 & 100 & 0.0002 & 0.0002 & 0.0199 \\
\hline$n-C_{8}$ & 0.0769 & 0.0044 & 8 & 114 & 0.0000 & 0.0000 & 0.0037 \\
\hline $\mathrm{n}-\mathrm{C}_{9}$ & 0.0634 & 0.0036 & 9 & 128 & 0.0000 & 0.0000 & 0.0030 \\
\hline $\mathrm{n}-\mathrm{C}_{10}$ & 0.0740 & 0.0042 & 10 & 142 & 0.0000 & 0.0000 & 0.0036 \\
\hline$n-C_{11}$ & 0.4098 & 0.0233 & 11 & 156 & 0.0001 & 0.0001 & 0.0197 \\
\hline$n-C_{12}$ & 0.1071 & 0.0061 & 12 & 170 & 0.0000 & 0.0000 & 0.0051 \\
\hline$n-C_{13}$ & 0.1052 & 0.0060 & 13 & 184 & 0.0000 & 0.0000 & 0.0051 \\
\hline$n-C_{14}$ & 0.3754 & 0.0213 & 14 & 198 & 0.0001 & 0.0001 & 0.0181 \\
\hline$n-C_{15}$ & 0.0591 & 0.0034 & 15 & 212 & 0.0000 & 0.0000 & 0.0028 \\
\hline$n-C_{16}$ & 0.0565 & 0.0032 & 16 & 226 & 0.0000 & 0.0000 & 0.0027 \\
\hline$n-C_{17+}$ & 0.0326 & 0.0018 & 17 & 240 & 0.0000 & 0.0000 & 0.0016 \\
\hline i-paraffins & $\begin{array}{l}\text { wt } \% \text { in Hydrocarbon } \\
\text { liquid phase }\end{array}$ & $\begin{array}{l}\text { weight } \\
\text { (g/day) }\end{array}$ & $\begin{array}{l}\text { Carbon } \\
\text { number }\end{array}$ & $\begin{array}{l}\text { Molecular weight } \\
\mathrm{g} / \mathrm{mol}\end{array}$ & $\mathrm{mol} /$ day & $\mathrm{mmol} / \mathrm{min}$ & $\begin{array}{l}\text { g carbon } \\
\text { /day }\end{array}$ \\
\hline $\mathrm{i}-\mathrm{C}_{5}$ & 6.5901 & 0.3740 & 5 & 44 & 0.0085 & 0.0059 & 0.5100 \\
\hline $\mathrm{i}-\mathrm{C}_{6}$ & 3.6867 & 0.2092 & 6 & 86 & 0.0024 & 0.0017 & 0.1752 \\
\hline $\mathrm{i}-\mathrm{C}_{7}$ & 10.5824 & 0.6006 & 7 & 100 & 0.0060 & 0.0042 & 0.5045 \\
\hline $\mathrm{i}-\mathrm{C}_{8}$ & 6.3608 & 0.3610 & 8 & 114 & 0.0032 & 0.0022 & 0.3040 \\
\hline $\mathrm{i}-\mathrm{C}_{9}$ & 5.3770 & 0.3052 & 9 & 128 & 0.0024 & 0.0017 & 0.2575 \\
\hline $\mathrm{i}-\mathrm{C}_{10}$ & 7.3999 & 0.4200 & 10 & 142 & 0.0030 & 0.0021 & 0.3549 \\
\hline $\mathrm{i}-\mathrm{C}_{11}$ & 3.3578 & 0.1906 & 11 & 156 & 0.0012 & 0.0008 & 0.1613 \\
\hline $\mathrm{i}-\mathrm{C}_{12}$ & 3.2602 & 0.1850 & 12 & 170 & 0.0011 & 0.0008 & 0.1567 \\
\hline $\mathrm{i}-\mathrm{C}_{13}$ & 2.1474 & 0.1219 & 13 & 184 & 0.0007 & 0.0005 & 0.1033 \\
\hline $\mathrm{i}-\mathrm{C}_{14}$ & 1.7614 & 0.1000 & 14 & 198 & 0.0005 & 0.0004 & 0.0848 \\
\hline $\mathrm{i}-\mathrm{C}_{15}$ & 0.8845 & 0.0502 & 15 & 212 & 0.0002 & 0.0002 & 0.0426 \\
\hline $\mathrm{i}-\mathrm{C}_{16}$ & 0.3872 & 0.0220 & 16 & 226 & 0.0001 & 0.0001 & 0.0187 \\
\hline \multirow[t]{2}{*}{$\mathrm{i}-\mathrm{C}_{17+}$} & 0.1711 & 0.0097 & 17 & 240 & 0.0000 & 0.0000 & 0.0083 \\
\hline & & & & & & Total in oil & 5.1840 \\
\hline Alcohols & $\begin{array}{l}\text { wt } \% \text { in aqueous } \\
\text { liquid phase }\end{array}$ & $\begin{array}{l}\text { weight } \\
\text { (g/day) }\end{array}$ & $\begin{array}{l}\text { Carbon } \\
\text { number }\end{array}$ & $\begin{array}{l}\text { Molecular weight } \\
\text { g/mol }\end{array}$ & $\mathrm{mol} / \mathrm{day}$ & $\mathrm{mmol} / \mathrm{min}$ & $\begin{array}{l}\text { g carbon } \\
\text { /day }\end{array}$ \\
\hline Methanol & 0.0000 & 0.0000 & 1 & 32 & 0.0000 & 0.0000 & 0.0000 \\
\hline Ethanol & 0.0000 & 0.0000 & 2 & 46 & 0.0000 & 0.0000 & 0.0000 \\
\hline 2-Propanol & 0.1000 & 0.0021 & 3 & 60 & 0.0000 & 0.0000 & 0.0013 \\
\hline 1-Propanol & 0.0000 & 0.0000 & 3 & 60 & 0.0000 & 0.0000 & 0.0000 \\
\hline 2-Butanol & 0.2000 & 0.0042 & 4 & 74 & 0.0001 & 0.0000 & 0.0027 \\
\hline 1-Butanol & 0.0000 & 0.0000 & 4 & 74 & 0.0000 & 0.0000 & 0.0000 \\
\hline 2-Pentanol & 0.0000 & 0.0000 & 5 & 88 & 0.0000 & 0.0000 & 0.0000 \\
\hline 1-Pentanol & 0.0000 & 0.0000 & 5 & 88 & 0.0000 & 0.0000 & 0.0000 \\
\hline \multirow[t]{2}{*}{ Water } & 99.7000 & 2.1062 & 0 & 18 & 0.1170 & 0.0813 & 0.0000 \\
\hline & & & & & & $\begin{array}{l}\text { Total in } \\
\text { aqueous }\end{array}$ & 0.0040 \\
\hline \multicolumn{3}{|c|}{ Total carbon due to oil and aqueous phase } & \multicolumn{2}{|c|}{$5.1880 \mathrm{~g}$ carbon /day } & & & \\
\hline
\end{tabular}




\begin{tabular}{|c|c|c|c|c|c|c|c|}
\hline \multicolumn{8}{|c|}{$\begin{array}{l}\text { Base catalyst weight }=0.5 \mathrm{~g}, \mathrm{ZSM}-5 \text { weight }=0.5 \mathrm{~g}, \mathrm{H}_{2} / \mathrm{CO} \text { ratio }=1, \\
\text { total feed rate }=100 \mathrm{scc} / \mathrm{min} \text {, reactor pressure }=300 \mathrm{psi}, \mathrm{TOS}=24-48 \mathrm{~h}, \text { Organic phase } \mathrm{wt}=3.25 \mathrm{~g}, \text { Aqueous phase } \mathrm{wt}=1.5 \mathrm{~g}\end{array}$} \\
\hline Aromatics & $\begin{array}{l}\text { wt } \% \text { in } \\
\text { Hydrocarbon } \\
\text { liquid phase }\end{array}$ & $\begin{array}{l}\text { weight } \\
\text { (g/day) }\end{array}$ & $\begin{array}{l}\text { Carbon } \\
\text { number }\end{array}$ & $\begin{array}{l}\text { Molecular } \\
\text { weight } \mathrm{g} / \mathrm{mol}\end{array}$ & $\mathrm{mol} /$ day & $\mathrm{mmol} / \mathrm{min}$ & $\begin{array}{l}\text { g carbon } \\
\text { /day }\end{array}$ \\
\hline toluene & 1.0357 & 0.0337 & 7.0000 & 92.0000 & 0.0004 & 0.0003 & 0.0307 \\
\hline p-xylene & 3.3722 & 0.1096 & 8.0000 & 106.0000 & 0.0010 & 0.0007 & 0.0993 \\
\hline $\begin{array}{l}\text { propyl- } \\
\text { benzene }\end{array}$ & 3.3797 & 0.1098 & 9.0000 & 120.0000 & 0.0009 & 0.0006 & 0.0989 \\
\hline $\begin{array}{l}\text { butyl- } \\
\text { benzene }\end{array}$ & 1.1367 & 0.0369 & 10.0000 & 134.0000 & 0.0003 & 0.0002 & 0.0331 \\
\hline n-praffins & $\begin{array}{l}\text { wt } \% \text { in } \\
\text { Hydrocarbon } \\
\text { liquid phase }\end{array}$ & $\begin{array}{l}\text { weight } \\
\text { (g/day) }\end{array}$ & $\begin{array}{l}\text { Carbon } \\
\text { number }\end{array}$ & $\begin{array}{l}\text { Molecular } \\
\text { weight } \mathrm{g} / \mathrm{mol}\end{array}$ & $\mathrm{mol} /$ day & $\mathrm{mmol} / \mathrm{min}$ & $\begin{array}{l}\text { g carbon } \\
\text { /day }\end{array}$ \\
\hline $\mathrm{n}-\mathrm{C}_{5}$ & 0.6063 & 0.0197 & 5 & 44 & 0.0004 & 0.0003 & 0.0269 \\
\hline $\mathrm{n}-\mathrm{C}_{6}$ & 5.6893 & 0.1849 & 6 & 86 & 0.0022 & 0.0015 & 0.1548 \\
\hline $\mathrm{n}-\mathrm{C}_{7}$ & 5.0600 & 0.1645 & 7 & 100 & 0.0016 & 0.0011 & 0.1381 \\
\hline $\mathrm{n}-\mathrm{C}_{8}$ & 3.1135 & 0.1012 & 8 & 114 & 0.0009 & 0.0006 & 0.0852 \\
\hline n-C $C_{9}$ & 2.5818 & 0.0839 & 9 & 128 & 0.0007 & 0.0005 & 0.0708 \\
\hline $\mathrm{n}-\mathrm{C}_{10}$ & 2.0503 & 0.0666 & 10 & 142 & 0.0005 & 0.0003 & 0.0563 \\
\hline $\mathrm{n}-\mathrm{C}_{11}$ & 0.5547 & 0.0180 & 11 & 156 & 0.0001 & 0.0001 & 0.0153 \\
\hline$n-C_{12}$ & 0.3289 & 0.0107 & 12 & 170 & 0.0001 & 0.0000 & 0.0091 \\
\hline$n-C_{13}$ & 0.1538 & 0.0050 & 13 & 184 & 0.0000 & 0.0000 & 0.0042 \\
\hline$n-C_{14}$ & 0.1524 & 0.0050 & 14 & 198 & 0.0000 & 0.0000 & 0.0042 \\
\hline$n-C_{15}$ & 0.1205 & 0.0039 & 15 & 212 & 0.0000 & 0.0000 & 0.0033 \\
\hline$n-C_{16}$ & 0.0989 & 0.0032 & 16 & 226 & 0.0000 & 0.0000 & 0.0027 \\
\hline $\mathrm{n}-\mathrm{C}_{17+}$ & 0.1569 & 0.0051 & 17 & 240 & 0.0000 & 0.0000 & 0.0043 \\
\hline i-paraffins & $\begin{array}{l}\text { wt } \% \text { in } \\
\text { Hydrocarbon } \\
\text { liquid phase }\end{array}$ & $\begin{array}{l}\text { weight } \\
\text { (g/day) }\end{array}$ & $\begin{array}{l}\text { Carbon } \\
\text { number }\end{array}$ & $\begin{array}{l}\text { Molecular } \\
\text { weight } \mathrm{g} / \mathrm{mol}\end{array}$ & $\mathrm{mol} /$ day & $\mathrm{mmol} / \mathrm{min}$ & $\begin{array}{l}\text { g carbon } \\
\text { /day }\end{array}$ \\
\hline $\mathrm{i}-\mathrm{C}_{5}$ & 2.2777 & 0.0740 & 5 & 44 & 0.0017 & 0.0012 & 0.1009 \\
\hline $\mathrm{i}-\mathrm{C}_{6}$ & 1.8112 & 0.0589 & 6 & 86 & 0.0007 & 0.0005 & 0.0493 \\
\hline $\mathrm{i}-\mathrm{C}_{7}$ & 16.8435 & 0.5474 & 7 & 100 & 0.0055 & 0.0038 & 0.4598 \\
\hline $\mathrm{i}-\mathrm{C}_{8}$ & 18.5675 & 0.6034 & 8 & 114 & 0.0053 & 0.0037 & 0.5082 \\
\hline $\mathrm{i}-\mathrm{C}_{9}$ & 12.3717 & 0.4021 & 9 & 128 & 0.0031 & 0.0022 & 0.3393 \\
\hline $\mathrm{i}-\mathrm{C}_{10}$ & 8.6809 & 0.2821 & 10 & 142 & 0.0020 & 0.0014 & 0.2384 \\
\hline $\mathrm{i}-\mathrm{C}_{11}$ & 4.9417 & 0.1606 & 11 & 156 & 0.0010 & 0.0007 & 0.1359 \\
\hline $\mathrm{i}-\mathrm{C}_{12}$ & 2.8981 & 0.0942 & 12 & 170 & 0.0006 & 0.0004 & 0.0798 \\
\hline $\mathrm{i}-\mathrm{C}_{13}$ & 0.8350 & 0.0271 & 13 & 184 & 0.0001 & 0.0001 & 0.0230 \\
\hline $\mathrm{i}-\mathrm{C}_{14}$ & 0.4625 & 0.0150 & 14 & 198 & 0.0001 & 0.0001 & 0.0128 \\
\hline $\mathrm{i}-\mathrm{C}_{15}$ & 0.2233 & 0.0073 & 15 & 212 & 0.0000 & 0.0000 & 0.0062 \\
\hline $\mathrm{i}-\mathrm{C}_{16}$ & 0.0408 & 0.0013 & 16 & 226 & 0.0000 & 0.0000 & 0.0011 \\
\hline \multirow[t]{2}{*}{$\mathrm{i}-\mathrm{C}_{17+}$} & 0.4539 & 0.0148 & 17 & 240 & 0.0001 & 0.0000 & 0.0125 \\
\hline & & & & & & Total in oil & 2.8044 \\
\hline Alcohols & $\begin{array}{l}\text { wt } \% \text { in aqueous } \\
\text { liquid phase }\end{array}$ & $\begin{array}{l}\text { weight } \\
\text { (g/day) }\end{array}$ & $\begin{array}{l}\text { Carbon } \\
\text { number }\end{array}$ & $\begin{array}{l}\text { Molecular } \\
\text { weight } \mathrm{g} / \mathrm{mol}\end{array}$ & $\mathrm{mol} /$ day & $\mathrm{mmol} / \mathrm{min}$ & $\begin{array}{l}\text { g carbon } \\
\text { /day }\end{array}$ \\
\hline Methanol & 0.1000 & 0.0015 & 1 & 32 & 0.0000 & 0.0000 & 0.0006 \\
\hline Ethanol & 0.3000 & 0.0045 & 2 & 46 & 0.0001 & 0.0001 & 0.0023 \\
\hline 2-Propanol & 2.3100 & 0.0347 & 3 & 60 & 0.0006 & 0.0004 & 0.0208 \\
\hline 1-Propanol & 0.0000 & 0.0000 & 3 & 60 & 0.0000 & 0.0000 & 0.0000 \\
\hline 2-Butanol & 0.1000 & 0.0015 & 4 & 74 & 0.0000 & 0.0000 & 0.0010 \\
\hline 1-Butanol & 0.0000 & 0.0000 & 4 & 74 & 0.0000 & 0.0000 & 0.0000 \\
\hline 2-Pentanol & 0.0000 & 0.0000 & 5 & 88 & 0.0000 & 0.0000 & 0.0000 \\
\hline 1-Pentanol & 0.0000 & 0.0000 & 5 & 88 & 0.0000 & 0.0000 & 0.0000 \\
\hline \multirow[t]{2}{*}{ Water } & 97.1900 & 1.4579 & 0 & 18 & 0.0810 & 0.0562 & 0.0000 \\
\hline & & & & & & Total in aqueous & 0.0241 \\
\hline \multicolumn{3}{|c|}{ Total carbon due to oil and aqueous phase } & \multicolumn{2}{|c|}{2.8285 g carbon /day } & & & \\
\hline
\end{tabular}




\begin{tabular}{|c|c|c|c|c|c|c|c|}
\hline \multicolumn{8}{|c|}{$\begin{array}{l}\text { Base catalyst weight }=0.5 \mathrm{~g}, \mathrm{ZSM}-5 \text { weight }=0.5 \mathrm{~g}, \mathrm{H}_{2} / \mathrm{CO} \text { ratio }=1, \\
\text { total feed rate }=100 \mathrm{scc} / \mathrm{min} \text {, reactor pressure }=300 \mathrm{psi}, \mathrm{TOS}=24-48 \mathrm{~h}, \text { Organic phase } \mathrm{wt}=57802 \mathrm{~g}, \text { Aqueous phase } \mathrm{wt}=1.5 \mathrm{~g}\end{array}$} \\
\hline Aromatics & $\begin{array}{l}\text { wt\% in } \\
\text { Hydrocarbon liquid } \\
\text { phase }\end{array}$ & $\begin{array}{l}\text { weight } \\
\text { (g/day) }\end{array}$ & $\begin{array}{l}\text { Carbon } \\
\text { number }\end{array}$ & $\begin{array}{l}\text { Molecular } \\
\text { weight } \mathrm{g} / \mathrm{mol}\end{array}$ & & & $\begin{array}{l}\text { g carbon } \\
\text { /day }\end{array}$ \\
\hline toluene & 3.0615 & 0.1770 & 7 & 92 & 0.0019 & 0.0013 & 0.1616 \\
\hline p-xylene & 7.0070 & 0.4050 & 8 & 106 & 0.0038 & 0.0027 & 0.3668 \\
\hline $\begin{array}{l}\text { propyl- } \\
\text { benzene }\end{array}$ & 5.8745 & 0.3396 & 9 & 120 & 0.0028 & 0.0020 & 0.3056 \\
\hline $\begin{array}{l}\text { butyl- } \\
\text { benzene }\end{array}$ & 1.3564 & 0.0784 & 10 & 134 & 0.0006 & 0.0004 & 0.0702 \\
\hline n-praffins & $\begin{array}{l}\text { wt\% in } \\
\text { Hydrocarbon liquid } \\
\text { phase }\end{array}$ & $\begin{array}{l}\text { weight } \\
\text { (g/day) }\end{array}$ & $\begin{array}{l}\text { Carbon } \\
\text { number }\end{array}$ & $\begin{array}{l}\text { Molecular } \\
\text { weight } \mathrm{g} / \mathrm{mol}\end{array}$ & $\mathrm{mol} /$ day & $\mathrm{mmol} / \mathrm{min}$ & $\begin{array}{l}\text { g carbon } \\
\text { /day }\end{array}$ \\
\hline $\mathrm{n}-\mathrm{C}_{5}$ & 1.0999 & 0.0636 & 5 & 44 & 0.0014 & 0.0010 & 0.0867 \\
\hline $\mathrm{n}-\mathrm{C}_{6}$ & 4.2079 & 0.2432 & 6 & 86 & 0.0028 & 0.0020 & 0.2036 \\
\hline $\mathrm{n}-\mathrm{C}_{7}$ & 3.5942 & 0.2077 & 7 & 100 & 0.0021 & 0.0014 & 0.1745 \\
\hline $\mathrm{n}-\mathrm{C}_{8}$ & 1.3840 & 0.0800 & 8 & 114 & 0.0007 & 0.0005 & 0.0674 \\
\hline $\mathrm{n}-\mathrm{C}_{9}$ & 0.7068 & 0.0409 & 9 & 128 & 0.0003 & 0.0002 & 0.0345 \\
\hline $\mathrm{n}-\mathrm{C}_{10}$ & 1.1379 & 0.0658 & 10 & 142 & 0.0005 & 0.0003 & 0.0556 \\
\hline$n-C_{11}$ & 0.7025 & 0.0406 & 11 & 156 & 0.0003 & 0.0002 & 0.0344 \\
\hline$n-C_{12}$ & 0.2084 & 0.0120 & 12 & 170 & 0.0001 & 0.0000 & 0.0102 \\
\hline $\mathrm{n}-\mathrm{C}_{13}$ & 0.1339 & 0.0077 & 13 & 184 & 0.0000 & 0.0000 & 0.0066 \\
\hline $\mathrm{n}-\mathrm{C}_{14}$ & 0.1047 & 0.0060 & 14 & 198 & 0.0000 & 0.0000 & 0.0051 \\
\hline $\mathrm{n}-\mathrm{C}_{15}$ & 0.0448 & 0.0026 & 15 & 212 & 0.0000 & 0.0000 & 0.0022 \\
\hline $\mathrm{n}-\mathrm{C}_{16}$ & 0.0432 & 0.0025 & 16 & 226 & 0.0000 & 0.0000 & 0.0021 \\
\hline$n-C_{17+}$ & 0.0234 & 0.0014 & 17 & 240 & 0.0000 & 0.0000 & 0.0012 \\
\hline i-paraffins & $\begin{array}{l}\text { wt\% in } \\
\text { Hydrocarbon liquid } \\
\text { phase }\end{array}$ & $\begin{array}{l}\text { weight } \\
\text { (g/day) }\end{array}$ & $\begin{array}{l}\text { Carbon } \\
\text { number }\end{array}$ & $\begin{array}{l}\text { Molecular } \\
\text { weight } \mathrm{g} / \mathrm{mol}\end{array}$ & $\mathrm{mol} /$ day & $\mathrm{mmol} / \mathrm{min}$ & $\begin{array}{l}\text { g carbon } \\
\text { /day }\end{array}$ \\
\hline $\mathrm{i}-\mathrm{C}_{5}$ & 1.0999 & 0.0636 & 5 & 44 & 0.0014 & 0.0010 & 0.0867 \\
\hline${\mathrm{i}-\mathrm{C}_{6}}_{6}$ & 4.2079 & 0.2432 & 6 & 86 & 0.0028 & 0.0020 & 0.2036 \\
\hline $\mathrm{i}-\mathrm{C}_{7}$ & 3.5942 & 0.2077 & 7 & 100 & 0.0021 & 0.0014 & 0.1745 \\
\hline $\mathrm{i}-\mathrm{C}_{8}$ & 1.3840 & 0.0800 & 8 & 114 & 0.0007 & 0.0005 & 0.0674 \\
\hline $\mathrm{i}-\mathrm{C}_{9}$ & 0.7068 & 0.0409 & 9 & 128 & 0.0003 & 0.0002 & 0.0345 \\
\hline $\mathrm{i}-\mathrm{C}_{10}$ & 1.1379 & 0.0658 & 10 & 142 & 0.0005 & 0.0003 & 0.0556 \\
\hline $\mathrm{i}-\mathrm{C}_{11}$ & 0.7025 & 0.0406 & 11 & 156 & 0.0003 & 0.0002 & 0.0344 \\
\hline $\mathrm{i}-\mathrm{C}_{12}$ & 0.2084 & 0.0120 & 12 & 170 & 0.0001 & 0.0000 & 0.0102 \\
\hline $\mathrm{i}-\mathrm{C}_{13}$ & 0.1339 & 0.0077 & 13 & 184 & 0.0000 & 0.0000 & 0.0066 \\
\hline $\mathrm{i}-\mathrm{C}_{14}$ & 0.1047 & 0.0060 & 14 & 198 & 0.0000 & 0.0000 & 0.0051 \\
\hline $\mathrm{i}-\mathrm{C}_{15}$ & 0.0448 & 0.0026 & 15 & 212 & 0.0000 & 0.0000 & 0.0022 \\
\hline $\mathrm{i}-\mathrm{C}_{16}$ & 0.0432 & 0.0025 & 16 & 226 & 0.0000 & 0.0000 & 0.0021 \\
\hline \multirow[t]{2}{*}{ i- $\mathrm{C}_{17+}$} & 0.0234 & 0.0014 & 17 & 240 & 0.0000 & 0.0000 & 0.0012 \\
\hline & & & & & & Total in oil & 2.2722 \\
\hline Alcohols & $\begin{array}{l}\text { wt } \% \text { in aqueous } \\
\text { liquid phase }\end{array}$ & $\begin{array}{l}\text { weight } \\
\text { (g/day) }\end{array}$ & $\begin{array}{l}\text { Carbon } \\
\text { number }\end{array}$ & $\begin{array}{l}\text { Molecular } \\
\text { weight } \mathrm{g} / \mathrm{mol}\end{array}$ & $\mathrm{mol} /$ day & $\mathrm{mmol} / \mathrm{min}$ & $\begin{array}{l}\text { g carbon } \\
\text { /day }\end{array}$ \\
\hline Methanol & 0.0000 & 0.0000 & 1 & 32 & 0.0000 & 0.0000 & 0.0000 \\
\hline Ethanol & 0.0000 & 0.0000 & 2 & 46 & 0.0000 & 0.0000 & 0.0000 \\
\hline 2-Propanol & 0.3000 & 0.0045 & 3 & 60 & 0.0001 & 0.0001 & 0.0027 \\
\hline 1-Propanol & 0.0000 & 0.0000 & 3 & 60 & 0.0000 & 0.0000 & 0.0000 \\
\hline 2-Butanol & 0.0000 & 0.0000 & 4 & 74 & 0.0000 & 0.0000 & 0.0000 \\
\hline 1-Butanol & 0.0000 & 0.0000 & 4 & 74 & 0.0000 & 0.0000 & 0.0000 \\
\hline 2-Pentanol & 0.0000 & 0.0000 & 5 & 88 & 0.0000 & 0.0000 & 0.0000 \\
\hline 1-Pentanol & 0.0000 & 0.0000 & 5 & 88 & 0.0000 & 0.0000 & 0.0000 \\
\hline \multirow[t]{2}{*}{ water } & 99.7000 & 1.4955 & 0 & 18 & 0.0831 & 0.0577 & 0.0000 \\
\hline & & & & & & $\begin{array}{l}\text { Total in } \\
\text { aqueous }\end{array}$ & 0.0027 \\
\hline \multicolumn{3}{|c|}{ Total carbon due to oil and aqueous phase } & \multicolumn{2}{|c|}{$2.2749 \mathrm{~g}$ carbon /day } & & & \\
\hline
\end{tabular}




\begin{tabular}{|c|c|c|c|c|c|c|c|}
\hline \multicolumn{8}{|c|}{$\begin{array}{l}\text { Mixed-bed catalyst arrangement, ZSM- } 5 \text { weight }=0.25 \mathrm{~g} \\
\text { Base catalyst weight }=0.5 \mathrm{~g}, \mathrm{~T}=300^{\circ} \mathrm{C}, \mathrm{H}_{2} / \mathrm{CO} \text { ratio }=1 \text {, } \\
\text { total feed rate }=100 \mathrm{scc} / \mathrm{min} \text {, reactor pressure }=300 \mathrm{psi}, \mathrm{T}\end{array}$} \\
\hline Aromatics & $\begin{array}{l}\text { wt } \% \text { in } \\
\text { Hydrocarbon } \\
\text { liquid phase }\end{array}$ & weight (g/day) & $\begin{array}{l}\text { Carbon } \\
\text { number }\end{array}$ & $\begin{array}{l}\text { Molecular } \\
\text { weight } \mathrm{g} / \mathrm{mol}\end{array}$ & $\mathrm{mol} /$ day & $\mathrm{mmol} / \mathrm{min}$ & $\begin{array}{l}\text { g carbon } \\
\text { /day }\end{array}$ \\
\hline toluene & 2.0917 & 0.0784 & 7 & 92 & 0.0009 & 0.0006 & 0.0716 \\
\hline p-xylene & 5.0754 & 0.1902 & 8 & 106 & 0.0018 & 0.0012 & 0.1723 \\
\hline $\begin{array}{l}\text { propyl- } \\
\text { benzene }\end{array}$ & 4.7711 & 0.1788 & 9 & 120 & 0.0015 & 0.0010 & 0.1609 \\
\hline $\begin{array}{l}\text { butyl- } \\
\text { benzene }\end{array}$ & 0.9424 & 0.0353 & 10 & 134 & 0.0003 & 0.0002 & 0.0316 \\
\hline n-praffins & $\begin{array}{l}\text { wt } \% \text { in } \\
\text { Hydrocarbon } \\
\text { liquid phase }\end{array}$ & weight (g/day) & $\begin{array}{l}\text { Carbon } \\
\text { number }\end{array}$ & $\begin{array}{l}\text { Molecular } \\
\text { weight } \mathrm{g} / \mathrm{mol}\end{array}$ & $\mathrm{mol} / \mathrm{day}$ & $\mathrm{mmol} / \mathrm{min}$ & $\begin{array}{l}\text { g carbon } \\
\text { /day }\end{array}$ \\
\hline $\mathrm{n}-\mathrm{C}_{5}$ & 0.1960 & 0.0073 & 5 & 44 & 0.0002 & 0.0001 & 0.0100 \\
\hline $\mathrm{n}-\mathrm{C}_{6}$ & 5.8053 & 0.2176 & 6 & 86 & 0.0025 & 0.0018 & 0.1821 \\
\hline $\mathrm{n}-\mathrm{C}_{7}$ & 6.3243 & 0.2370 & 7 & 100 & 0.0024 & 0.0016 & 0.1991 \\
\hline $\mathrm{n}-\mathrm{C}_{8}$ & 3.3020 & 0.1237 & 8 & 114 & 0.0011 & 0.0008 & 0.1042 \\
\hline $\mathrm{n}-\mathrm{C}_{9}$ & 2.3884 & 0.0895 & 9 & 128 & 0.0007 & 0.0005 & 0.0755 \\
\hline $\mathrm{n}-\mathrm{C}_{10}$ & 1.7604 & 0.0660 & 10 & 142 & 0.0005 & 0.0003 & 0.0558 \\
\hline $\mathrm{n}-\mathrm{C}_{11}$ & 0.1776 & 0.0067 & 11 & 156 & 0.0000 & 0.0000 & 0.0056 \\
\hline $\mathrm{n}-\mathrm{C}_{12}$ & 0.6218 & 0.0233 & 12 & 170 & 0.0001 & 0.0001 & 0.0197 \\
\hline $\mathrm{n}-\mathrm{C}_{13}$ & 0.4922 & 0.0184 & 13 & 184 & 0.0001 & 0.0001 & 0.0156 \\
\hline $\mathrm{n}-\mathrm{C}_{14}$ & 0.0432 & 0.0016 & 14 & 198 & 0.0000 & 0.0000 & 0.0014 \\
\hline $\mathrm{n}-\mathrm{C}_{15}$ & 0.3099 & 0.0116 & 15 & 212 & 0.0001 & 0.0000 & 0.0099 \\
\hline $\mathrm{n}-\mathrm{C}_{16}$ & 0.2626 & 0.0098 & 16 & 226 & 0.0000 & 0.0000 & 0.0084 \\
\hline $\mathrm{n}-\mathrm{C}_{17+}$ & 0.4130 & 0.0155 & 17 & 240 & 0.0001 & 0.0000 & 0.0132 \\
\hline i-paraffins & $\begin{array}{l}\text { wt } \% \text { in } \\
\text { Hydrocarbon } \\
\text { liquid phase } \\
\end{array}$ & weight (g/day) & $\begin{array}{l}\text { Carbon } \\
\text { number }\end{array}$ & $\begin{array}{l}\text { Molecular } \\
\text { weight } \mathrm{g} / \mathrm{mol}\end{array}$ & $\mathrm{mol} / \mathrm{day}$ & $\mathrm{mmol} / \mathrm{min}$ & $\begin{array}{l}\text { g carbon } \\
\text { /day }\end{array}$ \\
\hline $\mathrm{i}-\mathrm{C}_{5}$ & 2.8035 & 0.1051 & 5 & 44 & 0.0024 & 0.0017 & 0.1433 \\
\hline $\mathrm{i}-\mathrm{C}_{6}$ & 2.9994 & 0.1124 & 6 & 86 & 0.0013 & 0.0009 & 0.0941 \\
\hline $\mathrm{i}-\mathrm{C}_{7}$ & 17.0442 & 0.6387 & 7 & 100 & 0.0064 & 0.0044 & 0.5365 \\
\hline $\mathrm{i}-\mathrm{C}_{8}$ & 15.4824 & 0.5802 & 8 & 114 & 0.0051 & 0.0035 & 0.4886 \\
\hline $\mathrm{i}-\mathrm{C}_{9}$ & 9.6031 & 0.3599 & 9 & 128 & 0.0028 & 0.0020 & 0.3037 \\
\hline $\mathrm{i}-\mathrm{C}_{10}$ & 7.8008 & 0.2923 & 10 & 142 & 0.0021 & 0.0014 & 0.2471 \\
\hline $\mathrm{i}-\mathrm{C}_{11}$ & 4.8371 & 0.1813 & 11 & 156 & 0.0012 & 0.0008 & 0.1534 \\
\hline $\mathrm{i}-\mathrm{C}_{12}$ & 2.2294 & 0.0836 & 12 & 170 & 0.0005 & 0.0003 & 0.0708 \\
\hline $\mathrm{i}-\mathrm{C}_{13}$ & 0.7713 & 0.0289 & 13 & 184 & 0.0002 & 0.0001 & 0.0245 \\
\hline $\mathrm{i}-\mathrm{C}_{14}$ & 0.7620 & 0.0286 & 14 & 198 & 0.0001 & 0.0001 & 0.0242 \\
\hline $\mathrm{i}-\mathrm{C}_{15}$ & 0.1863 & 0.0070 & 15 & 212 & 0.0000 & 0.0000 & 0.0059 \\
\hline $\mathrm{i}-\mathrm{C}_{16}$ & 0.1774 & 0.0066 & 16 & 226 & 0.0000 & 0.0000 & 0.0056 \\
\hline \multirow[t]{2}{*}{$\mathrm{i}-\mathrm{C}_{17+}$} & 0.3256 & 0.0122 & 17 & 240 & 0.0001 & 0.0000 & 0.0104 \\
\hline & & & & & & Total in oil & 3.2450 \\
\hline Alcohols & $\begin{array}{l}\text { wt \% in aqueous } \\
\text { liquid phase }\end{array}$ & weight (g/day) & $\begin{array}{l}\text { Carbon } \\
\text { number }\end{array}$ & $\begin{array}{l}\begin{array}{l}\text { Molecular } \\
\text { weight } \mathrm{g} / \mathrm{mol}\end{array} \\
\end{array}$ & mol/day & $\mathrm{mmol} / \mathrm{min}$ & $\begin{array}{l}\text { g carbon } \\
\text { /day }\end{array}$ \\
\hline Methanol & 10.5000 & 0.1260 & 1 & 32 & 0.0039 & 0.0027 & 0.0473 \\
\hline Ethanol & 20.6000 & 0.2472 & 2 & 46 & 0.0054 & 0.0037 & 0.1290 \\
\hline 2-Propanol & 4.2000 & 0.0504 & 3 & 60 & 0.0008 & 0.0006 & 0.0302 \\
\hline 1-Propanol & 9.8000 & 0.1176 & 3 & 60 & 0.0020 & 0.0014 & 0.0706 \\
\hline 2-Butanol & 1.4000 & 0.0168 & 4 & 74 & 0.0002 & 0.0002 & 0.0109 \\
\hline 1-Butanol & 7.8000 & 0.0936 & 4 & 74 & 0.0013 & 0.0009 & 0.0607 \\
\hline 2-Pentanol & 0.0000 & 0.0000 & 5 & 88 & 0.0000 & 0.0000 & 0.0000 \\
\hline 1-Pentanol & 6.4000 & 0.0768 & 5 & 88 & 0.0009 & 0.0006 & 0.0524 \\
\hline \multirow[t]{2}{*}{ Water } & 39.3000 & 0.4716 & 0 & 18 & 0.0262 & 0.0182 & 0.0000 \\
\hline & & & & & & $\begin{array}{r}\text { Total in } \\
\text { aqueous }\end{array}$ & 0.3537 \\
\hline \multicolumn{3}{|c|}{ Total carbon due to oil and aqueous phase } & \multicolumn{2}{|c|}{$3.5987 \mathrm{~g}$ carbon /day } & & & \\
\hline
\end{tabular}




\begin{tabular}{|c|c|c|c|c|c|c|c|}
\hline \multicolumn{8}{|c|}{$\begin{array}{l}\text { Mixed-bed catalyst arrangement, ZSM-5 weight }=0.5 \mathrm{~g} \\
\text { Base catalyst weight }=0.5 \mathrm{~g}, \mathrm{~T}=300^{\circ} \mathrm{C}, \mathrm{H}_{2} / \mathrm{CO} \text { ratio }=1, \\
\text { total feed rate }=100 \mathrm{scc} / \mathrm{min}, \text { reactor pressure }=300 \mathrm{psi}, \mathrm{TOS}=24-48 \mathrm{~h}, \text { Organic phase wt }=4.2094 \mathrm{~g}, \text { Aqueous phase wt }=1.5 \mathrm{~g}\end{array}$} \\
\hline Aromatics & $\begin{array}{l}\text { wt } \% \text { in } \\
\text { Hydrocarbon } \\
\text { liquid phase }\end{array}$ & $\begin{array}{l}\text { weight } \\
\text { (g/day) }\end{array}$ & $\begin{array}{l}\text { Carbon } \\
\text { number }\end{array}$ & $\begin{array}{l}\text { Molecular } \\
\text { weight } \\
\text { g/mol }\end{array}$ & $\mathrm{mol} / \mathrm{day}$ & $\mathrm{mmol} / \mathrm{min}$ & g carbon /day \\
\hline toluene & 3.8369 & 0.1615 & 7 & 92 & 0.0018 & 0.0012 & 0.1475 \\
\hline p-xylene & 9.3795 & 0.3948 & 8 & 106 & 0.0037 & 0.0026 & 0.3576 \\
\hline $\begin{array}{l}\text { propyl- } \\
\text { benzene }\end{array}$ & 7.7203 & 0.3250 & 9 & 120 & 0.0027 & 0.0019 & 0.2925 \\
\hline \multirow[t]{2}{*}{ butyl-benzene } & 1.2106 & 0.0510 & 10 & 134 & 0.0004 & 0.0003 & 0.0456 \\
\hline & & 0.0000 & & & & & \\
\hline n-praffins & $\begin{array}{l}\text { wt } \% \text { in } \\
\text { Hydrocarbon } \\
\text { liquid phase }\end{array}$ & $\begin{array}{l}\text { weight } \\
\text { (g/day) }\end{array}$ & $\begin{array}{l}\text { Carbon } \\
\text { number }\end{array}$ & $\begin{array}{l}\text { Molecular } \\
\text { weight } \\
\text { g/mol }\end{array}$ & mol/day & $\mathrm{mmol} / \mathrm{min}$ & g carbon /day \\
\hline $\mathrm{n}-\mathrm{C}_{5}$ & 0.7774 & 0.0327 & 5 & 44 & 0.0007 & 0.0005 & 0.0446 \\
\hline $\mathrm{n}-\mathrm{C}_{6}$ & 3.8665 & 0.1628 & 6 & 86 & 0.0019 & 0.0013 & 0.1363 \\
\hline $\mathrm{n}-\mathrm{C}_{7}$ & 3.8877 & 0.1637 & 7 & 100 & 0.0016 & 0.0011 & 0.1375 \\
\hline $\mathrm{n}-\mathrm{C}_{8}$ & 1.9161 & 0.0807 & 8 & 114 & 0.0007 & 0.0005 & 0.0679 \\
\hline $\mathrm{n}-\mathrm{C}_{9}$ & 1.5164 & 0.0638 & 9 & 128 & 0.0005 & 0.0003 & 0.0539 \\
\hline$n-C_{10}$ & 1.1022 & 0.0464 & 10 & 142 & 0.0003 & 0.0002 & 0.0392 \\
\hline $\mathrm{n}-\mathrm{C}_{11}$ & 0.1297 & 0.0055 & 11 & 156 & 0.0000 & 0.0000 & 0.0046 \\
\hline$n-C_{12}$ & 0.5038 & 0.0212 & 12 & 170 & 0.0001 & 0.0001 & 0.0180 \\
\hline$n-C_{13}$ & 0.5127 & 0.0216 & 13 & 184 & 0.0001 & 0.0001 & 0.0183 \\
\hline$n-C_{14}$ & 0.4908 & 0.0207 & 14 & 198 & 0.0001 & 0.0001 & 0.0175 \\
\hline $\mathrm{n}-\mathrm{C}_{15}$ & 0.3016 & 0.0127 & 15 & 212 & 0.0001 & 0.0000 & 0.0108 \\
\hline$n-C_{16}$ & 0.2824 & 0.0119 & 16 & 226 & 0.0001 & 0.0000 & 0.0101 \\
\hline $\mathrm{n}-\mathrm{C}_{17+}$ & 1.0857 & 0.0457 & 17 & 240 & 0.0002 & 0.0001 & 0.0388 \\
\hline i-paraffins & $\begin{array}{l}\text { wt } \% \text { in } \\
\text { Hydrocarbon } \\
\text { liquid phase }\end{array}$ & $\begin{array}{l}\text { weight } \\
\text { (g/day) }\end{array}$ & $\begin{array}{l}\text { Carbon } \\
\text { number }\end{array}$ & $\begin{array}{l}\text { Molecular } \\
\text { weight } \\
\text { g/mol }\end{array}$ & $\mathrm{mol} / \mathrm{day}$ & $\mathrm{mmol} / \mathrm{min}$ & g carbon /day \\
\hline $\mathrm{i}-\mathrm{C}_{5}$ & 2.3723 & 0.0999 & 5 & 44 & 0.0023 & 0.0016 & 0.1362 \\
\hline $\mathrm{i}-\mathrm{C}_{6}$ & 2.7912 & 0.1175 & 6 & 86 & 0.0014 & 0.0009 & 0.0984 \\
\hline $\mathrm{i}-\mathrm{C}_{7}$ & 15.4657 & 0.6510 & 7 & 100 & 0.0065 & 0.0045 & 0.5469 \\
\hline $\mathrm{i}-\mathrm{C}_{8}$ & 14.2032 & 0.5979 & 8 & 114 & 0.0052 & 0.0036 & 0.5035 \\
\hline $\mathrm{i}-\mathrm{C}_{9}$ & 8.1685 & 0.3438 & 9 & 128 & 0.0027 & 0.0019 & 0.2901 \\
\hline $\mathrm{i}-\mathrm{C}_{10}$ & 8.2233 & 0.3462 & 10 & 142 & 0.0024 & 0.0017 & 0.2925 \\
\hline $\mathrm{i}-\mathrm{C}_{11}$ & 4.3375 & 0.1826 & 11 & 156 & 0.0012 & 0.0008 & 0.1545 \\
\hline $\mathrm{i}-\mathrm{C}_{12}$ & 2.4700 & 0.1040 & 12 & 170 & 0.0006 & 0.0004 & 0.0881 \\
\hline $\mathrm{i}-\mathrm{C}_{13}$ & 1.3396 & 0.0564 & 13 & 184 & 0.0003 & 0.0002 & 0.0478 \\
\hline $\mathrm{i}-\mathrm{C}_{14}$ & 0.9463 & 0.0398 & 14 & 198 & 0.0002 & 0.0001 & 0.0338 \\
\hline $\mathrm{i}-\mathrm{C}_{15}$ & 0.3459 & 0.0146 & 15 & 212 & 0.0001 & 0.0000 & 0.0124 \\
\hline $\mathrm{i}-\mathrm{C}_{16}$ & 0.3103 & 0.0131 & 16 & 226 & 0.0001 & 0.0000 & 0.0111 \\
\hline \multirow[t]{2}{*}{$\mathrm{i}-\mathrm{C}_{17+}$} & 0.5055 & 0.0213 & 17 & 240 & 0.0001 & 0.0001 & 0.0181 \\
\hline & & & & & & Total in oil & 3.6739 \\
\hline Alcohols & $\begin{array}{l}\text { wt } \% \text { in } \\
\text { aqueous liquid } \\
\text { phase }\end{array}$ & $\begin{array}{l}\text { weight } \\
\text { (g/day) }\end{array}$ & $\begin{array}{l}\text { Carbon } \\
\text { number }\end{array}$ & $\begin{array}{l}\text { Molecular } \\
\text { weight } \\
\mathrm{g} / \mathrm{mol}\end{array}$ & mol/day & $\mathrm{mmol} / \mathrm{min}$ & g carbon /day \\
\hline Methanol & 8.5000 & 0.1275 & 1 & 32 & 0.0040 & 0.0028 & 0.0478 \\
\hline Ethanol & 18.2000 & 0.2730 & 2 & 46 & 0.0059 & 0.0041 & 0.1424 \\
\hline 2-Propanol & 2.9000 & 0.0435 & 3 & 60 & 0.0007 & 0.0005 & 0.0261 \\
\hline 1-Propanol & 6.8000 & 0.1020 & 3 & 60 & 0.0017 & 0.0012 & 0.0612 \\
\hline 2-Butanol & 1.1000 & 0.0165 & 4 & 74 & 0.0002 & 0.0002 & 0.0107 \\
\hline 1-Butanol & 6.2000 & 0.0930 & 4 & 74 & 0.0013 & 0.0009 & 0.0603 \\
\hline 2-Pentanol & 0.0000 & 0.0000 & 5 & 88 & 0.0000 & 0.0000 & 0.0000 \\
\hline 1-Pentanol & 2.1000 & 0.0315 & 5 & 88 & 0.0004 & 0.0002 & 0.0215 \\
\hline \multirow[t]{2}{*}{ Water } & 54.2000 & 0.8130 & 0 & 18 & 0.0452 & 0.0314 & 0.0000 \\
\hline & & & & & & $\begin{array}{l}\text { Total in } \\
\text { aqueous }\end{array}$ & 0.3222 \\
\hline \multicolumn{3}{|c|}{ Total carbon due to oil and aqueous phase } & \multicolumn{2}{|c|}{3.9961 g carbon /day } & & & \\
\hline
\end{tabular}




\begin{tabular}{|c|c|c|c|c|c|c|c|}
\hline \multicolumn{8}{|c|}{$\begin{array}{l}\text { Mixed-bed catalyst arrangement, ZSM- } 5 \text { weight }=1 \mathrm{~g} \\
\text { Base catalyst weight }=0.5 \mathrm{~g}, \mathrm{~T}=300^{\circ} \mathrm{C}, \mathrm{H}_{2} / \mathrm{CO} \text { ratio }=1, \\
\text { total feed rate }=100 \mathrm{scc} / \mathrm{min}, \text { reactor pressure }=300 \mathrm{Psi}, \mathrm{TOS}=24-48 \mathrm{~h} \text {, Organic phase wt }=3.0891 \mathrm{~g}, \text { Aqueous phase wt }=2.3 \mathrm{~g}\end{array}$} \\
\hline Aromatics & $\begin{array}{l}\text { wt } \% \text { in } \\
\text { Hydrocarbon } \\
\text { liquid phase }\end{array}$ & $\begin{array}{l}\text { weight } \\
\text { (g/day) }\end{array}$ & $\begin{array}{l}\text { Carbon } \\
\text { number }\end{array}$ & $\begin{array}{l}\text { Molecular } \\
\text { weight } \mathrm{g} / \mathrm{mol}\end{array}$ & $\mathrm{mol} / \mathrm{day}$ & $\mathrm{mmol} / \mathrm{min}$ & $\begin{array}{l}\text { g carbon } \\
\text { /day }\end{array}$ \\
\hline toluene & 4.9485 & 0.1529 & 7 & 92 & 0.0017 & 0.0012 & 0.1396 \\
\hline p-xylene & 10.5501 & 0.3259 & 8 & 106 & 0.0031 & 0.0021 & 0.2952 \\
\hline $\begin{array}{l}\text { propyl- } \\
\text { benzene }\end{array}$ & 8.4248 & 0.2603 & 9 & 120 & 0.0022 & 0.0015 & 0.2342 \\
\hline \multirow[t]{2}{*}{$\begin{array}{l}\text { butyl- } \\
\text { benzene }\end{array}$} & 1.1905 & 0.0368 & 10 & 134 & 0.0003 & 0.0002 & 0.0329 \\
\hline & & 0.0000 & & & & & \\
\hline n-praffins & $\begin{array}{l}\text { wt } \% \text { in } \\
\text { Hydrocarbon } \\
\text { liquid phase }\end{array}$ & $\begin{array}{l}\text { weight } \\
\text { (g/day) }\end{array}$ & $\begin{array}{l}\text { Carbon } \\
\text { number }\end{array}$ & $\begin{array}{l}\text { Molecular } \\
\text { weight } \mathrm{g} / \mathrm{mol}\end{array}$ & $\mathrm{mol} /$ day & $\mathrm{mmol} / \mathrm{min}$ & $\begin{array}{l}\text { g carbon } \\
\text { /day }\end{array}$ \\
\hline $\mathrm{n}-\mathrm{C}_{5}$ & 1.4829 & 0.0458 & 5 & 44 & 0.0010 & 0.0007 & 0.0625 \\
\hline $\mathrm{n}-\mathrm{C}_{6}$ & 4.6485 & 0.1436 & 6 & 86 & 0.0017 & 0.0012 & 0.1202 \\
\hline$n-C_{7}$ & 3.8531 & 0.1190 & 7 & 100 & 0.0012 & 0.0008 & 0.1000 \\
\hline $\mathrm{n}-\mathrm{C}_{8}$ & 1.6444 & 0.0508 & 8 & 114 & 0.0004 & 0.0003 & 0.0428 \\
\hline $\mathrm{n}-\mathrm{C}_{9}$ & 1.0613 & 0.0328 & 9 & 128 & 0.0003 & 0.0002 & 0.0277 \\
\hline $\mathrm{n}-\mathrm{C}_{10}$ & 0.7200 & 0.0222 & 10 & 142 & 0.0002 & 0.0001 & 0.0188 \\
\hline$n-C_{11}$ & 0.4823 & 0.0149 & 11 & 156 & 0.0001 & 0.0001 & 0.0126 \\
\hline $\mathrm{n}-\mathrm{C}_{12}$ & 0.2281 & 0.0070 & 12 & 170 & 0.0000 & 0.0000 & 0.0060 \\
\hline $\mathrm{n}-\mathrm{C}_{13}$ & 0.3053 & 0.0094 & 13 & 184 & 0.0001 & 0.0000 & 0.0080 \\
\hline$n-C_{14}$ & 0.2624 & 0.0081 & 14 & 198 & 0.0000 & 0.0000 & 0.0069 \\
\hline $\mathrm{n}-\mathrm{C}_{15}$ & 0.0000 & 0.0000 & 15 & 212 & 0.0000 & 0.0000 & 0.0000 \\
\hline$n-C_{16}$ & 0.0000 & 0.0000 & 16 & 226 & 0.0000 & 0.0000 & 0.0000 \\
\hline $\mathrm{n}-\mathrm{C}_{17+}$ & 0.0000 & 0.0000 & 17 & 240 & 0.0000 & 0.0000 & 0.0000 \\
\hline i-paraffins & $\begin{array}{l}\text { wt } \% \text { in } \\
\text { Hydrocarbon } \\
\text { liquid phase }\end{array}$ & $\begin{array}{l}\text { weight } \\
\text { (g/day) }\end{array}$ & $\begin{array}{l}\text { Carbon } \\
\text { number }\end{array}$ & $\begin{array}{l}\text { Molecular } \\
\text { weight } \mathrm{g} / \mathrm{mol}\end{array}$ & $\mathrm{mol} / \mathrm{day}$ & $\mathrm{mmol} / \mathrm{min}$ & $\begin{array}{l}\text { g carbon } \\
\text { /day }\end{array}$ \\
\hline $\mathrm{i}-\mathrm{C}_{5}$ & 4.1856 & 0.1293 & 5 & 44 & 0.0029 & 0.0020 & 0.1763 \\
\hline $\mathrm{i}-\mathrm{C}_{6}$ & 3.0916 & 0.0955 & 6 & 86 & 0.0011 & 0.0008 & 0.0800 \\
\hline i-C $\mathrm{C}_{7}$ & 16.5978 & 0.5127 & 7 & 100 & 0.0051 & 0.0036 & 0.4307 \\
\hline $\mathrm{i}-\mathrm{C}_{8}$ & 12.6468 & 0.3907 & 8 & 114 & 0.0034 & 0.0024 & 0.3290 \\
\hline i-C 9 & 5.0421 & 0.1558 & 9 & 128 & 0.0012 & 0.0008 & 0.1314 \\
\hline $\mathrm{i}-\mathrm{C}_{10}$ & 6.4920 & 0.2005 & 10 & 142 & 0.0014 & 0.0010 & 0.1695 \\
\hline $\mathrm{i}-\mathrm{C}_{11}$ & 3.7736 & 0.1166 & 11 & 156 & 0.0007 & 0.0005 & 0.0986 \\
\hline $\mathrm{i}-\mathrm{C}_{12}$ & 2.5339 & 0.0783 & 12 & 170 & 0.0005 & 0.0003 & 0.0663 \\
\hline $\mathrm{i}-\mathrm{C}_{13}$ & 0.7627 & 0.0236 & 13 & 184 & 0.0001 & 0.0001 & 0.0200 \\
\hline $\mathrm{i}-\mathrm{C}_{14}$ & 0.7509 & 0.0232 & 14 & 198 & 0.0001 & 0.0001 & 0.0197 \\
\hline $\mathrm{i}-\mathrm{C}_{15}$ & 0.4616 & 0.0143 & 15 & 212 & 0.0001 & 0.0000 & 0.0121 \\
\hline $\mathrm{i}-\mathrm{C}_{16}$ & 0.0000 & 0.0000 & 16 & 226 & 0.0000 & 0.0000 & 0.0000 \\
\hline \multirow[t]{2}{*}{$\mathrm{i}-\mathrm{C}_{17+}$} & 0.0000 & 0.0000 & 17 & 240 & 0.0000 & 0.0000 & 0.0000 \\
\hline & & & & & & Total in oil & 2.6408 \\
\hline Alcohols & $\begin{array}{l}\text { wt } \% \text { in aqueous } \\
\text { liquid phase }\end{array}$ & $\begin{array}{l}\text { weight } \\
\text { (g/day) }\end{array}$ & $\begin{array}{l}\text { Carbon } \\
\text { number }\end{array}$ & $\begin{array}{l}\text { Molecular } \\
\text { weight } \mathrm{g} / \mathrm{mol}\end{array}$ & $\mathrm{mol} / \mathrm{day}$ & $\mathrm{mmol} / \mathrm{min}$ & $\begin{array}{l}\text { g carbon } \\
\text { /day }\end{array}$ \\
\hline Methanol & 2.8000 & 0.0644 & 1 & 32 & 0.0020 & 0.0014 & 0.0242 \\
\hline Ethanol & 4.1000 & 0.0943 & 2 & 46 & 0.0021 & 0.0014 & 0.0492 \\
\hline 2-Propanol & 1.1000 & 0.0253 & 3 & 60 & 0.0004 & 0.0003 & 0.0152 \\
\hline 1-Propanol & 1.3000 & 0.0299 & 3 & 60 & 0.0005 & 0.0003 & 0.0179 \\
\hline 2-Butanol & 0.5000 & 0.0115 & 4 & 74 & 0.0002 & 0.0001 & 0.0075 \\
\hline 1-Butanol & 0.6000 & 0.0138 & 4 & 74 & 0.0002 & 0.0001 & 0.0090 \\
\hline 2-Pentanol & 0.0000 & 0.0000 & 5 & 88 & 0.0000 & 0.0000 & 0.0000 \\
\hline 1-Pentanol & 0.0000 & 0.0000 & 5 & 88 & 0.0000 & 0.0000 & 0.0000 \\
\hline \multirow[t]{2}{*}{ Water } & 89.6000 & 2.0608 & 0 & 18 & 0.1145 & 0.0795 & 0.0000 \\
\hline & & & & & & Total in aqueous & 0.0987 \\
\hline \multicolumn{3}{|c|}{ Total carbon due to oil and aqueous phase } & \multicolumn{2}{|c|}{$2.7395 \mathrm{~g}$ carbon /day } & & & \\
\hline
\end{tabular}




\begin{tabular}{|c|c|c|c|c|c|c|c|}
\hline \multicolumn{8}{|c|}{$\begin{array}{l}\text { Base catalyst weight }=0.5 \mathrm{~g}, \mathrm{~T}=300^{\circ} \mathrm{C}, \mathrm{H}_{2} / \mathrm{CO} \text { ratio }=1 \text {, total feed rate }=100 \mathrm{scc} / \mathrm{min} \text {, reactor pressure }=300 \mathrm{psi} \\
\mathrm{ZSM}-5 \text { weight }=1 \mathrm{~g} \text {, Organic phase wt }(24-48 \mathrm{~h})=7.62 \mathrm{~g} \text {, Aqueous phase wt }(24-48 \mathrm{~h})=2.3 \mathrm{~g}\end{array}$} \\
\hline Aromatics & $\begin{array}{l}\text { wt\% in } \\
\text { Hydrocarbo } \\
\text { n liquid } \\
\text { phase }\end{array}$ & $\begin{array}{l}\text { weight } \\
\text { (g/day) }\end{array}$ & $\begin{array}{l}\text { Carbon } \\
\text { number }\end{array}$ & $\begin{array}{l}\text { Molecular } \\
\text { weight } \mathrm{g} / \mathrm{mol}\end{array}$ & $\mathrm{mol} /$ day & $\mathrm{mmol} / \mathrm{min}$ & $\begin{array}{l}\text { g carbon } \\
\text { /day }\end{array}$ \\
\hline toluene & 6.8455 & 0.5216 & 7 & 92 & 0.0057 & 0.0039 & 0.4763 \\
\hline p-xylene & 11.0089 & 0.8389 & 8 & 106 & 0.0079 & 0.0055 & 0.7597 \\
\hline $\begin{array}{l}\text { propyl- } \\
\text { benzene }\end{array}$ & 8.4654 & 0.6451 & 9 & 120 & 0.0054 & 0.0037 & 0.5806 \\
\hline $\begin{array}{l}\text { butyl- } \\
\text { benzene }\end{array}$ & 1.3622 & 0.1038 & 10 & 134 & 0.0008 & 0.0005 & 0.0930 \\
\hline & & 0.0000 & & & & & \\
\hline n-praffins & $\begin{array}{l}\text { wt\% in } \\
\text { Hydrocarbo } \\
\text { n liquid } \\
\text { phase }\end{array}$ & $\begin{array}{l}\text { weight } \\
\text { (g/day) }\end{array}$ & $\begin{array}{l}\text { Carbon } \\
\text { number }\end{array}$ & $\begin{array}{l}\text { Molecular } \\
\text { weight } \mathrm{g} / \mathrm{mol}\end{array}$ & $\mathrm{mol} / \mathrm{day}$ & $\mathrm{mmol} / \mathrm{min}$ & $\begin{array}{l}\text { g carbon } \\
\text { /day }\end{array}$ \\
\hline $\mathrm{n}-\mathrm{C}_{5}$ & 1.0289 & 0.0784 & 5 & 44 & 0.0018 & 0.0012 & 0.1069 \\
\hline$n-C_{6}$ & 4.3825 & 0.3339 & 6 & 86 & 0.0039 & 0.0027 & 0.2796 \\
\hline $\mathrm{n}-\mathrm{C}_{7}$ & 2.7556 & 0.2100 & 7 & 100 & 0.0021 & 0.0015 & 0.1764 \\
\hline $\mathrm{n}-\mathrm{C}_{8}$ & 1.1798 & 0.0899 & 8 & 114 & 0.0008 & 0.0005 & 0.0757 \\
\hline $\mathrm{n}-\mathrm{C}_{9}$ & 0.9667 & 0.0737 & 9 & 128 & 0.0006 & 0.0004 & 0.0622 \\
\hline$n-C_{10}$ & 0.8891 & 0.0678 & 10 & 142 & 0.0005 & 0.0003 & 0.0573 \\
\hline $\mathrm{n}-\mathrm{C}_{11}$ & 0.4850 & 0.0370 & 11 & 156 & 0.0002 & 0.0002 & 0.0313 \\
\hline$n-C_{12}$ & 0.3497 & 0.0266 & 12 & 170 & 0.0002 & 0.0001 & 0.0226 \\
\hline$n-C_{13}$ & 0.2169 & 0.0165 & 13 & 184 & 0.0001 & 0.0001 & 0.0140 \\
\hline $\mathrm{n}-\mathrm{C}_{14}$ & 0.3071 & 0.0234 & 14 & 198 & 0.0001 & 0.0001 & 0.0199 \\
\hline$n-C_{15}$ & 0.0596 & 0.0045 & 15 & 212 & 0.0000 & 0.0000 & 0.0039 \\
\hline$n-C_{16}$ & 0.0373 & 0.0028 & 16 & 226 & 0.0000 & 0.0000 & 0.0024 \\
\hline n-C $C_{17+}$ & 0.2703 & 0.0206 & 17 & 240 & 0.0001 & 0.0001 & 0.0175 \\
\hline i-paraffins & $\begin{array}{l}\text { wt\% in } \\
\text { Hydrocarbo } \\
\text { n liquid } \\
\text { phase }\end{array}$ & $\begin{array}{l}\text { weight } \\
\text { (g/day) }\end{array}$ & $\begin{array}{l}\text { Carbon } \\
\text { number }\end{array}$ & $\begin{array}{l}\text { Molecular } \\
\text { weight } \mathrm{g} / \mathrm{mol}\end{array}$ & $\mathrm{mol} /$ day & $\mathrm{mmol} / \mathrm{min}$ & $\begin{array}{l}\text { g carbon } \\
\text { /day }\end{array}$ \\
\hline $\mathrm{i}-\mathrm{C}_{5}$ & 1.2832 & 0.0978 & 5 & 44 & 0.0022 & 0.0015 & 0.1333 \\
\hline $\mathrm{i}-\mathrm{C}_{6}$ & 2.4117 & 0.1838 & 6 & 86 & 0.0021 & 0.0015 & 0.1539 \\
\hline${\mathrm{i}-\mathrm{C}_{7}}_{7}$ & 13.9700 & 1.0645 & 7 & 100 & 0.0106 & 0.0074 & 0.8942 \\
\hline $\mathrm{i}-\mathrm{C}_{8}$ & 12.9020 & 0.9831 & 8 & 114 & 0.0086 & 0.0060 & 0.8279 \\
\hline${\mathrm{i}-\mathrm{C}_{9}}_{\mathrm{s}}$ & 8.4753 & 0.6458 & 9 & 128 & 0.0050 & 0.0035 & 0.5449 \\
\hline $\mathrm{i}-\mathrm{C}_{10}$ & 7.8914 & 0.6013 & 10 & 142 & 0.0042 & 0.0029 & 0.5082 \\
\hline $\mathrm{i}-\mathrm{C}_{11}$ & 3.7504 & 0.2858 & 11 & 156 & 0.0018 & 0.0013 & 0.2418 \\
\hline $\mathrm{i}-\mathrm{C}_{12}$ & 4.4465 & 0.3388 & 12 & 170 & 0.0020 & 0.0014 & 0.2870 \\
\hline $\mathrm{i}-\mathrm{C}_{13}$ & 2.2063 & 0.1681 & 13 & 184 & 0.0009 & 0.0006 & 0.1425 \\
\hline $\mathrm{i}-\mathrm{C}_{14}$ & 1.3136 & 0.1001 & 14 & 198 & 0.0005 & 0.0004 & 0.0849 \\
\hline $\mathrm{i}-\mathrm{C}_{15}$ & 0.3917 & 0.0298 & 15 & 212 & 0.0001 & 0.0001 & 0.0253 \\
\hline $\mathrm{i}-\mathrm{C}_{16}$ & 0.1660 & 0.0126 & 16 & 226 & 0.0001 & 0.0000 & 0.0107 \\
\hline $\mathrm{i}-\mathrm{C}_{17+}$ & 0.2066 & 0.0157 & 17 & 240 & 0.0001 & 0.0000 & 0.0134 \\
\hline & & & & & & Total in oil & 6.6471 \\
\hline Alcohols & $\begin{array}{l}\text { wt } \% \text { in } \\
\text { aqueous } \\
\text { liquid phase }\end{array}$ & $\begin{array}{l}\text { weight } \\
\text { (g/day) }\end{array}$ & $\begin{array}{l}\text { Carbon } \\
\text { number }\end{array}$ & $\begin{array}{l}\text { Molecular } \\
\text { weight } \mathrm{g} / \mathrm{mol}\end{array}$ & $\mathrm{mol} /$ day & $\mathrm{mmol} / \mathrm{min}$ & $\begin{array}{l}\text { g carbon } \\
\text { /day }\end{array}$ \\
\hline Methanol & 0.0000 & 0.0000 & 1 & 32 & 0.0000 & 0.0000 & 0.0000 \\
\hline Ethanol & 0.0558 & 0.0000 & 2 & 46 & 0.0000 & 0.0000 & 0.0000 \\
\hline 2-Propanol & 0.2000 & 0.0000 & 3 & 60 & 0.0000 & 0.0000 & 0.0000 \\
\hline 1-Propanol & 0.5000 & 0.0000 & 3 & 60 & 0.0000 & 0.0000 & 0.0000 \\
\hline 2-Butanol & 0.3000 & 0.0000 & 4 & 74 & 0.0000 & 0.0000 & 0.0000 \\
\hline 1-Butanol & 0.0000 & 0.0000 & 4 & 74 & 0.0000 & 0.0000 & 0.0000 \\
\hline 2-Pentanol & 0.2000 & 0.0000 & 5 & 88 & 0.0000 & 0.0000 & 0.0000 \\
\hline 1-Pentanol & 0.1000 & 0.0000 & 5 & 88 & 0.0000 & 0.0000 & 0.0000 \\
\hline Water & 98.6442 & 0.0000 & 0 & 18 & 0.0000 & 0.0000 & 0.0000 \\
\hline & & & & & & $\begin{array}{c}\text { Total in } \\
\text { aqueous }\end{array}$ & 0.0000 \\
\hline Total Carb & due to oil and & deous phase & $6.6471 q$ & on /day & & & \\
\hline
\end{tabular}




\begin{tabular}{|c|c|c|c|c|c|c|c|}
\hline \multicolumn{8}{|c|}{$\begin{array}{l}\text { Catalyst stability testing in separate-bed, TOS }=48-96 \mathrm{~h} \\
\text { Base catalyst weight }=0.5 \mathrm{~g}, \mathrm{~T}=300^{\circ} \mathrm{C}, \mathrm{H}_{2} / \mathrm{CO} \text { ratio }=1 \text {, total feed rate }=100 \mathrm{scc} / \mathrm{min} \text {, reactor pressure }=300 \mathrm{psi} \text {, } \\
\text { ZSM-5 weight }=1 \mathrm{~g}, \text { Organic phase wt }(48-96 \mathrm{~h})=15.6 \mathrm{~g}, \text { Aqueous phase wt }(48-96 \mathrm{~h})=4.64 \mathrm{~g}\end{array}$} \\
\hline Aromatics & $\begin{array}{l}\text { wt } \% \text { in } \\
\text { Hydrocarbon } \\
\text { liquid phase }\end{array}$ & $\begin{array}{l}\text { weight } \\
\text { (g/day) }\end{array}$ & $\begin{array}{l}\text { Carbon } \\
\text { number }\end{array}$ & $\begin{array}{l}\text { Molecular } \\
\text { weight } \mathrm{g} / \mathrm{mol}\end{array}$ & $\mathrm{mol} /$ day & $\mathrm{mmol} / \mathrm{min}$ & $\begin{array}{l}\text { g carbon } \\
\text { /day }\end{array}$ \\
\hline toluene & 3.5595 & 0.2776 & 7.0000 & 92.0000 & 0.0030 & 0.0021 & 0.2535 \\
\hline p-xylene & 6.9342 & 0.5409 & 8.0000 & 106.0000 & 0.0051 & 0.0035 & 0.4898 \\
\hline $\begin{array}{l}\text { propyl- } \\
\text { benzene }\end{array}$ & 5.4249 & 0.4231 & 9.0000 & 120.0000 & 0.0035 & 0.0024 & 0.3808 \\
\hline \multirow[t]{2}{*}{$\begin{array}{l}\text { butyl- } \\
\text { benzene }\end{array}$} & 1.1981 & 0.0934 & 10.0000 & 134.0000 & 0.0007 & 0.0005 & 0.0837 \\
\hline & & 0.0000 & & & & & \\
\hline n-praffins & $\begin{array}{l}\text { wt } \% \text { in } \\
\text { Hydrocarbon } \\
\text { liquid phase }\end{array}$ & $\begin{array}{l}\text { weight } \\
\text { (g/day) }\end{array}$ & $\begin{array}{l}\text { Carbon } \\
\text { number }\end{array}$ & $\begin{array}{l}\text { Molecular } \\
\text { weight } \mathrm{g} / \mathrm{mol}\end{array}$ & $\mathrm{mol} /$ day & $\mathrm{mmol} / \mathrm{min}$ & $\begin{array}{l}\text { g carbon } \\
\text { /day }\end{array}$ \\
\hline $\mathrm{n}-\mathrm{C}_{5}$ & 1.3533 & 0.1056 & 5.0000 & 44.0000 & 0.0024 & 0.0017 & 0.1439 \\
\hline $\mathrm{n}-\mathrm{C}_{6}$ & 5.0000 & 0.3900 & 6.0000 & 86.0000 & 0.0045 & 0.0031 & 0.3265 \\
\hline $\mathrm{n}-\mathrm{C}_{7}$ & 3.9000 & 0.3042 & 7.0000 & 100.0000 & 0.0030 & 0.0021 & 0.2555 \\
\hline $\mathrm{n}-\mathrm{C}_{8}$ & 2.1479 & 0.1675 & 8.0000 & 114.0000 & 0.0015 & 0.0010 & 0.1411 \\
\hline $\mathrm{n}-\mathrm{C}_{9}$ & 1.5243 & 0.1189 & 9.0000 & 128.0000 & 0.0009 & 0.0006 & 0.1003 \\
\hline $\mathrm{n}-\mathrm{C}_{10}$ & 1.1072 & 0.0864 & 10.0000 & 142.0000 & 0.0006 & 0.0004 & 0.0730 \\
\hline $\mathrm{n}-\mathrm{C}_{11}$ & 0.3472 & 0.0271 & 11.0000 & 156.0000 & 0.0002 & 0.0001 & 0.0229 \\
\hline$n-C_{12}$ & 0.1124 & 0.0088 & 12.0000 & 170.0000 & 0.0001 & 0.0000 & 0.0074 \\
\hline$n-C_{13}$ & 0.0673 & 0.0053 & 13.0000 & 184.0000 & 0.0000 & 0.0000 & 0.0045 \\
\hline$n-C_{14}$ & 0.1384 & 0.0108 & 14.0000 & 198.0000 & 0.0001 & 0.0000 & 0.0092 \\
\hline$n-C_{15}$ & 0.0363 & 0.0028 & 15.0000 & 212.0000 & 0.0000 & 0.0000 & 0.0024 \\
\hline$n-C_{16}$ & 0.0424 & 0.0033 & 16.0000 & 226.0000 & 0.0000 & 0.0000 & 0.0028 \\
\hline $\mathrm{n}-\mathrm{C}_{17+}$ & 0.0000 & 0.0000 & 17.0000 & 240.0000 & 0.0000 & 0.0000 & 0.0000 \\
\hline i-paraffins & $\begin{array}{l}\text { wt } \% \text { in } \\
\text { Hydrocarbon } \\
\text { liquid phase }\end{array}$ & $\begin{array}{l}\text { weight } \\
\text { (g/day) }\end{array}$ & $\begin{array}{l}\text { Carbon } \\
\text { number }\end{array}$ & $\begin{array}{l}\text { Molecular } \\
\text { weight } \mathrm{g} / \mathrm{mol}\end{array}$ & mol/day & $\mathrm{mmol} / \mathrm{min}$ & $\begin{array}{l}\text { g carbon } \\
\text { /day }\end{array}$ \\
\hline $\mathrm{i}-\mathrm{C}_{5}$ & 4.1485 & 0.3236 & 5 & 44 & 0.0074 & 0.0051 & 0.4413 \\
\hline $\mathrm{i}-\mathrm{C}_{6}$ & 2.9794 & 0.2324 & 6 & 86 & 0.0027 & 0.0019 & 0.1946 \\
\hline $\mathrm{i}-\mathrm{C}_{7}$ & 17.8000 & 1.3884 & 7 & 100 & 0.0139 & 0.0096 & 1.1663 \\
\hline $\mathrm{i}-\mathrm{C}_{8}$ & 16.2000 & 1.2636 & 8 & 114 & 0.0111 & 0.0077 & 1.0641 \\
\hline i-C $\mathrm{C}_{9}$ & 10.8000 & 0.8424 & 9 & 128 & 0.0066 & 0.0046 & 0.7108 \\
\hline $\mathrm{i}-\mathrm{C}_{10}$ & 6.8000 & 0.5304 & 10 & 142 & 0.0037 & 0.0026 & 0.4482 \\
\hline $\mathrm{i}-\mathrm{C}_{11}$ & 3.4549 & 0.2695 & 11 & 156 & 0.0017 & 0.0012 & 0.2280 \\
\hline $\mathrm{i}-\mathrm{C}_{12}$ & 3.0367 & 0.2369 & 12 & 170 & 0.0014 & 0.0010 & 0.2006 \\
\hline $\mathrm{i}-\mathrm{C}_{13}$ & 0.8396 & 0.0655 & 13 & 184 & 0.0004 & 0.0002 & 0.0555 \\
\hline $\mathrm{i}-\mathrm{C}_{14}$ & 0.6138 & 0.0479 & 14 & 198 & 0.0002 & 0.0002 & 0.0406 \\
\hline $\mathrm{i}-\mathrm{C}_{15}$ & 0.2455 & 0.0191 & 15 & 212 & 0.0001 & 0.0001 & 0.0163 \\
\hline $\mathrm{i}-\mathrm{C}_{16}$ & 0.1342 & 0.0105 & 16 & 226 & 0.0000 & 0.0000 & 0.0089 \\
\hline \multirow[t]{2}{*}{$\mathrm{i}-\mathrm{C}_{17+}$} & 0.0499 & 0.0039 & 17 & 240 & 0.0000 & 0.0000 & 0.0033 \\
\hline & & & & & & Total in oil & 6.8758 \\
\hline Alcohols & $\begin{array}{l}\text { wt } \% \text { in } \\
\text { aqueous liquid } \\
\text { phase }\end{array}$ & $\begin{array}{l}\text { weight } \\
\text { (g/day) }\end{array}$ & $\begin{array}{l}\text { Carbon } \\
\text { number }\end{array}$ & $\begin{array}{l}\text { Molecular } \\
\text { weight } \mathrm{g} / \mathrm{mol}\end{array}$ & $\mathrm{mol} / \mathrm{day}$ & $\mathrm{mmol} / \mathrm{min}$ & $\begin{array}{l}\text { g carbon } \\
\text { /day }\end{array}$ \\
\hline Methanol & 0.1200 & 0.0028 & 1 & 32 & 0.0001 & 0.0001 & 0.0010 \\
\hline Ethanol & 0.0800 & 0.0019 & 2 & 46 & 0.0000 & 0.0000 & 0.0010 \\
\hline 2-Propanol & 0.2200 & 0.0051 & 3 & 60 & 0.0001 & 0.0001 & 0.0031 \\
\hline 1-Propanol & 0.1000 & 0.0023 & 3 & 60 & 0.0000 & 0.0000 & 0.0014 \\
\hline 2-Butanol & 0.0800 & 0.0019 & 4 & 74 & 0.0000 & 0.0000 & 0.0012 \\
\hline 1-Butanol & 0.0000 & 0.0000 & 4 & 74 & 0.0000 & 0.0000 & 0.0000 \\
\hline 2-Pentanol & 0.0000 & 0.0000 & 5 & 88 & 0.0000 & 0.0000 & 0.0000 \\
\hline 1-Pentanol & 0.0000 & 0.0000 & 5 & 88 & 0.0000 & 0.0000 & 0.0000 \\
\hline \multirow[t]{2}{*}{ water } & 99.4000 & 2.3061 & 0 & 18 & 0.1281 & 0.0890 & 0.0000 \\
\hline & & & & & & $\begin{array}{l}\text { Total in } \\
\text { aqueous }\end{array}$ & 0.0066 \\
\hline \multicolumn{3}{|c|}{ Total carbon due to oil and aqueous phase } & \multicolumn{2}{|c|}{$6.8824 \mathrm{~g}$ carbon /day } & & & \\
\hline
\end{tabular}




\begin{tabular}{|c|c|c|c|c|c|c|c|}
\hline \multicolumn{8}{|c|}{$\begin{array}{l}\text { Catalyst stability testing in separate-bed, } \mathrm{TOS}=96-144 \mathrm{~h} \\
\text { Base catalyst weight }=0.5 \mathrm{~g}, \mathrm{~T}=300^{\circ} \mathrm{C}, \mathrm{H}_{2} / \mathrm{CO} \text { ratio }=1 \text {, total feed rate }=100 \mathrm{scc} / \mathrm{min} \text {, reactor pressure }=300 \mathrm{psi} \text {, } \\
\text { ZSM-5 weight }=1 \mathrm{~g}, \text { Organic phase wt }(96-144 \mathrm{~h})=14.9 \mathrm{~g}, \text { Aqueous phase wt }(96-144 \mathrm{~h})=4.5 \mathrm{~g}\end{array}$} \\
\hline Aromatics & $\begin{array}{l}\text { wt\% in } \\
\text { Hydrocarbon } \\
\text { liquid phase }\end{array}$ & $\begin{array}{l}\text { weight } \\
\text { (g/day) }\end{array}$ & $\begin{array}{l}\text { Carbon } \\
\text { number }\end{array}$ & $\begin{array}{l}\text { Molecular } \\
\text { weight } \mathrm{g} / \mathrm{mol}\end{array}$ & mol/day & $\mathrm{mmol} / \mathrm{min}$ & $\begin{array}{l}\text { g carbon } \\
\text { /day }\end{array}$ \\
\hline toluene & 2.2808 & 0.1699 & 7 & 92 & 0.0018 & 0.0013 & 0.1551 \\
\hline p-xylene & 2.1947 & 0.1635 & 8 & 106 & 0.0015 & 0.0011 & 0.1481 \\
\hline $\begin{array}{l}\text { propyl- } \\
\text { benzene }\end{array}$ & 2.2363 & 0.1666 & 9 & 120 & 0.0014 & 0.0010 & 0.1499 \\
\hline \multirow[t]{2}{*}{ butyl-benzene } & 1.1550 & 0.0860 & 10 & 134 & 0.0006 & 0.0004 & 0.0771 \\
\hline & & 0.0000 & & & & & \\
\hline n-praffins & $\begin{array}{l}\text { wt } \% \text { in } \\
\text { Hydrocarbon } \\
\text { liquid phase }\end{array}$ & $\begin{array}{l}\text { weight } \\
\text { (g/day) }\end{array}$ & $\begin{array}{l}\text { Carbon } \\
\text { number }\end{array}$ & $\begin{array}{l}\text { Molecular } \\
\text { weight } \mathrm{g} / \mathrm{mol}\end{array}$ & $\mathrm{mol} / \mathrm{day}$ & $\mathrm{mmol} / \mathrm{min}$ & $\begin{array}{l}\text { g carbon } \\
\text { /day }\end{array}$ \\
\hline $\mathrm{n}-\mathrm{C}_{5}$ & 2.2420 & 0.1670 & 5 & 44 & 0.0038 & 0.0026 & 0.2278 \\
\hline $\mathrm{n}-\mathrm{C}_{6}$ & 8.1943 & 0.6105 & 6 & 86 & 0.0071 & 0.0049 & 0.5111 \\
\hline $\mathrm{n}-\mathrm{C}_{7}$ & 2.3800 & 0.1773 & 7 & 100 & 0.0018 & 0.0012 & 0.1489 \\
\hline $\mathrm{n}-\mathrm{C}_{8}$ & 3.1695 & 0.2361 & 8 & 114 & 0.0021 & 0.0014 & 0.1988 \\
\hline $\mathrm{n}-\mathrm{C}_{9}$ & 0.5141 & 0.0383 & 9 & 128 & 0.0003 & 0.0002 & 0.0323 \\
\hline $\mathrm{n}-\mathrm{C}_{10}$ & 1.3400 & 0.0998 & 10 & 142 & 0.0007 & 0.0005 & 0.0844 \\
\hline $\mathrm{n}-\mathrm{C}_{11}$ & 0.0175 & 0.0013 & 11 & 156 & 0.0000 & 0.0000 & 0.0011 \\
\hline $\mathrm{n}-\mathrm{C}_{12}$ & 0.0175 & 0.0013 & 12 & 170 & 0.0000 & 0.0000 & 0.0011 \\
\hline$n-C_{13}$ & 0.0386 & 0.0029 & 13 & 184 & 0.0000 & 0.0000 & 0.0024 \\
\hline $\mathrm{n}-\mathrm{C}_{14}$ & 0.0188 & 0.0014 & 14 & 198 & 0.0000 & 0.0000 & 0.0012 \\
\hline$n-C_{15}$ & 0.0292 & 0.0022 & 15 & 212 & 0.0000 & 0.0000 & 0.0018 \\
\hline$n-C_{16}$ & 0.0000 & 0.0000 & 16 & 226 & 0.0000 & 0.0000 & 0.0000 \\
\hline $\mathrm{n}-\mathrm{C}_{17+}$ & 0.0000 & 0.0000 & 17 & 240 & 0.0000 & 0.0000 & 0.0000 \\
\hline i-paraffins & $\begin{array}{l}\text { wt\% in } \\
\text { Hydrocarbon } \\
\text { liquid phase }\end{array}$ & $\begin{array}{l}\text { weight } \\
\text { (g/day) }\end{array}$ & $\begin{array}{l}\text { Carbon } \\
\text { number }\end{array}$ & $\begin{array}{l}\text { Molecular } \\
\text { weight } \mathrm{g} / \mathrm{mol}\end{array}$ & mol/day & $\mathrm{mmol} / \mathrm{min}$ & $\begin{array}{l}\text { g carbon } \\
\text { /day }\end{array}$ \\
\hline $\mathrm{i}-\mathrm{C}_{5}$ & 9.8570 & 0.7343 & 5 & 44 & 0.0167 & 0.0116 & 1.0014 \\
\hline $\mathrm{i}-\mathrm{C}_{6}$ & 0.8322 & 0.0620 & 6 & 86 & 0.0007 & 0.0005 & 0.0519 \\
\hline $\mathrm{i}-\mathrm{C}_{7}$ & 30.7700 & 2.2924 & 7 & 100 & 0.0229 & 0.0159 & 1.9256 \\
\hline $\mathrm{i}-\mathrm{C}_{8}$ & 15.6975 & 1.1695 & 8 & 114 & 0.0103 & 0.0071 & 0.9848 \\
\hline $\mathrm{i}-\mathrm{C}_{9}$ & 7.8118 & 0.5820 & 9 & 128 & 0.0045 & 0.0032 & 0.4910 \\
\hline $\mathrm{i}-\mathrm{C}_{10}$ & 3.1319 & 0.2333 & 10 & 142 & 0.0016 & 0.0011 & 0.1972 \\
\hline $\mathrm{i}-\mathrm{C}_{11}$ & 2.8223 & 0.2103 & 11 & 156 & 0.0013 & 0.0009 & 0.1779 \\
\hline $\mathrm{i}-\mathrm{C}_{12}$ & 1.8802 & 0.1401 & 12 & 170 & 0.0008 & 0.0006 & 0.1187 \\
\hline $\mathrm{i}-\mathrm{C}_{13}$ & 0.6705 & 0.0500 & 13 & 184 & 0.0003 & 0.0002 & 0.0424 \\
\hline $\mathrm{i}-\mathrm{C}_{14}$ & 0.4627 & 0.0345 & 14 & 198 & 0.0002 & 0.0001 & 0.0292 \\
\hline $\mathrm{i}-\mathrm{C}_{15}$ & 0.1818 & 0.0135 & 15 & 212 & 0.0001 & 0.0000 & 0.0115 \\
\hline $\mathrm{i}-\mathrm{C}_{16}$ & 0.0565 & 0.0042 & 16 & 226 & 0.0000 & 0.0000 & 0.0036 \\
\hline \multirow[t]{2}{*}{$\mathrm{i}-\mathrm{C}_{17+}$} & 0.0000 & 0.0000 & 17 & 240 & 0.0000 & 0.0000 & 0.0000 \\
\hline & & & & & & Total in oil & 6.7764 \\
\hline Alcohols & $\begin{array}{l}\text { wt } \% \text { in } \\
\text { aqueous } \\
\text { liquid phase }\end{array}$ & $\begin{array}{l}\text { weight } \\
\text { (g/day) }\end{array}$ & $\begin{array}{l}\text { Carbon } \\
\text { number }\end{array}$ & $\begin{array}{l}\text { Molecular } \\
\text { weight } \mathrm{g} / \mathrm{mol}\end{array}$ & $\mathrm{mol} /$ day & $\mathrm{mmol} / \mathrm{min}$ & $\begin{array}{l}\text { g carbon } \\
\text { /day }\end{array}$ \\
\hline Methanol & 0.2460 & 0.0055 & 1 & 32 & 0.0002 & 0.0001 & 0.0021 \\
\hline Ethanol & 0.1000 & 0.0023 & 2 & 46 & 0.0000 & 0.0000 & 0.0012 \\
\hline 2-Propanol & 0.0000 & 0.0000 & 3 & 60 & 0.0000 & 0.0000 & 0.0000 \\
\hline 1-Propanol & 0.0000 & 0.0000 & 3 & 60 & 0.0000 & 0.0000 & 0.0000 \\
\hline 2-Butanol & 0.2000 & 0.0045 & 4 & 74 & 0.0001 & 0.0000 & 0.0029 \\
\hline 1-Butanol & 0.0000 & 0.0000 & 4 & 74 & 0.0000 & 0.0000 & 0.0000 \\
\hline 2-Pentanol & 0.2200 & 0.0050 & 5 & 88 & 0.0001 & 0.0000 & 0.0034 \\
\hline 1-Pentanol & 0.1000 & 0.0023 & 5 & 88 & 0.0000 & 0.0000 & 0.0015 \\
\hline \multirow[t]{2}{*}{ Water } & 99.1340 & 2.2305 & 0 & 18 & 0.1239 & 0.0861 & 0.0000 \\
\hline & & & & & & $\begin{array}{c}\text { Total in } \\
\text { aqueous }\end{array}$ & 0.0090 \\
\hline \multicolumn{3}{|c|}{ Total carbon due to oil and aqueous phase } & 6.7854 & & & & \\
\hline
\end{tabular}




\begin{tabular}{|c|c|c|c|c|c|c|c|}
\hline \multicolumn{8}{|c|}{$\begin{array}{l}\text { Catalyst stability testing in separate-bed, } \mathrm{TOS}=144-192 \mathrm{~h} \\
\text { Base catalyst weight }=0.5 \mathrm{~g}, \mathrm{~T}=300^{\circ} \mathrm{C}, \mathrm{H}_{2} / \mathrm{CO} \text { ratio }=1 \text {, total feed rate }=100 \mathrm{scc} / \mathrm{min} \text {, reactor pressure }=300 \mathrm{psi} \text {, } \\
\text { ZSM-5 weight }=1 \mathrm{~g}, \text { Organic phase wt }(144-192 \mathrm{~h})=14.04 \mathrm{~g}, \text { Aqueous phase wt }=4.24 \mathrm{~g}\end{array}$} \\
\hline Aromatics & $\begin{array}{l}\text { wt } \% \text { in } \\
\text { Hydrocarbon } \\
\text { liquid phase }\end{array}$ & $\begin{array}{l}\text { weight } \\
\text { (g/day) }\end{array}$ & $\begin{array}{l}\text { Carbon } \\
\text { number }\end{array}$ & $\begin{array}{l}\text { Molecular } \\
\text { weight } \\
\text { g/mol }\end{array}$ & $\mathrm{mol} / \mathrm{day}$ & $\mathrm{mmol} / \mathrm{min}$ & $\begin{array}{l}\text { g carbon } \\
\text { /day }\end{array}$ \\
\hline toluene & 2.2297 & 0.1565 & 7 & 92 & 0.0017 & 0.0012 & 0.1429 \\
\hline p-xylene & 2.2517 & 0.1581 & 8 & 106 & 0.0015 & 0.0010 & 0.1432 \\
\hline $\begin{array}{l}\text { propyl- } \\
\text { benzene }\end{array}$ & 0.9768 & 0.0686 & 9 & 120 & 0.0006 & 0.0004 & 0.0617 \\
\hline $\begin{array}{l}\text { butyl- } \\
\text { benzene }\end{array}$ & 0.6449 & 0.0453 & 10 & 134 & 0.0003 & 0.0002 & 0.0405 \\
\hline n-praffins & $\begin{array}{l}\text { wt } \% \text { in } \\
\text { Hydrocarbon } \\
\text { liquid phase }\end{array}$ & $\begin{array}{l}\text { weight } \\
\text { (g/day) }\end{array}$ & $\begin{array}{l}\text { Carbon } \\
\text { number }\end{array}$ & $\begin{array}{l}\text { Molecular } \\
\text { weight } \\
\text { g/mol }\end{array}$ & mol/day & $\mathrm{mmol} / \mathrm{min}$ & $\begin{array}{l}\text { g carbon } \\
\text { /day }\end{array}$ \\
\hline$n-C_{5}$ & 1.9413 & 0.1363 & 5 & 44 & 0.0031 & 0.0022 & 0.1858 \\
\hline$n-C_{6}$ & 9.2000 & 0.6458 & 6 & 86 & 0.0075 & 0.0052 & 0.5407 \\
\hline$n-C_{7}$ & 3.2000 & 0.2246 & 7 & 100 & 0.0022 & 0.0016 & 0.1887 \\
\hline$n-C_{8}$ & 4.8503 & 0.3405 & 8 & 114 & 0.0030 & 0.0021 & 0.2867 \\
\hline $\mathrm{n}-\mathrm{C}_{9}$ & 0.0623 & 0.0044 & 9 & 128 & 0.0000 & 0.0000 & 0.0037 \\
\hline$n-C_{10}$ & 0.0177 & 0.0012 & 10 & 142 & 0.0000 & 0.0000 & 0.0011 \\
\hline$n-C_{11}$ & 0.0194 & 0.0014 & 11 & 156 & 0.0000 & 0.0000 & 0.0012 \\
\hline$n-C_{12}$ & 0.0270 & 0.0019 & 12 & 170 & 0.0000 & 0.0000 & 0.0016 \\
\hline$n-C_{13}$ & 0.0288 & 0.0020 & 13 & 184 & 0.0000 & 0.0000 & 0.0017 \\
\hline $\mathrm{n}-\mathrm{C}_{14}$ & 0.0204 & 0.0014 & 14 & 198 & 0.0000 & 0.0000 & 0.0012 \\
\hline $\mathrm{n}-\mathrm{C}_{15}$ & 0.0376 & 0.0026 & 15 & 212 & 0.0000 & 0.0000 & 0.0022 \\
\hline$n-C_{16}$ & 0.0669 & 0.0047 & 16 & 226 & 0.0000 & 0.0000 & 0.0040 \\
\hline$n-C_{17+}$ & 0.0000 & 0.0000 & 17 & 240 & 0.0000 & 0.0000 & 0.0000 \\
\hline i-paraffins & $\begin{array}{l}\text { wt\% in } \\
\text { Hydrocarbon } \\
\text { liquid phase }\end{array}$ & $\begin{array}{l}\text { weight } \\
\text { (g/day) }\end{array}$ & $\begin{array}{l}\text { Carbon } \\
\text { number }\end{array}$ & $\begin{array}{l}\text { Molecular } \\
\text { weight } \\
\text { g/mol }\end{array}$ & $\mathrm{mol} / \mathrm{day}$ & $\mathrm{mmol} / \mathrm{min}$ & $\begin{array}{l}\text { g carbon } \\
\text { /day }\end{array}$ \\
\hline $\mathrm{i}-\mathrm{C}_{5}$ & 5.0426 & 0.3540 & 5 & 44 & 0.0080 & 0.0056 & 0.4827 \\
\hline $\mathrm{i}-\mathrm{C}_{6}$ & 5.9292 & 0.4162 & 6 & 86 & 0.0048 & 0.0034 & 0.3485 \\
\hline $\mathrm{i}-\mathrm{C}_{7}$ & 32.1000 & 2.2534 & 7 & 100 & 0.0225 & 0.0156 & 1.8929 \\
\hline $\mathrm{i}-\mathrm{C}_{8}$ & 15.1000 & 1.0600 & 8 & 114 & 0.0093 & 0.0065 & 0.8926 \\
\hline $\mathrm{i}-\mathrm{C}_{9}$ & 6.8000 & 0.4774 & 9 & 128 & 0.0037 & 0.0026 & 0.4028 \\
\hline $\mathrm{i}-\mathrm{C}_{10}$ & 4.3922 & 0.3083 & 10 & 142 & 0.0022 & 0.0015 & 0.2606 \\
\hline $\mathrm{i}-\mathrm{C}_{11}$ & 2.3957 & 0.1682 & 11 & 156 & 0.0011 & 0.0007 & 0.1423 \\
\hline $\mathrm{i}-\mathrm{C}_{12}$ & 1.3485 & 0.0947 & 12 & 170 & 0.0006 & 0.0004 & 0.0802 \\
\hline $\mathrm{i}-\mathrm{C}_{13}$ & 0.7060 & 0.0496 & 13 & 184 & 0.0003 & 0.0002 & 0.0420 \\
\hline $\mathrm{i}-\mathrm{C}_{14}$ & 0.3754 & 0.0263 & 14 & 198 & 0.0001 & 0.0001 & 0.0224 \\
\hline $\mathrm{i}-\mathrm{C}_{15}$ & 0.1326 & 0.0093 & 15 & 212 & 0.0000 & 0.0000 & 0.0079 \\
\hline $\mathrm{i}-\mathrm{C}_{16}$ & 0.0597 & 0.0042 & 16 & 226 & 0.0000 & 0.0000 & 0.0036 \\
\hline \multirow[t]{2}{*}{$\mathrm{i}-\mathrm{C}_{17+}$} & 0.0957 & 0.0067 & 17 & 240 & 0.0000 & 0.0000 & 0.0057 \\
\hline & & & & & & Total in oil & 6.1910 \\
\hline Alcohols & $\begin{array}{l}\text { wt \% in aqueous } \\
\text { liquid phase }\end{array}$ & $\begin{array}{l}\text { weight } \\
\text { (g/day) }\end{array}$ & $\begin{array}{l}\text { Carbon } \\
\text { number }\end{array}$ & $\begin{array}{l}\text { Molecular } \\
\text { weight } \\
\text { g/mol }\end{array}$ & mol/day & $\mathrm{mmol} / \mathrm{min}$ & $\begin{array}{l}\text { g carbon } \\
\text { /day }\end{array}$ \\
\hline Methanol & 0.4000 & 0.0085 & 1 & 32 & 0.0003 & 0.0002 & 0.0032 \\
\hline Ethanol & 0.7600 & 0.0161 & 2 & 46 & 0.0004 & 0.0002 & 0.0084 \\
\hline 2-Propanol & 0.1000 & 0.0021 & 3 & 60 & 0.0000 & 0.0000 & 0.0013 \\
\hline 1-Propanol & 0.0000 & 0.0000 & 3 & 60 & 0.0000 & 0.0000 & 0.0000 \\
\hline 2-Butanol & 0.2000 & 0.0042 & 4 & 74 & 0.0001 & 0.0000 & 0.0028 \\
\hline 1-Butanol & 0.0000 & 0.0000 & 4 & 74 & 0.0000 & 0.0000 & 0.0000 \\
\hline 2-Pentanol & 0.3000 & 0.0064 & 5 & 88 & 0.0001 & 0.0001 & 0.0043 \\
\hline 1-Pentanol & 0.1000 & 0.0021 & 5 & 88 & 0.0000 & 0.0000 & 0.0014 \\
\hline \multirow[t]{2}{*}{ Water } & 98.1400 & 2.0806 & 0 & 18 & 0.1156 & 0.0803 & 0.0000 \\
\hline & & & & & & $\begin{array}{l}\text { Total in } \\
\text { aqueous }\end{array}$ & 0.0182 \\
\hline \multicolumn{3}{|c|}{ Total carbon due to oil and aqueous phase } & \multicolumn{2}{|c|}{6.2092 g carbon /day } & & & \\
\hline
\end{tabular}




\begin{tabular}{|c|c|c|c|c|c|c|c|}
\hline \multicolumn{8}{|c|}{$\begin{array}{l}\text { Base catalyst weight }=0.5 \mathrm{~g}, \mathrm{~T}=300^{\circ} \mathrm{C}, \mathrm{H}_{2} / \mathrm{CO} \text { ratio }=1 \text {, total feed rate }=100 \mathrm{scc} / \mathrm{min} \text {, reactor pressure }=300 \mathrm{psi} \text {, } \\
\text { ZSM-5 weight }=1 \mathrm{~g} \text {, Organic phase wt }(192-240 \mathrm{~h})=13.68 \mathrm{~g}, \text { Aqueous phase wt }(192-240 \mathrm{~h})=3.92 \mathrm{~g}\end{array}$} \\
\hline Aromatics & $\begin{array}{l}\text { wt\% in } \\
\text { Hydrocarbon } \\
\text { liquid phase }\end{array}$ & $\begin{array}{l}\text { weight } \\
\text { (g/day) }\end{array}$ & $\begin{array}{l}\text { Carbon } \\
\text { number }\end{array}$ & $\begin{array}{l}\text { Molecular } \\
\text { weight } \\
\mathrm{g} / \mathrm{mol}\end{array}$ & & & $\begin{array}{l}\text { g carbon } \\
\text { /day }\end{array}$ \\
\hline toluene & 1.9753 & 0.1351 & 7 & 92 & 0.0015 & 0.0010 & 0.1234 \\
\hline p-xylene & 2.2794 & 0.1559 & 8 & 106 & 0.0015 & 0.0010 & 0.1412 \\
\hline $\begin{array}{l}\text { propyl- } \\
\text { benzene }\end{array}$ & 0.8475 & 0.0580 & 9 & 120 & 0.0005 & 0.0003 & 0.0522 \\
\hline butyl-benzene & 0.3153 & 0.0216 & 10 & 134 & 0.0002 & 0.0001 & 0.0193 \\
\hline n-praffins & $\begin{array}{l}\text { wt } \% \text { in } \\
\text { Hydrocarbon } \\
\text { liquid phase }\end{array}$ & $\begin{array}{l}\text { weight } \\
\text { (g/day) }\end{array}$ & $\begin{array}{l}\text { Carbon } \\
\text { number }\end{array}$ & $\begin{array}{l}\text { Molecular } \\
\text { weight } \\
\mathrm{g} / \mathrm{mol}\end{array}$ & mol/day & $\mathrm{mmol} / \mathrm{min}$ & $\begin{array}{l}\text { g carbon } \\
\text { /day }\end{array}$ \\
\hline $\mathrm{n}-\mathrm{C}_{5}$ & 1.7240 & 0.1179 & 5 & 44 & 0.0027 & 0.0019 & 0.1608 \\
\hline $\mathrm{n}-\mathrm{C}_{6}$ & 10.4295 & 0.7134 & 6 & 86 & 0.0083 & 0.0058 & 0.5972 \\
\hline $\mathrm{n}-\mathrm{C}_{7}$ & 2.2938 & 0.1569 & 7 & 100 & 0.0016 & 0.0011 & 0.1318 \\
\hline $\mathrm{n}-\mathrm{C}_{8}$ & 7.5656 & 0.5175 & 8 & 114 & 0.0045 & 0.0032 & 0.4358 \\
\hline $\mathrm{n}-\mathrm{C}_{9}$ & 0.2299 & 0.0157 & 9 & 128 & 0.0001 & 0.0001 & 0.0133 \\
\hline$n-C_{10}$ & 0.1943 & 0.0133 & 10 & 142 & 0.0001 & 0.0001 & 0.0112 \\
\hline $\mathrm{n}-\mathrm{C}_{11}$ & 0.0326 & 0.0022 & 11 & 156 & 0.0000 & 0.0000 & 0.0019 \\
\hline $\mathrm{n}-\mathrm{C}_{12}$ & 0.0188 & 0.0013 & 12 & 170 & 0.0000 & 0.0000 & 0.0011 \\
\hline $\mathrm{n}-\mathrm{C}_{13}$ & 0.0404 & 0.0028 & 13 & 184 & 0.0000 & 0.0000 & 0.0023 \\
\hline $\mathrm{n}-\mathrm{C}_{14}$ & 0.0304 & 0.0021 & 14 & 198 & 0.0000 & 0.0000 & 0.0018 \\
\hline $\mathrm{n}-\mathrm{C}_{15}$ & 0.0566 & 0.0039 & 15 & 212 & 0.0000 & 0.0000 & 0.0033 \\
\hline $\mathrm{n}-\mathrm{C}_{16}$ & 0.0411 & 0.0028 & 16 & 226 & 0.0000 & 0.0000 & 0.0024 \\
\hline $\mathrm{n}-\mathrm{C}_{17+}$ & 0.0000 & 0.0000 & 17 & 240 & 0.0000 & 0.0000 & 0.0000 \\
\hline i-paraffins & $\begin{array}{l}\text { wt } \% \text { in } \\
\text { Hydrocarbon } \\
\text { liquid phase }\end{array}$ & $\begin{array}{l}\text { weight } \\
\text { (g/day) }\end{array}$ & $\begin{array}{l}\text { Carbon } \\
\text { number }\end{array}$ & $\begin{array}{l}\text { Molecular } \\
\text { weight } \\
\mathrm{g} / \mathrm{mol}\end{array}$ & mol/day & $\mathrm{mmol} / \mathrm{min}$ & $\begin{array}{l}\text { g carbon } \\
\text { /day }\end{array}$ \\
\hline $\mathrm{i}-\mathrm{C}_{5}$ & 5.7493 & 0.3932 & 5 & 44 & 0.0089 & 0.0062 & 0.5362 \\
\hline${\mathrm{i}-\mathrm{C}_{6}}_{\mathrm{f}}$ & 0.7777 & 0.0532 & 6 & 86 & 0.0006 & 0.0004 & 0.0445 \\
\hline${\mathrm{i}-\mathrm{C}_{7}}$ & 36.9467 & 2.5272 & 7 & 100 & 0.0253 & 0.0175 & 2.1228 \\
\hline i- $\mathrm{C}_{8}$ & 10.4400 & 0.7141 & 8 & 114 & 0.0063 & 0.0044 & 0.6013 \\
\hline i- $\mathrm{C}_{9}$ & 8.3046 & 0.5680 & 9 & 128 & 0.0044 & 0.0031 & 0.4793 \\
\hline $\mathrm{i}-\mathrm{C}_{10}$ & 5.3290 & 0.3645 & 10 & 142 & 0.0026 & 0.0018 & 0.3080 \\
\hline $\mathrm{i}-\mathrm{C}_{11}$ & 2.2815 & 0.1561 & 11 & 156 & 0.0010 & 0.0007 & 0.1320 \\
\hline $\mathrm{i}-\mathrm{C}_{12}$ & 1.2249 & 0.0838 & 12 & 170 & 0.0005 & 0.0003 & 0.0710 \\
\hline $\mathrm{i}-\mathrm{C}_{13}$ & 0.4833 & 0.0331 & 13 & 184 & 0.0002 & 0.0001 & 0.0280 \\
\hline $\mathrm{i}-\mathrm{C}_{14}$ & 0.3582 & 0.0245 & 14 & 198 & 0.0001 & 0.0001 & 0.0208 \\
\hline $\mathrm{i}-\mathrm{C}_{15}$ & 0.0303 & 0.0021 & 15 & 212 & 0.0000 & 0.0000 & 0.0018 \\
\hline $\mathrm{i}-\mathrm{C}_{16}$ & 0.0500 & 0.0034 & 16 & 226 & 0.0000 & 0.0000 & 0.0029 \\
\hline \multirow[t]{2}{*}{$\mathrm{i}-\mathrm{C}_{17+}$} & 0.0000 & 0.0000 & 17 & 240 & 0.0000 & 0.0000 & 0.0000 \\
\hline & & & & & & Total in oil & 6.0477 \\
\hline Alcohols & $\begin{array}{l}\text { wt } \% \text { in } \\
\text { aqueous liquid } \\
\text { phase }\end{array}$ & $\begin{array}{l}\text { weight } \\
\text { (g/day) }\end{array}$ & $\begin{array}{l}\text { Carbon } \\
\text { number }\end{array}$ & $\begin{array}{l}\text { Molecular } \\
\text { weight } \\
\mathrm{g} / \mathrm{mol}\end{array}$ & $\mathrm{mol} /$ day & $\mathrm{mmol} / \mathrm{min}$ & $\begin{array}{l}\text { g carbon } \\
\text { /day }\end{array}$ \\
\hline Methanol & 0.1200 & 0.0024 & 1 & 32 & 0.0001 & 0.0001 & 0.0009 \\
\hline Ethanol & 0.0000 & 0.0000 & 2 & 46 & 0.0000 & 0.0000 & 0.0000 \\
\hline 2-Propanol & 0.1500 & 0.0029 & 3 & 60 & 0.0000 & 0.0000 & 0.0018 \\
\hline 1-Propanol & 0.3000 & 0.0059 & 3 & 60 & 0.0001 & 0.0001 & 0.0035 \\
\hline 2-Butanol & 0.1000 & 0.0020 & 4 & 74 & 0.0000 & 0.0000 & 0.0013 \\
\hline 1-Butanol & 0.6000 & 0.0118 & 4 & 74 & 0.0002 & 0.0001 & 0.0076 \\
\hline 2-Pentanol & 0.5000 & 0.0098 & 5 & 88 & 0.0001 & 0.0001 & 0.0067 \\
\hline 1-Pentanol & 0.6000 & 0.0118 & 5 & 88 & 0.0001 & 0.0001 & 0.0080 \\
\hline \multirow[t]{2}{*}{ Water } & 97.6300 & 1.9135 & 0 & 18 & 0.1063 & 0.0738 & 0.0000 \\
\hline & & & & & & $\begin{array}{l}\text { Total in } \\
\text { aqueous }\end{array}$ & 0.0289 \\
\hline \multicolumn{3}{|c|}{ Total carbon due to oil and aqueous phase } & \multicolumn{2}{|c|}{$6.0766 \mathrm{~g}$ carbon /day } & & & \\
\hline
\end{tabular}




\title{
Addition of Zeolite ZSM-5 to an Iron-based Fischer-Tropsch Catalyst supported on Activated Carbon: Effect of Reactor Conditions
}

\author{
Avinashkumar V. Karre \\ Thesis submitted to the \\ College of Engineering and Mineral Resources \\ at West Virginia University \\ in partial fulfillment of the requirements \\ for the degree of \\ Master of Science \\ in \\ Chemical Engineering
}

Department of Chemical Engineering

APROVAL OF THE EXAMINING COMMITTEE

Dady B. Dadyburjor, Ph.D., Chair

Edwin L. Kugler, Ph.D.

Charter D. Stinespring, Ph.D.

Date

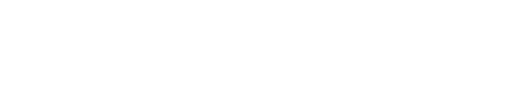

